RENATA MARCONATO

\title{
ANÁLISE DO CUSTO DE TRANSPORTE DE FERTILIZANTES COM USO DE MODELAGEM DIGITAL DE TERRENO
}




\title{
RENATA MARCONATO
}

\section{ANÁLISE DO CUSTO DE TRANSPORTE DE FERTILIZANTES COM USO DE MODELAGEM DIGITAL DE TERRENO}

\author{
Dissertação apresentada à Escola \\ Politécnica da Universidade de São \\ Paulo para obtenção do título de \\ Mestre em Engenharia.
}




\title{
RENATA MARCONATO
}

\section{ANÁLISE DO CUSTO DE TRANSPORTE DE FERTILIZANTES COM USO DE MODELAGEM DIGITAL DE TERRENO}

\author{
Dissertação apresentada à Escola \\ Politécnica da Universidade de São \\ Paulo para obtenção do título de \\ Mestre em Engenharia. \\ Área de Concentração: \\ Engenharia de Transportes \\ Ênfase: \\ Informações Espaciais \\ Orientador: \\ Prof. Assoc. José Alberto Quintanilha
}


Este exemplar foi revisado e alterado em relação à versão original, sob responsabilidade única do autor e com a anuência de seu orientador.

São Paulo, 23 de novembro de 2012.

Assinatura do autor

Assinatura do orientador

FICHA CATALOGRÁFICA

Marconato, Renata

Avaliação do custo de transporte de fertilizantes com uso de Modelagem Digital de Terreno / R. Marconato. -- ed.rev. -- São Paulo, 2012.

p. 176

Dissertação (Mestrado) - Escola Politécnica da Universidade de São Paulo. Departamento de Engenharia de Transportes.

1. Transporte de cargas (Custos; Avaliação) 2. Fertilizantes I. Universidade de São Paulo. Escola Politécnica. Departamento de Engenharia de Transportes II. t. 


\section{AGRADECIMENTOS}

Agradeço a todos os meus orientadores: os professores, os colegas da academia e do escritório, os amigos, os meus pais, os meus chefes, o meu marido e minha filha, os funcionários da faculdade, e acima de tudo, a Deus.

Dentre tantos, agradeço a generosidade ímpar dos Professores Quintanilha e Alexandre e dos colegas Jun, Cláudia e Mariana, do Professor Marcelo, do colega economista Sérgio Vale e da professora Ana Paula.

À Escola Politécnica da Universidade de São Paulo, ao seu Departamento de Engenharia de Transportes e ao Laboratório de Geoprocessamento, muito obrigada. 


\section{RESUMO}

A indústria brasileira de fertilizantes encontra-se submetida a um sistema de tributação que pode anular a concorrência do produto nacional em relação ao importado, em função da configuração geográfica da oferta doméstica e do fato do produto importado desfrutar de benefícios tarifários. Tais benéficos são justificados pela grande dependência que a agricultura brasileira tem deste importante insumo e, a localização do consumidor em relação aos principais portos de entrada do produto e da indústria nacional é uma informação estratégica para o mercado e para a viabilidade de projetos de investimentos domésticos. O presente estudo analisou os custos logísticos que incidem sobre os principais fertilizantes importados através da utilização de uma nova metodologia: o uso de um modelo digital de terreno. O modelo foi gerado interpolando-se indicadores de preços construídos a partir das variáveis que atuam na formação dos preços dos fertilizantes importados por meio de três métodos diferentes. O produto do estudo é um modelo digital que descreve o comportamento do preço do fertilizante importado de uma forma contínua sobre a superfície. Este modelo foi usado para analisar a área de abrangência do fertilizante importado de cada um dos principais portos e elaborar simulações a partir da manipulação das variáveis do modelo.

Palavras Chave: Fretes, Indicadores de Preços, Custo logísticos, Modelo Digital de Terreno 


\begin{abstract}
The Brazilian fertilizer industry is subject to a tax system that can cancel the competition of the national product with regard to imported, depending on the geographic configuration of the domestic supply and the fact that the imported products take advantage of tariff benefits. Such benefits are justified by the large dependence of the Brazilian agriculture has this important input. Therefore, the location of the consumer market in relation to the main ports of entry of the input and the domestic industry is a strategic information to the market and the viability of domestic investment projects. This study analyzed the logistics costs imposed on the main imported fertilizers by using a new methodology: the use of a digital terrain model. The model was generated interpolating price indicators constructed from the variables that act in the formation of prices of imported fertilizers by three different methods. The product of the study is a digital model that describes the behavior of the imported fertilizer price in a continuous manner over the surface. This model was used to analyze the coverage area of the imported fertilizer for each of the main ports and prepare simulations from the manipulation of model variables.
\end{abstract}

Keywords: Freight, Price Indicators, Logistic cost, Digital Terrain Model 


\section{LISTA DE ILUSTRAÇÕES}

Figura 1 - Evolução anual da balança comercial brasileira e do agronegócio - 1989 a 2011 - (em US\$ bilhões)...................... 27

Figura 2 - Evolução das vendas de fertilizantes no mercado brasileiro...

Figura 3 - Participação percentual da importação e da produção doméstica na oferta de fertilizantes.

Figura 4 - Importação de fertilizantes: principais portos de origem e Estados de destino em 2007.

Figura 5 - Cadeia Produtiva dos Fertilizantes.

Figura 6 - Mapa da distribuição da indústria de fertilizantes nacional (misturadoras e produtoras).

Figura 7 - Exemplo de uma amostragem regular

Figura 8 - Exemplo de uma amostragem irregular. 46

Figura 9 - Exemplo de uma malha triangular ...

Figura 10 - Exemplo de uma triangulação de Delaunay..

Figura 11 - Ilustração dos componentes de uma variável aleatória Z........

Figura 12 - Semivariograma experimental com os parâmetros.

Figura 13 - Bandas Rotativas.

Figura 14 - Preços dos fretes dos fertilizantes do corredor Santos/Cubatão em 2008.

Figura 15 - Preços dos fretes dos fertilizantes do corredor Santos/Cubatão em 2009.

Figura 16 - Preços dos fretes dos fertilizantes do corredor Santos/Cubatão em 2010.

Figura 17 - Distância e valor total em pedágios na rota para todas as rotas disponíveis em 2010 no corredor do porto de Santos/Cubatão.

Figura 18 - Número de praças de pedágios e distância percorrida no corredor Santos/Cubatão...

Figura 19 - Despesa total com pedágios por rota e o frete total.

Figura 20 - Preços dos fretes dos fertilizantes do corredor Paranaguá em 2008. 
Figura 21 - Preços dos fretes dos fertilizantes do corredor Paranaguá em 2009.......

Figura 22 - Preços dos fretes dos fertilizantes do corredor Paranaguá em 2010...

Figura 23 - Preços dos fretes dos fertilizantes do corredor Rio Grande em 2008.

Figura 24 - Preços dos fretes dos fertilizantes do corredor Rio Grande em 2009...

Figura 25 - Preços dos fretes dos fertilizantes do corredor Rio Grande em 2010.

Figura 26 - Resultado da interpolação pelo algoritmo Natural Neighbours e distribuição dos pontos com valores dos fretes disponíveis pelo Sifreca

Figura 27 - Resultado da interpolação pelo algoritmo Thin Plate Spline e distribuição dos pontos com valores dos fretes disponíveis pelo Sifreca.

Figura 28 - Resultado da interpolação pelo algoritmo Spline com tensão e distribuição dos pontos com valores dos fretes disponíveis pelo Sifreca.

Figura 29 - Resultado da interpolação pelo algoritmo Função Multiquadrática e distribuição dos pontos com valores dos fretes disponíveis pelo Sifreca

Figura 30 - Resultado da interpolação pelo algoritmo Função Multiquadrática Inversa e distribuição dos pontos com valores dos fretes disponíveis pelo Sifreca.

Figura 31 - Grade resultante da interpolação pelo algoritmo Função Local Polinomial (grau 2) e distribuição dos pontos com valores dos fretes disponíveis pelo Sifreca.

Figura 32 - Grade resultante da interpolação pelo algoritmo Função Global Polinomial (grau 2) e distribuição dos pontos com valores dos fretes disponíveis pelo Sifreca. 
Figura 33 - Grade resultante da interpolação pelo algoritmo IDW e distribuição dos pontos com valores dos fretes disponíveis 109 pelos Sifreca.

Figura 34 - Grade resultante da interpolação por Krigagem Linear e distribuição dos pontos com valores dos fretes disponíveis pelos Sifreca

Figura 35 - Grade resultante da interpolação por Krigagem Gaussiana e distribuição dos pontos com valores dos fretes disponíveis pelos Sifreca.

Figura 36 - Grade resultante da interpolação por Krigagem Exponencial e distribuição dos pontos com valores dos fretes disponíveis pelos Sifreca.

Figura 37 - Grade resultante da interpolação por Krigagem Circular e distribuição dos pontos com valores dos fretes disponíveis pelos Sifreca.

Figura 38 - Grade resultante da interpolação por Krigagem Esférica e distribuição dos pontos com valores dos fretes disponíveis pelos Sifreca.

Figura 39 - Resultados do modelo do variograma para os fretes do corredor por porto de Santos/Cubatão.

Figura 40 - Resultados do modelo do variograma para os fretes do corredor por porto de Paranaguá...

Figura 41 - Resultados do modelo do variograma para os fretes do corredor por porto de Rio Grande.

Figura 42 - Resultados da validação cruzada do semivariograma estimado para o corredor Santos /Cubatão.

Figura 43 - Resultados da validação cruzada do variograma estimado para o corredor de Paranaguá.

Figura 44 - Resultados da validação cruzada do variograma estimado para o corredor de Rio Grande.

Figura 45 - Resultado da interpolação por Krigagem Ordinária e distribuição dos pontos com valores dos fretes disponíveis pelos Sifreca para o Porto de Paranaguá. 
Figura 46 - Média, Valor Máximo e Mínimo das realizações pela metodologia de TB, para o modelo ajustado a partir dos dados do corredor do Porto de Santos/Cubatão.

Figura 47 - Média, Valor Máximo e Mínimo das realizações pela metodologia de TB, para o modelo ajustado a partir dos dados do corredor do Porto de Paranaguá.

Figura 48 - Média, Valor Máximo e Mínimo das realizações pela metodologia de TB, para o modelo ajustado a partir dos dados do corredor do Porto de Rio Grande.

Figura 49 - Resultados das realizações pela metodologia de TB: (a) Média, (b) menor média, (c) maior média, e processamento das realizações: (d) Valores mínimos de todas as realizações e (e) valores máximos de todas as realizações, para o corredor do Porto de Santos.

Figura 50 - Resultados das realizações pela metodologia de TB: (a) Média, (b) menor média, (c) maior média, e processamento das realizações: (d) Valores mínimos de todas as realizações e (e) valores máximos de toadas as realizações, para o corredor do Porto de Paranaguá................................ 126

Figura 51 - Resultados das realizações pela metodologia de TB: (a) Média, (b) menor média, (c) maior média, e processamento das realizações: (d) Valores mínimos de todas as realizações e (e) valores máximos de todas as realizações, para o corredor do Porto de Rio Grande.

Figura 52 - Desvios dos erros dos dados estimados por regressão loglog dos fretes contra distância apenas para o corredor de Paranaguá

Figura 53 - Desvios dos erros dos dados estimados por regressão loglog dos fretes contra distância de todos os corredores

Figura 54 - Desvios dos erros dos dados estimados por regressão loglog dos fretes contra distância para os principais corredores..

Figura 55 - Desvios dos dados interpolados pela krigagem linear em relação aos fretes reais 
Figura 56 - Desvios dos dados interpolados pela krigagem gaussina em relação aos fretes reais

Figura 57 - Desvios dos dados interpolados pela krigagem exponencial em relação aos fretes reais

Figura 58 - Desvios dos dados interpolados pela krigagem circular em relação aos fretes reais

Figura 59 - Desvios dos dados interpolados pela krigagem esférica em relação aos fretes reais

Figura 60 - Desvios dos dados interpolados pela algoritmo Vizinho Natural (Nat. Neighbours) em relação aos fretes reais.

Figura 61 - Desvios dos dados interpolados pelo polinômio de base radial - Tin Plate Spline, em relação aos fretes reais

Figura 62 - Desvios dos dados interpolados pelo polinômio de base radial - Inverso do quadrado, em relação aos fretes reais .....

Figura 63 - Desvios dos dados interpolados pelo polinômio de base radial - Multiquadrática, em relação aos fretes reais

Figura 64 - Desvios dos dados interpolados pelo polinômio de base radial - Spline com tensão, em relação aos fretes reais

Figura 65 - Desvios dos dados interpolados por Polinômio Local (grau 2), em relação aos fretes reais

Figura 66 - Desvios dos dados interpolados por Polinômio Global (grau 2), em relação aos fretes reais

Figura 67 - Desvios dos dados interpolados por IDW (Inverso da distância ponderada), em relação aos fretes reais

Figura 68 - Desvios dos dados interpolados Krigagem Ordinária baseado no semivariograma, em relação aos fretes reais......

Figura 69 - Desvios dos dados estimados pela média dos resultados das realizações do Turning Bands baseado no semivariograma, em relação aos fretes reais

Figura 70 - Resultado da interpolação por IDW dos fretes reais com origem no Porto de Paranaguá, sobrepostos pela distribuição dos valores reais dos fretes ambos legendados com a mesma classificação de valores 
Figura 71 - Resultado da interpolação por IDW dos fretes reais com origem no Porto de Santos/Cubatão, sobrepostos pela distribuição dos valores reais dos fretes ambos legendados com a mesma classificação de valores.

Figura 72 - Resultado da interpolação por IDW dos fretes reais com origem no Porto de Rio Grande, sobrepostos pela distribuição dos valores reais dos fretes ambos legendados com a mesma classificação de valores

Figura 73 - Predição dos valores a partir do modelo IDW para todas as sedes dos municípios para uma região delimitada (a) e superfície resultante da interpolação destes valores para o porto de Paranaguá (b)

Figura 74 - Predição dos valores a partir do modelo IDW para todas as sedes dos municípios para uma região delimitada (a) e superfície resultante da interpolação destes valores para o porto de Santos /Cubatão (b)

Figura 75 - Predição dos valores a partir do modelo IDW para todas as sedes dos municípios para uma região delimitada (a) e superfície resultante da interpolação destes valores para o porto de Rio Grande (b).

Figura 76 - Resultado da álgebra de mapas pela qual foi extraída as áreas de influência dos três portos de origem dos fertilizantes importados.

Figura 77 - Isolinhas de fretes partindo de Santos.

Figura 78 - Isolinhas de fretes partindo de Paranaguá...... 146

Figura 79 - Isolinhas de fretes partindo de Rio Grande...... 146

Figura 80 - Rotas e retas para extração do perfil dos preços dos fretes por corredor.

Figura 81 - Perfil dos preços do frete entre o porto de Santos e Rondonópolis sobre a rota rodoviária

Figura 82 - Perfil dos preços do frete entre o porto de Paranaguá e Rondonópolis sobre a rota rodoviária. 
Figura 83 - Perfil dos preços do frete entre o porto de Rio Grande e Rondonópolis sobre a rota rodoviária

Figura 84 - Área de influência dos portos para o fertilizante MAP (escura: Santos, média: Paranaguá e branco: Rio Grande)....

Figura 85 - Área de influência dos portos para o fertilizante Ureia (mais escura: Santos, médio: Paranaguá e branco: Rio Grande).....

Figura 86 - Área de influência dos portos para o fertilizante $\mathrm{KCl}$ (escura: Santos, médio: Paranaguá e branco: Rio Grande)

Figura 87 - Evolução do volume exportado de soja pelos principais portos.

Figura 88 - Evolução do volume importado de fertilizantes pelos principais portos.

Figura 89 - Evolução do volume importado de fertilizante e exportado de soja em Santos e Paranaguá e relação importação de fertilizantes e exportação de soja.

Figura 90 - Diferença entre os valores reais de fretes e os menores valores obtidos com a simulação do TB para o Porto de Santos.

Figura 91 - Diferença entre os valores reais de fretes e os maiores valores obtidos com a simulação do TB para o Porto de Santos.

Figura 92 - Diferença entre os valores reais de fretes e os menores valores obtidos com a simulação do TB para o Porto de Paranaguá.

Figura 93 - Diferença entre os valores reais de fretes e os maiores valores obtidos com a simulação do TB para o Porto de Paranaguá.

Figura 94 - Diferença entre os valores reais de fretes e os menores valores obtidos com a simulação do TB para o Porto de Rio Grande.

Figura 95 - Diferença entre os valores reais de fretes e os maiores valores obtidos com a simulação do TB para o Porto de Rio Grande. 
Figura 96 - Resultado da interpolação por IDW dos menores valores fornecidos pela simulação Turning Bands para o porto de Santos.

Figura 97 - Resultado da interpolação por IDW dos maiores valores máximos fornecidos pela simulação Turning Bands para o porto de Santos.

Figura 98 - Resultado da interpolação por IDW dos menores valores fornecidos pela simulação Turning Bands para o porto de Rio Grande

160

Figura 99 - Resultado da interpolação por IDW dos maiores valores fornecidos pela simulação Turning Bands para o porto de Rio Grande.

Figura 100 - Resultado da interpolação por IDW dos menores valores fornecidos pela simulação Turning Bands para o porto de Paranaguá.

Figura 101 - Resultado da interpolação por IDW dos maiores valores fornecidos pela simulação Turning Bands para o porto de Paranaguá.

Figura 102 - Resultado dos cruzamentos entre as os modelos de fretes de Santos, Paranaguá e Rio Grande a partir dos maiores valores simulados pelo TB

Figura 103 - Resultado dos cruzamentos entre as os modelos fretes de Santos, Paranaguá e Rio Grande a partir dos menores valores simulados pelo TB

Figura 104 - Resultado dos cruzamentos entre as os indicadores de preços de fertilizantes (Uréia) entre os portos de Santos, Paranaguá e Rio Grande a partir dos menores valores de fretes simulados pelo TB.

Figura 105 - Resultado dos cruzamentos entre as os indicadores de preços de fertilizantes $(\mathrm{KCl})$ entre os portos de Santos, Paranaguá e Rio Grande a partir dos menores valores de fretes simulados pelo TB. 
Figura 106 - Resultado dos cruzamentos entre as os indicadores de preços de fertilizantes (MAP) entre os portos de Santos, Paranaguá e Rio Grande a partir dos menores valores de fretes simulados pelo TB.

Figura 107 - Resultado dos cruzamentos entre as os indicadores de preços de fertilizantes (Uréia) entre os portos de Santos, Paranaguá e Rio Grande a partir dos maiores valores de fretes simulados pelo TB...

Figura 108 - Resultado dos cruzamentos entre as os indicadores de preços de fertilizantes $(\mathrm{KCl})$ entre os portos de Santos, Paranaguá e Rio Grande a partir dos maiores valores de fretes simulados pelo TB...

Figura 109 - Resultado dos cruzamentos entre as os indicadores de preços de fertilizantes (MAP) entre os portos de Santos, Paranaguá e Rio Grande a partir dos maiores valores de fretes simulados pelo TB. 


\section{LISTA DE TABELAS}

Tabela 1 - Produção e exportação das principais commodities agrícolas mundiais

Tabela 2 - Maiores produtores e exportadores mundiais de carnes........... 26

Tabela 3 - Número de empregos por setores no Brasil (mil unidades)....... 28

Tabela 4 - Distribuição das Empresas de Fertilizantes no Brasil em 2009. 36

Tabela 5 - Alíquota de ICMS incidente sobre o fertilizante doméstico e o importado.

Tabela 6 - Comparativo entre técnicas de interpolação e seus pressupostos.

Tabela 7 - Momento do Transporte $(\mathrm{R} \$ / \mathrm{t} . \mathrm{km})$ para diferentes distâncias nos corredores de origem dos Portos de Paranaguá, Rio Grande e Cubatão, média do segundo semestre de 2008, 2009 e 2010

Tabela 8 - Preços médios, mínimos e máximos dos fretes de fertilizantes anuais, do primeiro e segundo semestres de 2008, 2009 e 2010, para rotas acima de $100 \mathrm{~km}$.

Tabela 9 - Resultados do modelo linear................................................ 101

Tabela 10 - Resultados do modelo log-log................................................. 103

Tabela 11 - Estatística dos erros das regressões....................................... 129

Tabela 12 - Estatística dos valores reais e dos estimados pelas regressões.

Tabela 13 - Estatística dos erros das interpolações.

Tabela 14 - Estatística dos valores reais e dos estimados pelas interpolações

Tabela 15 - Estatística dos erros das krigagem ordinária da média das realizações do Turning Bands.

Tabela 16 - Coeficiente de Correlação, Variância, Desvio Padrão, Desvio Médio e Coeficiente de Variação dos valores interpolados em relação ao indicador de preço real pela krigagem ordinária e pela média das realizações do Turning Bands. 


\section{LISTA DE ABREVIATURASb}

IBGE

ICMS

CEPEA

CONFAZ

FAO

MDE

MDT

MNE

MNT

TB

NPK

SIFRECA

USDA
Instituto Brasileiro de Geografia e Estatística Imposto Sobre Comercialização de Mercadorias e Serviços Centro de Estudos Avançados em economia Aplicada Conselho Interfazendário

Food Organization Modelo Digital de Elevação Modelo Digital de Terreno Modelo Numérico de Elevação Modelo Numérico de Terreno Turning Bands Nitrogênio, Fósforo e Potássio Sistema de Informações de Fretes United States Department of Agriculture 


\section{SUMÁRIO}

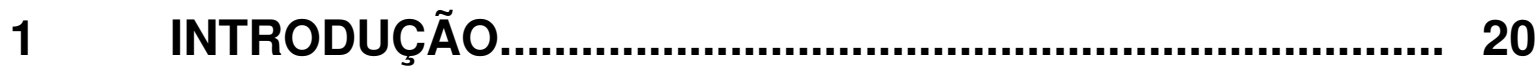

2 OBJETIVOS............................................................ 23

3 REVISÃO BIBLIOGRÁFICA........................................... 24

3.1 A AGRICULTURA BRASILEIRA: SUA POSIÇÃO NO MUNDO COMO FONTE DE ALIMENTOS E DEMANDANTE DE INSUMOS AGROPECUÁRIOS................................................. 24

3.2 O MERCADO DE FERTILIZANTES NO BRASIL........................ 29

3.3 BREVE HISTÓRICO DA INDÚSTRIA NACIONAL DE FERTILIZANTES................................................................ 32

3.4 ESTRUTURA DA INDÚSTRIA NACIONAL DE FERTILIZANTES................................................................. 34

3.5 A FORMAÇÃO DE PREÇOS DOS FERTILIZANTES IMPORTADOS NO BRASIL.................................................... 40

3.6 O USO DE MODELOS DIGITAIS DE ELEVAÇÃO EM ESTUDOS SÓCIO-ECONÔMICOS............................................ 42

3.7 MODELAGEM NUMÉRICA DE TERRENO................................. 44

3.8 MÉTODOS DE INTERPOLAÇÃO............................................ 47

3.8.1 Malha Triangular ou Triangular Irregular Network (TIN) .............. 51

3.8.2 Malha Regular...................................................................... 56

3.8.3 Método Geoestatístico e Krigagem.............................................. 60

3.8.4 Superfície de Tendência.............................................................. 69

3.9 SIMULAÇÃO ESTOCÁSTICA................................................... 71

3.9.1 Simulação por Bandas Rotativas (Turning Bands)...................... 73

3.10 FRETES E OS MODELOS DE REGRESSÃO............................. 75

$4 \quad$ METODOLOGIA ............................................................ 78

$4.1 \quad$ PRIMEIRA FASE DO ESTUDO............................................... 78

4.2 SEGUNDA FASE DO ESTUDO................................................... 80

4.3 TERCEIRA FASE DO ESTUDO.............................................. 82 
4.4 ORGANOGRAMA DE EXECUÇÃO DO ESTUDO...................... 82

$5 \quad$ RESULTADOS................................................................ 84

5.1 SOBRE OS FRETES............................................................ 84

5.2 ESTIMATIVA DOS PREÇOS DE FRETES POR MEIO DA REGRESSÃO

5.3 ESTIMATIVAS DOS PREÇOS DOS FRETES POR MEIO DE

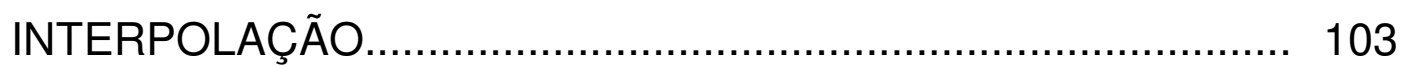

5.4 ESTIMATIVAS DOS PREÇOS DOS FRETES POR MEIO DA

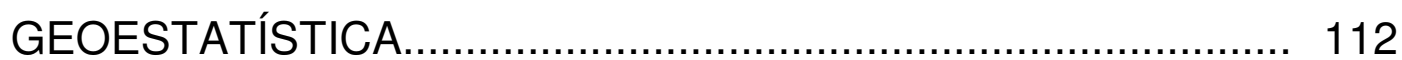

5.4.1 Estimação do variograma e krigagem....................................... 112

5.4.2 Simulações com uso da metologia de Turning Bands (TB)......... 122

5.5 COMPARAÇÃO ENTRE OS RESULTADOS DAS ESTIMAÇÕES DOS PREÇOS A PARTIR DOS DIVERSOS MÉTODOS

5.6 ANÁLISE DOS FRETES E INDICADORES DE FERTILIZANTES POR MEIO DE INTERPOLAÇÃO IDW

5.7 SIMULAÇÕES SOBRE OS PREÇOS DOS FRETES POR MEIO DE SIMULAÇÃO ESTOCÁSTICA (TURNING

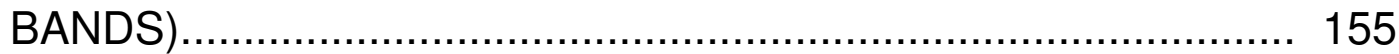

6 CONCLUSÕES.............................................................. 168

7 REFERÊNCIAS BIBLIOGRÁFICAS.................................. 170 


\section{INTRODUÇÃO}

De acordo com a Associação Nacional para Difusão de Adubos (ANDA, 2011), a agricultura brasileira consome anualmente 11 milhões de toneladas de nitrogênio, fósforo e potássio, contidos em 28,4 milhões de toneladas de mais de uma dezena de produtos fertilizantes, dos quais $50 \%$ a $75 \%$ originários do mercado internacional. (ANDA, 2011)

No Brasil, a indústria de fertilizantes é submetida a uma estrutura de custos na qual o valor do frete é o fator fundamental na formação dos preços dos produtos finais, dado que a grande parte do consumo ocorre em regiões distantes dos locais de origem da oferta.

Esta estrutura de custos, um sistema de tributação diferenciado para o produto importado e a dependência geográfica das matérias-primas manteve os investimentos do setor em um crescimento bastante inferior ao crescimento da demanda nacional a partir da década de 90 .

$\mathrm{Na}$ cadeia de produção dos fertilizantes, o segmento extrativo-mineral fornece os insumos básicos para produção das matérias-primas. Das matérias-primas rocha fosfática, enxofre e amônia - são produzidos os produtos intermediários: ácido nítrico, sulfúrico e fosfórico, que combinados entre si formam os fertilizantes básicos. Os mais importantes são o MAP, o DAP, o Superfosfato Simples e a Uréia. Da rocha potássica extrai-se diretamente o Cloreto de Potássio, outro produto básico importante. A mistura desses produtos origina as granulações e as formulações de NPK, conhecidos também como fertilizantes complexos (FERNANDES, 2009).

A oferta de fertilizantes no Brasil deriva de uma indústria nacional que se divide em dois grandes segmentos: um setor integrado, que se localiza próximo aos portos, de onde vem parte da matéria-prima, ou próximo às minas, de onde se retira a matéria-prima para sua produção. Este segmento extrai a matéria-prima, produz os fertilizantes e os comercializa. Um segundo setor, conhecido como "misturador", adquire os produtos intermediários do mercado doméstico ou os importa, faz as misturas das fórmulas de nitrogênio, fósforo e potássio e comercializa estes produtos. 
As perspectivas de crescimento da produção agrícola brasileira dependem, em grande parte, da continuidade de uma oferta de insumos segura. Mesmo existindo projetos de ampliação da capacidade instalada de produção de fertilizantes domésticos, grande parte do suprimento destes insumos será, por longo tempo, dependente da oferta externa de fertilizantes, tanto por conta da demora natural da maturação de investimentos neste setor, quanto pela escassez de matéria-prima.

Há entretanto uma peculiaridade neste setor, que reside no fato de que a indústria brasileira de fertilizantes se encontra submetida a um sistema de tributação que pode anular a concorrência do produto nacional em relação ao importado. Isso se deve a função da configuração geográfica da oferta e do fato que o produto importado desfruta de certos benefícios tarifários, como a isenção do imposto de importação e a falta de isonomia na tributação do ICMS em relação ao produto nacional.

Portanto, é de grande interesse para um setor estratégico para a economia nacional, compreender as forças que atuam sobre a formação de preços deste importante insumo para a agricultura, principalmente ao que diz respeito as questões sobre a infra-estrutura doméstica, que afetam de diferentes formas, os custos e a renda do setor agrícola nacional

Este quadro faz com que a localização geográfica de uma nova planta industrial ou de uma empresa misturadora se torne um fator estratégico nesse mercado.

Para analisar o comportamento dos preços dos fertilizantes importados no Brasil, este estudo apropriou-se da modelagem digital de elevação, comumente utilizada na geodésia e topografia, para construir um modelo de preços dos principais fertilizantes importados pelo país.

Modelo Digital de Elevação (MDE), Modelo Digital de Terreno (MDT), Modelo numérico de Elevação (MNE) ou Modelo numérico do Terreno (MNT), são alguns termos utilizados para designar os modelos digitais que representam a superfície terrestre, sua topografia ou seu uso e cobertura. É uma representação de uma superfície contínua comumente usada para produzir mapas topográficos.

Esta espacialização de dados em superfícies contínuas é amplamente utilizada em estudos que possuem como foco análises ambientais, na topografia, em estudos 
hidrológicos e também em análises sócio-econômicas, predominantemente, em estudos de distribuição populacionais.

Neste estudo, o uso do MDT produziu um modelo que descreveu o comportamento do preço do fertilizante importado de uma forma contínua sobre a superfície, que foi objeto de análises e simulações.

Este trabalho foi dividido em sete capítulos, os quais: Introdução, onde foram esclarecidas as motivações do trabalho e os Objetivos, no segundo capítulo.

A Revisão Bibliográfica, terceiro capítulo, contém um rápido esclarecimento da posição da agricultura brasileira e a conseqüente importância do mercado de fertilizantes para este setor da economia nacional, o comportamento do mercado nos últimos anos, um breve histórico da indústria nacional de fertilizantes, sua estrutura, uma revisão de estudos que utilizam técnicas similares para análise espacial de dados sócio-econômicos, uma revisão sobre Modelos de Elevação Digital, uma revisão sobre os principais interpoladores utilizados na elaboração de modelos digitais de elevação.

Em um quarto capítulo é apresentada a Metodologia utilizada na pesquisa e, na seqüência, o quinto capítulo é dedicado a Análise dos Resultados da pesquisa.

As conclusões fazem parte do sexto capítulo, e finalizando o trabalho, são elencadas as Referências Bibliográficas no capítulo sete. 


\section{OBJETIVOS}

O objetivo principal da pesquisa é estudar e demonstrar a dependência espacial da distribuição dos custos logísticos da indústria de fertilizantes no Brasil usando um Modelo de Elevação Digital para, a partir dele:

- identificar as regiões de influência dos principais portos importadores destes insumos e simular diferentes quadros de concorrência a partir de manipulações dos preços dos fretes rodoviários;

- e mostrar que técnicas de MDT são úteis para a visualização e análise de dados com relação no espaço.

Também é objetivo paralelo ao estudo, testar três métodos diferentes para a estimação dos fretes rodoviários: a análise de regressão, o uso de métodos simples de interpolação e da geoestatística.

Técnicas de modelagem digital de elevação, usualmente aplicadas na topografia ou em estudos geodésicos foram utilizadas para alcançar estes objetivos.

O produto deste estudo é um modelo digital que descreve o comportamento do preço do fertilizante de uma forma contínua sobre a superfície.

Tal modelo pode ser usado para uma avaliação prática dos conflitos de interesses comumente encontrados no setor, ao ponto que materializa o comportamento do mercado em um modelo visualmente detalhado.

Pode servir também como um modelo geral a ser replicado para demais mercados em que pesem conflitos de interesse entre as indústrias nacional e internacional, ou mesmo extrapolado para a escala mundial, para produtos que são alvo de conflitos no comércio internacional. 


\section{REVISÃO BIBLIOGRÁFICA}

3.1 A AGRICULTURA BRASILEIRA: SUA POSIÇÃO NO MUNDO COMO FONTE DE ALIMENTOS E DEMANDANTE DE INSUMOS AGROPECUÁRIOS

O Brasil ocupa o primeiro lugar nas exportações das principais commodities agrícolas no mercado mundial. De acordo com o Departamento de Agricultura dos Estados Unidos (USDA), o país encabeça a lista dos principais fornecedores globais de açúcar, soja em grão, suco de laranja e carne de frango. O país é também o segundo maior exportador de farelo de soja e carne bovina, terceiro maior exportador de milho e ocupa a quarta colocação nas vendas de carne suína, como pode ser visto nas tabelas 1 e 2 . 
Tabela 1. Produção e exportação das principais commodities agrícolas mundiais

\begin{tabular}{|c|c|c|c|c|c|}
\hline & \multicolumn{2}{|c|}{ Produção } & & \multicolumn{2}{|c|}{ Exportação } \\
\hline & Mil t & Part. & & Mil t & Part. \\
\hline \multicolumn{6}{|l|}{ Açúcar } \\
\hline Brasil & 35.750 & $21,2 \%$ & Brasil & 23.800 & $42,0 \%$ \\
\hline India & 28.300 & $16,8 \%$ & Tailândia & 8.700 & $15,3 \%$ \\
\hline UE & 16.740 & $9,9 \%$ & Australia & 2.950 & $5,2 \%$ \\
\hline China & 11.840 & $7,0 \%$ & India & 2.500 & $4,4 \%$ \\
\hline Tailândia & 10.170 & $6,0 \%$ & UE & 2.210 & $3,9 \%$ \\
\hline Total & 168.247 & $100,0 \%$ & Total & 56.694 & $100,0 \%$ \\
\hline \multicolumn{6}{|c|}{ Soja em Grão } \\
\hline EUA & 83.172 & $32,4 \%$ & Brasil & 39.000 & $40,7 \%$ \\
\hline Brasil & 74.000 & $28,8 \%$ & EUA & 34.700 & $36,2 \%$ \\
\hline Argentina & 50.500 & $19,6 \%$ & Argentina & 9.800 & $10,2 \%$ \\
\hline China & 13.500 & $5,3 \%$ & Paraguai & 5.800 & $6,1 \%$ \\
\hline India & 11.000 & $4,3 \%$ & Canada & 2.880 & $3,0 \%$ \\
\hline Total & 257.001 & $100,0 \%$ & Total & 95.812 & $100,0 \%$ \\
\hline \multicolumn{6}{|c|}{ Farelo de Soja } \\
\hline Argentina & 30.790 & $17 \%$ & Argentina & 29.760 & $49 \%$ \\
\hline China & 47.599 & $26 \%$ & Brasil & 14.750 & $24 \%$ \\
\hline EUA & 35.094 & $19 \%$ & EUA & 7.983 & $13 \%$ \\
\hline Brasil & 28.290 & $16 \%$ & India & 4.300 & $7 \%$ \\
\hline UE & 9.376 & $5 \%$ & Paraguai & 1.125 & $2 \%$ \\
\hline Total & 180.604 & $100 \%$ & Total & 60.599 & $100 \%$ \\
\hline \multicolumn{6}{|l|}{ Milho } \\
\hline EUA & 313.918 & $36 \%$ & EUA & 41.912 & $44 \%$ \\
\hline China & 191.750 & $22 \%$ & Argentina & 18.500 & $19 \%$ \\
\hline UE & 64.314 & $7 \%$ & Ucrânia & 12.000 & $13 \%$ \\
\hline Brasil & 61.000 & $7 \%$ & Brasil & 8.500 & $9 \%$ \\
\hline Argentina & 26.000 & $3 \%$ & India & 2.200 & $2 \%$ \\
\hline Total & 868.060 & $100 \%$ & Total & 94.912 & $100 \%$ \\
\hline \multicolumn{6}{|c|}{ Suco de Laranja } \\
\hline Brasil & 1.440 & $62 \%$ & Brasil & 1.240 & $80 \%$ \\
\hline EUA & 645 & $28 \%$ & EUA & 155 & $10 \%$ \\
\hline Mexico & 85 & $4 \%$ & Mexico & 79 & $5 \%$ \\
\hline UE & 73 & $3 \%$ & UE & 45 & $3 \%$ \\
\hline África do Sul & 22 & $1 \%$ & África do S। & 18 & $1 \%$ \\
\hline Total & 2.313 & $100 \%$ & Total & 1.548 & $100 \%$ \\
\hline
\end{tabular}

Fonte: USDA, Elaboração do autor 
Tabela 2. Maiores produtores e exportadores mundiais de carnes

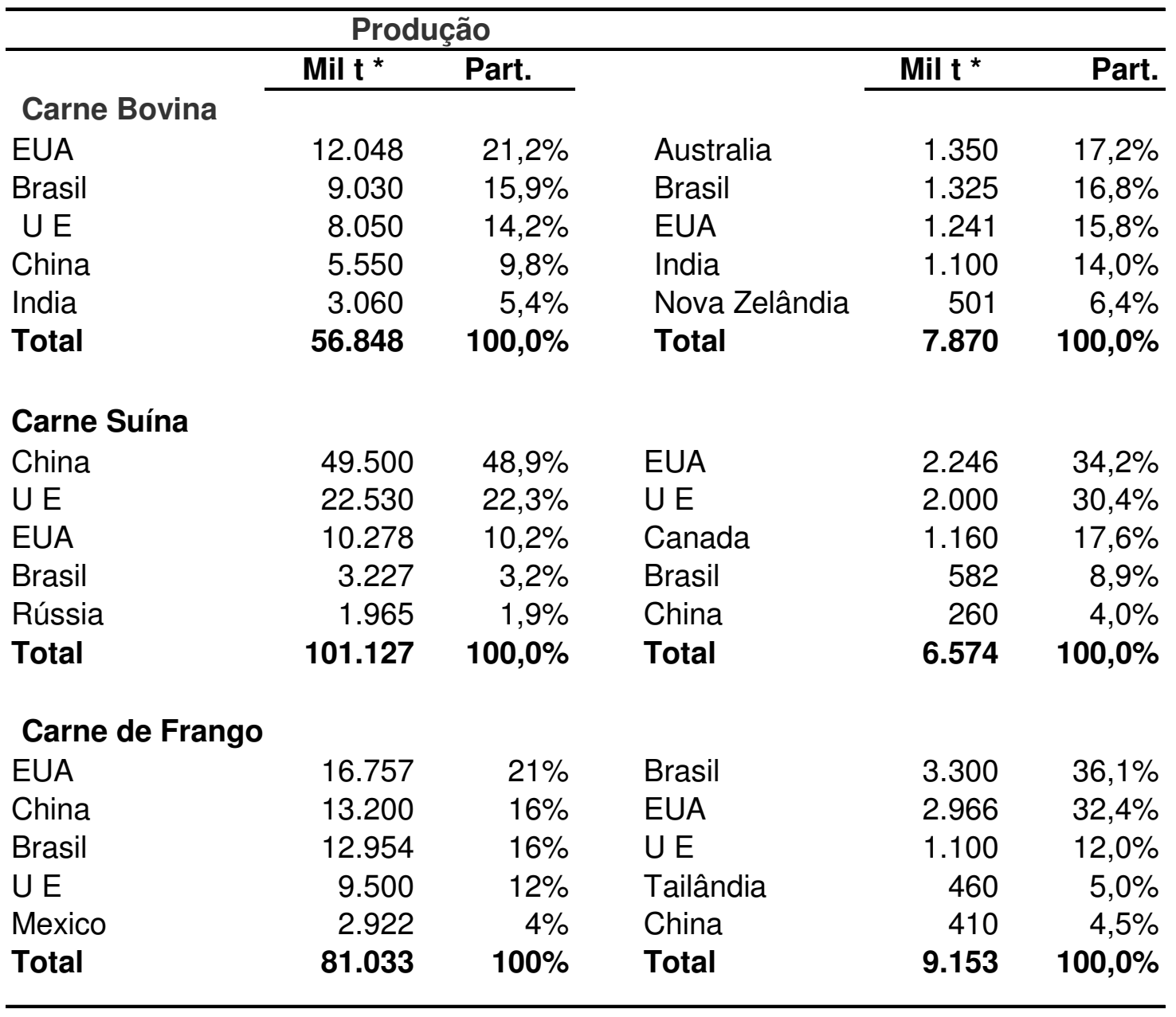

Fonte: USDA, Elaboração do autor

Esse desempenho em produzir relevante excedente exportável resulta da conjunção de fatores como disponibilidade de solo, água e energia, que somados ao desenvolvimento de uma tecnologia apropriada à agricultura tropical, levou ao robusto crescimento da produtividade agrícola.

Vale ressaltar, que o ganho de produtividade e a expansão da agricultura no País também foi fruto de estudos e pesquisas motivadas a corrigir os baixos índices de fertilidade do solo em regiões como o Cerrado brasileiro, do desenvolvimento de novas técnicas de plantio e do aumento da intensidade do uso de máquinas nas propriedades rurais. 
Por conta da forte participação brasileira no mercado internacional de commodities a agrícolas, as exportações agropecuárias do país respondem por 37\% de suas exportações totais, produzindo, em 2011, um saldo de US $\$ 77,5$ bilhões na Balança Comercial do agronegócio e com isso, contribuindo para um saldo total da Balança Comercial brasileira de US\$29, 8 bilhões (Figura 1).

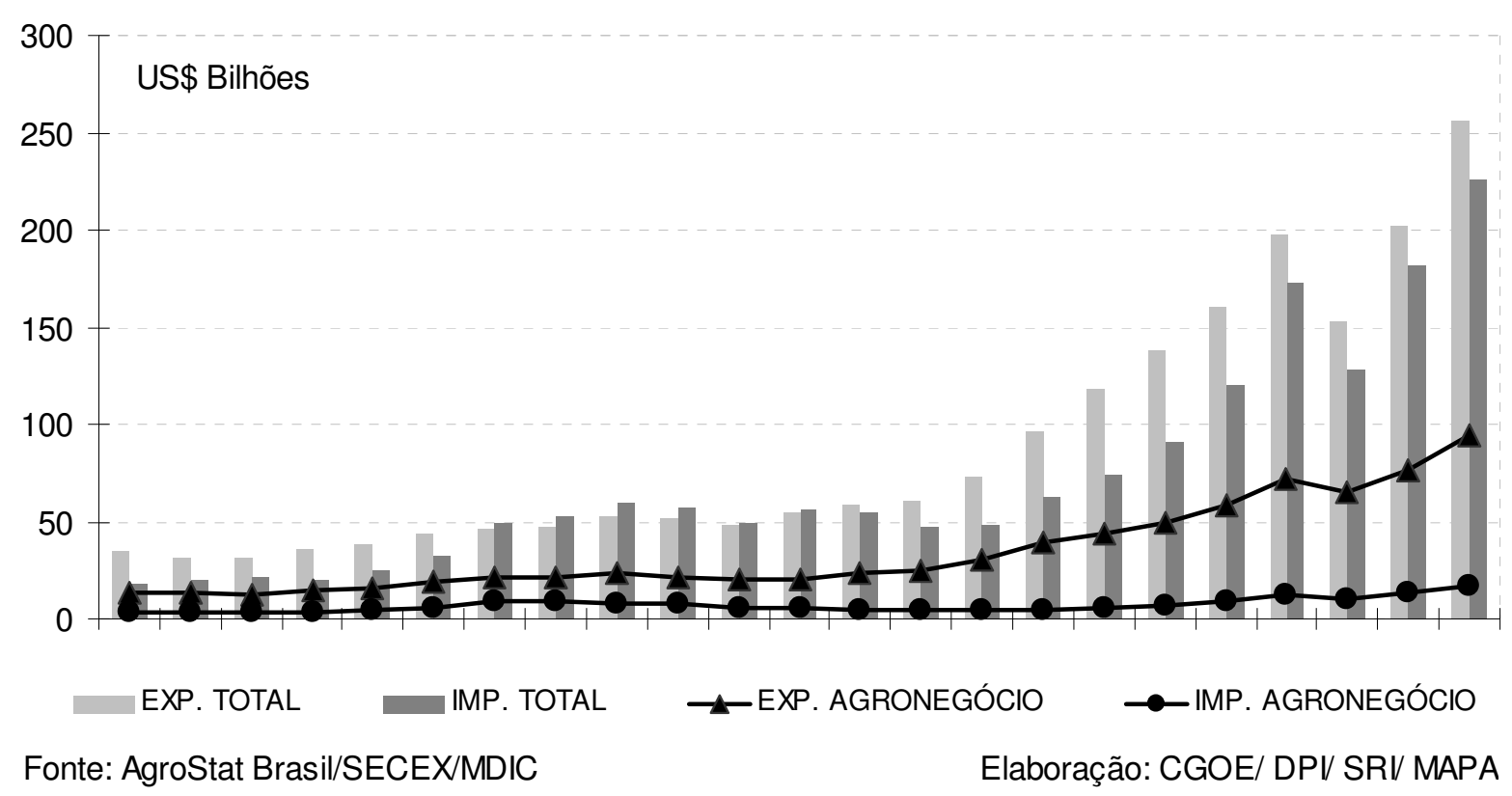

Figura 1 - Evolução anual da balança comercial brasileira e do agronegócio - 1989 a 2011 - (em US\$ bilhões)

A importância do Brasil na oferta mundial de alimentos reflete-se na organização de sua economia. De acordo com dados do Centro de Economia Aplicada para a Agricultura (CEPEA, 2010), o Produto Interno Bruto da Agropecuária nacional respondeu, em 2010, por 22\% do Produto Interno Bruto total do país, com o montante de $\mathrm{R} \$ 821$ milhões, sendo que deste valor, 70\% correspondeu à produção agrícola e 30\% à produção pecuária.

Mais de 1,1 milhão de empregos encontram-se no setor agropecuário, de acordo com dados o IMEA (2011), levantados em um estudo sobre o mercado de trabalho do agronegócio brasileiro, o que corresponde a 3,2\% da demanda total de empregos no país (Tabela 3). 
Tabela 3. Número de empregos por setores no Brasil (mil unidades)

\begin{tabular}{lcc}
\hline & \multicolumn{2}{c}{ Número de empregos em 2010 } \\
\cline { 2 - 3 } Agropecuário & No & $\%$ total \\
\cline { 2 - 3 } Indústria da Transformação & 7.141 & 3,2 \\
Comércio & 8.382 & 17,89 \\
Outros setores & 26.391 & 19,02 \\
Empregos totais & 44.068 & \\
\hline População Total & $\mathbf{1 9 0 . 7 3 3}$ & $\mathbf{2 3 , 1}$ \\
\hline Fonte: Ministério do trabalho/RAIS; IMEA (2011)
\end{tabular}

Apesar do histórico de sucesso, o Brasil possui ainda um grande potencial de crescimento da produção agrícola, dada a sua disponibilidade de terras agricultáveis, que o coloca na posição de permanecer como um dos principais fornecedores de alimentos no mundo, suprindo a crescente demanda por grãos, cereais e carnes, derivada do desenvolvimento econômico de nações como a China e a Índia.

Segundo dados da FAO (2010), se considerada a área cultivada com culturas temporárias, como com grãos, cereais e oleaginosas, o Brasil utiliza $35 \%$ da área utilizada pelos Estados Unidos, $56 \%$ da área utilizada pela China e $39 \%$ do que é cultivado pela Índia, outros grandes produtores mundiais de alimentos.

Além do Brasil possuir espaço considerável para ganho de produtividade na produção destes produtos, ele é um dos poucos países que tem ainda boa disponibilidade de água e terras, principalmente solos já ocupados com pastagens degradadas, para ampliar a área plantada.

Entretanto, para o país manter sua produção agrícola crescendo alinhada a demanda por alimentos no mundo e em seu próprio mercado doméstico, aproveitando de suas vantagens físicas e climáticas, algumas restrições ao suprimento de insumos e infra-estrutura devem ser equacionadas.

O Brasil tem o reconhecido crescimento de sua produtividade agrícola altamente relacionado com a utilização de um conjunto de insumos: os fertilizantes químicos. Ao mesmo tempo, a maior parte dos fertilizantes consumidos pela agricultura brasileira tem origem no mercado internacional, vinculando fortemente a 
renda da produção agrícola à oferta destes insumos nos principais países produtores além de outras variáveis econômicas como o câmbio, e institucionais, como a organização das tarifas e tributações.

Além desta dependência estar vinculada a muitas variáveis controláveis ou não pelo mercado e pela administração publica, a infra-estrutura de transportes e portuária domésticas são um ponto de grande atenção para o setor, já que a formação do preço dos fertilizantes importados são, em grande proporção constituídas pelos fretes e custos portuários.

Ainda que existam projetos de ampliação da capacidade instalada de produção de fertilizantes domésticos, a agricultura brasileira continuará, por longo período de tempo, dependente da oferta externa de fertilizantes, seja pela demora natural da maturação de investimentos neste setor, seja pela escassez de matéria-prima.

É de grande interesse a um setor estratégico da economia nacional compreender as forças que atuam sobre a formação de preços deste importante insumo para a agricultura, principalmente ao que diz respeito as questões sobre a infra-estrutura doméstica, que afetam de diferentes formas, os custos e a renda do setor agrícola nacional

\subsection{O MERCADO DE FERTILIZANTES NO BRASIL}

O consumo de fertilizantes no Brasil cresceu 4,4\% ao ano nos últimos 25 anos. Em 2011, alcançou, segundo a Associação Nacional para Difusão de Adubos (ANDA), 11,6 milhões de toneladas de nutrientes (NPK), o que significa um volume de 28,3 milhões de toneladas de produtos intermediários. A produção interna compôs $35 \%$ desta demanda totalizando 9,8 milhões de toneladas de produtos intermediários.

A Figura 2 mostra a evolução das vendas de fertilizantes no Brasil, tanto em produto quanto em volume de nutrientes (NPK) entre 1985 e 2011. 


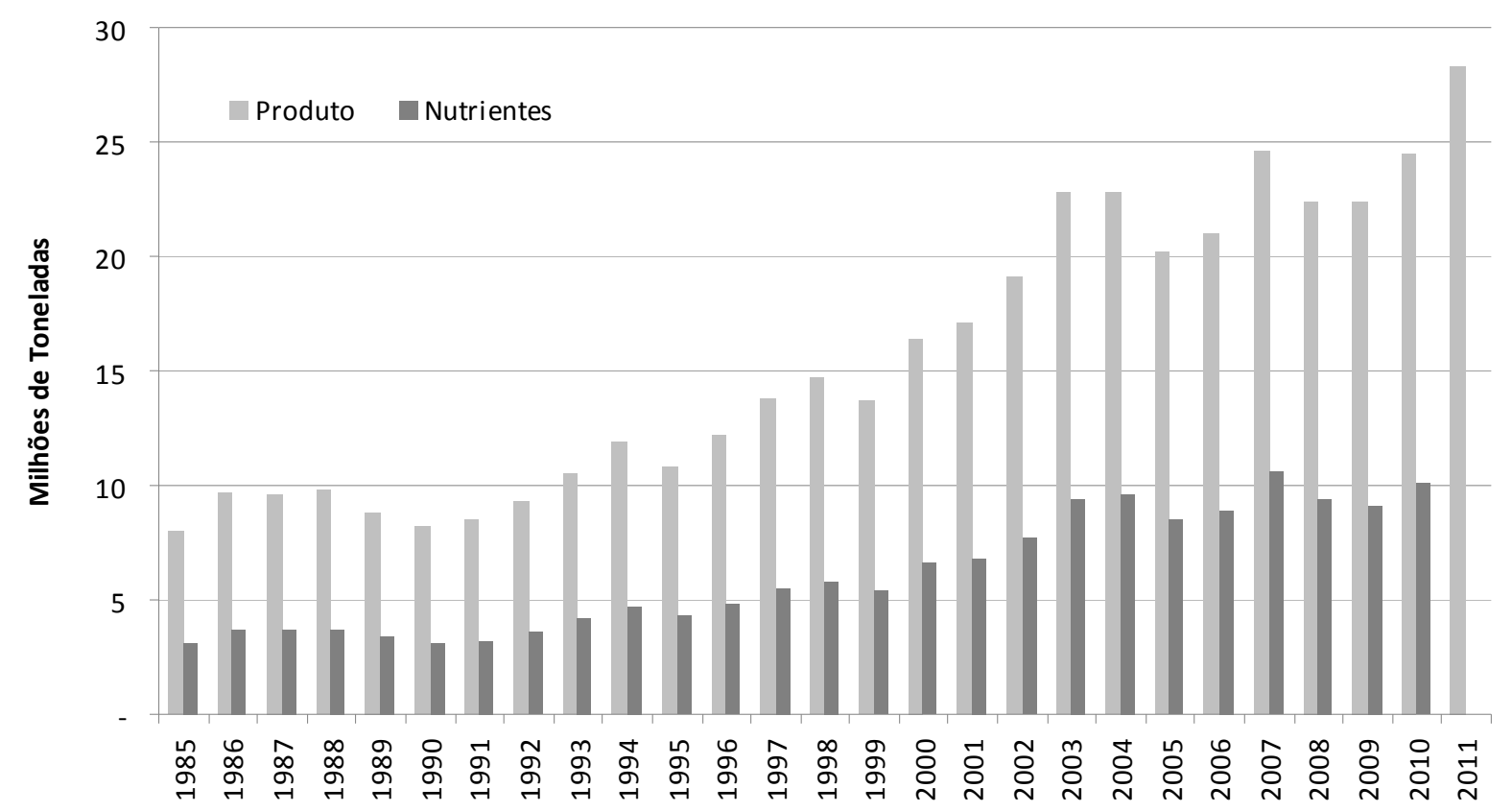

Figura 2. Evolução das vendas de fertilizantes no mercado brasileiro. Fonte: ANDA (2011)

A importação de nitrogênio $(N)$ passou de $4 \%$ da oferta em 1983, para $78 \%$ em 2011. O fósforo $\left(\mathrm{P}_{2} \mathrm{O}_{4}\right)$, cuja importação era nula em 1983 , passou para $53 \%$ da oferta em 2011. Já o potássio $\left(\mathrm{K}_{2} \mathrm{O}\right)$ seguiu o caminho contrário com a abertura de uma mina em Sergipe, passando de uma importação de 100\% para $93 \%$ da oferta no mercado doméstico. Comparando-se a oferta global de nutrientes, a importação de NPK apresentou elevação de $32 \%$ para $75 \%$ neste período.

A Figura 3 apresenta a participação do produto importado e do nacional na oferta interna de fertilizantes no Brasil, para cada um dos nutrientes e para o total de NPK, nos anos de 1983 e 2011. 

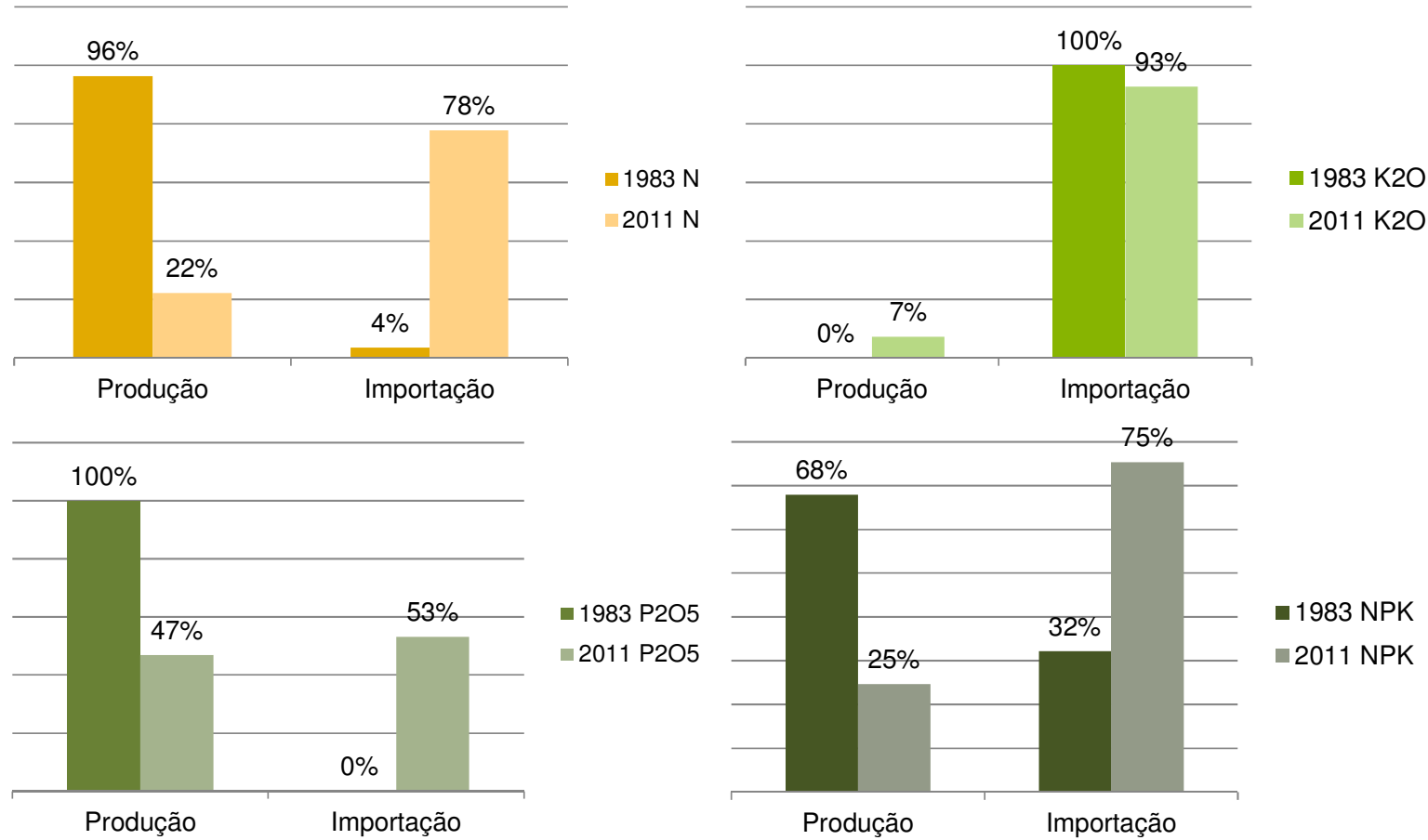

Figura 3. Participação percentual da importação e da produção doméstica na oferta de fertilizantes. Fonte: ANDA, 2011. Elaborada pelo autor

Os fertilizantes importados têm como principal porta de entrada no país, os portos de Paranaguá, Santos e Rio Grande. Destes e outros demais portos, os produtos dirigem-se para os principais estados consumidores: São Paulo, Paraná, Rio Grande do Sul, Mato Grosso, Minas Gerais e Goiás. O Mato Grosso do Sul e o Maranhão também estão se tornando grandes consumidores destes insumos.

A Figura 4 apresenta o mapa com os principais portos de origem e Estados de destino dos fertilizantes importados pelo Brasil no ano de 2011. 


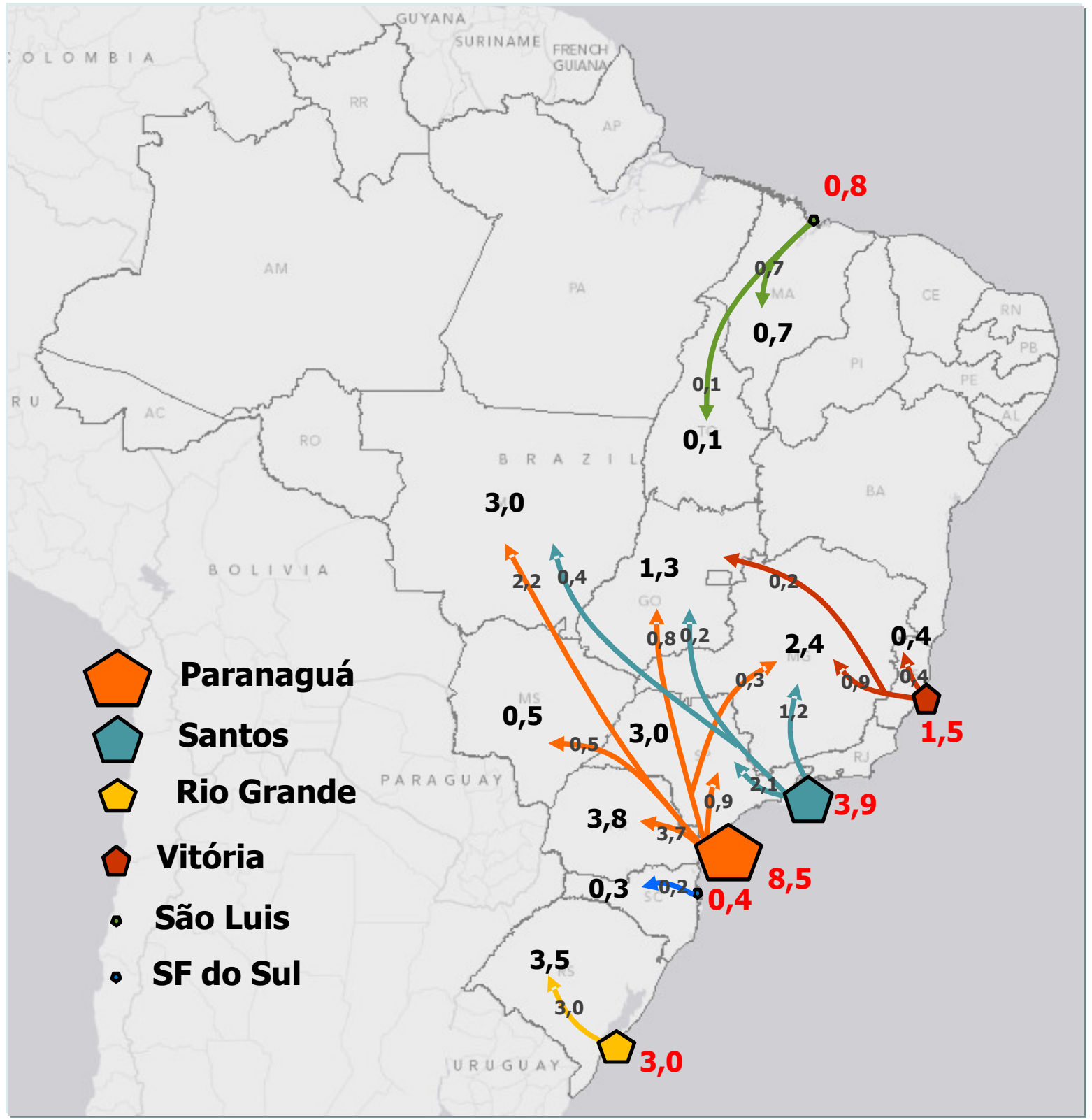

Figura 4. Importação de fertilizantes: principais portos de entrada e Estados de destino em 2011. Elaborada pelo autor com dados da Secex

3.3 BREVE HISTÓRICO DA INDÚSTRIA NACIONAL DE FERTILIZANTES

As primeiras fábricas de fertilizantes surgiram no Brasil na década de 40 e funcionavam como misturadoras de NPK, sendo que toda a matéria-prima era 
importada em condições favoráveis por meio de política cambial promovida pelo Estado.

Na década de 60 a produção interna restringia-se a exploração de uma mina de fosfato e a alguns produtores de Super Fosfato Simples.

A partir de 1970, o setor entrou em uma fase de investimentos promovida pelo II Plano Nacional de Desenvolvimento, em uma tentativa de reduzir a dependência externa do insumo. Nos 20 anos seguintes, grande parte das minas que atualmente são exploradas tiveram seu início, como Tapira e Araxá, ambas no Estado de Minas Gerais e Catalão, em Goiás (FERNANDES et al, 2009).

A década de 90 trouxe, junto com a abertura da economia, a privatização do setor e um movimento de concentração neste mercado.

Conforme relatório da Secretaria de Acompanhamento Econômico (SEAE, 2011), até 2009, as duas maiores empresas do setor de fertilizantes no país eram a Fosfértil e a Ultrafértil. Elas atuavam no segmento de fosfatados e nitrogenados e pertenciam ao consórcio Fertifós, que surgiu pós o processo de privatização e de fusões e aquisições na década de noventa. Ambas passaram a ser controladas pelo grupo Fertifós, formado pelas empresas IAP, Manah, Solorrico, Fertibrás, Fertiza e Takenaka/Ouro Verde. Em 2000, o Grupo Bunge comprou as empresas IAP, Takenaka/Ouro Verde e Manah e a Cargill adquiriu a Solorrico e a Fertiza. A Bunge passou a deter 52,3\% do controle de Fosfértil. A Cargill ficou com $33,1 \%$ e a Fertibrás com 12,76\%. A Fertifós ficou com o controle acionário exclusivo da Ultrafértil.

Posteriormente, a Cargill Fertilizantes foi adquirida pela Mosaic, que havia surgido da união das empresas Cargill Fertilizantes com a IMC Global e a Fertibrás foi adquirida pelo Grupo Yara. Em 2003, a Bunge adquiriu da companhia Paulista de Ferros e Ligas, subsidiária da Vale do Rio Doce S/A (CVRD), a totalidade da Dijon Participações Ltda, que possuía $11,12 \%$ do capital da Fosfértil.

Em 2010, houve a aquisição de todos ativos de fertilizantes do Grupo Bunge, a Bunge Participações S.A. pela Companhia Vale do Rio Doce (CVRD). A CVRD adquiriu também a participação acionária na Yara Brasil Fertilizantes S.A, incluindo a participação da empresa na Fosfértil (por intermédio da Fertibrás). O Grupo Vale adquiriu também as ações de titularidade da Mosaic Fertilizantes do Brasil S.A., 
consolidando a sua participação na Fertifós e na Fertilizantes Fosfatados S.A. (SEAE, 2011).

Atualmente a cadeia pode ser dividida em quatro sub-segmentos: o primeiro, de matérias-primas, é altamente concentrado por conta do acesso restrito aos recursos naturais (minas); o segundo é o de produtos intermediários; o terceiro de produtos básicos; e o quarto, extremamente pulverizado, é o das misturadoras, de alcance regional.

A fabricação de fertilizantes compostos não envolve qualquer complexidade técnica e é feita pela mistura de fertilizantes simples nas proporções adequadas. (DIAS; FERNANDES, 2006). Algumas empresas, no entanto, atuam de forma integral, ocupando todos os elos da cadeia, desde a exploração das minas à distribuição do produto final. Outras atuam em alguns elos somente, como por exemplo, na produção de fertilizantes simples, utilizando matéria-prima das outras empresas.

\subsection{ESTRUTURA DA INDÚSTRIA NACIONAL DE FERTILIZANTES}

Adubo ou fertilizante é um produto mineral ou orgânico, natural ou sintético, fornecedor de um ou mais nutrientes vegetais (ALCARDE et al, 1998). Sob o ponto de vista químico, os fertilizantes dividem-se em minerais e orgânicos. Os minerais, foco deste estudo, são os compostos desprovidos de carbono ou aqueles constituídos de compostos orgânicos sintéticos, como é o caso da uréia.

Os fertilizantes minerais simples (ou básicos) são os constituídos fundamentalmente de um composto químico, contendo um ou mais nutrientes vegetais, quer sejam eles macro ou micronutrientes ou ambos. Os fertilizantes mistos ou misturas de fertilizantes são os fertilizantes resultantes da mistura de dois ou mais fertilizantes simples.

Na cadeia de produção dos fertilizantes, o segmento extrativo-mineral fornece os insumos básicos para produção das matérias-primas. Das matérias-primas - 
rocha fosfática, enxofre e amônia (extraída principalmente do gás natural) - são produzidos os produtos intermediários: ácido nítrico, sulfúrico e fosfórico, que combinados entre si formam os fertilizantes básicos (simples), dentre os quais os mais importantes são o MAP, o DAP, o Super fosfato simples e a uréia. Da rocha potássica extrai-se diretamente o Cloreto de Potássio, outro produto básico importante.

A mistura destes produtos, por sua vez, origina as granulações e as formulações de NPK, conhecidos também como fertilizantes complexos, mistos ou misturas de fertilizantes. A Figura 5 explica a produção dos fertilizantes minerais, desde a extração das matérias-primas.

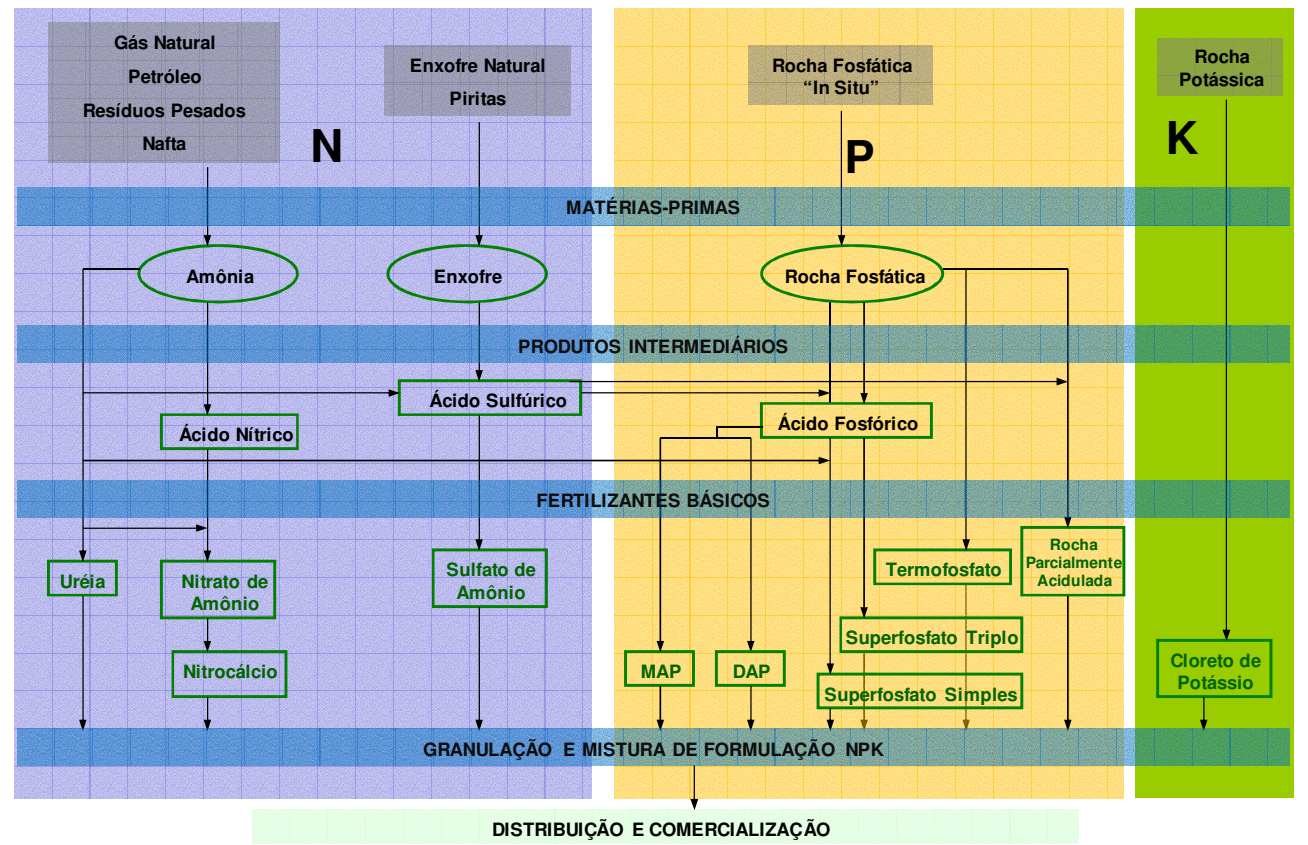

Figura 5. Cadeia Produtiva dos Fertilizantes. Adaptado de DIAS, V.P., FERNADES, E., 2006

A indústria brasileira de fertilizantes em 2011 era composta de 14 empresas, que possuíam capacidade para produzir 16,9 milhões de toneladas de matériasprimas, das quais derivava a produção de 14,3 milhões de toneladas de produtos intermediários, também chamados de fertilizantes básicos. Na Tabela 4 são apresentadas estas empresas, segundo sua distribuição geográfica e com suas respectivas capacidades de produção. 
Tabela 4: Distribuição das Empresas de Fertilizantes no Brasil em 2011

\begin{tabular}{|c|c|c|c|c|c|c|c|}
\hline \multirow{2}{*}{ Produto } & \multirow{2}{*}{ Empresa } & \multirow{2}{*}{ Localização } & \multirow{2}{*}{ UF } & \multicolumn{3}{|c|}{ Concentração } & \multirow{2}{*}{$\begin{array}{l}\text { Capacidade } \\
\text { Usual de } \\
\text { Produção } \\
\text { (t/ano) }\end{array}$} \\
\hline & & & & $\mathbf{N}$ & $\mathrm{P}_{2} \mathrm{O}_{5}$ & $\mathrm{~K}_{2} \mathrm{O}$ & \\
\hline \multicolumn{8}{|l|}{ Matérias-Primas } \\
\hline \multirow[t]{5}{*}{ Ácido Fosfórico } & Copebrás & Catalão & $\mathrm{GO}$ & & & & 140.000 \\
\hline & & Cubatão & $\mathrm{SP}$ & & & & 140.000 \\
\hline & Vale Fertilizantes & Cajati & $\mathrm{SP}$ & & & & 222.000 \\
\hline & & Piaçagüera & $\mathrm{SP}$ & & & & 146.000 \\
\hline & & Uberaba & MG & & & & 907.000 \\
\hline \multirow[t]{10}{*}{ Ácido Sulfúrico } & Copebrás & Catalão & GO & & & & 560.000 \\
\hline & & Cubatão & $\mathrm{SP}$ & & & & 624.000 \\
\hline & Fertilizantes Heringer & Paranaguá & PR & & & & 200.000 \\
\hline & Galvani & Luis Ed. Magalhães & $\mathrm{BA}$ & & & & 140.000 \\
\hline & & Paulínia & $\mathrm{SP}$ & & & & 400.000 \\
\hline & Vale Fertilizantes & Araxá & $M G$ & & & & 693.000 \\
\hline & & Cajati & $\mathrm{SP}$ & & & & 629.000 \\
\hline & & Cubatão & $\mathrm{SP}$ & & & & 354.000 \\
\hline & & Piaçagüera & $\mathrm{SP}$ & & & & 456.000 \\
\hline & & Uberaba & $M G$ & & & & 2.570 .000 \\
\hline \multirow[t]{4}{*}{ Amônia Anidra } & Petrobrás & Camaçari & BA & 82,2 & & & 445.500 \\
\hline & & Laranjeiras & SE & 82,2 & & & 412.500 \\
\hline & Vale Fertilizantes & Araucaria & $\mathrm{PR}$ & 82 & & & 412.000 \\
\hline & & Piaçagüera & $\mathrm{SP}$ & 82 & & & 209.000 \\
\hline \multirow[t]{12}{*}{ Rocha Fosfática } & Copebrás & Catalão & GO & & 38 & & 1.300 .000 \\
\hline & Galvani & AngicoDias & $\mathrm{BA}$ & & 33 & & 215.000 \\
\hline & & Irecê & $\mathrm{BA}$ & & 33 & & 115.000 \\
\hline & & Lagamar & $M G$ & & 28 & & 220.000 \\
\hline & Vale Fertilizantes & Araxá & MG & & 35 & & 990.000 \\
\hline & & Araxá & $M G$ & & 33 & & 660.000 \\
\hline & & Cajati & $\mathrm{SP}$ & & 36 & & 548.000 \\
\hline & & Catalão & GO & & 36,5 & & 875.000 \\
\hline & & Catalão & GO & & 34 & & 125.000 \\
\hline & & Patos de Minas & $M G$ & & 24 & & 44.000 \\
\hline & & Tapira & $M G$ & & 35,5 & & 2.003 .000 \\
\hline & & Tapira & $M G$ & & 33,5 & & 167.000 \\
\hline \multicolumn{8}{|l|}{ Intermediários } \\
\hline Cloreto de Potassio & Vale Potassio Nordeste & Taquari Vassouras & SE & & & 58 & 654.000 \\
\hline Fosfato & Copebrás (Gr) & Catalão & GO & 9 & 48 & & 150.000 \\
\hline \multirow[t]{3}{*}{ Monoamônio MAP } & Vale Fertilizantes (Gr) & Piaçaguera & $\mathrm{SP}$ & 11 & 52,5 & & 337.000 \\
\hline & & Uberaba & $M G$ & 10,5 & 54 & & 855.000 \\
\hline & & Uberaba & MG & 10,5 & 54 & & 150.000 \\
\hline $\begin{array}{l}\text { Fosfato Natural } \\
\text { de Apl. Direta }\end{array}$ & Itafós & Arraias & TO & & 24 & & 100.000 \\
\hline Nitrato de Amônio & Vale Fertilizantes & Piaçagüera & $\mathrm{SP}$ & 34 & & & 407.000 \\
\hline \multirow[t]{2}{*}{ Sulfato de Amônio } & Proquigel & Candeias & $\mathrm{BA}$ & 21 & & & 400.000 \\
\hline & Vale Fertilizantes & Cubatão & $\mathrm{SP}$ & 20,5 & & & 77.000 \\
\hline Superfosfato & Bunge Fertilizantes & Rio Grande & RS & & 18 & & 250.000 \\
\hline \multirow[t]{10}{*}{ Simples (Pó) } & Cibrafertil & Camaçari & $\mathrm{BA}$ & & 18 & & 300.000 \\
\hline & Copebrás & Catalão & GO & & 18 & & 550.000 \\
\hline & & Cubatão & $\mathrm{SP}$ & & 18 & & 400.000 \\
\hline & Fertilizantes Heringer & Paranaguá & PR & & 18 & & 250.000 \\
\hline & Fospar & Paranaguá & $\mathrm{PR}$ & & 19 & & 520.000 \\
\hline & Galvani & Luis Ed. Magalhães & $\mathrm{BA}$ & & 18 & & 450.000 \\
\hline & & Paulínia & $\mathrm{SP}$ & & 18 & & 700.000 \\
\hline & Timac Agro & Candeias & $\mathrm{BA}$ & & 18 & & 180.000 \\
\hline & & Rio Grande & RS & & 18 & & 300.000 \\
\hline & & Santa Luzia do Norte & $A L$ & & 18 & & 120.000 \\
\hline
\end{tabular}




\begin{tabular}{|c|c|c|c|c|c|}
\hline & & & & & (Continuação) \\
\hline Superfosfato & Vale Fertilizantes & Araxá & $M G$ & 18 & 1.347 .000 \\
\hline Simples (Pó) & & Catalão & GO & 18 & 350.000 \\
\hline & & Cubatão & $\mathrm{SP}$ & 18 & 637.000 \\
\hline & & Cubatão & $\mathrm{SP}$ & 18 & 330.400 \\
\hline & & Guará & $\mathrm{SP}$ & 18 & 401.000 \\
\hline & & Patos de Minas & MG & 22 & 250.000 \\
\hline & & Uberaba & $M G$ & 18 & 280.000 \\
\hline & YaraBrasil & RioGrande & RS & 18 & 600.000 \\
\hline Superfosfato & Copebrás & Catalão & GO & 41 & 60.000 \\
\hline Triplo (Pó) & TimacAgro & RioGrande & $\mathrm{RS}$ & 42 & 50.000 \\
\hline & Vale Fertilizantes & Uberaba & $M G$ & 44,5 & 929.000 \\
\hline & YaraBrasil & Rio Grande & RS & 42 & 50.000 \\
\hline Termofosfato & Mineração Curimbaba & Poços de Caldas & MG & 18 & 180.000 \\
\hline Uréia & Petrobrás & Camaçari & $\mathrm{BA}$ & 46 & 429.000 \\
\hline & & Laranjeiras & SE & 46 & 594.000 \\
\hline & Vale Fertilizantes & Araucária & PR & 46 & 630.000 \\
\hline
\end{tabular}

A Figura 6 apresenta o mapa com a distribuição geográfica da indústria nacional de fertilizantes e os principais portos importadores do produto: Paranaguá, Porto de Santos e Rio Grande do Sul. É possível notar que a indústria está localizada junto às minas, no caso das rochas fosfática e potássica, ou junto aos portos, por onde importa a matéria-prima. Já as misturados estão distribuídas mais próximas às regiões de produção agrícola. 


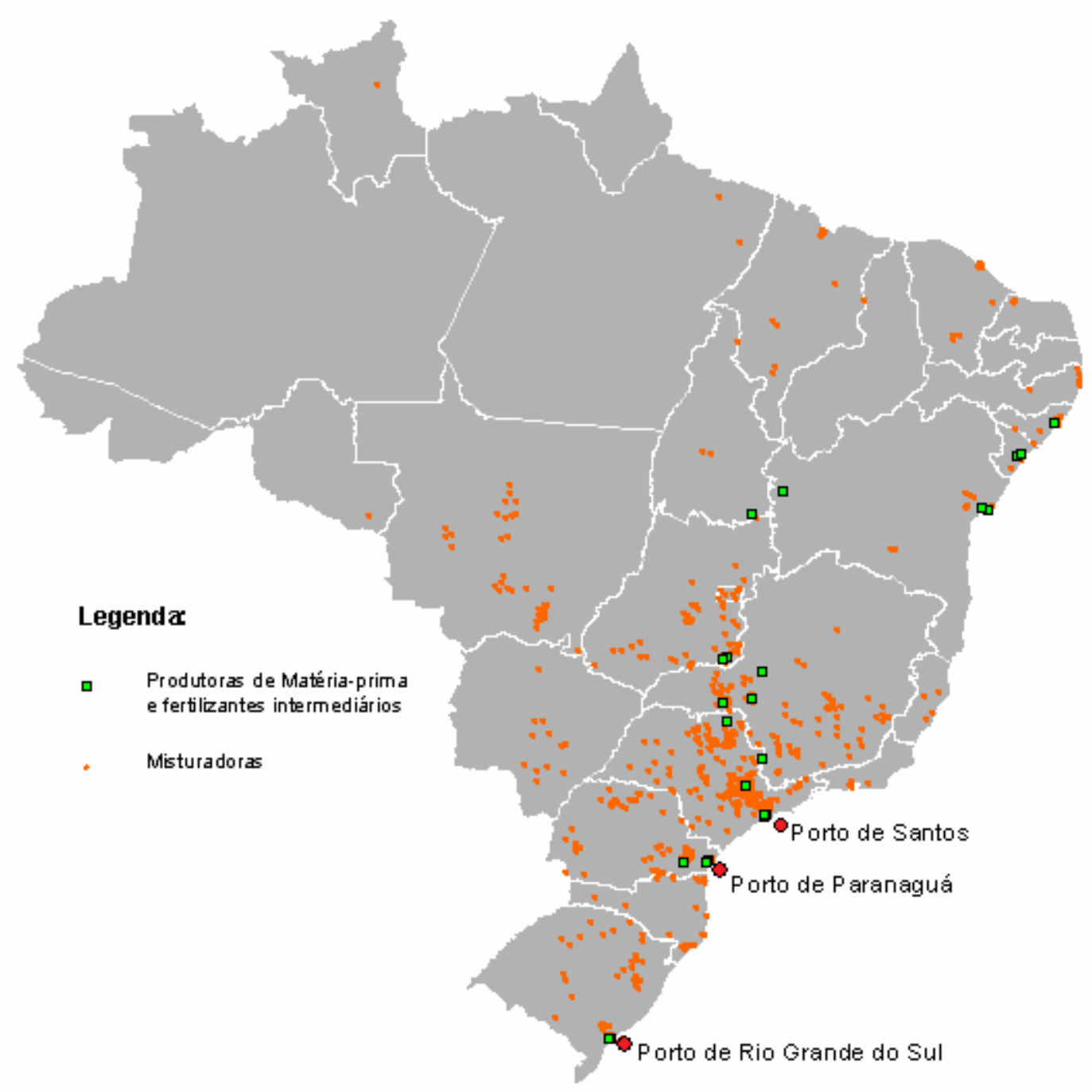

Figura 6. Mapa da distribuição da indústria de fertilizantes nacional (misturadoras e produtoras). Elaborada pelo autor com dados da ANDA (2010) e Associação dos Misturadures de Adubos (http://www.amabrasil.agr.br/).

Quanto à capacidade de expansão da indústria nacional, no caso dos fertilizantes nitrogenados, pode-se afirmar que, em tese, haveria condição para ampliar a produção doméstica, no entanto, sua produção depende basicamente da oferta de gás natural.

O gás natural é a matéria-prima para a fabricação da amônia, que é a base para a produção de fertilizantes nitrogenados. De acordo com a Associação Internacional da Indústria de Fertilizantes (IFA), a produção de amônia consome cerca de $5 \%$ da oferta global de gás natural. 
Segundo o Sumário Mineral do Departamento Nacional de Pesquisa Mineral DNPM (FERNANDES, 2010), o volume total comercializado de gás natural no Brasil foi de 19,7 bilhões $\mathrm{m}^{3}$ em 2008, sendo que a importação respondeu por 10,3 bilhões de m3.

Quanto à oferta futura, no Plano de Negócios da Petrobras 2009-2013 existem 5 projetos de investimento na produção de gás natural, com previsão de gerar um incremento de 22 milhões m3/dia na produção nacional (cerca de 8 bilhões de m3 anuais).

Conforme investimentos divulgados pela Petrobrás, a capacidade de produção de uréia deve chegar a 2.9 milhões de toneladas no ano de 2017.

Ao que se refere aos fertilizantes fosfatados, este é o nutriente com maior capacidade de expansão da produção doméstica. Em 2011, o Brasil possuía a capacidade de produzir 7,3 milhões de toneladas de rocha fosfática (2,6 milhões de toneladas de $\mathrm{P}_{2} \mathrm{O}_{5}$ ) segundo a ANDA (2011).

O Brasil pode se tornar auto-suficiente na produção de adubos fosfatados, uma vez que o país possui reservas, tecnologia, recursos humanos e bens de capital para ampliar a capacidade produtiva.

Segundo o DNPM (2009), no entanto, a viabilidade da exploração das reservas disponíveis a partir de 2008 se deu em função da elevação dos preços dos fertilizantes no mercado internacional, já que os baixos preços anteriormente praticados compensavam a importação do produto de países cujos preços de extração eram mais baratos, como Marrocos.

De acordo com os investimentos levantados pela ANDA, a produção nacional de fertilizantes fosfatados deve chegar a 4 milhões de toneladas de $\mathrm{P}_{2} \mathrm{O}_{5}$ em 2017 .

Com relação aos fertilizantes potássicos, o Brasil não conta com muitas reservas naturais, sendo difícil a produção doméstica desse nutriente, o que contribuiu para que o país sempre apresentasse significativa dependência do mercado externo.

A única fonte produtora de potássio fertilizante no Brasil, o Complexo de Mina/Usina de Taquari-Vassouras/SE, está a cargo da VALE, desde o final do ano 
de 1991 e, de acordo com o contrato de arrendamento feito com a PETROBRAS, deverá operar o Complexo por vinte e cinco anos.

No entanto, existem alguns projetos previstos para a área arrendada pela VALE. A empresa iniciou a operação em uma Planta Piloto em Sergipe, em 2010, na sub-bacia Taquari/Vassouras, com objetivo de definir a viabilidade do aproveitamento dos depósitos de carnalita por processo de dissolução. Se comprovada a viabilidade da lavra e beneficiamento, o início do projeto produtivo se dará em 2014, com a produção anual estimada, de 1,2 milhões de toneladas de $\mathrm{KCl}$ por ano e vida útil prevista de 40 anos (OLIVEIRA, 2010).

O Estado do Amazonas possui reservas de silvinita $(\mathrm{KCl}+\mathrm{NaCl})$ descobertas na década de 80 pela PETROMISA/PETROBRAS localizadas nos Municípios de Nova Olinda do Norte e Itacoatiara, a $140 \mathrm{~km}$ a sudeste de Manaus. Estes depósitos, que pertencem às Formações Monte Alegre, Itaituba, Nova Olinda e Andirá possuem reservas medidas que somam 152,5 milhões de toneladas, com teores que variam entre $14,31 \%$ a $38,69 \%$ de cloreto de potássio (NAVA; HORBE, 2008).

A atividade nesta área, que estava desativada há quase 30 anos, após a extinção da Petromisa, subsidiária da Petrobrás que atuava no segmento, ainda não estava definida até meados de 2010. Se comprovado o potencial das jazidas, serão feitos investimentos na exploração do mineral para a produção de fertilizantes.

\subsection{A FORMAÇÃO DE PREÇOS DOS FERTILIZANTES IMPORTADOS NO BRASIL}

Os fertilizantes, tanto na forma de produtos intermediários quanto na forma de matérias-primas são adquiridos no mercado externo a preços formados no mercado internacional, derivados da demanda e ofertas mundiais.

Parte da formação de preços dos fertilizantes importados comercializados no Brasil, ou seja, a parte referente aos custos logísticos do produto, inicia-se com o produto já embarcado no porto de origem. As principais origens dos nutrientes 
importados pelo País são os portos do Mar Báltico, no caso do MAP (Monoamônio fosfato), o Golfo Árabe no caso da uréia e Vancouver, no Canadá, no caso do Cloreto de Potássio.

Sobre o preço FOB (preço no qual já incidiram os custos portuários) no porto de origem, adiciona-se o valor do frete e seguro marítimo até um dos três principais portos de destino no Brasil - Santos, Paranaguá ou Rio Grande. Incidem então sobre o produto tarifas e impostos. No caso dos fertilizantes, o imposto sobre importação está zerado, incidindo sobre o produto somente o imposto da marinha mercante. São adicionadas as despesas aduaneiras e portuárias, como o frete interno no porto e o produto tem seu preço convertido em Reais. Carregado nos caminhões, o fertilizante é transportado às misturadoras que unem os três produtos para formar as formulações de nitrogênio, fósforo e potássio e distribuí-las na região de consumo, somando-se aos produtos os custos de frete do porto até o destino.

Sobre o fertilizante produzido no Brasil incidem o frete até o destino de consumo e o Imposto sobre a circulação de Mercadorias e Serviços (ICMS). Este é o principal imposto incidente sobre insumos agrícolas no Brasil. O setor é isento de IPI e, desde 2004 (Lei no 10.925) a alíquota de PIS/COFINS está zerada. O Senado Federal é responsável pela definição das alíquotas mínimas estaduais e interestaduais do ICMS.

O Conselho Interfazendário - CONFAZ, é o órgão que congrega todos os Secretários de Fazenda dos Estados, e cabe a ele legislar sobre isenções, benefícios e incentivos fiscais, reduções de base de cálculo etc. Aos Estados cabe fixar a alíquota interna, respeitado o limite mínimo estipulado pelo Senado.

No caso dos insumos agrícolas, o Convênio ICMS 100/97 determinou que o ICMS interestadual tivesse redução de base de cálculo de $60 \%$ ou $30 \%$ conforme o produto considerado. As alíquotas atualmente vigentes são de $12 \%$ ou $7 \%$, dependendo da região de origem e/ou destino do produto. Dentro dos Estados, o mesmo Convênio 100 autorizou a concessão de isenção ou redução da base de cálculo nas operações internas. Hoje, o ICMS está isento (por exemplo, nos Estados de São Paulo e Goiás) ou diferido (nos Estados de Minas Gerais e Paraná) nas operações internas. 
O produto importado pagava até março de 2006, Imposto de Importação de 4\% na matéria-prima e de 0 a $2 \%$ no produto intermediário. A partir de então, o imposto de importação foi zerado. Por obediência a acordo sancionado pela OMC, o produto importado não pode ser tributado por ICMS, nos Estados, se o produto nacional não o for. Assim, não há ICMS na importação de produtos diretamente para o Estado consumidor.

A Tabela 5 apresenta a situação tributária vigente em 2008, no que diz respeito ao ICMS incidente sobre o fertilizante nacional e o importado.

Tabela 5. Alíquota de ICMS incidente sobre o fertilizante doméstico e o importado

\begin{tabular}{llcc}
\hline Produto nacional produzido no Brasil e remetido à & $\begin{array}{r}\text { Produto } \\
\text { em outros países e remetido à }\end{array}$ \\
\hline Estados & Alíquota (\%) & Estados & Alíquota \\
& & & (\%) \\
\hline MT & $4,9 \%(7 \%$ com $30 \%$ de redução $)$ & MT & $0 \%$ \\
SP & $8,4 \%(12 \%$ com $30 \%$ de redução $)$ & SP & $0 \%$ \\
PR & $8,4 \%(12 \%$ com $30 \%$ de redução $)$ & PR & $0 \%$ \\
GO & $4,9 \%(7 \%$ com $30 \%$ de redução $)$ & GO & $0 \%$ \\
MS & $4,9 \%(7 \%$ com 30\% de redução $)$ & MS & $0 \%$ \\
\hline
\end{tabular}

Fonte: CONFAZ Fonte: http://www.fazenda.gov.br/confaz/

\subsection{O USO DE MODELOS DIGITAIS DE ELEVAÇÃO EM ESTUDOS SÓCIO- ECONÔMICOS}

A espacialização de dados em superfícies contínuas é amplamente utilizada em estudos que possuem como foco análises ambientais, na topografia, em estudos hidrológicos e em análises sócio-econômicas, predominantemente neste caso, em estudos de distribuição populacionais. 
Durante a condução deste estudo, não foi identificada a utilização de Modelos Digitais de Elevação para análise de dados sócio-econômicos semelhante ao que o trabalho propõe.

Foram levantados alguns estudos em que foram utilizados interpoladores para espacializar dados sócio-econômicos. Grande parte deles utilizou a técnica para estimar valores não conhecidos ou apenas para elaborar uma análise visual das informações, e trabalhou com dados primários, extraídos de pesquisas ou de levantamentos de campo. Vale observar que a maioria dos estudos levantados, que propuseram a espacialização de informações sócio-econômicas, utilizaram a krigagem como método de interpolação dos dados.

Barros Filho (2007) avaliou os resultados obtidos da aplicação do método de Krigagem Ordinária na análise espacial da habitabilidade intra-urbana na cidade do Recife (Brasil). No estudo, foram construídos índices de habitabilidade, utilizando-se dados do Censo Demográfico e gerados mapas a partir da interpolação destes índices.

Montero, Larraz e Chasco (2008) utilizaram o método de krigagem para espacializar variáveis ambientais, no caso, contaminantes do ar, criar uma superfície de dados e com ela, elaborar um índice ambiental para a cidade de Madri. A krigagem também foi utilizada por Wang e Kockelman (2009) para estimar o volume médio de tráfego projetado para o Estado do Texas, EUA, onde detectores de tráfego não estavam presentes.

Em Hermann e Haddad (2005), para estimar os preços implícitos das amenidades urbanas para a cidade de São Paulo, foram construídas curvas de nível baseadas nos resíduos da regressão sobre variáveis de controle. A função das curvas de nível, neste caso, foi auxiliar na seleção das variáveis explicativas. Neste estudo, como sugeriram os autores, a utilização dos mapas de curva de nível foi acompanhada por um conjunto de cartas temáticas sobre a região de estudo, para que fosse possível extrair alguma informação relevante sobre o fenômeno.

Weir-Smith e Schwabe (2010) compararam a estimação de dados por meio de dois métodos, à interpolação por "quadratic spline" e por meio de redes neurais. Os dados utilizados na pesquisa foram o uso de álcool por presidiários na África do Sul. 
Estes dados foram escolhidos para nortear políticas públicas contra o uso de substâncias tóxicas na África do Sul.

Vale ressaltar, que a proposta de utilização da modelagem digital de terreno no presente estudo não se caracterizou por ser inovadora, mas por se mostrar necessária ao tipo de avaliação a avaliação da competitividade geográfica entre um mesmo produto de diferentes origens.

\subsection{MODELAGEM NUMÉRICA DE TERRENO}

Segundo Barros (2006) diversas terminologias são utilizadas para designar os modelos digitais que representam a superfície terrestre, sua topografia ou seu uso e cobertura. Os termos mais usados são: MDE (Modelo Digital de Elevação), MDT (Modelo Digital de Terreno), MDS (Modelo Digital de Superfície), MNT (Modelo numérico do Terreno), MNE (Modelo numérico de Elevação).

Para Fernandes (2004) a diferença entre MDT e MDE é o fato do primeiro conter apenas altimetria, enquanto o segundo pode conter outras feições, além desta.

De acordo com Podobnikar (2009), um Modelo Digital de Terreno (MDT) é a representação de uma superfície contínua comumente usada para produzir mapas topográficos.

Para Câmara, Monteiro e Medeiros (2004), um Modelo Digital de Elevação (MDE) é uma representação matemática computacional da distribuição de um fenômeno espacial que ocorre dentro de uma região da superfície terrestre.

Os Modelos Digitais de Terreno são criados pela integração de dados obtidos de uma vasta gama de técnicas, dentre as quais, o sensoriamento remoto e 0 levantamento de campo.

Segundo Podobnikar (2005), um Modelo Digital de Terreno, além de conter os valores de altura formando uma rede (conhecido como Modelo Digital de Elevação- 
DEM), também é composto por elementos que descrevem a topografia da superfície, como a inclinação.

Um modelo numérico de terreno (MNT) pode representar dados de relevo, informações geológicas, levantamentos de profundidades do mar, dados geofísicos ou geoquímicos; gerando mapas topográficos, de declividade, ou mesmo apresentações tridimensionais de algumas variáveis.

Sobre um modelo digital de terreno é possível visualizar os modelos em projeção geométrica planar; gerar imagens em níveis de cinza, gerar imagens sombreadas e imagens temáticas, calcular volumes e áreas, desenhar perfis e secções transversais, desenhar perspectivas tridimensionais, além de gerar mapeamentos, como mapas de declividade e de exposição, mapas de drenagem, mapas de curvas de nível e mapas de visibilidade.

Os produtos das análises dos modelos digitais podem ser integrados aos demais tipos de dados geográficos e desenvolver, a partir desses conjuntos de dados, aplicações de geoprocessamento, como, planejamento urbano e rural, análises de aptidão agrícola, determinação de áreas de riscos, geração de relatórios de impacto ambiental e outros.

A geração de um Modelo Digital de Terreno é composta pela etapa de aquisição das amostras e da geração do modelo propriamente dita, ou interpolação dos dados. Os dados de um modelo numérico de terreno estão representados por três coordenadas $\mathrm{x}, \mathrm{y}$ e $\mathrm{z}$, onde $\mathrm{x}$ e y são as coordenadas geográficas e z a altura.

A amostragem é a aquisição de um conjunto de dados que representem a variação do fenômeno espacial de interesse. Para realização de modelos digitais de elevação topográficos, de solos, geológicos, entre outros, a amostragem é feita a partir de levantamentos in loco, utilizando-se técnicas estatísticas para delimitar o tamanho e desenho das amostras, via sensoriamento remoto, aerofotogrametria, ou pela captura de dados cartográficos, via escaneamento e digitalização.

De acordo com Câmara, Monteiro e Medeiros (2004), a definição de uma amostragem representativa, deve-se considerar a quantidade e também o posicionamento das amostras em relação ao comportamento do fenômeno a ser modelado. 
A superamostragem de uma região homogênea ou plana pode acarretar em uma redundância de informação, enquanto que uma pequena amostragem em uma área heterogênea pode incorrer na falta de informação.

Quanto a posição relativa das amostras, estas classificam-se em regular, semiregular e irregular. A amostragem regular é aquela cuja posição espacial (x,y) das amostras mantém uma distribuição regular. A Figura 7 apresenta um exemplo de uma amostragem regular. As amostragens semi-regulares são aquelas que preservam a regularidade de distribuição espacial em uma das direções, x ou y.

$\begin{array}{lllllllllll}+ & + & + & + & + & + & + & + & + & + \\ + & + & + & + & + & + & + & + & + & + \\ + & + & + & + & + & + & + & + & + & + \\ + & + & + & + & + & + & + & + & + & + \\ + & + & + & + & + & + & + & + & + & + \\ + & + & + & + & + & + & + & + & + & + \\ + & + & + & + & + & + & + & + & + & +\end{array}$

Figura 7. Exemplo de uma amostragem regular Fonte: Câmara, Monteiro e Medeiros (2004)

As amostragens irregulares são as que não apresentam nenhum critério de distribuição. A Figura 8 apresenta um exemplo de amostragem irregular.

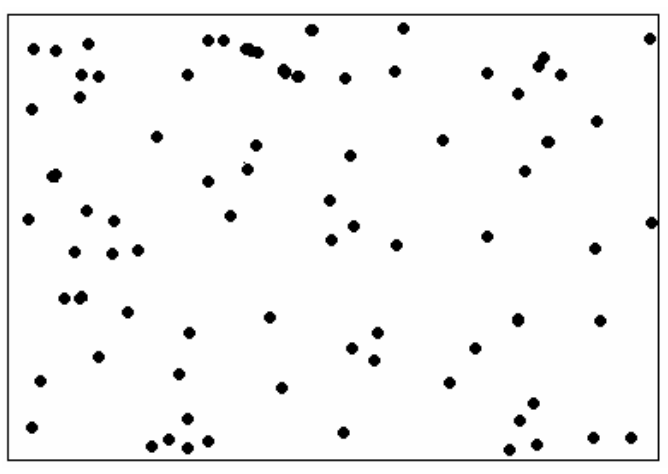

Figura 8. Exemplo de uma amostragem irregular Fonte: Câmara, Monteiro e Medeiros (2004)

No caso de dados sócio-econômicos, a obtenção das amostras está comumente relacionada à restrição geográfica dos dados, como a localização da ocorrência de acidentes de trânsito, a infecção por algum tipo de doença, a renda 
relacionada à sede do município, a setores censitários ou ao endereço do indivíduo, etc.

\subsection{MÉTODOS DE INTERPOLAÇÃO}

A interpolação consiste na criação de estruturas de dados e na definição de superfícies de ajuste com o objetivo de se obter uma representação contínua do fenômeno a partir das amostras (CÂMARA; MONTEIRO; MEDEIROS, 2004). De forma simplificada, interpolar é utilizar pontos com valores conhecidos para estimar os valores desconhecidos de outros pontos.

Steinberg e Steinberg (2005) fazem uma analogia entre a interpolação espacial e a regressão dentro da estatística tradicional. Para ele, a principal diferença entre a regressão tradicional e a interpolação espacial é que, ao invés de encontrar dados em um espaço hipotético, as estimativas são relacionadas a um espaço geográfico real. Segundo o autor, há dois pressupostos básicos na interpolação espacial:

- os pontos mais próximos tendem a ter características mais semelhantes do que os pontos mais distantes;

- regiões entre os pontos amostrados podem possuir valores intermediários entre eles.

Reforçando este pressuposto, Brenning e Dubois (2008) indicam que o ponto comum para o desenvolvimento de interpoladores espaciais é que a observação de medições em locais próximos uns dos outros são mais semelhantes que em localidades distantes umas das outras. Esta afirmação independe de qualquer formulação matématica específica na concepção de um interpolador.

Ambos pressupostos aponta para a primeira lei da geografia de Tobler (1970), que afirmou que as localidades mais próximas entre si são mais parecidas que as que estão distantes. 
Existem diversos métodos de interpolar os dados de acordo com o tipo de grade escolhida. As duas estruturas (grades) mais utilizadas para interpolação de dados são a Grade ou Malha Regular e a Malha Triangular (Triangular Irregular Network - TIN).

Quanto aos métodos de interpolação, é possível dividi-los em globais e locais. No primeiro, considera-se toda a população de pontos, ou seja, estes interpoladores determinam uma função que é aplicada em toda a região a interpolar. Nos locais, são considerados somente os pontos próximos ao ponto a ser estimado. Os interpoladores locais aplicam algoritmos repetidamente a subconjuntos do conjunto total de pontos, sendo que uma alteração em um valor de entrada altera somente o resultado do subconjunto (Burrough, 1986).

Quanto ao tipo, existem os determinísticos, que não permitem avaliação da incerteza associada aos valores previstos e os estocásticos, que permitem a avaliação da incerteza, com base na variância estimada.

Quanto à técnica, os interpoladores exatos respeitam os valores da amostra, e portanto, a superfície estimada passa por todos os pontos amostrados. Os interpoladores inexatos ou aproximados estimam um valor diferente do medido. Eles baseiam-se no fato de que em muitas amostras, existem tendências globais com variações suaves, e simultaneamente, flutuações locais, que variam rapidamente (Matos, 2005).

De acordo com Druck et al (2004) pode-se considerar três grandes abordagens diferentes na geração de superfícies digitais:

- Os Modelos Determinísticos de efeitos Locais, que utilizam funções como inverso do quadrado da distância. Neles, predominam os efeitos puramente locais e não é feita qualquer hipótese estatística sobre a variabilidade espacial.

- Os Modelos Determinísticos de efeitos Globais, em que predomina a variação em larga escala na caracterização do fenômeno em estudo e a variabilidade local não é relevante. É o caso dos interpoladores por superfícies de tendência, que serão detalhados mais adiante.

- Os Modelos Estatísticos de efeitos Locais e Globais, no qual, cada ponto da superfície é estimado apenas a partir da interpolação das amostras mais próximas, utilizando um estimador estatístico. Esses procedimentos requerem que tanto a 
variabilidade local quanto a global sejam modeladas. Eles podem ser estimados através de procedimentos como a krigagem.

Uma visão geral das técnicas, comparações e pressupostos dos modelos foi apresentada por Hartkamp et al (1999) e encontra-se resumida no na Tabela 6. 
Tabela 6. Comparativo entre técnicas de interpolação e seus pressupostos

\begin{tabular}{|c|c|c|c|c|c|c|c|}
\hline Método & $\begin{array}{l}\text { Determinístico/Est } \\
\text { ocástico }\end{array}$ & Local/Global & Transição & $\begin{array}{l}\text { Interepolador } \\
\text { Exato }\end{array}$ & $\begin{array}{c}\text { Carga } \\
\text { Computacional }\end{array}$ & Estrutura de saída & Pressupostos do Modelo \\
\hline Classificação & $\begin{array}{l}\text { Determinístico } \\
\text { "suave" }\end{array}$ & Global & $\begin{array}{l}\text { Abrupto se único } \\
\text { usado }\end{array}$ & Não & Pequena & Polígonos classificados & Homogêneo dentro dos limites \\
\hline Superfície de Tendência & $\begin{array}{l}\text { Essencialmente } \\
\text { determinístico }\end{array}$ & Global & Gradual & Não & Pequena & Contínua, em grade & $\begin{array}{c}\text { Explicação fenomenológica da } \\
\text { tendência, dados normalmente } \\
\text { distribuídos }\end{array}$ \\
\hline Modelos de Regressão & $\begin{array}{l}\text { Essencialmente } \\
\text { determinístico }\end{array}$ & Global com refinamentos & $\begin{array}{l}\text { Gradual se os } \\
\text { dados possuírem } \\
\text { variação gradual }\end{array}$ & Não & Pequena & $\begin{array}{l}\text { Polígonos ou contínua. } \\
\text { Grade }\end{array}$ & $\begin{array}{l}\text { Explicação fenomenológica do } \\
\text { modelo de regressão }\end{array}$ \\
\hline Polígonos de Thiessen & Determinístico & Local & Abrupto & Sim & Pequena & Polígonos ou grade & $\begin{array}{l}\text { Opreditordo ponto estimado é o } \\
\text { ponto mais próximo }\end{array}$ \\
\hline Interpolação Picnofilatica & Determinístico & Local & Gradual & $\begin{array}{l}\text { Não, mas conserva } \\
\text { volume }\end{array}$ & $\begin{array}{l}\text { Pequena, } \\
\text { moderada }\end{array}$ & Grades ou contornos & $\begin{array}{l}\text { Contínua. Asuavidade da variação } \\
\text { é melhor que nas áreas ad hoc }\end{array}$ \\
\hline Interpolação Linear & Determinístico & Local & Gradual & Sim & Pequena & Grade & $\begin{array}{c}\text { Grande densidade de dados não } \\
\text { traz problemas para a } \\
\text { aproximação }\end{array}$ \\
\hline Thin plane spline & $\begin{array}{l}\text { Determinístico com } \\
\text { componente local } \\
\text { estocástico }\end{array}$ & Local & Gradual & $\begin{array}{l}\text { Sim, dentro dos } \\
\text { limites }\end{array}$ & Pequena & $\begin{array}{l}\text { Grades com linhas de } \\
\text { contornos }\end{array}$ & $\begin{array}{l}\text { Superfície subjacente é suave em } \\
\text { todos os lugares }\end{array}$ \\
\hline krigagem & Estocástico & $\begin{array}{l}\text { Local com variogramas, } \\
\text { quando estratificado, com } \\
\text { tendência }\end{array}$ & Gradual & Sim & Moderada & Grade & $\begin{array}{c}\text { Estacionariedade e hipótese } \\
\text { intrínsica }\end{array}$ \\
\hline Simulação condicional & Estocástica & $\begin{array}{l}\text { Local com variogramas, } \\
\text { com variogramas quando } \\
\text { estratificado, com tendência }\end{array}$ & Irregular & Sim & Moderada & Grade & $\begin{array}{c}\text { Estacionariedade e hipótese } \\
\text { intrínsica }\end{array}$ \\
\hline
\end{tabular}

Fonte: Adaptado de Hartkamp et al (1999) 
Nas seções 3.8.1 e 3.8.2 segue uma breve descrição das duas principais estruturas de modelagem de elevação digital, a Malha Triangular Irregular e a Malha ou Grade Regular, e os métodos de interpolação mais comumente utilizados em cada uma delas, além da técnica de superfície de tendência.

\subsubsection{Malha Triangular ou Triangular Irregular Network (TIN)}

Uma rede triangular é composta pelos pontos originais, ligados três a três, formando triângulos Irregulares (Matos, 2005). A Figura 9 apresenta um exemplo de uma malha triangular irregular.

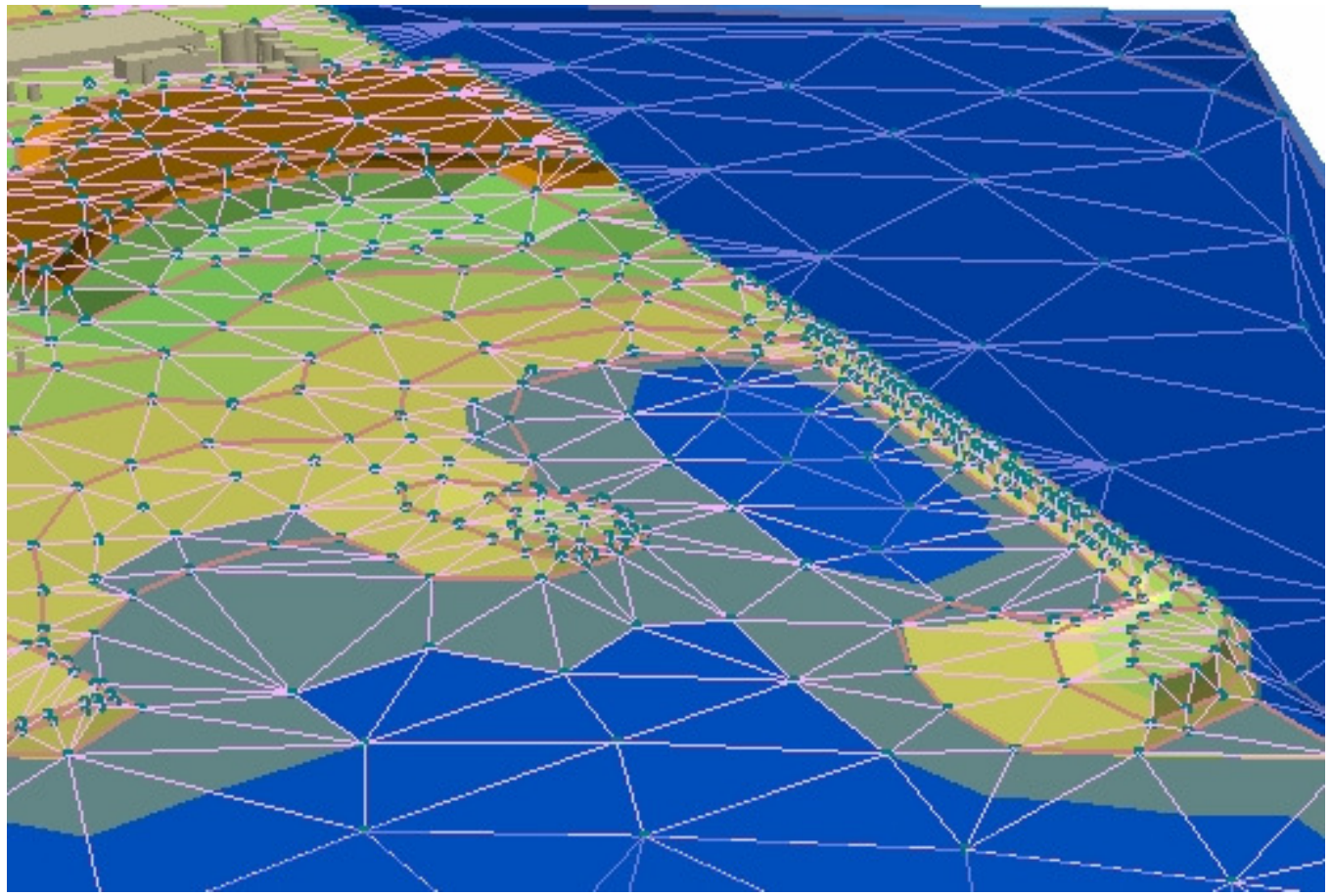

Figura 9. Exemplo de uma malha triangular

(http://www.gsd.harvard.edu/gis/manual/contours/index.htm. Acesso em: 12 jun. 2010) 
De acordo com Lee (1991), uma TIN aproxima-se de uma superfície de terreno por um conjunto de facetas triangulares. Cada triângulo é definido por três arestas e cada aresta é delimitada por dois vértices. Os vértices do triângulo são geralmente os pontos amostrados da superfície.

Segundo Landim (2000), na triangulação linear, pares de dados são unidos por linhas retas para a formação de uma rede triangular. Os pontos estimados de igual valor (isovalores) entre os dados medidos e posicionados nos vértices dos triângulos são conectados para os intervalos específicos.

Diferentemente da geração de grade regular, os valores de cota dos vértices dos elementos triangulares da malha triangular não precisam ser estimados por interpolações.

Os algoritmos mais comuns para interpolação em estrutura triangular (TIN) são a Triangulação de Delaunay e a Triangulação com Interpolação Linear, ou simplesmente, Triangulação Linear. Segue uma breve descrição destes dois algoritmos.

\section{A) Triangulação de Delaunay}

O algoritmo mais utilizado para geração de modelos triangulares é a malha de Delaunay. O critério utilizado na triangulação de Delaunay é o da maximização dos ângulos mínimos de cada triângulo. Isto é equivalente a dizer que a malha final deve conter triângulos o mais próximo de eqüiláteros possível, evitando-se a criação de triângulos afinados, ou seja, triângulos com ângulos internos muito agudos (CÂMARA; MONTEIRO; MEDEIROS, 2004). 
Segundo Felgueiras e Goodchild (1995) a triangulação de Delaunay é a linha reta dual do diagrama de Voronoi ${ }^{1}$ e é construída ligando os pontos cujos polígonos associados compartilham uma aresta em comum. As duas propriedades básicas da triangulação de Delaunay são:

1) se não existem mais que três pontos circulares, ela é unica (Figura 10),

2) e maximiza os ângulos mínimos internos de cada triângulo.

Essa segunda característica evita a criação de triângulos finos.

Uma forma de implementar a triangulação de Delaunay é através do critério do circuncírculo (CÂMARA; MONTEIRO; MEDEIROS, 2004). Uma triangulação é considerada de Delaunay se o círculo que passa pelos três vértices de cada triângulo da malha triangular não contém, no seu interior, nenhum ponto do conjunto das amostras além dos vértices do triângulo em questão. A Figura 10 apresenta um exemplo de uma triangulação de Delaunay.

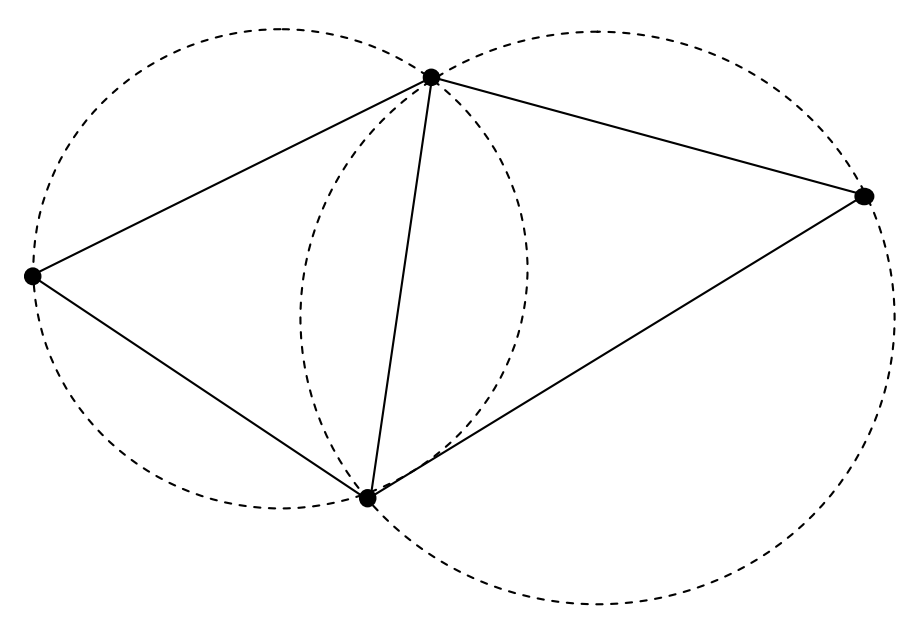

Figura 10. Exemplo de uma triangulação de Delaunay

\footnotetext{
${ }^{1}$ Segundo descrição de Rezende, Vanier-Almeida e Nobre, 2000), a construção do Diagrama de Voronoi ocorre ao tomar-se um conjunto de pontos não colineares, $P=\{p 1, p 2, \ldots, p n\}, n>2$, no plano Euclidiano, denominados como "pontos geradores" entre os quais são traçadas retas eqüidistantes entre si, que formarão as bordas dos polígonos. Cada polígono, fechado e adjacente a outro, contendo apenas um dos pontos geradores, é denominado Diagrama de Voronoi.
} 
Existem vários métodos de implementação da triangulação de Delaunay, que podem ser classificados em dois tipos básicos: algoritmo de passo único, que cria a triangulação de Delaunay numa única etapa, e os métodos de dois passos, que geram uma triangulação inicial qualquer e, em uma segunda etapa, transformam-na em uma triangulação de Delaunay.

A interpolação por Vizinhos Natural é uma técnica que utiliza a triangulação de Delaunay para avaliação de pesos para os pontos. Diferente das demais técnicas, ela não extrapola valores, resolvendo a interpolação somente para o interior do domínio dos dados. Este método faz a interpolação através da média ponderada dos pontos vizinhos, onde os pesos são proporcionais às áreas.

B) Triangulação com Interpolação Linear ou Triangulação Linear

De acordo com Felgueiras e Goodchild (1995), cada triângulo define um plano que é usado para determinar o valor $Z$ de cada ponto $(x, y)$ dentro do triângulo. $O u$ seja, considerando que há um comportamento linear dentro de cada triângulo, podese estimar o valor de qualquer ponto da superfície definida pela malha triangular.

A equação do plano pode ser expressa por:

$$
A x+B y+C z+D=0
$$

Para calcular A, B, C e D é suficiente usar o valor Z dos três vértices do triângulo.

Dessa forma, para qualquer ponto a ser estimado deve-se buscar o triângulo que o contém e, através de uma álgebra simples de solução de sistemas lineares, obtém-se facilmente o valor de cota desse ponto. 
Suponha que os três vértices do triângulo possuem as coordenadas: $\left(\mathrm{x}_{1}, \mathrm{y}_{1}, \mathrm{z}_{1}\right)$, $\left(x_{2}, y_{2}, z_{2}\right)$ e $\left(x_{3}, y_{3}, z_{3}\right)$. Estes três pontos definem o sistema de equações lineares a seguir:

$$
(A / D) x i+(B / D) y i+(C / D) z i=-1 ; \text { onde } i=1,2,3
$$

A solução para este sistema, usando a regra de Cramer, por exemplo, é dada por:

$$
\begin{aligned}
& A=y_{1}\left(z_{2}-z_{3}\right)+y_{2}\left(z_{3}-z_{1}\right)+y_{3}\left(z_{1}-z_{2}\right) \\
& B=z_{1}\left(x_{2}-x_{3}\right)+z_{2}\left(x_{3}-x_{1}\right)+z_{3}\left(x_{1}-x_{2}\right) \\
& C=x_{1}\left(y_{2}-y_{3}\right)+x_{2}\left(y_{3}-y_{1}\right)+x_{3}\left(y_{1}-y_{2}\right) e \\
& D=-x_{1}\left(y_{2} z_{3}-y_{3} z_{2}\right)-x_{2}\left(y_{3} z_{1}-y_{1} z_{3}\right)-x_{3}\left(y_{1} z_{2}-y_{2} z_{1}\right)
\end{aligned}
$$

A solução linear, segundo Felgueiras e Goodchild (1995), garante que a superfície plana se alinhe com dois outros triângulos adjacentes. Com isso, há uma continuidade entre as superfícies de triângulos vizinhos, mas o método não garante uma suavidade na transição entre as superfícies.

Além destes, há ainda mais dois outros tipos de ajustes utilizados sobre as malhas triangulares irregulares que valem a pena serem elencados: o Ajuste quíntico e o estocástico.

O primeiro foi proposto por Akima (1978) e pressupõe um ajuste a uma superfície polinomial de quinta ordem incompleta para cada triângulo da malha. $O$ polinômio de quinta ordem possui 21 coeficientes, que por sua vez, são obtidos considerando-se os valores de cota em cada vértice do triângulo (3 valores), as derivadas parciais de primeira ordem nas direções $x$ (3 valores) e y (3 valores) e, as derivadas parciais de segunda ordem nas direções x (3 valores), y (3 valores) e xy (3 valores).

Fournier (1982 apud Felgueiras e Goodchild, 1995) apresenta procedimentos para processar curvas e superfícies com base em modelos estocásticos. Ele descreve dois métodos para a construção de superfície. O primeiro é baseado na 
subdivisão de polígonos para criar polígonos fractais, e o segundo é baseado na definição de superfícies paramétricas estocásticas.

\subsubsection{Malha Regular}

De acordo com Matos (2005), a Malha Regular (comumente retangular ou quadrada) consiste em um conjunto de pontos regularmente espaçados. O seu processo de geração consiste em estimar cada ponto da malha (pixel) a partir do conjunto da amostras de entrada, que pode ser regularmente ou irregularmente espaçadas.

A grade regular é um modelo digital que aproxima superfícies através de um poliedro de faces retangulares. Os vértices desses poliedros podem ser os próprios pontos amostrados, se estes tenham sido adquiridos nas mesmas posições xy nos quais a grade é definida.

Os algoritmos comumente utilizados para geração das malhas regulares, dentre muitos outros, são: média simples, média ponderada, média ponderada por quadrante, média ponderada por quadrante e cota, vizinho mais próximo, a superfície de tendência, o inverso da distância, curvatura mínima e Krigagem.

A) Média Móvel, Média Simples, Média Ponderada, Média Ponderada por Quadrante, Média Ponderada por Cota e por Quadrante

A média das cotas das amostras vizinhas, usualmente conhecida como média móvel, é um dos esquemas de interpolação mais simples para estimação dos 
valores de cota dos pontos de uma grade regular retangular. Eles são locais e determinísticos e dados por (Felgueiras, 2001):

$$
Z_{i}=\frac{\sum_{i=1}^{n} W_{i j} Z_{i j}}{\sum_{i=1}^{n} W_{i j}}
$$

Onde:

- $Z_{i}$ é o valor de cota de um ponto i qualquer da grade;

- $Z_{j}$ é a cota de uma amostra j vizinha do ponto i da grade e;

- $W_{\mathrm{ij}}$ é um fator de ponderação .

São considerados segundo Felgueiras (2001), como variações deste modelo básico, o interpolador por média simples, por vizinho mais próximo, por média ponderada, por média ponderada por quadrante e, por média ponderada por quadrante e por cota.

$\mathrm{Na}$ interpolação por média simples, o valor de cota z do elemento da grade é igual a média aritmética dos valores de cota das amostras vizinhas. Considera-se, neste caso, que o fator de ponderação Wij igual a 1 para qualquer amostra vizinha.

A interpolação por vizinho mais próximo é definida pela escolha de apenas uma amostra vizinha para cada ponto da grade, ou seja, quando j é igual a 1. Este interpolador deve ser usado quando se deseja manter os valores de cotas das amostras na grade, sem gerar valores intermediários.

Se em (7), Wij=1, para qualquer amostra, temos a interpolação por médias simples. Se $W i j=1 / D^{k}{ }_{i j}$ em $(7)$, sendo $D^{k}{ }_{i j}$ o valor de distância da amostra $j$ ao ponto $i$, temos a interpolação por média ponderada.

$\mathrm{Na}$ interpolação por média ponderada, o valor de cota de cada elemento da grade é definido pela média ponderada dos valores de cota das amostras vizinhas. Neste caso, a ponderação mais usada é o inverso da distância euclidiana, também chamado de Inverse Distance Weighted (IDW). 
Seja:

$$
W_{i j}=\frac{1}{D_{i j}^{k}}
$$

Onde:

$-\mathrm{k}=\mathrm{n}$ e;

- $D_{i j}$ é o valor de distância da amostra j ao ponto i da grade.

Quanto mais distante uma amostra se encontra do ponto da grade, menor deve ser a sua influência, ou peso, no cálculo final do valor de cota do ponto da grade.

$$
D_{i j}=\sqrt{\left(x_{i}-x_{j}\right)^{2}+\left(y_{i}-y_{j}\right)^{2}} \quad i \neq j
$$

$\mathrm{Na}$ interpolação por média ponderada por quadrante inclui-se, além da ponderação, uma escolha das posições relativas das amostras que entram na estimativa do valor de cota da grade.

Neste caso, divide-se o espaço de projeção xy em 4 setores, tendo como referência o ponto da grade, e considera-se uma quantidade fixa de amostras por quadrante. Assim pode-se utilizar, por exemplo, 1 amostra por quadrante num total de 4, ou então, 2 amostras por quadrante num total de 8 , e assim por diante.

Este procedimento garante que a estimativa da cota final do ponto utiliza amostras representativas de cada uma das 4 regiões definidas pelos quadrantes.

No caso do interpolador por média ponderada por quadrante e por cota lou altitude), além da ponderação e dos quadrantes, considera-se também o valor de cota de cada amostra a ser usada na estimativa do ponto da grade. Esta interpolação é usada em dados amostrais obtidos a partir de curvas de nível, porque estas apresentam uma quantidade exagerada de pontos que têm o mesmo valor de altitude (MATOS, 2005). 
O interpolador por Vizinho Natural (Natural Neighbours) usa uma equação semelhante ao IDW, mas com a diferença que, utiliza um cálculo de pesos e método de seleção do conjunto de pontos diferentes do método anterior. O método do vizinho natural utiliza a triangulação de Delaunay para selecionar o vizinho mais apropriado para obter o valor de um determinado ponto (MATOS, 2005).

B) Funções de Base Radial

As Funções de Base Radial são interpoladores determinísticos, locais e exatos. Este método não permite que seja investigada a autocorrelação entre dados, sendo do menos flexível e mais automático que o método de krigagem.

Existem cinco funções básicas distintas: thin-plate spline (spline suave), spline with tension (spline com tensão), completely regularized spline (spline completamente regular), multiquadratic function (função multiquadrática) e inverse multiquadratic spline (spline multiquadrática inversa). Cada uma destas funções tem uma diferente forma e resulta em uma distinta superfície de interpolação.

Os Splines são técnicas de interpolação que usam polinômios para criar uma superfície que minimize a curvatura da mesma, resultando em uma superfície suavizada que passa através dos pontos da amostra (MATOS, 2005).

Uma curva spline aproxima-se de uma superfície flexível passando através de um conjunto de pontos. Portanto, esta técnica é bastante útil para criar modelos de elevação em áreas com leve variação do terreno e transições suaves, mas não capta mudanças bruscas em pequenas distâncias.

Como ilustra Barbosa et al (2008), um interpolante de mínima curvatura, também comumente chamado pela sigla TPS (Thin Plate Spline), pode ser ilustrado fisicamente como uma chapa fina de metal se estendendo para o infinito, presa em 
alguns pontos de controle, de maneira que a energia necessária despendida para isto seja mínima, desprezando-se a energia elástica e a energia gravitacional.

O TPS também aparece na literatura com os nomes de spline de curvatura mínima, spline biharmônica e mesmo superfície spline (YU, 2001).

\subsubsection{Método Geoestatístico e Krigagem}

A krigagem simples é um método que se tornou bastante popular na geoestatística. Utiliza funções de covariância (ou o variograma) para quantificar a variabilidade espacial, e mapas podem ser produzidos a partir de um conjunto incompleto de dados utilizando-se desta metodologia (Ingran, Cornford e Evans, 2008).

Conforme Weirich et al (2006), o método da Krigagem contido em duas etapas. Uma é o ajuste do modelo teórico de semivariograma, e a outra a krigagem propriamente dita.

Alguns autores, como Burrough (1986) conceituam semivariograma como a função que regionaliza a variável de interesse, fornecendo o componente estrutural da variável no espaço, o componente aleatório, e o erro residual. Tais valores são posteriormente utilizados como estimador (Weirich et al,2006).

Segundo Barros Filho (2007), a krigagem está baseada na teoria das variáveis regionalizadas. Uma variável regionalizada é uma variável distribuída no espaço (ou tempo) cujos valores são considerados como realizações de uma função aleatória (estocástica). Esta teoria permite incluir hipóteses estatísticas em processos espaciais locais.

De acordo com a teoria das variáveis regionalizadas, a variação espacial do valor de uma variável aleatória Z pode ser expressa pela soma de três componentes: (a) um componente estrutural associado a um valor médio ou a uma tendência constante; (b) um componente estocástico ou aleatório, que está espacialmente 
correlacionado e varia localmente; e (c) um ruído aleatório ou erro residual, que não está espacialmente correlacionado, e possui distribuição normal, média zero e variância $\sigma^{2}$. A Figura 11 ilustra os três componentes.

Pontos Amostrais

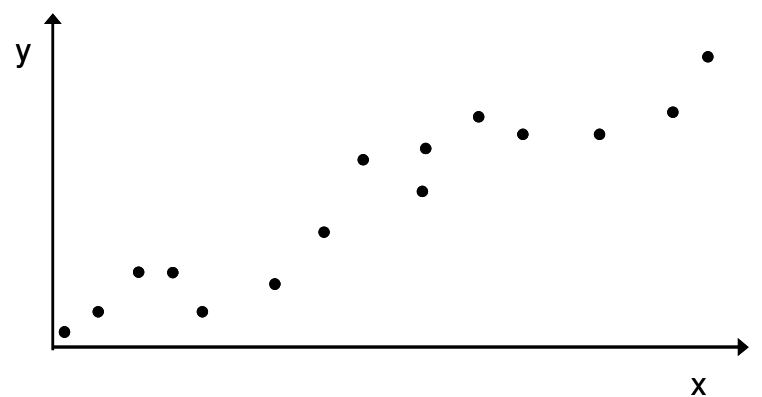

(b) componente estocástico - $\varepsilon^{\prime}(x)$
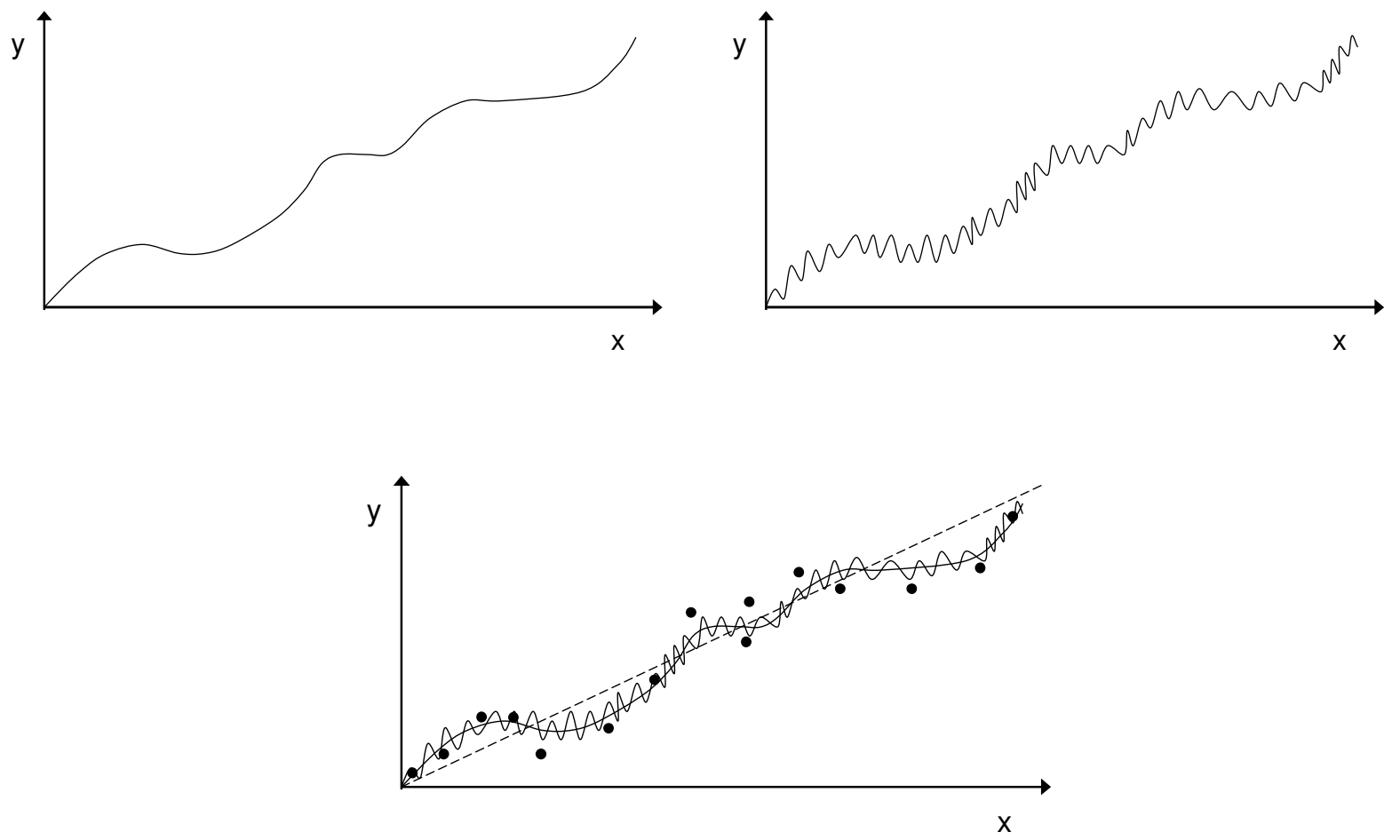

Figura 11. Ilustração dos três componentes de uma variável aleatória Z 
Se o vetor $\mathbf{x}$ representa uma posição em até três dimensões, então o valor da função aleatória Z, em x, é dada por (Druck et al, 2004):

$$
Z(\boldsymbol{x})=\mu(\boldsymbol{x})+\varepsilon^{\prime}(\boldsymbol{x})+\varepsilon^{\prime \prime}
$$

onde:

- $\mu(\boldsymbol{x})$ é uma função determinística que descreve a componente estrutural de $Z$ em $\mathbf{x}$;

- $\varepsilon^{\prime}(\boldsymbol{x})$ é um termo estocástico correlacionado, que varia localmente;

- $\varepsilon^{\prime \prime}$ é um ruído aleatório não correlacionado, com distribuição normal com média zero e variância $\sigma^{2}$.

ALMEIDA (2008) apresenta que, a partir de uma amostra $z(x i), i=1,2, \ldots, n, o$ variograma pode ser estimado por:

$$
2 \hat{\gamma}(h)=\frac{1}{N(\boldsymbol{h})} \sum_{i=1}^{N(h)}\left[Z\left(\boldsymbol{x}_{i}\right)-Z\left(\boldsymbol{x}_{i}-\boldsymbol{h}\right)\right]^{2}
$$

Onde:

- $2 \gamma(\boldsymbol{h})$ é o variograma estimado;

- $\mathrm{N}(\boldsymbol{h})$ é o número de pares de valores medidos, $z\left(\boldsymbol{x}_{\mathrm{i}}\right)$ e $\mathbf{z}\left(\boldsymbol{x}_{\mathbf{i}}+\boldsymbol{h}\right)$, separados por um vetor distância $\boldsymbol{h}$; 
- $z\left(\boldsymbol{x}_{i}\right)$ e $z\left(\boldsymbol{x}_{i}+\boldsymbol{h}\right)$ são valores da i-ésima observação da variável regionalizada, coletados nos pontos $\boldsymbol{x}_{i}$ e $\boldsymbol{x}_{i}+\boldsymbol{h}(i=1, \ldots, n)$, separados pelo vetor $\boldsymbol{h}$.

A função $\gamma(\mathbf{h})$ é o semivariograma. O prefixo "semi" vem em razão de que a equação do variograma experimental pode ser escrita na forma:

$$
\hat{\gamma}(h)=\frac{1}{2 N(\boldsymbol{h})} \sum_{i=1}^{N(h)}\left[Z\left(x_{i}\right)-Z\left(x_{i}-h\right)\right]^{2}
$$

Almeida (2008) descreve que o semivariograma pode ser representada por um gráfico onde no eixo das ordenadas está os valores da semivariância e, nas abscissas, a distância entre os pontos, e é composto por diversos parâmetros que servem para caracterizá-lo. São eles:

- Alcance ou amplitude (a): é a distância em que as amostras apresentam correlação espacial. A partir deste ponto, considera-se que não existe mais dependência espacial entre as amostras.

- Patamar (C): é aproximadamente igual à variância dos dados, se ela existe, e é obtido pela soma do efeito pepita (C0) com a variância estrutural (C1).

- Efeito Pepita (C0): Quando $h=0, C(0)$ é conhecido como efeito pepita. Representa a descontinuidade do semivariograma para distâncias menores do que a menor distância entre as amostras.

Se o valor de C(0) se aproxima do patamar, então terá efeito pepita puro, o que ocorre quando há ausência total de dependência espacial entre as amostras. 
Contribuição (C1): é a diferença entre o patamar $(C)$ e o efeito pepita (C0). Os parâmetros são apresentados na Figura 12.

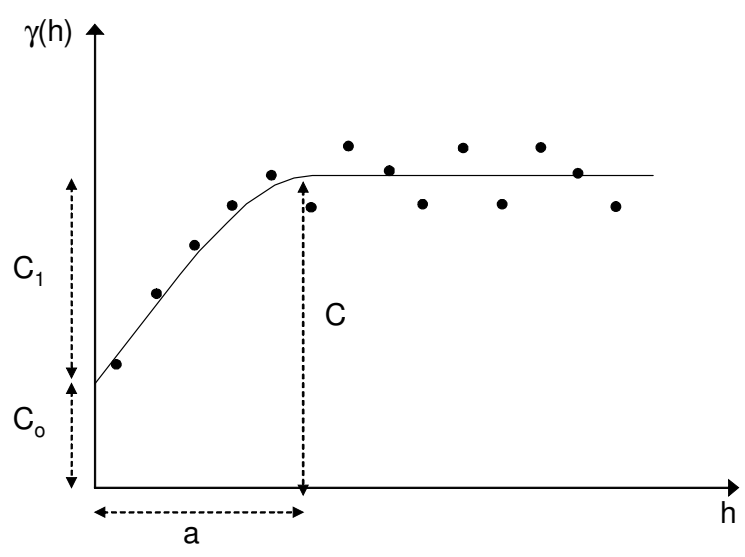

Figura 12. Semivariograma experimental com os parâmetros (adaptado de Almeida, 2008)

De acordo com Druck et al (2004), o procedimento de ajuste do modelo não é direto, nem automático, como no caso de uma regressão, mas deve ser interativo, pois nesse processo o intérprete faz um primeiro ajuste e verifica a adequação do modelo teórico. Dependendo do ajuste obtido, pode ou não redefinir o modelo, até obter um que seja considerado satisfatório.

Os modelos mais utilizados são o esférico, o linear, o circular, o exponencial e o gaussiano.

O método da krigagem foi primeiramente desenvolvido por Georges Matheron, em 1963, baseado na dissertação de mestrado de Daniel G. Krige, de 1951, um engenheiro de minas sul-africano que usou um protótipo desta técnica para estimar reservas de minério. Após décadas de desenvolvimento, a krigagem se tornou uma ferramenta central na geoestatísitca e hoje é uma técnica utilizada em diferentes áreas (Wang e Kockelman, 2009).

A krigagem é um método determinístico, de transição gradual e local, que pode ou não ser exato (Eberly et al, 2004). Similar ao método do Inverso da Distância (IDW), o método de krigagem utiliza pesos para calcular os valores dos pontos em 
locais desconhecidos. Na krigagem, no entanto, os pesos são baseados não somente na distância entre eles, mas também na variação entre as medidas dos pontos conhecidos, como uma função da distância. Por isso a krigagem é um processo composto por duas fases: a da análise da variação espacial (baseada no semivariograma experimental) e a do cálculo dos valores dos pontos desconhecidos (Eberly et al, 2004).

A krigagem fornece, em média, estimativas não tendenciosas - o que significa que a diferença entre valores estimados e observados para o mesmo ponto deve ser nula - e com variância mínima, ou seja, estes estimadores possuem a menor variância dentre todos os estimadores não tendenciosos.

Segue uma revisão da krigagem ordinária, baseada em Druck et al (2004).

Considere uma superfície sobre a qual se observe alguma propriedade, Z, em n pontos distintos, com coordenadas representadas pelo vetor $\boldsymbol{x}$. Tem-se um conjunto de valores $\left\{z\left(x_{i}\right), i=1, \ldots, n\right\}$, onde $x_{i}$ identifica uma posição em duas dimensões, representada pelos pares de coordenadas $\left(x_{i}, y_{i}\right)$. $O$ valor desconhecido de $Z\left(x_{0}\right)$ pode ser estimado a partir de uma combinação linear dos $n$ valores observados, adicionado a um parâmetro $\lambda_{0}$ :

$$
Z^{*}\left(x_{0}\right)=\lambda_{0}+\sum_{i=1}^{n} \lambda_{i} Z\left(x_{i}\right)
$$

É desejado um estimador não tendencioso, ou seja,

$$
E\left[Z\left(x_{0}\right)-Z^{*}\left(x_{0}\right)\right]=0
$$

Esta relação impõe que as duas médias sejam iguais; assim:

$$
E\left[Z\left(x_{0}\right)\right]=E\left[\lambda_{0}+\sum_{i=1}^{n} \lambda_{i} Z\left(x_{i}\right)\right] \Rightarrow m=\lambda_{0}+\sum_{i=1}^{n} \lambda_{i} m
$$


A krigagem ordinária não requer o prévio conhecimento da média m. Neste caso, para que a igualdade da Equação (12) seja satisfeita é necessário que $\lambda_{0=} 0 \mathrm{e}$ $\sum_{i=1}^{n} \lambda_{i}=1$. Portanto, o estimador de Krigagem ordinária é:

$$
Z^{*}\left(x_{0}\right)=\sum_{i=1}^{n} \lambda_{i} Z(x i), \operatorname{com} \sum_{i=1}^{n} \lambda_{i}=1
$$

Minimizando a variância do erro $\left(\operatorname{Var}\left[Z\left(\boldsymbol{x}_{0}\right)-Z^{*}\left(\boldsymbol{x}_{0}\right)\right]\right)$ na condição de $\sum_{i=1}^{n} \lambda_{i}=1$,os pesos $\lambda_{i}$ são obtidos a partir do seguinte sistema de equações, denominado sistema de krigagem ordinária:

$$
\left\{\begin{array}{l}
\sum_{i=1}^{n} \lambda_{j} C\left(x_{i}-x_{j}\right)-\alpha=C\left(x_{i}-x_{0}\right) \quad \text { para } i=1, \ldots, n \\
\sum_{i=1}^{n} \lambda_{j}=1
\end{array}\right.
$$

onde:

- $C\left(\boldsymbol{x}_{\mathrm{i}}, \boldsymbol{x}_{\mathrm{j}}\right)$ e $\mathrm{C}\left(\boldsymbol{x}_{\mathbf{i}}, \boldsymbol{x}_{0}\right)$ são, respectivamente, a semivariância entre os pontos $\boldsymbol{x}_{\mathrm{i}}$ e $x_{j}$ e entre os pontos $x_{i}$ e $x_{0}$.

- a é o multiplicador de Lagrange necessário para a minimização da variância do erro.

A variância de krigagem ordinária, ou seja, a variância minimizada do erro, $\left(\sigma^{2}{ }_{k o}\right)$, é dada pela expressão: 


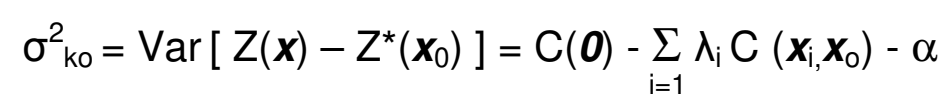

A krigagem ordinária é um interpolador exato no sentido de que, quando as equações acima forem usadas, os valores interpolados irão coincidir com os valores dos pontos amostrais (Druck, 2004).

Segue a apresentação breve dos modelos mais comumente usados na Krigagem, baseado em Câmara, Monteiro e Medeiros (2004):

- O modelo Linear não apresenta patamar, sendo portanto bastante simples, representado por:

$$
\gamma=C_{0}+C_{1}(h / a)
$$

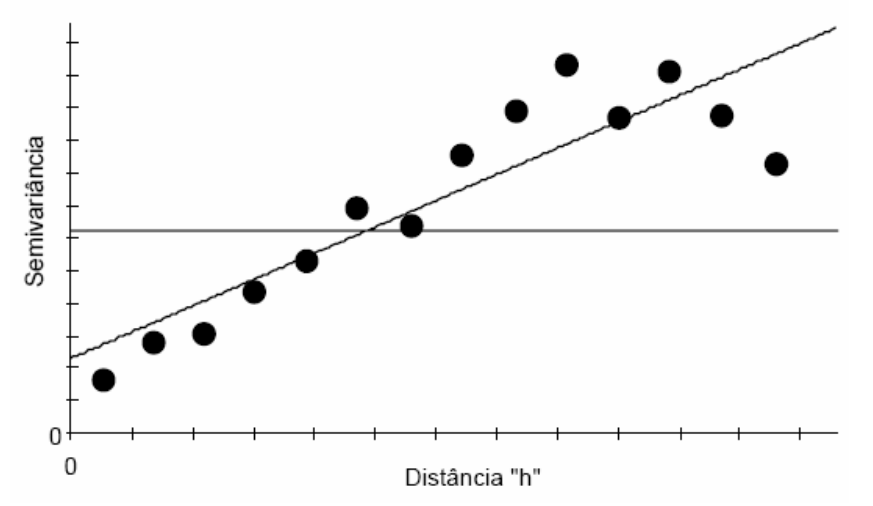

- O modelo Esférico apresenta patamar e pode ser representado por:

$$
\gamma= \begin{cases}C_{0}+C_{1}\left(1,5(h / a)-0,5(h / a)^{3},\right. & \text { se } h<a \\ C_{0}+C_{1} & \text { se } h \geq a\end{cases}
$$




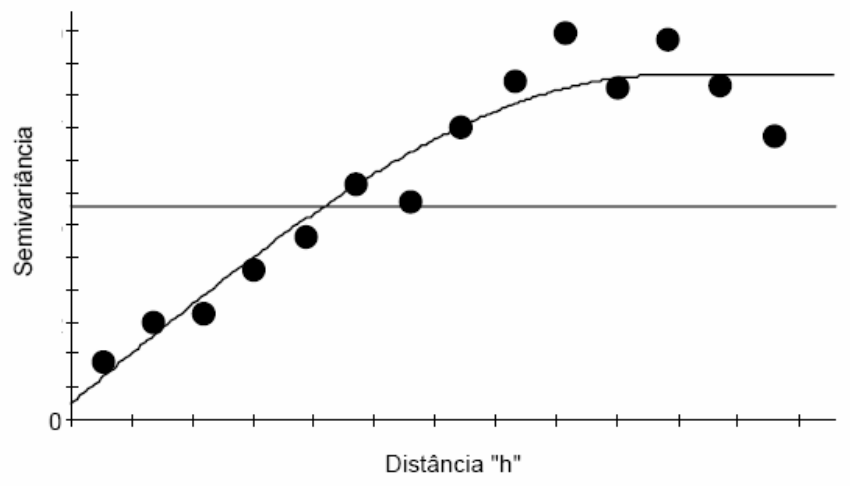

- Já o modelo Gaussiano é dado por:

$\gamma=C_{o}+C_{1}\left(1-\exp \left(-h^{2} / a\right)^{2}\right)$

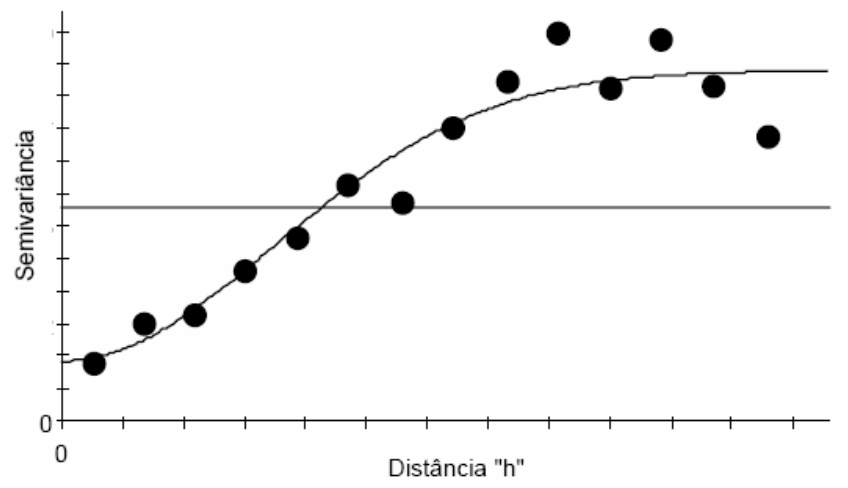

- O modelo Exponencial é dado por:

$$
\gamma=\left\{\begin{array}{l}
0, \text { se } h=0 \\
C_{o}+C_{1}(1-\exp (-h / a)), \text { se } h \neq 0
\end{array}\right.
$$

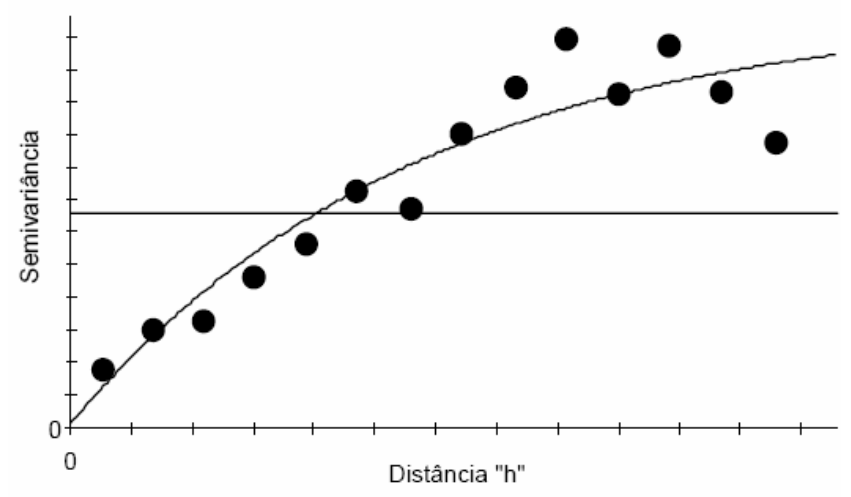

- E o Circular por: 


$$
\gamma(h)= \begin{cases}\text { Co }+ \text { C }\left(1-((2 / \pi) \text { cós }-1(h / a))+\sqrt{ } 1-\left(h^{2} / a^{2}\right)\right), & \text { se } 0<h \leq a \\ \text { Co }+C, & \text { se } h>a\end{cases}
$$

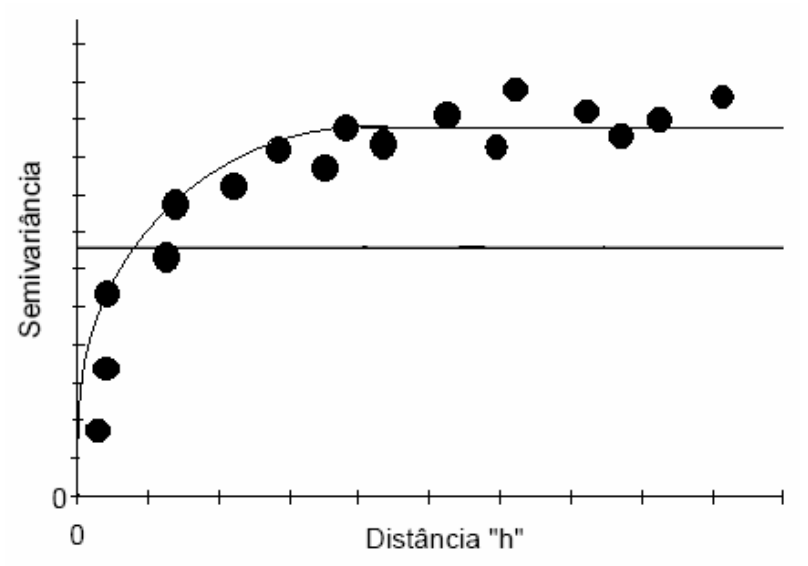

\subsubsection{Superfície de Tendência}

As superfícies de tendência são interpoladores determinísticos globais. Neste caso, portanto, na caracterização do fenômeno em estudo, predomina a variação em larga escala.

A vantagem deste método é sua simplicidade e facilidade de cálculo. No entanto, este método negligencia a variabilidade local, o que não é um fato realista para a grande parte dos dados naturais.

É o método pelo qual uma superfície contínua é ajustada aos pontos amostrados irregularmente espaçados por meio de regressão por mínimos quadrados (Matos, 2005). O ajuste é implementado por polinômios de diversas ordens (ou graus). 
No caso de polinômios de segunda ordem, as superfícies estão na forma:

$$
f(X, Y)=\sum_{r+s \leq p}\left(b_{r s} \cdot X^{r} \cdot Y^{s}\right)
$$

As primeiras famílias (1, 2 e 3 termos) são:

$b_{0}$

$b_{0}+b_{1} \cdot X+b_{2} \cdot Y$

$b_{0}+b_{1} \cdot X+b_{2} \cdot Y+b_{3} \cdot X_{2}+b_{4} \cdot X_{Y}+b_{5} \cdot Y_{2}$ plano com Z constante

plano qualquer no espaço

parabolóide

Assim por diante.

O número inteiro $\mathrm{p}$ é a ordem do polinômio. Os $\mathrm{P}$ coeficientes,

$$
P=(p+1)(p+2) / 2
$$

são determinados de maneira a minimizar a soma dos quadrados dos desvios.

$$
\sum_{i=1}^{n}(Z(X, Y)-f(X, Y))^{2}=\min
$$

Ainda segundo Matos (2005), a superfície de tendência só passa pelos pontos da amostra se o número de coeficientes for igual ao número de pontos fornecidos.

Para Jakob \& Young (2006), a interpolação polinomial global ajusta uma superfície suavizada definida por uma função matemática (polinomial) aos pontos observados. Esta superfície gradualmente muda e captura o padrão de escala dos dados, como se estivesse ajustando um plano aos pontos observados, que pode ser linear (função polinomial de primeira ordem), de segunda ordem (quadrática), de terceira ordem (cúbica), até a décima ordem. O resultado é uma superfície 
matemática suavizada que representa as tendências graduais da superfície da área de interesse.

A interpolação polinomial global ajusta um polinômio à superfície toda. A polinomial local ajusta muitos polinômios, cada um especificando sua vizinhança. Podem ser especificados a forma, o máximo e o mínimo número de pontos a serem usados, e a configuração do setor, assim como uma função de diminuição de pesos a partir da distância dos pontos.

\subsection{SIMULAÇÃO ESTOCÁSTICA}

A krigagem tem por objetivo alcançar a melhor estimativa local, obtendo o menor erro quadrático, sem considerar a estatística global dos valores das estimativas (Deustch e Journel, 1992).

Furuie (2009) cita que, como alternativa ao efeito de suavização decorrente de técnicas de interpolação baseadas em métodos de minimização da variância dos erros, é comumente proposto por vários autores, a técnica de Simulação estocástica.

De maneira clara Furuie (2009) explica que a Simulação estocástica consiste na criação de algoritmos para simular o comportamento espacial de determinada variável. O termo estocástico é atribuído pelo fato destes algoritmos não serem determinísticos, ou seja, quando há mais de uma opção entre o valor a ser assumido em determinado ponto de execução do algoritmo, a escolha será aleatória, gerando inúmeras realizações a partir de um conjunto inicial de dados.

Ao contrário da krigagem, o método de simulação estocástica possui precisão global. Ele reproduz a variabilidade espacial da amostragem em detrimento da precisão local.

Cada realização da simulação estocástica corresponde a um conjunto de valores simulados nos locais determinados pela malha escolhida e segundo Costa 
(1997), citado por Beretta (2010), os diversos valores resultantes dos cenários podem ser utilizados para quantificar a incerteza ao redor de uma estimativa média.

Segundo Deustch e Journel (1992), a simulação estocástica se diferencia dos algoritmos de interpolação por dois aspectos: (a) na maior parte dos métodos de interpolação o objetivo é fornecer uma melhor estimativa local $z^{*}(x 0)$ de cada valor não amostrado, um por vez, sem a preocupação específica para com as estatísticas espaciais resultantes das estimativas. Na simulação estocástica as feições globais resultantes (textura) e as estatísticas dos valores simulados são preponderantes sobre a precisão local; e (b), para um dado conjunto de dados locais e estatísticas condicionantes, a krigagem usada como um algoritmo de interpolação fornece um único modelo numérico que é considerado ótimo em algum sentido de precisão local. A simulação estocástica fornece vários modelos numéricos alternativos, sendo cada um uma representação ótima, no sentido da representação da realidade global. As diferenças entre os modelos e realizações alternativas fornecem uma medida da incerteza espacial conjunta.

Para Furuie (2009), um dos maiores reveses da simulação estocástica reside no fato de que serão geradas $n$ imagens a partir de um mesmo conjunto de dados, todas equiprováveis, dificultando a escolha de uma realização considerada ótima para qualquer situação. No entanto o autor cita Srivastava (1994) quando comenta que os modelos estocásticos, por oferecer uma vasta gama de possibilidades, permitem gerar múltiplos cenários de possibilidades, otimistas e pessimistas, permitindo lidar com as incertezas, o que em alguns casos torna-se uma vantagem.

De acordo com Watanabe, Rocha e Yamamoto (2012), a simulação por bandas rotativas (tradução usual para Turning Bands) é um método gaussiano, porque simula uma distribuição gaussiana $(\mathrm{N}[0,1])$. O primeiro passo para realizar a simulação é a transformação dos dados de uma distribuição qualquer para uma distribuição gaussiana normal. Com os dados transformados, é calculado o variograma experimental e ajustado o modelo teórico de variograma de maneira similar ao realizado na análise geoestatística para a krigagem ordinária.

Parte-se então para a simulação propriamente dita. De acordo com o autor, a simulação por bandas rotativas baseia-se no princípio de que um modelo de 
covariância multidimensional pode ser decomposto em $\mathbf{n}$ modelos de covariâncias unidimensionais. Esta decomposição é obtida pela geração de linhas no espaço, com valores sorteados seguindo uma distribuição $N(0,1)$. Posteriormente, as linhas são subdividas em bandas de largura $\mathbf{d}$ centradas nos pontos. Para integrar as $\mathbf{n}$ covariâncias unidimensionais na covariância multidimensional adiciona-se a contribuição de cada banda na simulação de um ponto no domínio, utilizando-se apenas os valores sorteados na linha, cuja projeção ortogonal coincide com as coordenadas do ponto simulado. Deste modo, a reprodução da covariância multidimensional irá depender do número de linhas utilizadas.

\subsubsection{Simulação por Bandas Rotativas (Turning Bands)}

O método de Simulação estocástica por Bandas Rotativas (Turning Bands), assim como outros métodos de simulação, envolve a transformação não linear dos dados contínuos para o domínio Gaussiano, construindo a distribuição espacial Gaussiana Multivariada. O método de Turning Bands foi proposto por Matheron (1973) e Journel e Huijbregts ( 1974).

O método é fundamentado na simulação de realizações de dados 2D e 3D por meio de sua simplificação em uma série de simulações unidimensionais independentes em linhas que cruzam o espaço R2 ou R3. O campo aleatório gerado será resultado da soma de diversos campos aleatórios gerados ao longo de linhas cujas orientações espaciais permeiam a esfera unitária R3. Uma das suas propriedades permite que se substitua a simulação de um campo aleatório multidimensional de covariância Cy pela simulação de um campo unidimensional de covariância Cx, determinando a covariância $\mathrm{Cx}$ associada a uma dada covariância isotrópica Cy (Furuie, 2009):

$$
C_{x}(r)=\frac{d}{d r}\left[r C_{y}(r)\right]
$$


O detalhamento deste método, na Figura 13 , é encontrado dentre vários, nos trabalhos de Journel e Huijbregts (1978).

Considere uma linha $D_{1}$ em um espaço tridimensional $R^{3}$, assim como uma função aleatória unidimensional $Y\left(x_{D 1}\right)$ definida nesta mesma linha $D_{1}$. Tal função aleatória será estacionária de segunda ordem, com esperança zero $E\left\{Y\left(X_{D 1}\right)\right\}=$ 0 e terá uma covariância unidimensional $C^{(1)}\left(h_{D 1}\right)$. Seja $x_{D 1}$ a projeção de um ponto $x$ qualquer na linha $D_{1}$, e considerando a função aleatória tridimensional definida por $Z_{1}(x)=Y\left(x_{D 1}\right), \forall x \in R^{3}$. Esta função aleatória $Z_{1}(x)$ será estacionária de segunda ordem, com esperança zero e uma covariância tridimensional igual a:

$$
E\left\{Z_{1}(x) Z_{1}(x+h)\right\}=E\left\{Y\left(X_{D 1}\right) \cdot\left(Y\left(X_{D 1}+h_{D 1}\right)\right\}=C^{(1)}\left(h_{D 1}\right)\right.
$$

Onde $h_{D 1}$ é a projeção do vetor h na linha $D_{1}$.
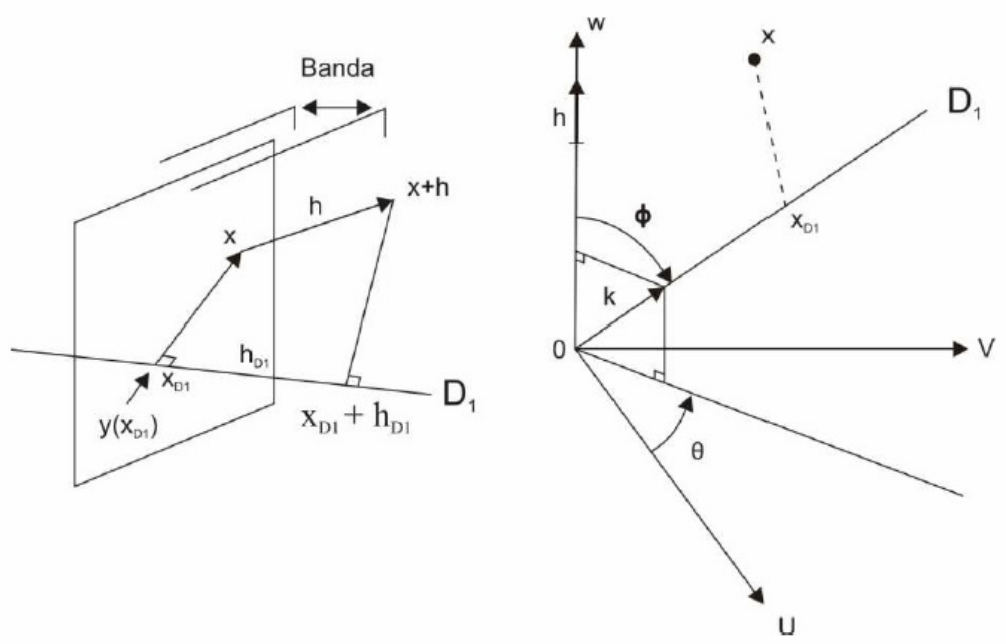

Figura 13. Bandas Rotativas. (Journel e Huijbregts, 1978) apresentado por (Furuie, 2009) 
Para se produzir a realização $Z 1(x)$, o valor $Z\left(x_{D 1}\right)$ simulado no ponto $x_{D 1}$, na linha $D_{1}$, é atribuído a todos os pontos dentro da banda centrada no plano perpendicular a $D_{1}$ no ponto $x_{1}$, sendo que a largura da Banda é definida pela quidistância entre os valores simulados na linha $D_{1}$.

Consideram-se $\mathrm{N}$ linhas $\mathrm{D}_{1}, \mathrm{D}_{2}, \ldots, \mathrm{D}_{\mathrm{N}}$ correspondendo ás direções dos vetores unitários distribuídos uniformemente sobre a esfera unitária. Em cada linha Di é gerada uma realização $\mathrm{y}\left(\mathrm{X}_{\mathrm{Di}}\right)$ da função aleatória $\mathrm{Y}\left(\mathrm{X}_{\mathrm{D} 1}\right)$, as $\mathrm{N}$ funções aleatórias \{ $\mathrm{Y}\left(\mathrm{X}_{\mathrm{D} 1}\right), \mathrm{i}=1$ a $\left.\mathrm{N}\right\}$ sendo independentes. Desta maneira, uma realização tridimensional $\mathrm{z}_{\mathrm{i}}(\mathrm{x})=\mathrm{y}\left(\mathrm{x}_{\mathrm{D} 1}\right), \forall \mathrm{x} \in \mathrm{R}^{3}$ corresponderá a cada realização unidmencional $\mathrm{y}\left(\mathrm{x}_{\mathrm{D} 1}\right)$. $\mathrm{O}$ valor atribuído a cada ponto $\mathrm{x}$ será a soma das $\mathrm{N}$ contribuições das $\mathrm{N}$ linhas:

$$
Z_{s}(x)=\frac{1}{\sqrt{N}} \sum_{i=1}^{N} Z_{i}(x)
$$

\subsection{FRETES E OS MODELOS DE REGRESSÃO}

O Brasil possui dimensões continentais e o fato de sua agropecuária estar inserida de forma substancial no mercado internacional, faz do transporte, e mais especificamente, dos fretes, parte importante do valor tanto de suas commodities agrícolas exportadas, como dos insumos utilizados em sua produção.

Para Caixeta Filho e Martins (2001), o fato do transporte de cargas de commodities agrícolas envolver grandes distâncias, o valor do frete acaba representando uma fração significativa no preço final dessas commodities. No caso dos fertilizantes, o mesmo raciocínio é válido, por conta do produto importado percorrer grandes distâncias para chegar ao consumidor. 
Ao mesmo tempo, Caixeta-Filho e Gameiro (2001) apresentam uma indicação da composição dos valores de fretes de cada modo de transportes baseados em seus custos. Segundo os autores, no transporte ferroviário a característica predominante são os altos custos fixos e custos variáveis relativamente baixos. No caso do transporte rodoviário, os custos fixos são relativamente baixos, mas os custos variáveis são mais altos. Sendo assim, os valores de fretes são uma combinação entre uma variável independente, que influencia os custos variáveis, e uma constante, representada pelos custos fixos.

Dentre as variáveis independentes que influenciam os fretes, os autores citam principalmente a distância percorrida, a condição das vias utilizadas, a sazonalidade de demanda, os custos de carga e descarga, entre outros. Para muitos autores, no entanto, a distância aparece como a principal variável independente que compõe o preço do frete.

De acordo com Martins (2008), em linhas gerais, constata-se que há uma concentração de abordagens que consideram a distância como principal fator de determinação de valores de fretes, pois impacta os custos variáveis (quilometragem rodada) do serviço, independentemente do modo utilizado.

Correa Júnior et al. (2001), também argumentam que os determinantes dos valores de fretes rodoviários são, primeiramente, dependentes da distância.

Grande parte dos autores apresentam, para elucidar suas pressuposições, modelagens matemáticas baseadas nas funções lineares e logarítmicas para tais argumentos.

Corrêa Junior (2001), cita diversos estudos na área de transportes nos quais a modelagem matemática é utilizada. Dentre eles, autores como Thompson (1960), que considerou que a determinação do frete estava diretamente relacionada à distância percorrida. Em seu estudo sobre a formação do frete de produtos químicos nos EUA, o autor utilizou a equação:

$$
F=u M^{x}+c
$$


Onde: $\mathrm{F}$ é o valor do frete por unidade transportada;

M a distância em milhas e;

c, u e x os coeficientes da equação.

Para Thompson (1960), o expoente de $M$ determinava a relação entre o frete praticado e a distância percorrida, sendo que essa relação poderia ser linear, se $\mathrm{x}=$ 1 , mas na maioria dos casos, era não-linear $(x<1)$. $O$ coeficiente $u$, seria o custo variável associado a cada milha percorrida, e c, o coeficiente associado aos custos fixos totais, independente da distância percorrida.

O mesmo autor, para as relações não-lineares, destacou o uso da forma logarítmica (ou log-log), representada por:

$$
\log (F-C)=x \log M+\log u
$$

Além de Thompson (1960), Corrêa Junior (2001), apresenta os estudos de Binkley \& Harrer (1981) em que ressaltam que o método linear se sobressai ao logarítmico na estimação de fretes marítimos para transporte de grãos e Martins (1998), que estima uma função linear relacionado a distância percorrida ao preço do frete rodoviário para o transporte de grãos e cereais no estado do Paraná. 


\section{METODOLOGIA}

Este estudo abrangeu três fases. Uma primeira fase foi dedicada ao cálculo do preço dos fertilizantes até o porto de entrada no Brasil; a segunda fase compreendeu na estimação dos valores de fretes por meio de três métodos diferentes e na escolha de um modelo mais apropriado e, na terceira fase, análises e simulações sobre os modelos para estabelecer as áreas de influência dos portos.

\subsection{PRIMEIRA FASE DO ESTUDO}

Neste estudo, o Modelo Digital de Terreno foi baseado na distribuição de indicadores de preços dos fertilizantes. A amostragem utilizada foi a irregular, pois os pontos que definem a localização geográfica $(x$ e $y$ ) do indicador de preços do fertilizante foram as sedes geográficas de cada município do território nacional (seguindo a referência do Instituto Brasileiro de Geografia e Estatística (IBGE, 2005). Isto porque esses pontos foram considerados como o destino final para o qual foram calculadas as distâncias rodoviárias em relação aos principais portos de importação do fertilizante: o Porto de Santos, o Porto de Paranaguá e o de Rio Grande.

De forma similar a um Modelo Digital de Terreno tradicional, os indicadores dos preços dos fertilizantes são uma das três informações necessárias para obter a massa de dados para a elaboração da malha digital. Cada ponto da amostra é formado por 3 dados: o valor da coordenada $x$, o valor da coordenada y e o valor $z$. Os valores de $\mathrm{x}$ e y referem-se ás coordenadas da sede de cada município da federação, o destino do produto. $O$ valor $z$ é o índice de custo do insumo, um indicador formado pelo preço do fertilizante no porto ou na fábrica convertido pelo câmbio, adicionado de impostos e do frete até o destino do produto. 
Parte da formação de preços dos fertilizantes importados comercializados no Brasil, ou seja, a parte referente aos custos logísticos do produto, inicia-se com o produto já embarcado no porto de origem.

As principais origens dos nutrientes importados pelo País são os portos do Mar Báltico no caso do MAP (Monoamônio fosfato), o Golfo Árabe no caso da Uréia e Vancouver, no Canadá, no caso do Cloreto de Potássio. Considera-se portanto, o preço FOB (já com os custos portuários incidentes) no porto de origem.

A esse preço foi adicionado o valor do frete e seguro marítimo até um dos três principais portos de destino no Brasil - Santos, Paranaguá ou Rio Grande. Incide então sobre o produto, tarifas e impostos. No caso dos fertilizantes, o imposto sobre importação está zerado, incidindo sobre o produto somente o imposto da Marinha Mercante. Foram adicionadas as despesas aduaneiras e portuárias, como o frete interno no porto e o produto teve seu preço convertido em Reais.

Carregado nos caminhões, o fertilizante é transportado às misturadoras que unem os três produtos para formar as formulações de nitrogênio, fósforo e potássio e distribuí-las na região de consumo, somando-se aos produtos os custos de frete do porto até o destino.

Sobre o fertilizante produzido no Brasil incidem o frete até o destino de consumo e o Imposto sobre a circulação de Mercadorias e Serviços (ICMS).

Para o estudo, optou-se por analisar os fertilizantes MAP, a Uréia e o Cloreto de Potássio, por conta da disponibilidade de dados e por ser possível, a partir deles, formular as misturas de NPK utilizadas na agricultura brasileira.

A amostra de dados foi criada a partir de cortes no tempo, já que o propósito do modelo era ter uma visão da concorrência do mercado em um momento no tempo, sobre a qual foram feitas simulações.

As fontes dos dados utilizados para elaboração dos índices de custo de fertilizantes foram os preços internacionais dos produtos (Associação Nacional para Difusão de Adubos), a taxa de câmbio (Banco Central do Brasil), os impostos incidentes sobre os fertilizantes (Imposto sobre a movimentação de mercadorias e serviços - ICMS) e os encargos nos portos. 
O modelo de internalização do preço dos fertilizantes importado foi elaborado em planilha Excell.

Para testar os resultados do modelo de calculo do indicador do frete, foram calculados os preços médios das misturas dos fertilizantes a partir de dados reais de fretes e comparados com os preços fornecidos pelo anuário estatístico da ANDA (2010).

\subsection{SEGUNDA FASE DO ESTUDO}

Para obter o preço em cada destino, foi necessário estimar os valores dos fretes de modo contínuo sobre a superfície para posteriormente somar, por meio de álgebra de mapas ${ }^{2}$, esta superfície de valores estimados de fretes com grades de valores constantes dos preços internalizados de cada fertilizantes calculados pelo modelo em excell, em cada um dos três portos de origem (Paranaguá, Santos e Rio Grande).

A estimação dos fretes para regiões onde não haviam dados suficientes foram elaboradas de três maneiras diferentes:

a) por meio de regressão;

b) por meio de interpolação espacial e,

c) com o uso da geoestatística.

Para estimar estes fretes desconhecidos pelo método da regressão, baseandose na literatura disponível, optou-se por testar e comparar os resultados da regressão linear simples (Equação 16) e do modelo funcional log-log (Equação 17).

\footnotetext{
${ }^{2}$ Operações algébricas realizadas entre mapas com auxílio de um software
} 
Outras formas funcionais foram testadas, como a regressão lin-log, mas as funções lineares e log-log foram as que apresentaram melhores resultados, sendo mantidas no estudo.

Para estimar a regressão linear, foram utilizados dados dos valores de fretes $(\mathrm{R} \$ / \mathrm{t})$ entre as origens (portos) e destinos para o transporte dos produtos de fertilizantes em geral, relacionando-os com as respectivas distâncias. A equação estimada foi dada por:

$$
Y=\beta_{1}+\beta_{2 *} X
$$

Para obter a elasticidade do preço do frete em relação à distância, utilizou-se a forma funcional log-log. A modelo estimado foi o seguinte:

$$
\log (Y)=\beta_{1}+\beta_{2} \log (X)
$$

Onde: Y: variável dependente que expressa o valor de frete rodoviário em função da tonelada de fertilizante transportado $(\mathrm{R} \$ / \mathrm{t})$;

X: variável independente que expressa a quilometragem percorrida $(\mathrm{km})$;

$\beta_{2}$ : coeficiente angular em função da faixa de quilometragem percorrida e do preço do frete da tonelada de fertilizante transportada;

$\beta_{l}$ : intercepto da função.

Os resultados das funções e comentários sobre elas foram apresentados no capítulo Resultados. 


\subsection{TERCEIRA FASE DO ESTUDO}

Dentre as três diferentes técnicas utilizadas para estimar os fretes, a que mostrou o menor desvio em relação aos valores reais foi escolhida para elaborar análises a respeito do comportamento dos fretes em si e, somadas às grades de valores constantes dos preços internalizados dos fertilizantes importados em cada porto, analisar o comportamento dos indicadores de preços na superfície e identificar as áreas de influência dos portos na importação destes insumos, com o auxílio da álgebra de mapas e isolinhas.

\subsection{ORGANOGRAMA DE EXECUÇÃO DO ESTUDO}

O organograma a seguir apresenta todo o desenvolvimento do projeto, em todas as suas fases.

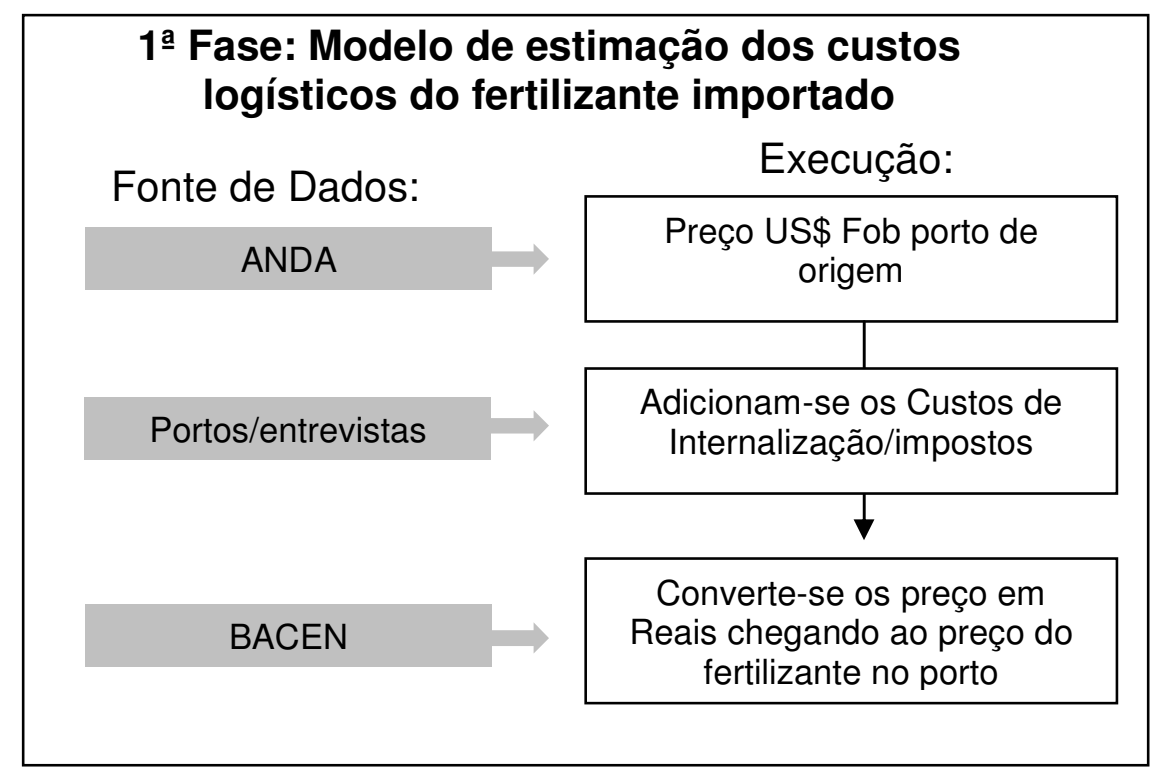




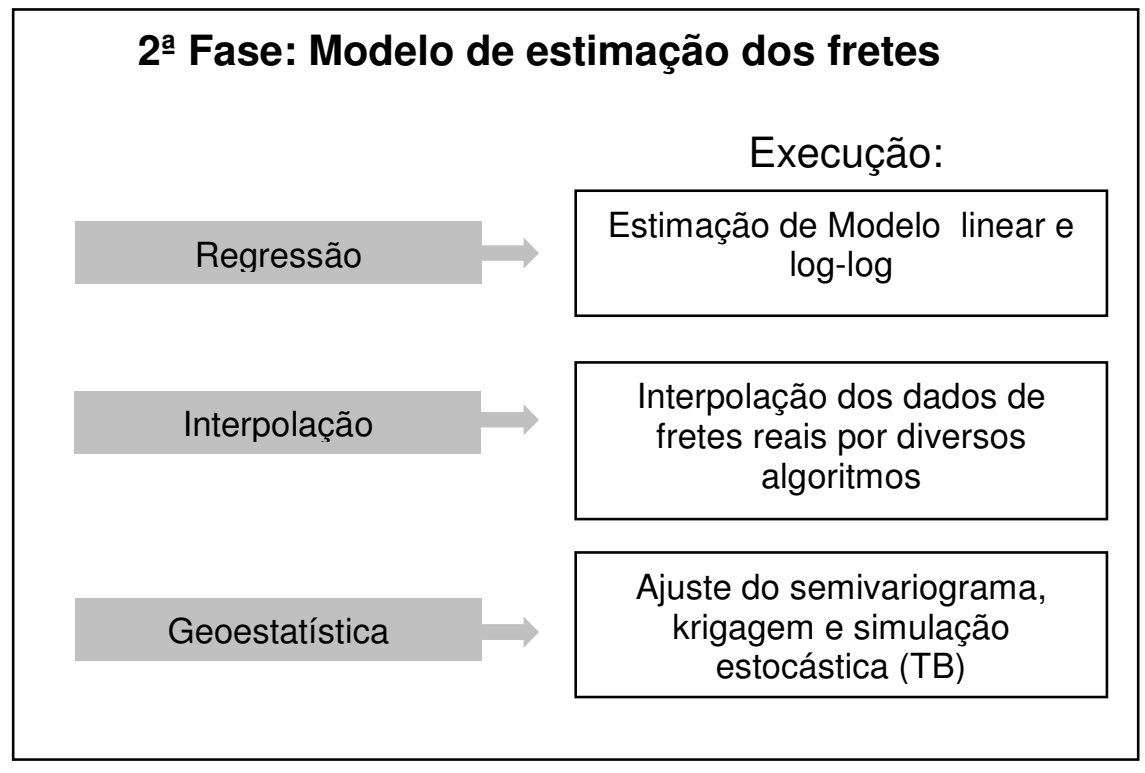

\section{3 - Fase: Análise}

Com auxílio do SIG, álgebra de mapas, simulações e métodos topológicos, são feitos cruzamentos dos mapas de fretes e dos indicadores de preços para entender 0 comportamento dos fretes e estabelecer as áreas de influência de cada porto na importação de fertilizantes. 


\section{RESULTADOS}

\subsection{SOBRE OS FRETES}

O frete rodoviário é a variável que determina a que preço o fertilizante importado chegará ao produtor nas diversas regiões do país. Pode-se dizer que, juntamente com os custos portuários do porto de desembarque do produto, estas são as duas principais variáveis na formação do preço do produto final dentro do território nacional.

No entanto, há uma grande dificuldade em se levantar os valores de fretes rodoviários de maneira sistemática de modo a formar uma série extensa de dados a qual possibilite uma análise mais precisa desta variável.

Foram utilizados no estudo, os preços de fretes rodoviários levantados pelo SIFRECA entre o período de setembro de 2007 a dezembro de 2010. Os valores fornecidos são levantados, entretanto, em períodos inter mensais, geralmente iniciando próximo ao vigésimo dia do mês. Uma dificuldade encontrada com relação aos preços dos fretes dos fertilizantes é a inconstância dos dados. Ou seja, os preços para uma determinada rota é levantado de maneira descontínua, apresentando quebras temporais ou mesmo, sendo suspensa a partir de uma certa data. Há também uma distribuição geográfica bastante heterogênea das rotas, concentrando o levantamento de diversas rotas para regiões próximas. Estas características são fruto da metodologia do levantamento dos dados e da dificuldade na obtenção de informações característica do setor de transportes.

Por conta desta dificuldade com relação aos dados de preços de fretes, houve a necessidade de se elaborar uma breve análise dos dados, lembrando que não foi objetivo do estudo a análise dos preços dos fretes dos fertilizantes em si. A análise baseou-se na observação da relação dos preços de fretes com a distância rodoviária 
e na investigação da existência de rotas específicas com valores diferenciados para os fertilizantes, não observando demais variáveis que impactam na formação do preço do frete, dada a grande correlação encontrada com a variável distância.

De acordo com Martins (2008), em linhas gerais, nos estudos sobre fretes, há uma concentração nos trabalhos sobre a formação dos fretes em abordagens que consideram a distância como principal fator de determinação de valores. Os resultados obtidos em seu estudo sobre a estimação dos parâmetros que relacionam os valores dos fretes com a distância percorrida no transporte do agronegócio brasileiro, indicaram para a maioria das formas funcionais estimadas, altos coeficientes de determinação (acima de 0,70), qualificando a distância percorrida como uma das variáveis mais importantes na formação do frete.

Em seu artigo Martins (2008) cita também Correa Junior et al (2001), quando afirma que os estudos que procuram identificar os determinantes dos fretes rodoviários são, primeiramente, dependentes das distâncias e, posteriormente, ajustados por outros fatores.

Uma importante relação no que diz respeito ao preço de frete no agronegócio nacional e a distância, é o fato de que maiores distâncias implicam em maiores fretes unitários, ou seja, em $\mathrm{R} \$$ por tonelada. Mas, observa-se uma relação inversa na remuneração do quilômetro percorrido, melhor dizendo, no momento do transporte, ou no preço em $\mathrm{R} \$ / \mathrm{t} . \mathrm{km}$. Este é o princípio da economia da distância teorizado por McCann (2001), claramente observado no caso particular dos preços do frete de fertilizantes no Brasil.

No presente estudo foram analisados os fretes dos três corredores principais de escoamento do produto para o interior do país, os corredores de Paranaguá, Santos/Cubatão e Rio Grande para todas as rotas disponíveis com origem nestes três portos, entre os anos de 2008 a 2010.

A tabela 7 mostra o momento médio do transporte de fertilizantes no segundo semestre dos anos de 2008, 2009 e 2010. Nota-se que, quanto maior a distância percorrida, menor é o momento do transporte, por conta da diluição dos custos fixos do fretamento pela maior distância percorrida. Nota-se também que, na maior parte das rotas apresentadas, houve baixa variação do preço no decorrer dos três anos 
analisados. Algumas rotas específicas, entretanto, apresentaram elevação mais significativa no decorrer do tempo.

Tabela 7. Momento do Transporte $(\mathrm{R} \$ / \mathrm{t} . \mathrm{km})$ para diferentes distâncias nos corredores de origem dos Portos de Paranaguá, Rio grande e Cubatão, média do segundo semestre de 2008, 2009 e 2010.

\begin{tabular}{llcrrr}
\hline Origem & Destino & Distância $(\mathrm{km})$ & 2008 & 2009 & 2010 \\
\hline \multirow{5}{*}{ Paranaguá PR } & Ponta Grossa PR & 207 & 0,12 & 0,13 & 0,14 \\
& Campo Mourão PR & 501 & 0,11 & 0,11 & 0,11 \\
& Rio Verde GO & 1250 & 0,07 & 0,07 & 0,09 \\
& Sorriso MT & 2134 & 0,06 & 0,06 & 0,06 \\
\hline \multirow{3}{*}{ Rio Grande RS } & São Gabriel RS & 353 & 0,12 & 0,14 & 0,17 \\
& Cascavel PR & 1034 & 0,08 & 0,08 & 0,08 \\
& Maringá PR & 1360 & 0,07 & 0,07 & 0,07 \\
\hline \multirow{3}{*}{ Cubatão SP } & Piracicaba SP & 205 & 0,18 & 0,18 & 0,18 \\
& Uberaba MG & 543 & 0,11 & 0,10 & 0,10 \\
& Rondonópolis MT & 1420 & 0,06 & 0,06 & 0,07 \\
\hline
\end{tabular}

Fonte: SIFRECA. Organizado pelo autor

Dada a característica do mercado de fertilizantes, das vendas se concentrarem no segundo semente do ano, a disponibilidade de preços de fretes também é maior neste período, para os três corredores analisados: Santos/Cubatão, Paranaguá e Rio Grande.

Além disso, para a maioria da rotas, os preços variam pouco no decorrer do ano. A tabela 8 mostra os preços máximo, médio e mínimo para os três corredores analisados nos anos de 2008, 2009 e 2010, em $R \$ / t$ e $R \$ / t . k m$, para rotas acima de $100 \mathrm{~km}$.

Observa-se no entanto, que para as rotas menores que $100 \mathrm{~km}$, há uma grande variabilidade nos preços entre os corredores analisados, por conta das características regionais de cada porto. O preço do frete da rota entre Cubatão e Guarulhos, cuja distância é de 88 quilômetros, foi de $R \$ 33,00$ no segundo semestre de 2009 , ou $R \$ 0,37$ / t.km. Entre Cubatão e Mogi das Cruzes, que se distanciam em 89 quilômetros, o preço na mesma época foi de $R \$ 36,00$, ou $R \$ 0,41 /$ t.km. 
Já o frete ente Paranaguá e Curitiba, na mesma época, cuja distância é de 90 quilômetros, foi de $R \$ 20,00$, ou $R \$ 0,22$ /t.km. Entre o Porto de Rio Grande e Pelotas, no Rio Grande do Sul, o preço foi $R \$ 23.50$, equivalente a $R \$ 0,39$ /t.km, já que a distância entre os pontos é de 60 quilômetros.

No segundo semestre de 2010, o momento do transporte entre Cubatão e Guarulhos passou para $\mathrm{R} \$ 0,53 / \mathrm{t} . \mathrm{km}$ e para a rota Cubatão-Mogi das Cruzes o valor foi de $R \$ 0,46 /$ t.km. A rota Paranaguá-Curitiba manteve-se com um preço de $R \$$ 0,22/t.km, assim como o preço entre Rio Grande e Pelotas continuou em $R \$$ 0,39/t.km. (Tabela 8)

Tabela 8. Preços médios, mínimos e máximos dos fretes de fertilizantes anuais, do primeiro e segundo semestres de 2008, 2009 e 2010, para rotas acima de $100 \mathrm{~km}$.

\begin{tabular}{|c|c|c|c|c|c|c|c|c|c|c|}
\hline \multirow[b]{2}{*}{ Corredor } & & \multicolumn{3}{|c|}{$2008(R \$ / t)$} & \multicolumn{3}{|c|}{$2009(R \$ / t)$} & \multicolumn{3}{|c|}{$2010(R \$ / t)$} \\
\hline & & 2008 & 1 Sem08 & 2 Sem08 & 2009 & 1 Sem09 & 2 Sem09 & 2010 & 1 Sem 10 & 2 Sem 10 \\
\hline & Máximo: & 113.0 & 70.0 & 113.0 & 121.3 & 117.5 & 125.0 & 118.1 & 117.4 & 123.2 \\
\hline \multirow[t]{3}{*}{ Cubatão /Santos } & Media: & 46.3 & 39.7 & 47.3 & 52.2 & 49.9 & 52.9 & 56.3 & 56.7 & 56.6 \\
\hline & Mínimo: & 26.0 & 29.3 & 26.0 & 32.0 & 32.0 & 33.9 & 24.5 & 23.9 & 26.4 \\
\hline & Máximo: & 138.9 & 138.9 & 133.9 & 155.0 & 137.5 & 155.0 & 164.9 & 164.9 & 172.5 \\
\hline \multirow[t]{3}{*}{ Paranaguá } & Media: & 73.4 & 70.0 & 72.9 & 69.8 & 70.3 & 69.5 & 87.7 & 80.8 & 90.1 \\
\hline & Mínimo: & 32.6 & 39.2 & 24.5 & 26.2 & 23.8 & 28.2 & 30.8 & 29.6 & 29.9 \\
\hline & Máximo: & 190.0 & 57.3 & 190.0 & 194.0 & 195.0 & 190.0 & 140.0 & 140.0 & 60.3 \\
\hline \multirow[t]{2}{*}{ Rio Grande } & Media: & 73.9 & 45.6 & 74.1 & 72.9 & 82.3 & 74.1 & 60.3 & 61.2 & 49.0 \\
\hline & Mínimo: & 31.6 & 31.6 & 31.6 & 39.4 & 42.7 & 39.4 & 34.0 & 37.5 & 34.0 \\
\hline & & \multicolumn{3}{|c|}{2008 (R\$/t.km) } & \multicolumn{3}{|c|}{2009 (R\$/t.km) } & \multicolumn{3}{|c|}{2010 (R\$/t.km) } \\
\hline \multirow[t]{2}{*}{ Corredor } & & 2008 & 1 Sem08 & 2 Sem08 & 2009 & 1 Sem09 & 2 Sem09 & 2010 & 1 Sem 10 & 2 Sem 10 \\
\hline & Máximo: & 0.18 & 0.15 & 0.18 & 0.26 & 0.24 & 0.26 & 0.21 & 0.21 & 0.23 \\
\hline \multirow[t]{3}{*}{ Cubatão /Santos } & Media: & 0.10 & 0.10 & 0.11 & 0.10 & 0.10 & 0.10 & 0.10 & 0.10 & 0.10 \\
\hline & Mínimo: & 0.00 & 0.07 & 0.06 & 0.04 & 0.04 & 0.05 & 0.04 & 0.04 & 0.04 \\
\hline & Máximo: & 0.23 & 0.31 & 0.21 & 0.21 & 0.21 & 0.22 & 0.19 & 0.18 & 0.20 \\
\hline \multirow[t]{3}{*}{ Paranaguá } & Media: & 0.09 & 0.09 & 0.09 & 0.09 & 0.09 & 0.09 & 0.09 & 0.08 & 0.10 \\
\hline & Mínimo: & 0.04 & 0.05 & 0.04 & 0.03 & 0.03 & 0.04 & 0.05 & 0.04 & 0.05 \\
\hline & Máximo: & 0.12 & 0.12 & 0.12 & 0.15 & 0.11 & 0.15 & 0.15 & 0.11 & 0.17 \\
\hline \multirow[t]{2}{*}{ Rio Grande } & Media: & 0.09 & 0.10 & 0.09 & 0.09 & 0.08 & 0.10 & 0.09 & 0.08 & 0.10 \\
\hline & Mínimo: & 0.07 & 0.08 & 0.07 & 0.07 & 0.07 & 0.07 & 0.07 & 0.07 & 0.08 \\
\hline
\end{tabular}

Fonte: SIFRECA. Elaborado pelo autor

Foi elaborada uma análise gráfica dos preços médios anuais, do primeiro e segundo semestres para os três anos em questão, para cada porto de origem.

A Figura 14 apresenta os preços médios de todas as rotas disponíveis originadas em Cubatão/Santos, por distância percorrida em 2008. Nota-se que há 
uma maior disponibilidade de dados no segundo semestre e uma variabilidade maior de preços entre as distâncias de 200 a 600 km. Há também um ponto destoante na série: a rota Cubatão - Goiânia, que apresenta um momento de transporte mais alto $R \$ 0,12 /$ t.km (R\$113,00/t) apesar da grande distância percorrida, de $965 \mathrm{~km}$. No entanto, há somente um dado para a rota, em agosto de 2008.

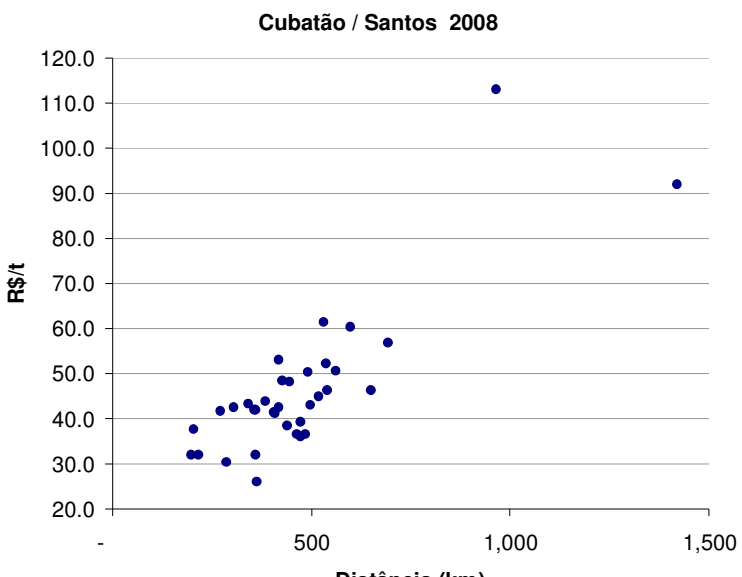

Cubatão / Santos 1 Sem 08

Cubatão / Santos 2 Sem08
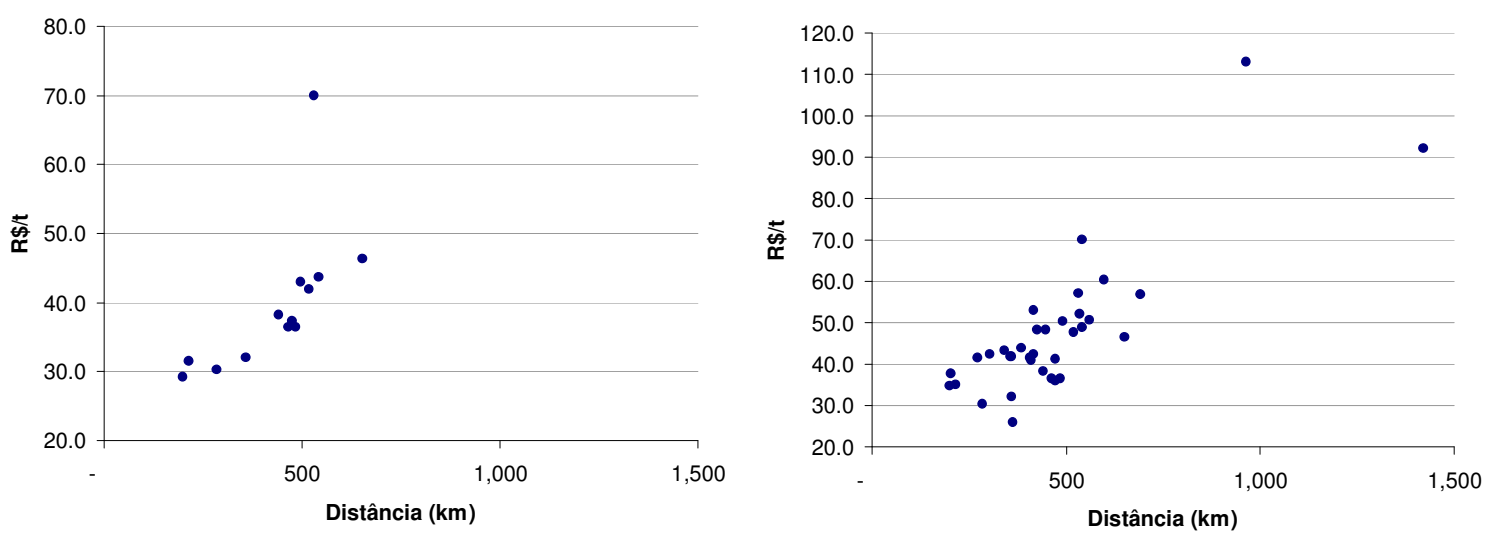

Figura 14. Preços dos fretes dos fertilizantes do corredor Santos/Cubatão em 2008

No ano seguinte, o número de rotas levantadas é maior, mas o comportamento é semelhante ao de 2008: há maior variação nos preços das rotas entre 200 e 700 $\mathrm{km}$. No primeiro semestre do ano nota-se que a rota Cubatão - Corumbá, com a distância de $1.500 \mathrm{~km}$, apresenta um valor fora da tendência do restante da série, de $\mathrm{R} \$ 105,00 / \mathrm{t}$, ou $\mathrm{R} \$ 0,07 / \mathrm{t} . \mathrm{km}$. no entanto, como no caso anterior, o dado se apresenta uma única vez no semestre, como pode ser visto na Figura 15. 


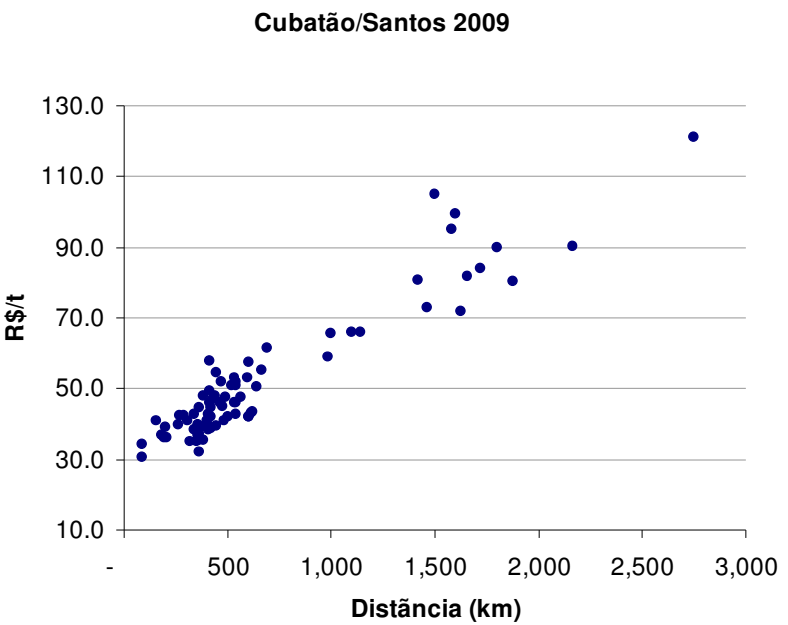

Cubatão/Santos 1 Sem09

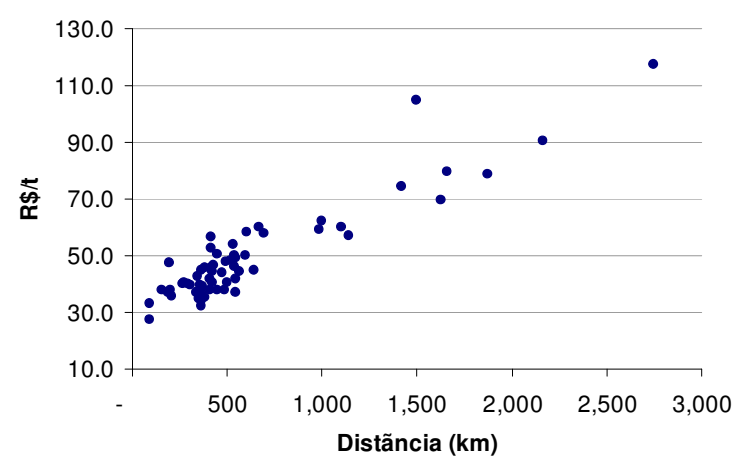

Cubatão/Santos 2 Sem09

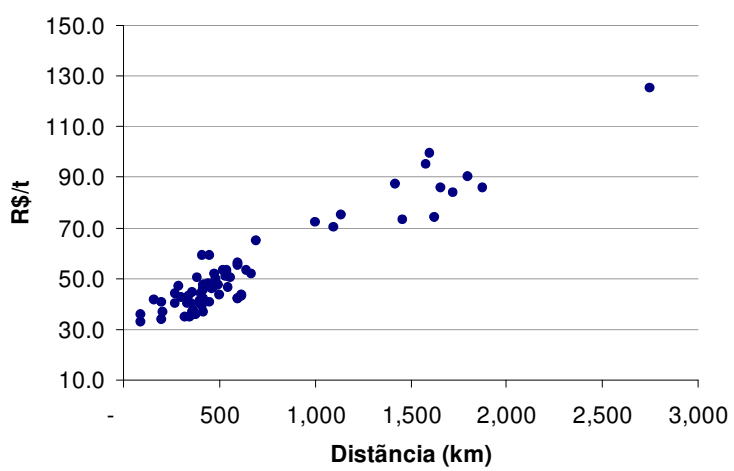

Figura 15. Preços dos fretes dos fertilizantes do corredor Santos/Cubatão em 2009

Em 2010 há um número maior de rotas levantadas e os preços no segundo semestre apresentam-se ligeiramente mais dispersos que no primeiro. Até $800 \mathrm{~km}$, os preços apresentam maior variabilidade e é possível identificar níveis diferenciados de preços (Figura 16). 

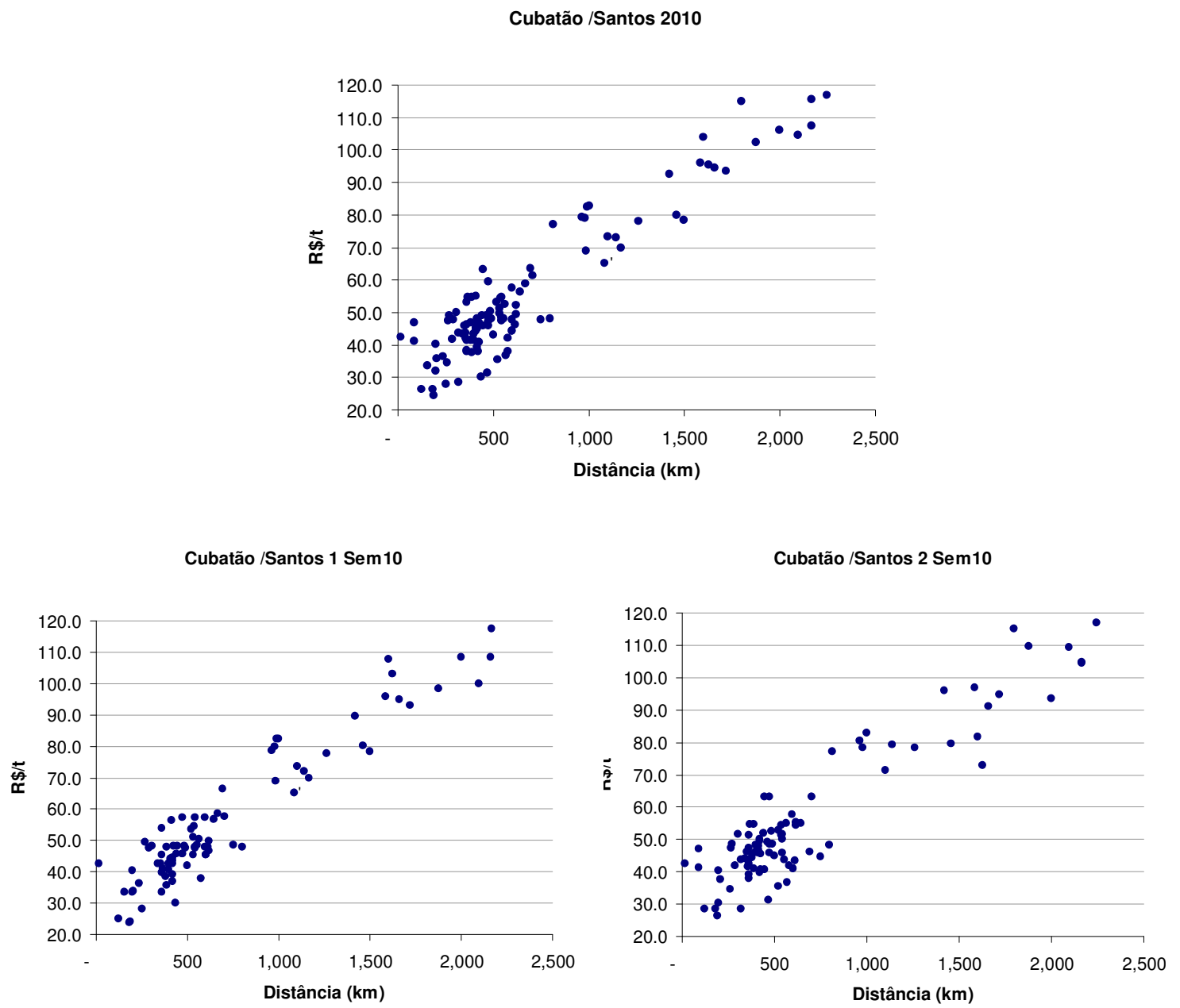

Figura 16. Preços dos fretes dos fertilizantes do corredor Santos/Cubatão em 2010

Examinando de forma mais detalhada estes níveis diferenciados de preços para distâncias até $800 \mathrm{~km}$, foi possível notar que é dentro desta faixa de distância, a partir do porto de Santos, que localiza-se o maior número de pedágios e que há uma grande dispersão, tanto no número de praças, quanto nos valores totais pagos por toda a rota percorrida.

A Figura 17 mostra a relação entre distância e valor total em pedágios na rota para todas as rotas disponíveis em 2010 no corredor do porto de Santos/Cubatão. Até a distância de $800 \mathrm{~km}$, os valores totais pagos com pedágios são crescentes, mas dispersos, e a partir desta distância, eles tornam-se praticamente constantes, por conta da ausência de rodovias pedagiadas principalmente após a divisa com o Estado de São Paulo. 


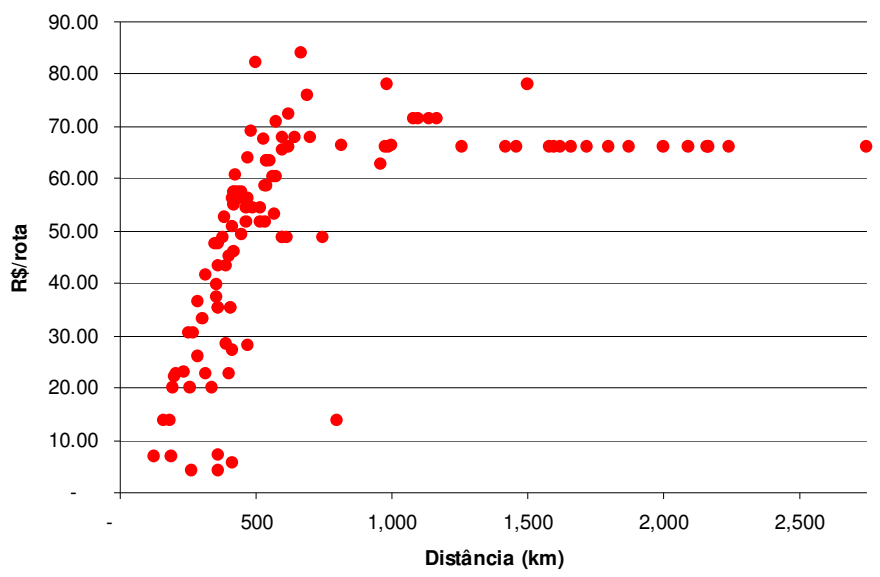

Figura 17. Distância e valor total em pedágios na rota para todas as rotas disponíveis em 2010 no corredor do porto de Santos/Cubatão.

O mesmo efeito pode ser visto de outra forma no gráfico da Figura 18. Ele mostra o número de praças de pedágio em função da distância. A partir de 1.200 km, aproximadamente, o número de praças de pedágios não se altera (com exceção da rota Santos/Cubatão-Corumbá, que possui 17 praças).

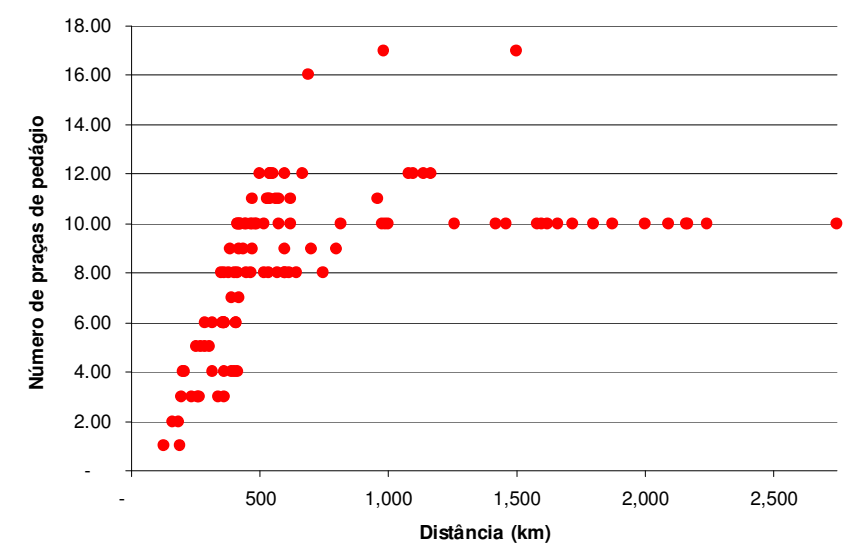

Figura 18. Número de praças de pedágios e distância percorrida no corredor Santos/Cubatão 
Por conta deste fato, as rotas que tem seu destino dentro ou próximas à divisa com São Paulo acabam tendo valores de frete mais dispersos e elevados, como é o caso da rota Cubatão-Uberaba. Já as rotas com distâncias maiores possuem longos trechos não pedagiados e têm a despesa com pedágio diluída pela distância.

Se comparados os valores totais de pedágios por rota e o frete total entre as distâncias (Figura 19), é visível uma grande dispersão dos preços para custos de frete até $R \$ 80,00$. Isto se dá em função da grande variabilidade de números de praças e valores diferenciados dos pedágios dentro das distâncias até 1.500 km.

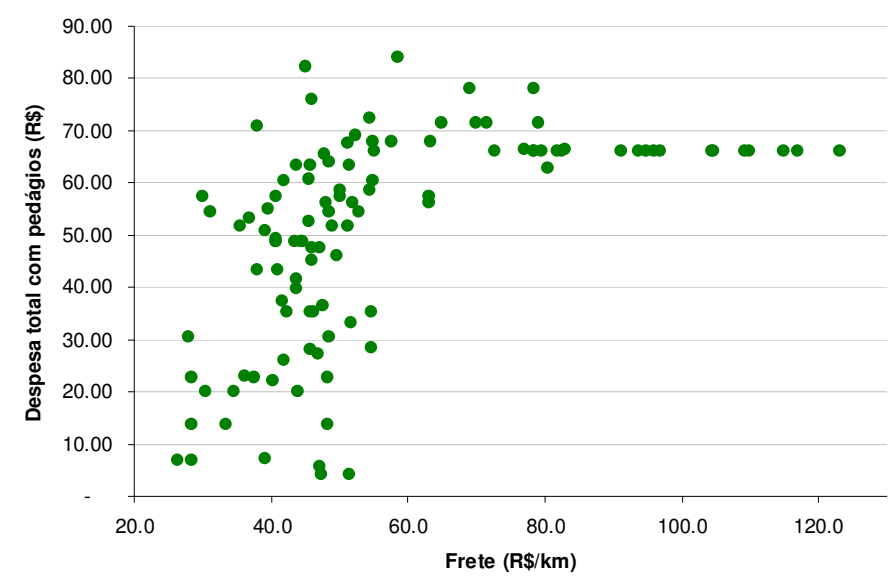

Figura 19. Despesa total com pedágios por rota e o frete total

No caso do corredor de Paranaguá, as distâncias entre 500 e 1.500 km apresentam maior variabilidade dos preços e é nítido um comportamento duplo disperso dentro destas distâncias, o que sugere uma diferenciação de preços entre rotas distintas (Figura 20).

Como no corredor de Santos/Cubatão, as rotas que passam pela região onde há uma concentração de pedágios apresentam maiores valores de frete que as rotas que não passam por esta região. A grande parte destas rotas de maior valor tem como destino municípios dos estados de São Paulo, Minas Gerais e Goiás. 

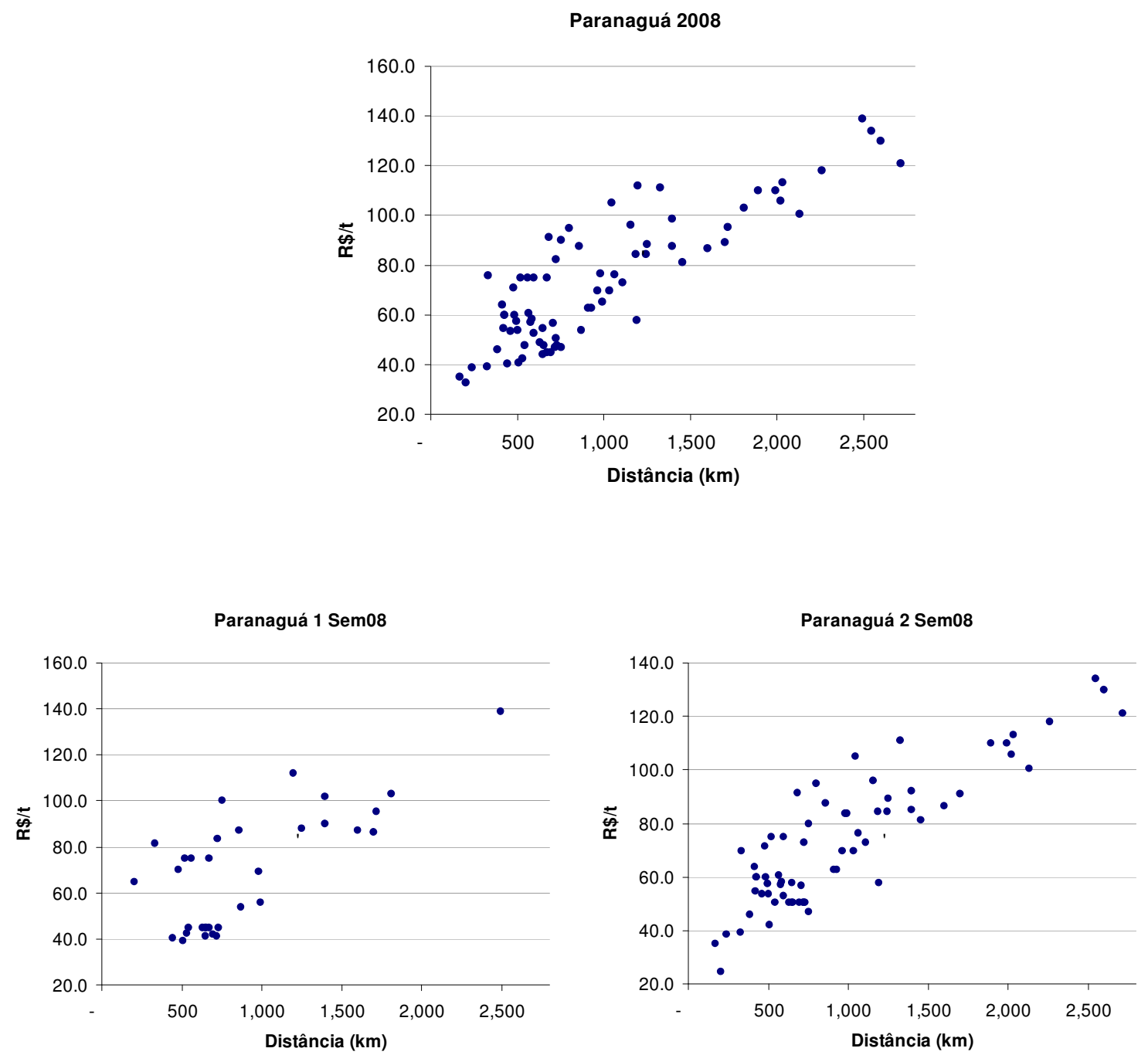

Figura 20. Preços dos fretes dos fertilizantes do corredor Paranaguá em 2008

Em 2009 (Figura 21) o mesmo comportamento se repete, mas há alguns pontos que se encontram muito fora da curva de preços geral, principalmente no primeiro semestre do ano, quando há um menor número de rotas avaliados e algum tipo de comprometimento do dado, como a rota entre Paranaguá e Campo Novo dos Parecis em Mato Grosso, que apresenta um preço de frete muito menor que as demais rotas com distâncias similares e próximas da mesma região. 
Paranaguá 2009

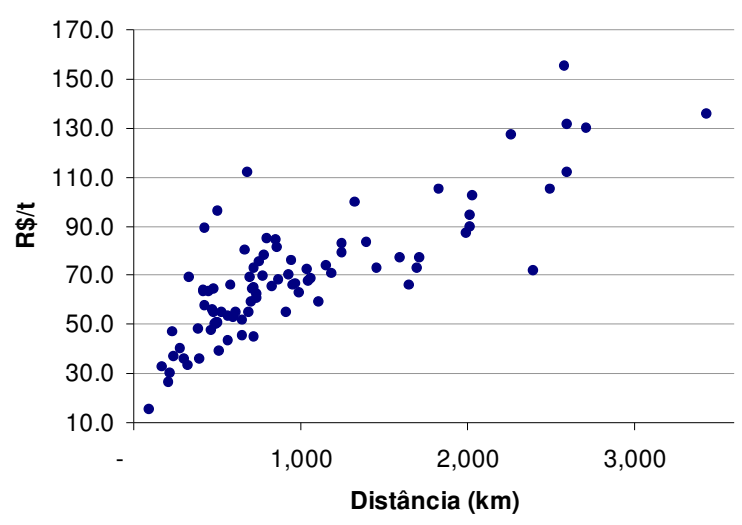

Paranaguá 1Sem09

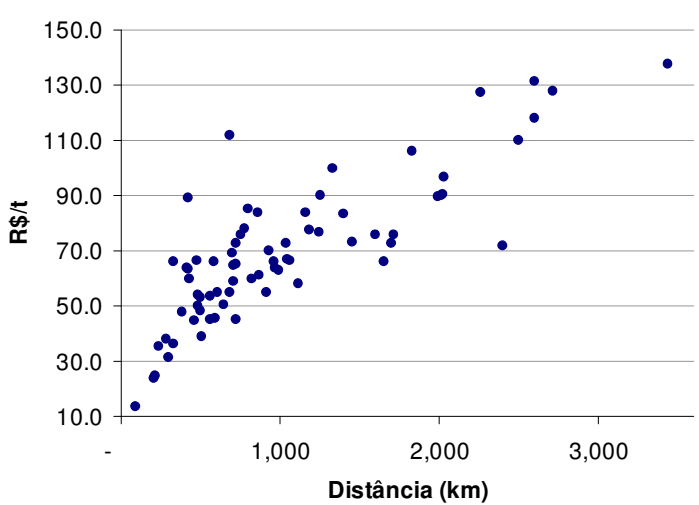

Paranaguá 2Sem09

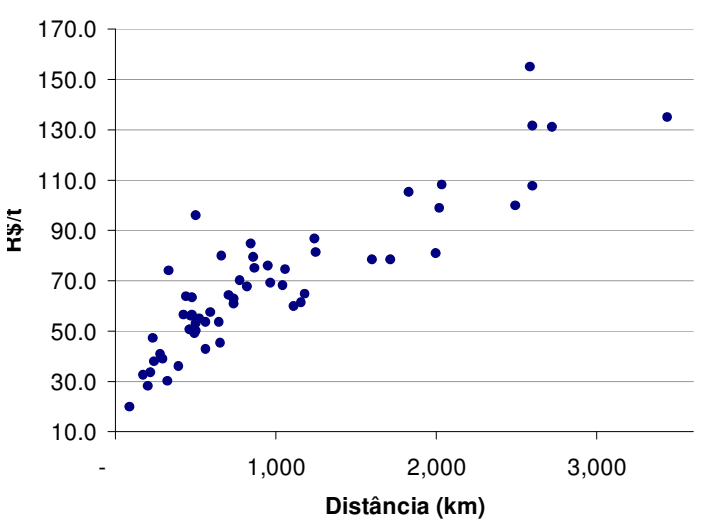

Figura 21. Preços dos fretes dos fertilizantes do corredor Paranaguá em 2009

Em 2010, há um aumento significativo de rotas levantadas, concentradas no segundo semestre, e uma maior dispersão dos preços. Entre 500 e 2.000 km, há um agrupamento de rotas de maior preço de frete em relação as demais originadas de Paranaguá (Figura 22). Estas rotas têm como parte do trecho percorrido algumas das rodovias mais modernas e movimentadas, ou também, mais pedagiadas, do complexo rodoviário nacional, como a BR 116, a Rodovia dos Bandeirantes, a Rodovia Raposo Tavares. 


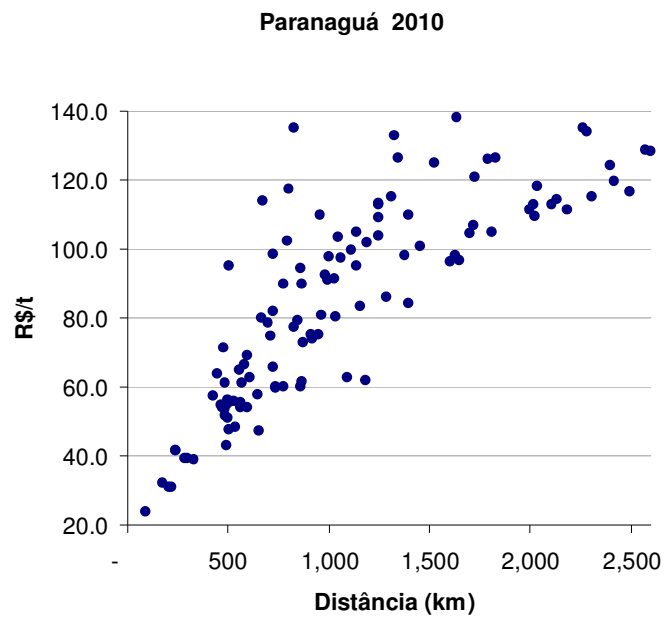

Paranaguá 1 Sem 10

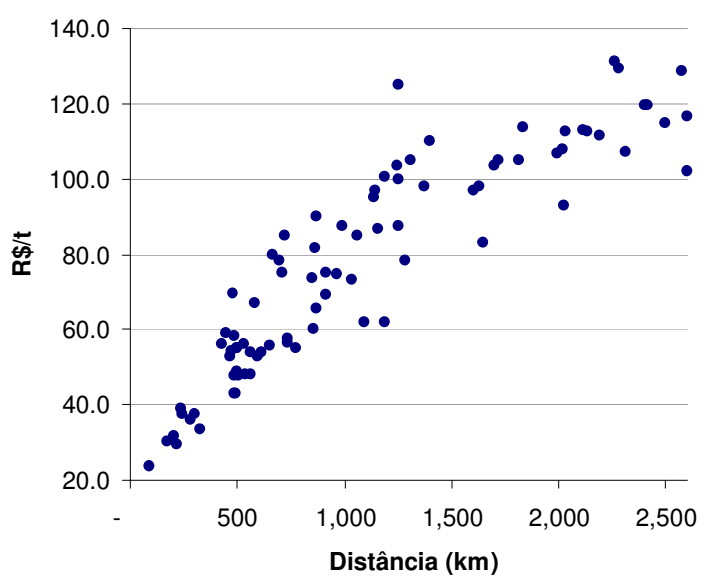

Paranaguá 2 Sem 10

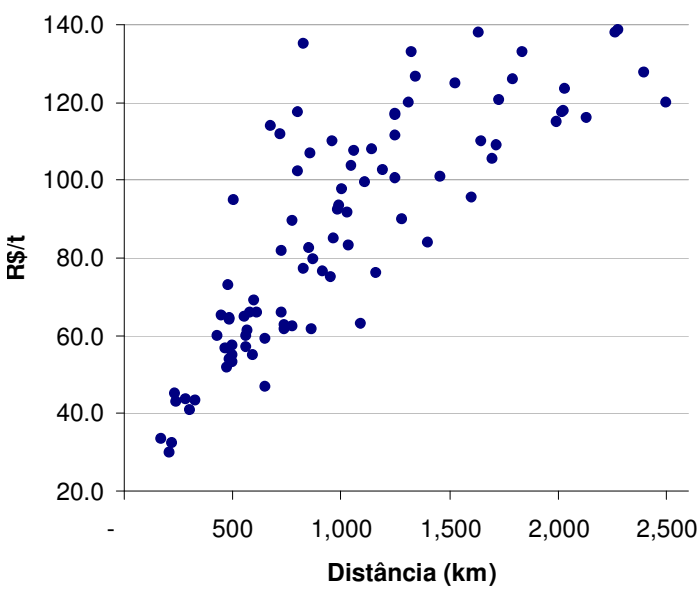

Figura 22. Preços dos fretes dos fertilizantes do corredor Paranaguá em 2010

É nítida nos preços de fretes do corredor do Porto de Rio Grande, a relação com a distância percorrida. Ainda assim, nas distâncias ao redor de $500 \mathrm{~km}$, há uma variação maior de preços do que no restante da série e a grande parte das rotas levantadas está concentrada no segundo semestre do ano, como se vê nos gráficos seguintes (Figura 23). 


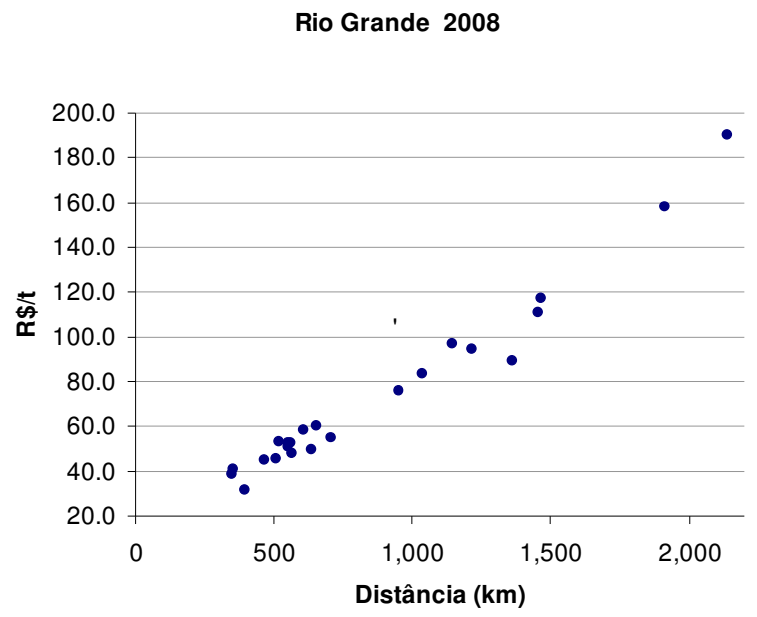

Rio Grande 1 Sem08

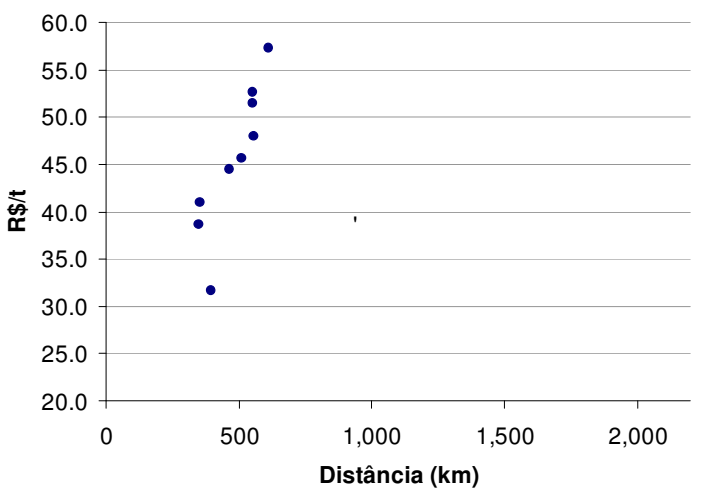

Rio Grande 2 Sem08

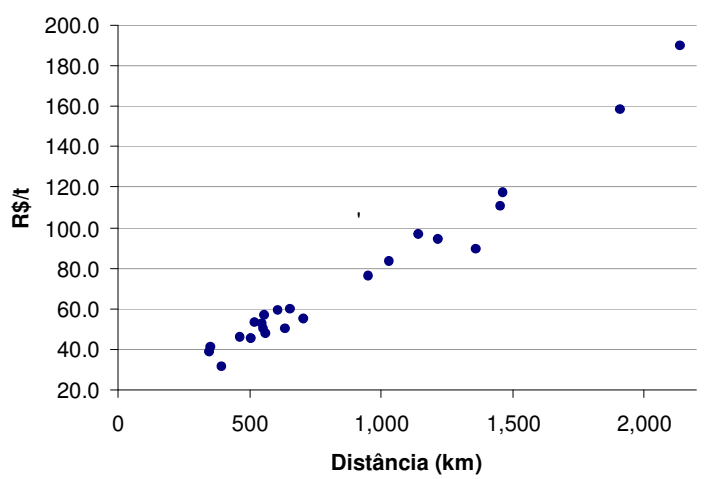

Figura 23. Preços dos fretes dos fertilizantes do corredor Rio Grande em 2008

No ano de 2009, o comportamento dos preços no corredor de Rio Grande é bastante similar ao do ano anterior, com a diferença que houve um maior número de rotas disponíveis para avaliação. Entre 500 e $700 \mathrm{~km}$, aproximadamente, há maior variabilidade de preços, tanto no primeiro quanto no segundo semestres (Figura 24).

O problema com os dados deste corredor é que a grande maioria das rotas concentram-se dentro do estado do Rio Grande do Sul. Ha apenas poucas rotas para os demais estados, como São Paulo, Minas Gerais, Mato Grosso do Sul e Mato Grosso. 
Rio Grande 2009

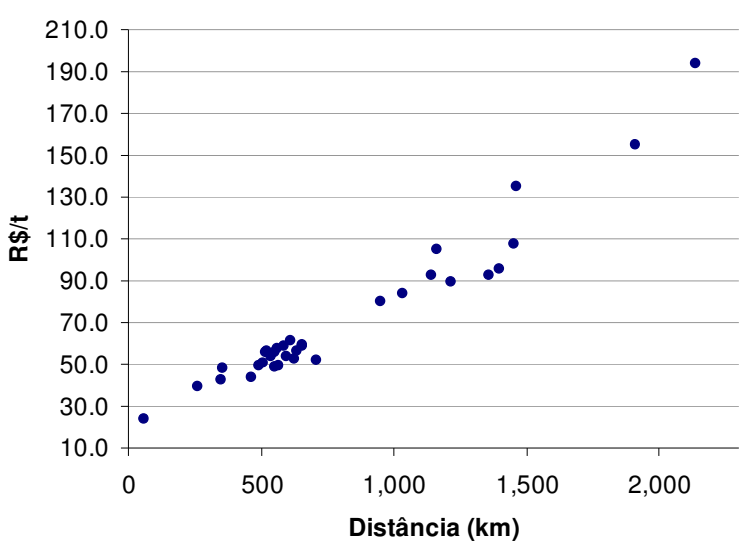

Rio Grande 1Sem09

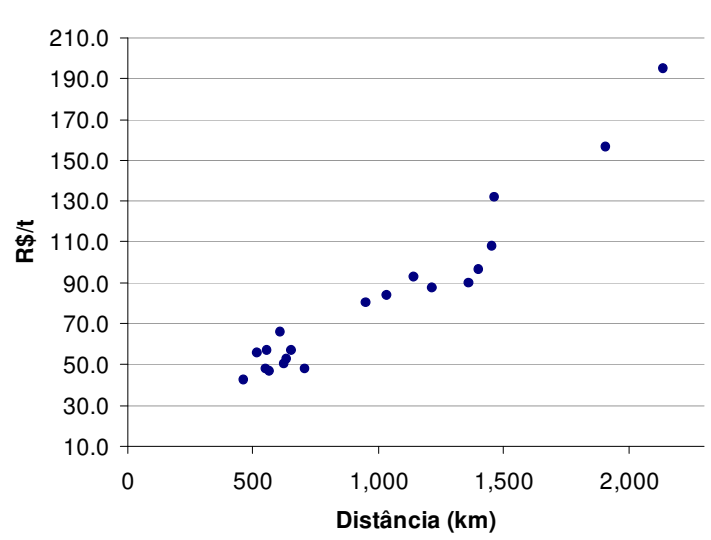

Rio Grande 2Sem09

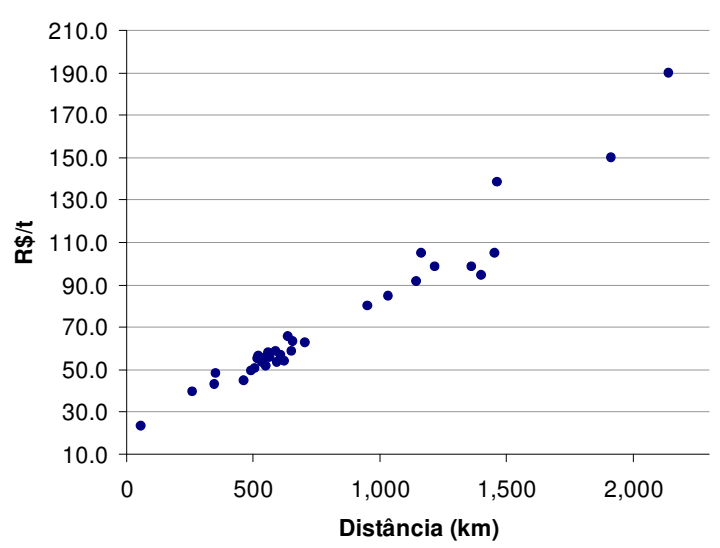

Figura 24. Preços dos fretes dos fertilizantes do corredor Rio Grande em 2009

O mesmo ocorre para os fretes da rota de Rio Grande em 2010 mostrados na Figura 25. No entanto, o número de rotas levantadas diminui muito em relação ao ano anterior. 

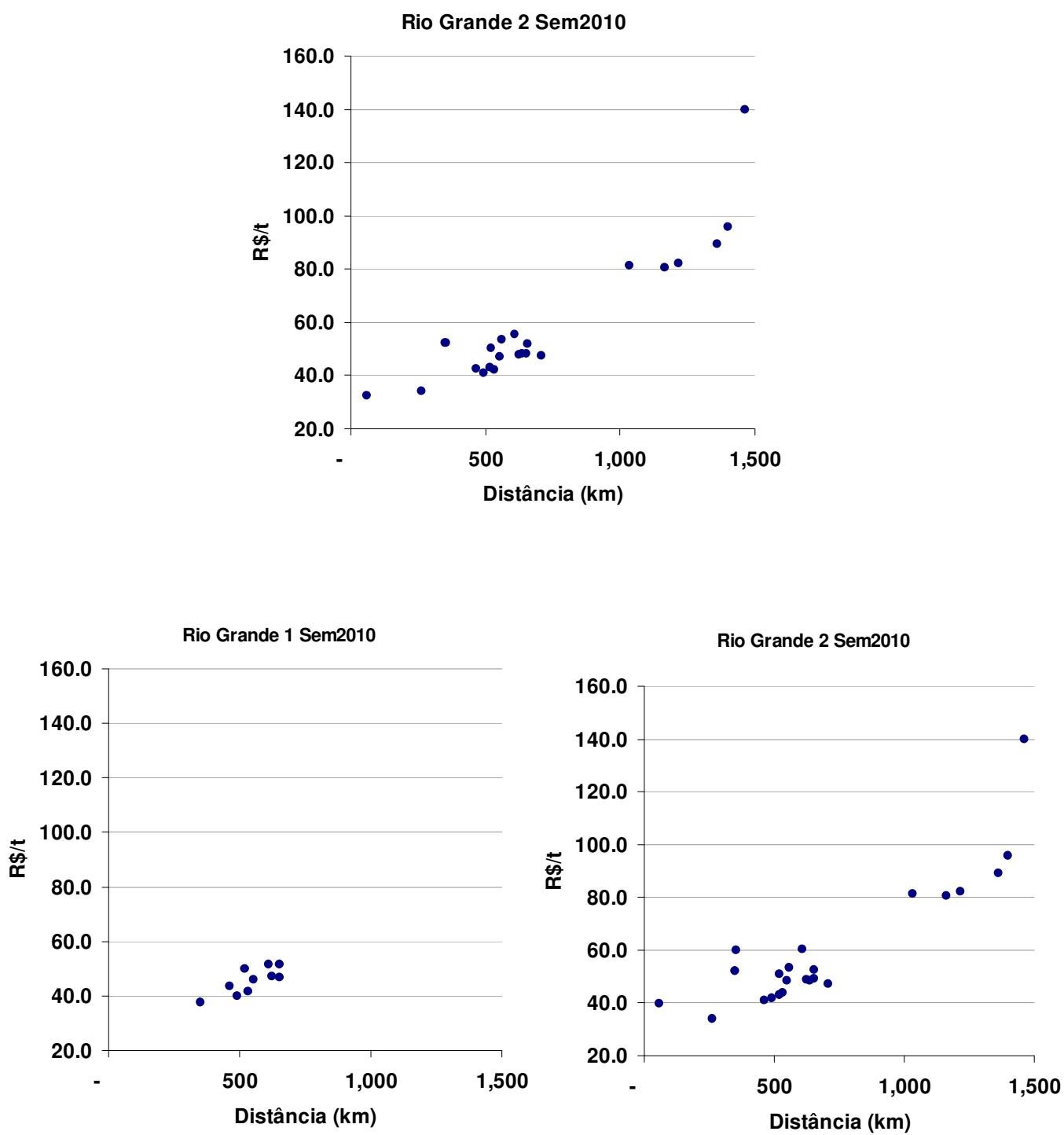

Figura 25. Preços dos fretes dos fertilizantes do corredor Rio Grande em 2010

Como comentado na seção de metodologia do estudo, foram estimados os fretes para os fertilizantes na partir de 3 metodologias: pela regressão dos preços dos fretes contra as distâncias, pela interpolação utilizando-se diversos algoritmos e pela geoestatística. Os resultados obtidos pelos três diferentes métodos serão apresentados a seguir. 


\subsection{ESTIMATIVA DOS PREÇOS DE FRETES POR MEIO DA REGRESSÃO}

Para que fosse possível obter o indicador do preço do fertilizante para todos os municípios do país, optou-se por estimar o valor do frete, para os quais este dado não era disponibilizado, utilizando modelos de regressão onde os preços de fretes de fertilizantes, fornecidos pelo SIFRECA, foram as variáveis independentes. Posteriormente, unindo-se o preço do frete estimado ao custo de internalização do fertilizante até o porto, o indicador de preço do produto em cada município seria estimado.

Em um primeiro momento analisou-se o preço do frete médio do segundo semestre de todas as rotas disponíveis levantadas pelo SIFRECA na tentativa de se obter uma só função para estimar o comportamento do frete do fertilizante em função da distância.

Depois foram estimadas as funções de todas as rotas disponíveis no segundo semestre de cada ano para os corredores dos portos de Paranaguá, de Santos/Cubatão e Rio Grande juntos.

Em um terceiro momento, foram estimadas as funções para cada um dos corredores com os preços médios do segundo semestre dos três anos disponíveis.

Os modelos funcionais utilizados para estimar os fretes foram o modelo linear e o $\log -\log ^{3}$.

A tabela 9 apresenta os resultados dos modelos lineares estimados.

No primeiro bloco de dados estão os resultados das regressões lineares estimadas a partir da média dos preços dos fretes do segundo semestre dos anos anos de 2008, 2009 e 2010, com valores de todos os corredores de transporte de fertilizantes fornecidos pelo SIFRECA.

O segundo bloco de dados da tabela apresenta os resultados das regressões realizadas com os valores médios de fretes do segundo semestre de 2008, 2009 e

\footnotetext{
${ }^{3} \mathrm{O}$ software usado para estimar as regressões foi o E-views 4.0.
} 
2010, estimados a partir dos dados reais apenas dos corredores de Paranaguá, Rio Grande e Santos/Cubatão.

No terceiro bloco de dados da tabela 9, estão os resultados das regressões estimadas a partir da média dos preços dos três anos em questão, mas apenas com dados das rotas de transporte de fertilizantes importadas pelo porto de Santos.

Nos quarto e quinto blocos de dados apresentados na tabela 9, estão os resultados das regressões estimadas a partir da média dos preços dos três anos em questão, apenas com dados das rotas de transporte de fertilizantes importadas pelo porto de Paranaguá e Rio Grande, respectivamente.

$\mathrm{Na}$ tabela 10 os mesmos passos foram seguidos, mas as regressões utilizadas foram do tipo log-log. Optou-se por testar as funções nas duas formas de regressão, que são as mais comumente usadas em modelos de estimação de fretes. As diversas formas de entradas dos dados, com todos os corredores, somente os corredores de interesse e dos corredores individualmente, foi uma forma de tentar lidar com a escassez dos dados de entrada (preços reais dos fretes) testando se as diversas formas de rodar as regressões poderiam apresentar resultados mais ou menos acurados, tomando as estatísticas das regressões como forma de comparação.

Apesar de todas as funções estimadas por meio do modelo linear apresentarem bons coeficientes de correlação, os critérios de Akaike e Schwars apresentaram valores demasiadamente altos, se comparados com os resultados dos modelos log-log, com exceção da curva estimada para o segundo semestre de 2008, com as rotas dos três corredores analisados, que apresentam valores de -0,463 e0,420 . Altos valores para Akaike e Schwars indicam uma distribuição dos resíduos da regressão bastante desigual, com ocorrência de pontos estimados cujos erros são muito destoantes, tanto positivamente quanto negativamente em relação ao valor real. Valores baixos para os critérios de Akaike e Schwars indicam que maior é a qualidade da informação do modelo.

Além disso, têm-se no modelo log-log, a possibilidade de tomar o coeficiente angular como uma medida de elasticidade do preço do frete em relação a distância. 
Por conta destes aspectos, o modelo log-log foi tomado como base para estimar os valores dos fretes, e comparar, mais á frente, seus resultados com os resultados conseguidos através dos interpoladores e por geoestatística.

Tabela 9. Resultados do modelo linear

\begin{tabular}{|c|c|c|c|c|c|c|c|}
\hline & Coeficiente & $\begin{array}{l}\text { Erro } \\
\text { Padrão }\end{array}$ & $\begin{array}{c}\text { Estatística } \\
\mathrm{t}\end{array}$ & Prob & R2 & Akaike & Schwarz \\
\hline $\begin{array}{l}2008 \text { Média 2sem - todos os } \\
\text { corredores }\end{array}$ & 0.0436 & 0.003 & 16.167 & 0.0000 & 0.619 & 8.909 & 8.947 \\
\hline $\begin{array}{l}2009 \text { Média 2sem - todos os } \\
\text { corredores }\end{array}$ & 0.0369 & 0.002 & 23.666 & 0.0000 & 0.731 & 8.179 & 8.211 \\
\hline $\begin{array}{l}2010 \text { Média 2sem - todos os } \\
\text { corredores }\end{array}$ & 0.0452 & 0.002 & 27.143 & 0.0000 & 0.736 & 8.353 & 8.380 \\
\hline $\begin{array}{l}2008 \text { Média 2sem - corredores } \\
\text { de Santos/Cubatão, Paranaguá } \\
\text { e Rio Grande }\end{array}$ & 0.5974 & 0.025 & 24.019 & 0.0000 & 0.813 & $(0.463)$ & $(0.420)$ \\
\hline $\begin{array}{l}2009 \text { Média 2sem - corredores } \\
\text { de Santos/Cubatão, Paranaguá } \\
\text { e Rio Grande }\end{array}$ & 0.0357 & 0.002 & 20.733 & 0.0000 & 0.676 & 8.268 & 8.300 \\
\hline $\begin{array}{l}2010 \text { Média 2sem - corredores } \\
\text { de Santos/Cubatão, Paranaguá } \\
\text { e Rio Grande }\end{array}$ & 0.0451 & 0.002 & 29.717 & 0.0000 & 0.780 & 8.281 & 8.309 \\
\hline $\begin{array}{l}\text { Corredor Santos/Cubatão Média } \\
\text { 2sem } 2008\end{array}$ & 0.0610 & 0.007 & 8.335 & 0.0000 & 0.685 & 7.348 & 7.438 \\
\hline $\begin{array}{l}\text { Corredor Santos/Cubatão Média } \\
\text { 2sem } 2009\end{array}$ & 0.0334 & 0.002 & 16.564 & 0.0000 & 0.766 & 7.332 & 7.389 \\
\hline $\begin{array}{l}\text { Corredor Santos/Cubatão Média } \\
\text { 2sem } 2010\end{array}$ & 0.0377 & 0.001 & 26.016 & 0.0000 & 0.861 & 7.049 & 7.098 \\
\hline $\begin{array}{l}\text { Corredor Paranaguá Média } \\
\text { 2sem } 2008\end{array}$ & 0.0366 & 0.002 & 15.336 & 0.0000 & 0.758 & 8.007 & 8.068 \\
\hline $\begin{array}{l}\text { Corredor Paranaguá Média } \\
\text { 2sem } 2009\end{array}$ & 0.0290 & 0.002 & 12.475 & 0.0000 & 0.641 & 8.308 & 8.364 \\
\hline $\begin{array}{l}\text { Corredor Paranaguá Média } \\
\text { 2sem } 2010\end{array}$ & 0.0419 & 0.002 & 18.258 & 0.0000 & 0.744 & 8.487 & 8.534 \\
\hline $\begin{array}{l}\text { Corredor Rio Grande Média } \\
\text { 2sem } 2008\end{array}$ & 0.0767 & 0.003 & 24.827 & 0.0000 & 0.966 & 7.009 & 7.107 \\
\hline $\begin{array}{l}\text { Corredor Rio Grande Média } \\
\text { 2sem } 2009\end{array}$ & 0.0712 & 0.003 & 23.686 & 0.0000 & 0.948 & 7.086 & 7.177 \\
\hline $\begin{array}{l}\text { Corredor Rio Grande Média } \\
\text { 2sem } 2010\end{array}$ & 0.0566 & 0.007 & 8.642 & 0.0000 & 0.781 & 7.844 & 7.943 \\
\hline
\end{tabular}

Fonte: Resultados da pesquisa 
A tabela 10 apresenta os valores das regressões log-log, no mesmo formato de blocos de dados da tabela anterior.

As curvas estimadas a partir do modelo funcional log-log apresentaram bons níveis para os coeficientes de determinação, entre 0,717 e 0,726 para o bloco de dados de todos os corredores disponíveis e 0,606 e 0,81 para o bloco de dados com as rotas apenas dos corredores analisados.

No caso das curvas estimadas para o corredor Santos/Cubatão, os coeficientes de determinação já não apresentam valores tão altos, com o máximo de 0,576 para o ano de 2008. O corredor de Paranaguá possui melhores coeficientes de determinação, com valores de 0,52 a 0,78 , em todas os blocos de dados.

Os maiores coeficientes de determinação foram os estimados para o corredor de Rio Grande para os anos de $2008(0,93)$ e $2009(0,89)$. Para o ano de 2010, o coeficiente de determinação estimado para este corredor foi muito baixo, de 0,265.

Ao contrário dos resultados dos modelos lineares, as curvas estimadas com 0 modelo log-log apresentam bons resultados para os critérios de Akaike e Schwarz, Nota-se que o coeficiente angular encontrado é muito similar em todas as curvas estimadas pelos diferentes blocos de dados. Todas encontram-se próximas do valor de 0,63, que indica que, para cada variação de $1 \%$ na distância percorrida, o frete apresenta uma variação de 0,63\%, em média.

Nos modelos funcionais log-log, os coeficientes angulares apresentaram-se significantes a 95\% de probabilidade sendo corroborados pelos altos valores da Estatística $t$ e probabilidade associada menor que 0,05. Os valores e as probabilidades da estatística t podem ser observadas nas tabelas 9 e 10, nas colunas "Estatística t" e "Prob". 
Tabela 10.Resultados do modelo log-log

\begin{tabular}{|c|c|c|c|c|c|c|c|}
\hline & Coeficiente & $\begin{array}{c}\text { Erro } \\
\text { Padrão }\end{array}$ & $\begin{array}{c}\text { Estatística } \\
\mathbf{t}\end{array}$ & Prob & $\mathbf{R 2}$ & Akaike & Schwarz \\
\hline $\begin{array}{l}2008 \text { Média 2sem - todos os } \\
\text { corredores }\end{array}$ & 0.6265 & 0.0028 & 220.9434 & 0.0000 & 0.7172 & $(0.0218)$ & $(0.0218)$ \\
\hline $\begin{array}{l}2009 \text { Média 2sem - todos os } \\
\text { corredores }\end{array}$ & 0.6269 & 0.0023 & 276.7938 & 0.0000 & 0.7196 & $(0.2593)$ & $(0.2593)$ \\
\hline $\begin{array}{l}2010 \text { Média 2sem - todos os } \\
\text { corredores }\end{array}$ & 0.6380 & 0.0021 & 306.4623 & 0.0000 & 0.7266 & $(0.1867)$ & $(0.1867)$ \\
\hline $\begin{array}{l}2008 \text { Média 2sem - corredores } \\
\text { de Santos/Cubatão, Paranaguá } \\
\text { e Rio Grande }\end{array}$ & 0.6293 & 0.0025 & 250.5172 & 0.0000 & 0.8103 & $(0.4653)$ & $(0.4438)$ \\
\hline $\begin{array}{l}2009 \text { Média 2sem - corredores } \\
\text { de Santos/Cubatão, Paranaguá } \\
\text { e Rio Grande }\end{array}$ & 0.6260 & 0.0026 & 241.8766 & 0.0000 & 0.6066 & 0.0106 & 0.0266 \\
\hline $\begin{array}{l}2010 \text { Média 2sem - corredores } \\
\text { de Santos/Cubatão, Paranaguá } \\
\text { e Rio Grande }\end{array}$ & 0.6373 & 0.0025 & 256.7384 & 0.0000 & 0.6500 & 0.1389 & 0.1529 \\
\hline $\begin{array}{l}\text { Corredor Santos/Cubatão Média } \\
\text { 2sem } 2008\end{array}$ & 0.6240 & 0.0051 & 122.9695 & 0.0000 & 0.5762 & $(0.5546)$ & $(0.5097)$ \\
\hline $\begin{array}{l}\text { Corredor Santos/Cubatão Média } \\
\text { 2sem } 2009\end{array}$ & 0.6201 & 0.0043 & 145.5840 & 0.0000 & 0.4281 & 0.0634 & 0.0919 \\
\hline $\begin{array}{l}\text { Corredor Santos/Cubatão Média } \\
\text { 2sem } 2010\end{array}$ & 0.6272 & 0.0045 & 140.4556 & 0.0000 & 0.2816 & 0.4189 & 0.4433 \\
\hline $\begin{array}{l}\text { Corredor Paranaguá Média 2sem } \\
2008\end{array}$ & 0.6300 & 0.0035 & 179.7856 & 0.0000 & 0.7249 & $(0.3021)$ & $(0.2716)$ \\
\hline $\begin{array}{l}\text { Corredor Paranaguá Média 2sem } \\
2009\end{array}$ & 0.6249 & 0.0041 & 153.9123 & 0.0000 & 0.5204 & 0.1248 & 0.1527 \\
\hline $\begin{array}{l}\text { Corredor Paranaguá Média 2sem } \\
2010\end{array}$ & 0.6469 & 0.0025 & 254.4196 & 0.0000 & 0.7811 & $(0.4900)$ & $(0.4664)$ \\
\hline $\begin{array}{l}\text { Corredor Rio Grande Média } \\
\text { 2sem } 2008\end{array}$ & 0.6337 & 0.0046 & 137.2917 & 0.0000 & 0.9308 & $(0.9366)$ & $(0.8875)$ \\
\hline $\begin{array}{l}\text { Corredor Rio Grande Média } \\
\text { 2sem } 2009\end{array}$ & 0.6433 & 0.0037 & 172.4394 & 0.0000 & 0.8900 & $(1.0608)$ & $(1.0154)$ \\
\hline $\begin{array}{l}\text { Corredor Rio Grande Média } \\
\text { 2sem } 2010\end{array}$ & 0.6291 & 0.0095 & 66.0030 & 0.0000 & 0.2650 & 0.4283 & 0.4283 \\
\hline
\end{tabular}

Fonte: Resultados da pesquisa

\subsection{ESTIMATIVAS DOS PREÇOS DOS FRETES POR MEIO DE INTERPOLAÇÃO}


Um segundo passo para estimar o valor do frete para os destinos para os quais não havia dados disponíveis foi a utilização de interpoladores espaciais partindo da base de dados disponibilizada pelo SIFRECA (Sistema de Informações de Fretes). Esses interpoladores exigem o fornecimento de três coordenadas: $X, Y$ e $Z$, sendo $X$ e $Y$ as coordenadas geográficas e $Z$, nos modelos de elevação de terrenos, o valor da cota. A rota escolhida para testar este método foi o corredor do porto de Paranaguá no ano de 2010. Os fretes totais (do porto ao destino) relacionados às coordenadas da sede do município (IBGE) foram os valores utilizados como o valor "Z", no lugar da cota dos modelos de elevação, para os interpoladores.

Foram comparados os seguintes algoritmos, disponíveis no sofware ArcGIS:

- Natural Neighbours

- Thin Plate Spline

- Spline com tensão

- Função Multiquadrática

- Função Multiquadrática Inversa

- Função Local Polinomial (grau 2)

- Função Global Polinomial (grau 2)

- IDW (Inverso da distância ponderado)

Também utilizou-se da Krigagem (sem uso da geoestatística), com base nos seguintes modelos:

- Linear

- Gaussiano

- Exponencial

- Circular

- Esférico 
Os resultados destes interpoladores podem ser visualizados na seqüência. Os mapas apresentam os resultados e os pontos dos valores dos fretes reais disponíveis pelo SIFRECA.

O primeiro mapa na Figura 26 apresenta o resultado da interpolação dos preços dos fretes com origem no Porto de Paranaguá utilizando-se o método de Natural Neighbours. Nota-se que com este algoritmo, os pontos extremos que compõem a amostra para a interpolação acabam sendo o limite da grade interpolada.

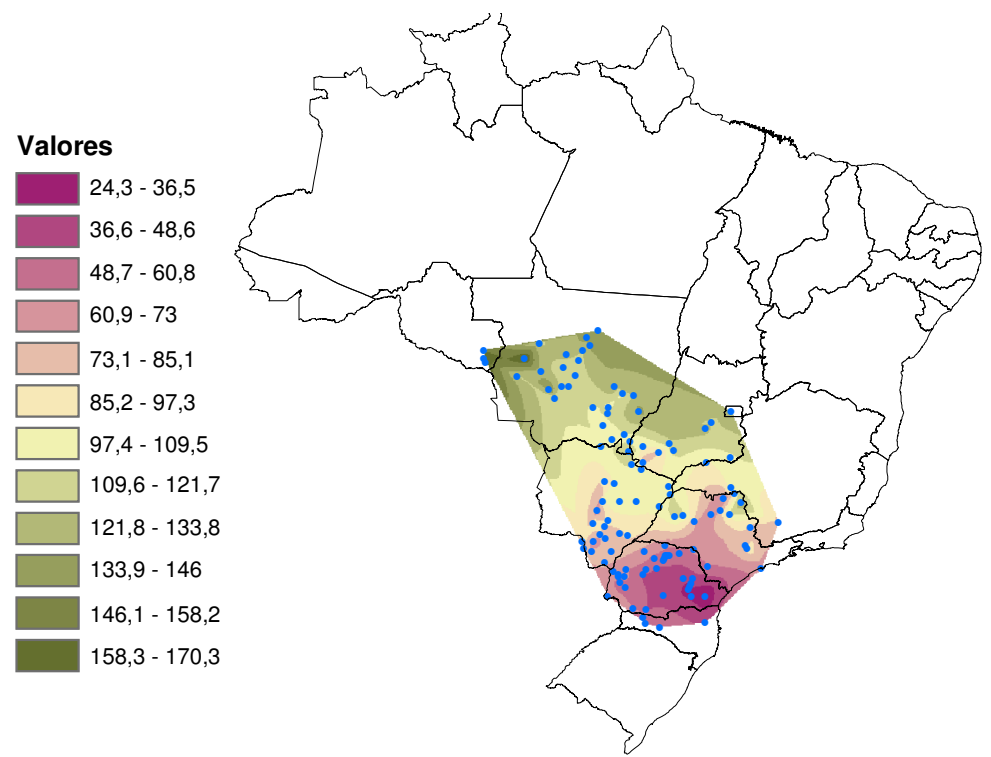

Figura 26. Resultado da interpolação pelo algoritmo Natural Neighbours e distribuição dos pontos com valores dos fretes disponíveis pelo Sifreca

A seguir é apresentado o resultado da interpolação a partir do algoritmo Thin Plate Spline (Spline de mínima curvatura), na Figura 27.

Na sequência, o algoritmo utilizado para interpolação foi o Spline com tensão e a grade criada por ele é apresentada no mapa da Figura 28. Apesar da faixa de valores ser semelhante ao do Thin Plate Spline, a superfície criada por este algoritmo é mais suave que no caso anterior, e como será visto nas estatísticas dos erros das interpolações, apesar de ter menor erro médio, apresenta maior desvio dos erros em relação á média. 


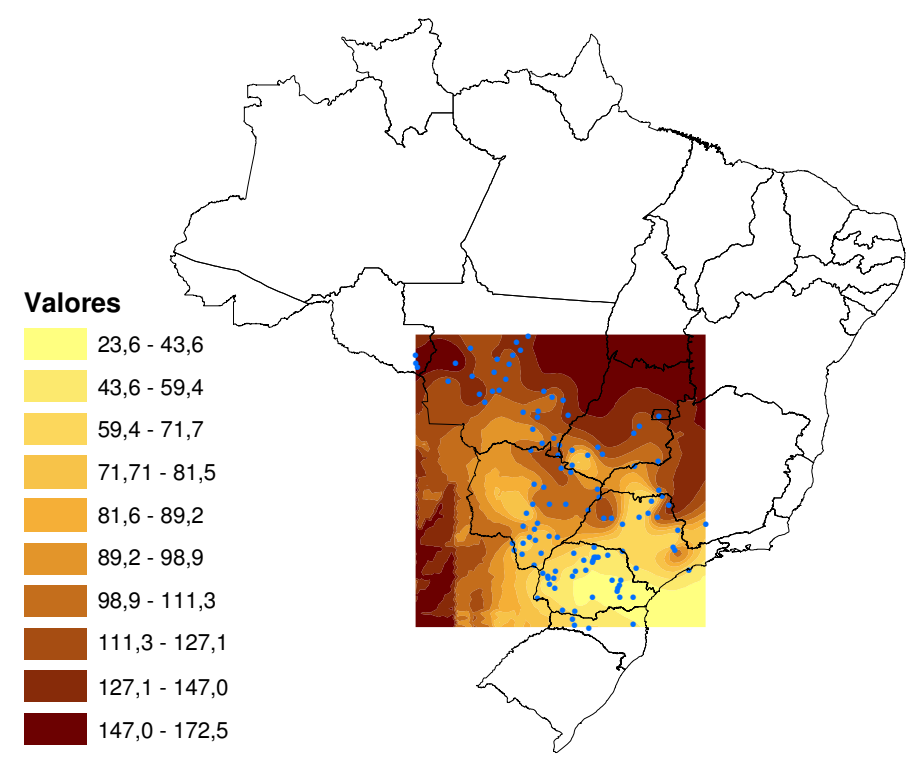

Figura 27. Resultado da interpolação pelo algoritmo Thin Plate Spline e distribuição dos pontos com valores dos fretes disponíveis pelo Sifreca

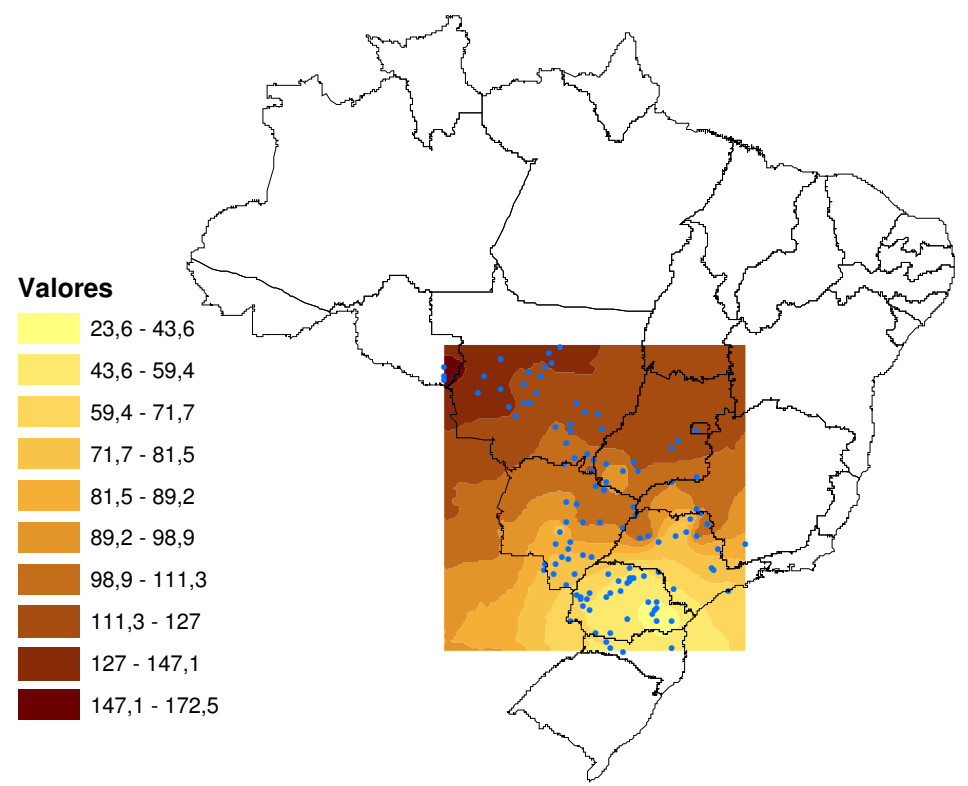

Figura 28. Resultado da interpolação pelo algoritmo Spline com tensão e distribuição dos pontos com valores dos fretes disponíveis pelo Sifreca

A função multiquadrática foi utilizada para interpolar os dados de frete que resultou na próxima grade apresentada no mapa da Figura 29. Este interpolador também faz parte da mesma família dos interporladores polinomiais do tipo spline. Apresenta menor erro que o Thin Plate Spline, e um desvio próximo deste. 


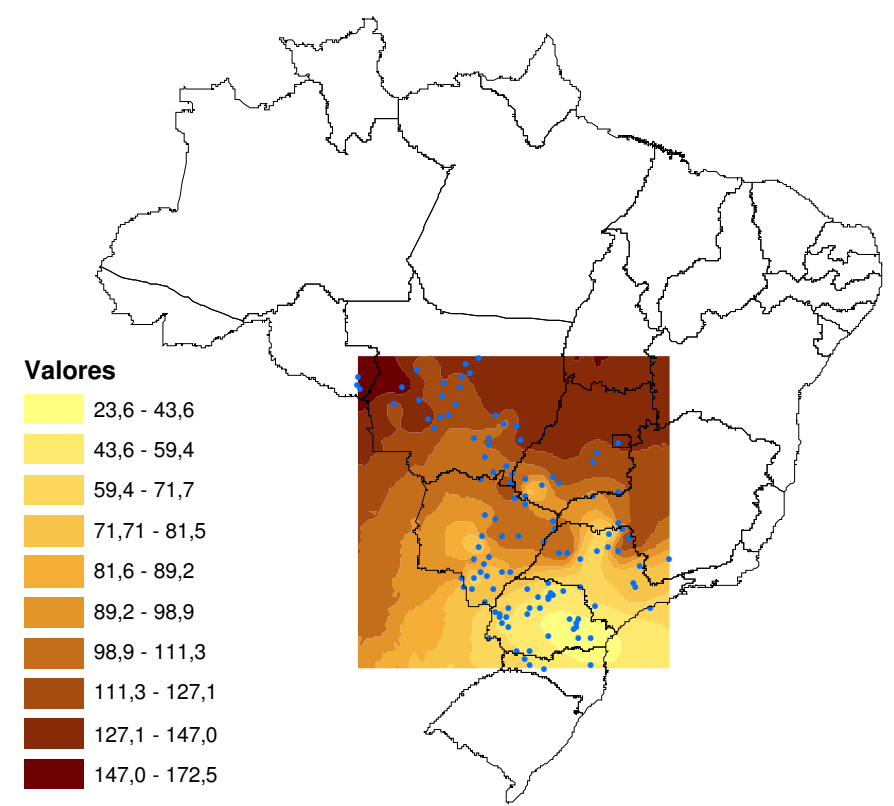

Figura 29. Resultado da interpolação pelo algoritmo Função Multiquadrática e distribuição dos pontos com valores dos fretes disponíveis pelo Sifreca

O mapa da Figura 30 apresenta a grade resultante da interpolação dos preços de fretes por meio da função multiquadrática inversa. Das demais funções polinomiais desta família de interpoladores, foi o que apresentou maior erro, mas menor desvio dos erros.

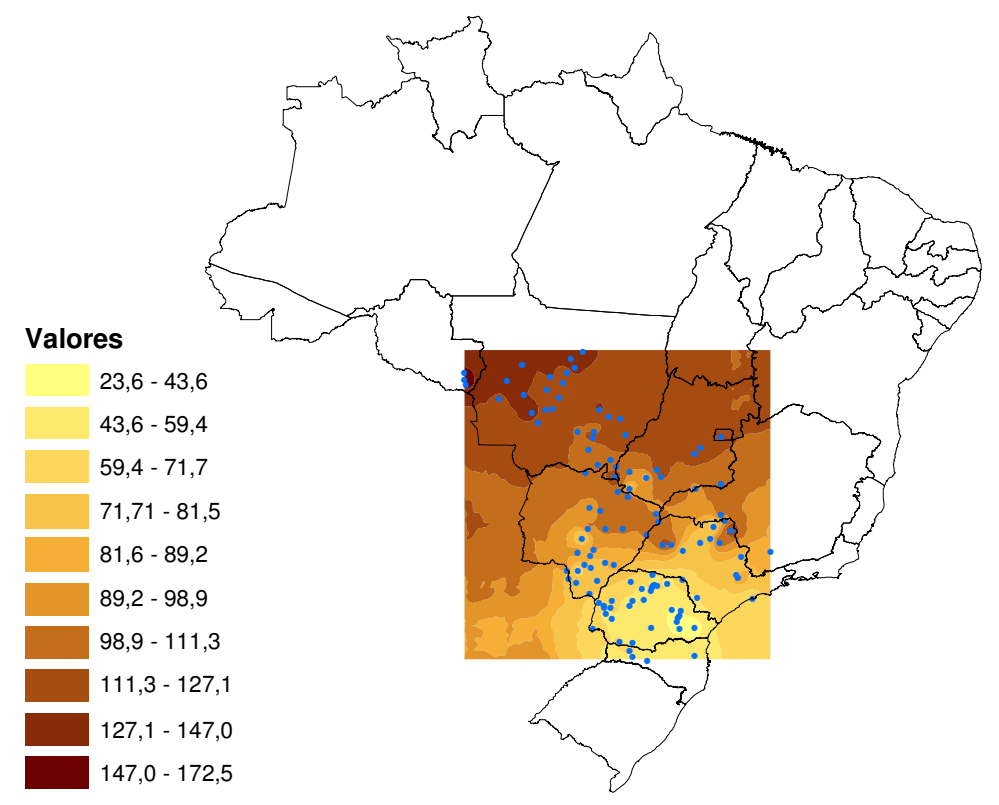

Figura 30. Resultado da interpolação pelo algoritmo Função Multiquadrática Inversa e distribuição dos pontos com valores dos fretes disponíveis pelo Sifreca 
A função polinomial Local é utilizada como interpolador o qual seu resultado é apresentado no próximo mapa da Figura 31. Este polinômio de segundo grau apresenta uma grade de valores radiais a partir do ponto de menor valor (próximo ao porto).

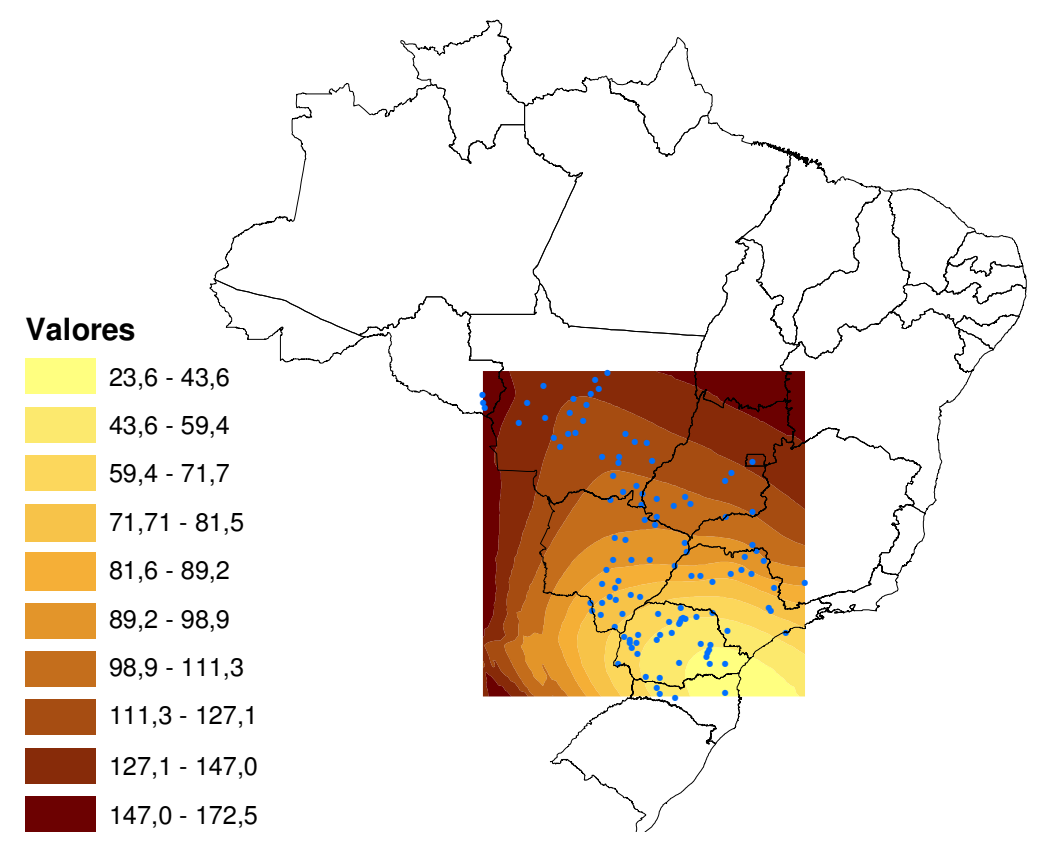

Figura 31. Grade resultante da interpolação pelo algoritmo Função Local Polinomial (grau 2) e distribuição dos pontos com valores dos fretes disponíveis pelo Sifreca

No próximo mapa (Figura 32), a função polinomial global de segundo grau apresenta o mesmo comportamento da função local, mas com contornos mais suavizados. Ambos apresentam, no entanto, alta variância dos erros, como será apresentado na próxima seção.

A Figura 33 apresenta o resultado da interpolação pelo algoritmo IDW (Ponderação pelo Inverso da Distância). Segundo as distribuições dos erros, que serão apresentadas na próxima seção, este interpolador apresenta erro bastante baixo em relação aos dados reais e com desvio baixo, em comparação aos demais interpoladores. 


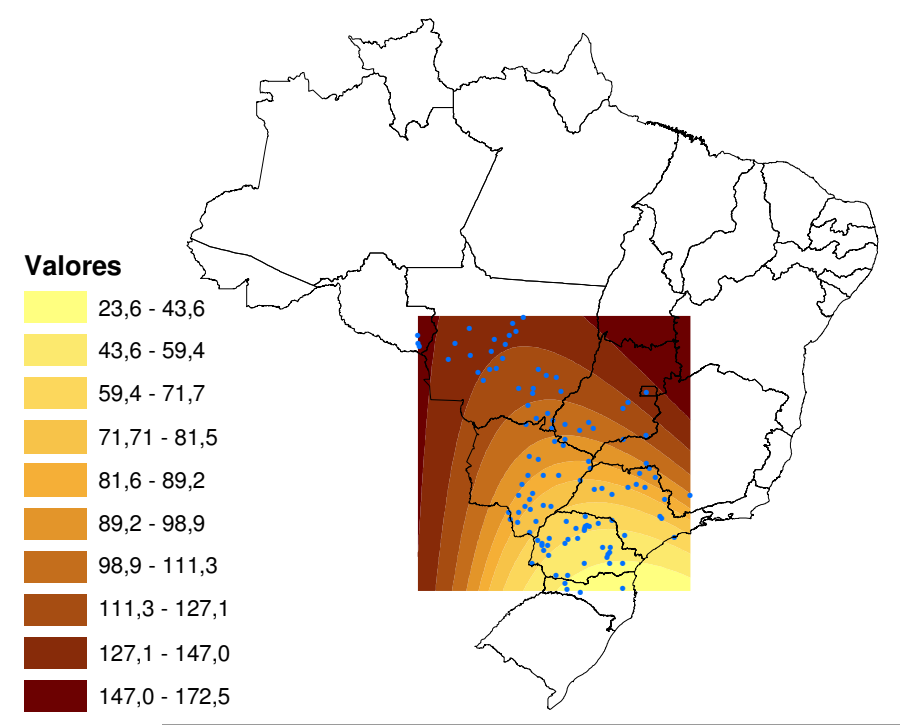

Figura 32. Grade resultante da interpolação pelo algoritmo Função Global Polinomial (grau 2) e distribuição dos pontos com valores dos fretes disponíveis pelo Sifreca

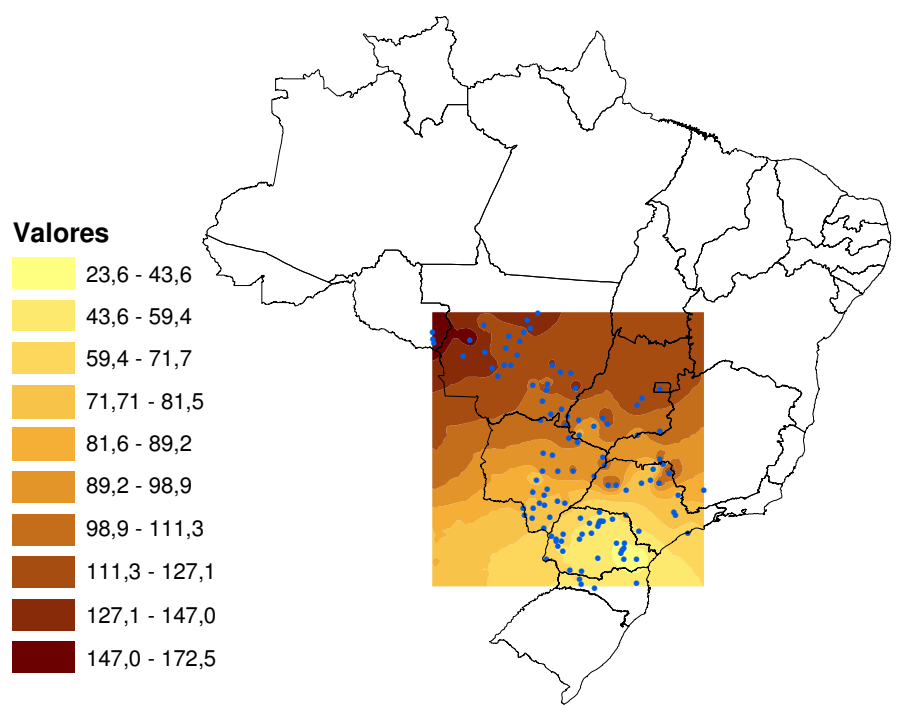

Figura 33. Grade resultante da interpolação pelo algoritmo IDW e distribuição dos pontos com valores dos fretes disponíveis pelo Sifreca

A seguir serão apresentados os resultados das interpolações baseadas na krigagem ordinária sem o uso da geoestatistica (semivariograma) e os modelos mais 
comumente utilizados: Linear, Gaussiana, Exponencial, Circular e esférico, nas Figuras 34 a 38.

Os diversos modelos apresentam resultados bastante próximos de suas estatísticas acerca dos erros em relação aos dados reais. Exceção fica a cargo do modelo gaussiano, que apresenta os maiores erros e desvios.

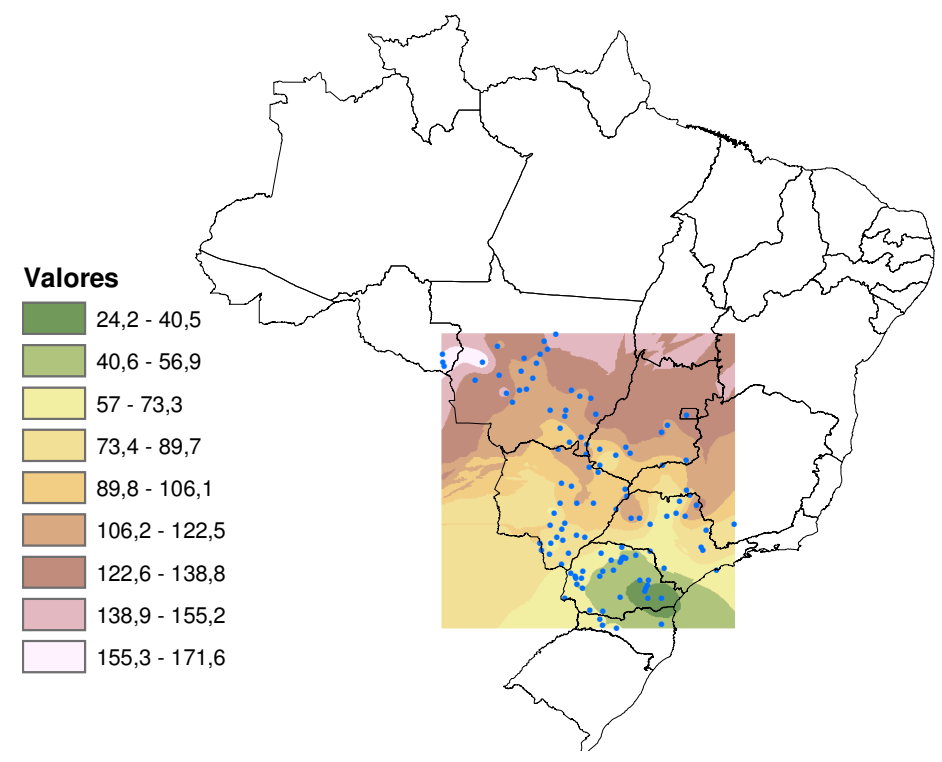

Figura 34. Grade resultante da interpolação por Krigagem Linear e distribuição dos pontos com valores dos fretes disponíveis pelo Sifreca

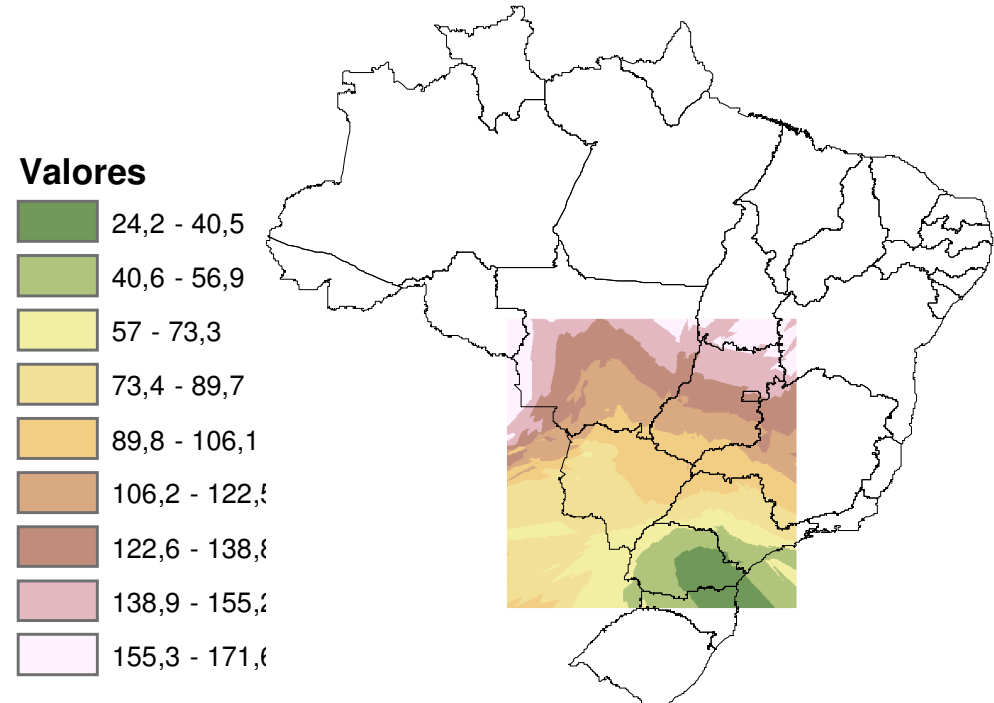

Figura 35. Grade resultante da interpolação por Krigagem Gaussiana e distribuição dos pontos com valores dos fretes disponíveis pelo Sifreca 


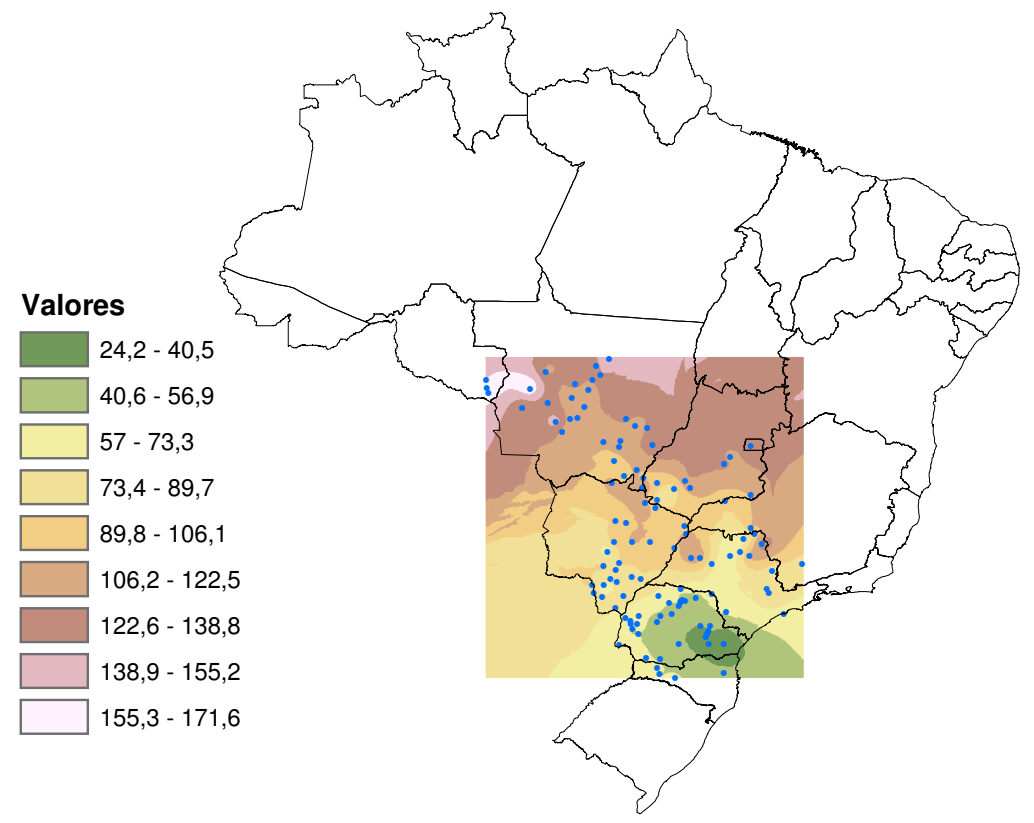

Figura 36. Grade resultante da interpolação por Krigagem Exponencial e distribuição dos pontos com valores dos fretes disponíveis pelo Sifreca

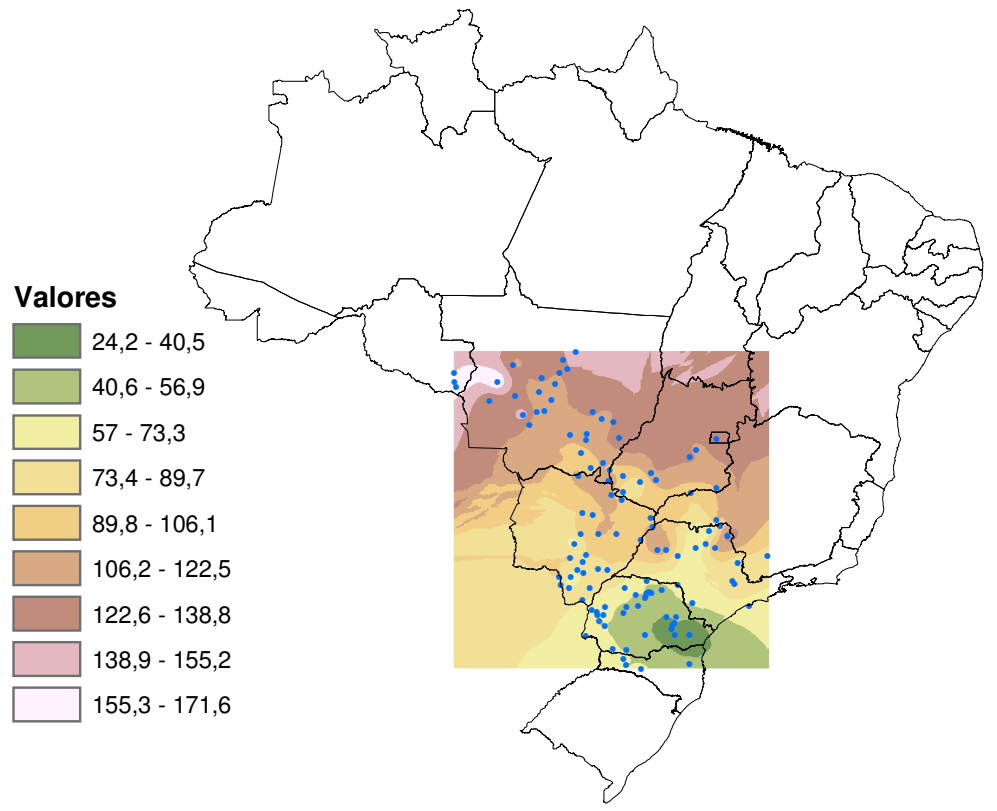

Figura 37. Grade resultante da interpolação por Krigagem Circular e distribuição dos pontos com valores dos fretes disponíveis pelo Sifreca 


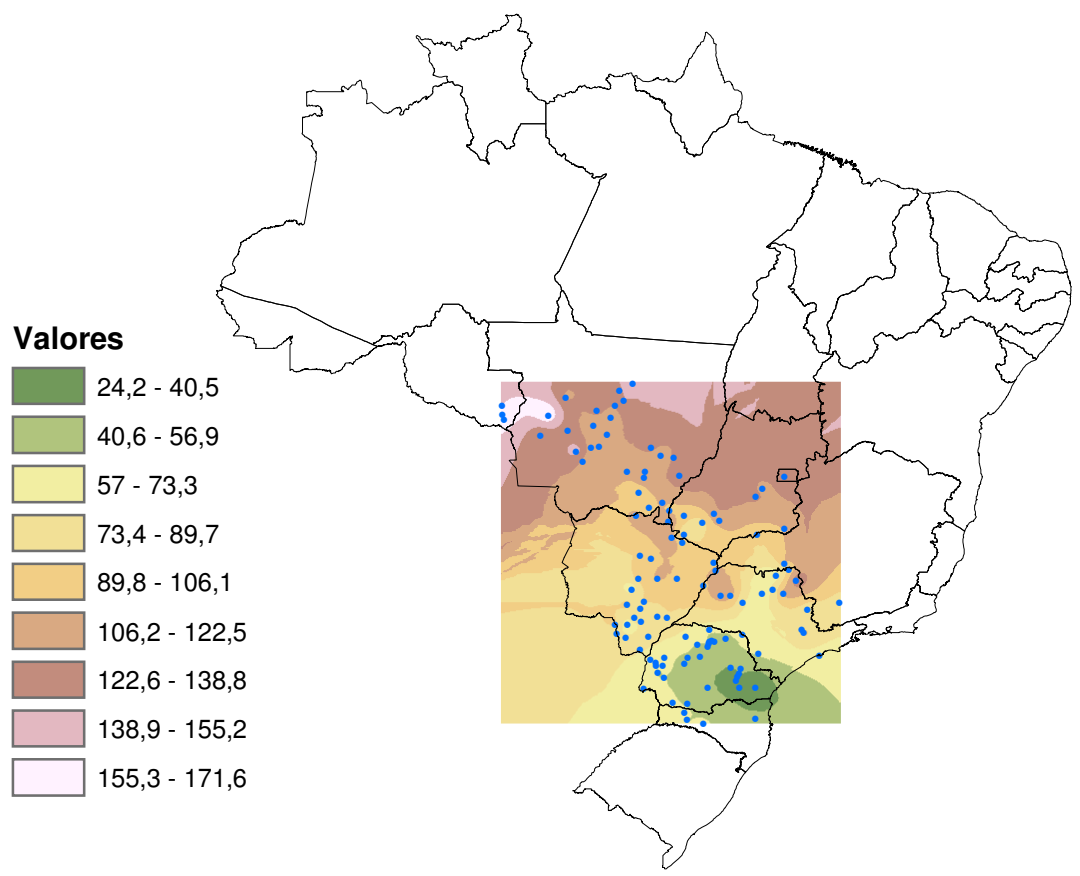

Figura 38. Grade resultante da interpolação por Krigagem Esférica e distribuição dos pontos com valores dos fretes disponíveis pelo Sifreca.

\subsection{ESTIMATIVAS DOS PREÇOS DOS FRETES POR MEIO DA GEOESTATÍSTICA}

\subsubsection{Estimação do variograma e krigagem}

Para o ajuste do variograma, foram utilizados os dados de fretes médios do segundo semestre para os três corredores: Santos/Cubatão, Paranaguá e Rio Grande. Para os dois primeiros o ajuste foi feito para os dados do ano de 2010. Para Rio Grande, não foi possível ajustar o modelo para 2010, por conta desta data apresentar poucos dados, ao contrário dos demais. O ajuste para Rio Grande foi feito com os dados de 2009. 
Antes de iniciar a estimação dos parâmetros do variograma, as informações, que foram obtidas para as sedes dos municípios no sistema "lat-long" foram transformadas para a projeção UTM - Transversa de Mercator, utilizando-se como referência o fuso 23 Sul, e o mesmo Datum dos dados originais, o South American 1969 - SAD69. Com isso obteve-se as coordenadas planas das informações para que fosse possível estimar o variograma utilizando-se o software ISATIS, versão 10.0 .

Houve a necessidade de processar, em primeiro momento, a transformação Gaussiana dos dados para normalizá-los antes de calcular o variograma. Com os dados transformados, o variograma foi calculado e seus resultados são apresentados na seqüência.

A Figura 39 apresenta a saída dos resultados da estimação do semivariograma e do semivariograma experimental do corredor do Porto de Santos/Cubatão. Foram identificadas estruturas em duas direções $0^{\circ}$ e $90^{\circ}$, que ajustadas pelo modelo esférico, apresentaram o mesmo patamar $\left(C^{0}+C^{1}=0,65\right)$ e alcance de $220 \mathrm{~km} \mathrm{e}$ $370 \mathrm{~km}$.

Notas-se que, a partir de aproximadamente $600 \mathrm{~km}$, uma quebra de padrão é identificada, o que justificaria uma composição de 2 semivariogramas para a rota em questão, um até a distância de $600 \mathrm{~km}$, e uma outra análise para os dados a partir destas distâncias. Tal quadro assemelha-se muito a uma quebra de estrutura ocorrida, por exemplo, nas aplicações de geologia, quando o comportamento é abruptamente modificado a partir de uma nova estrutura geológica. 


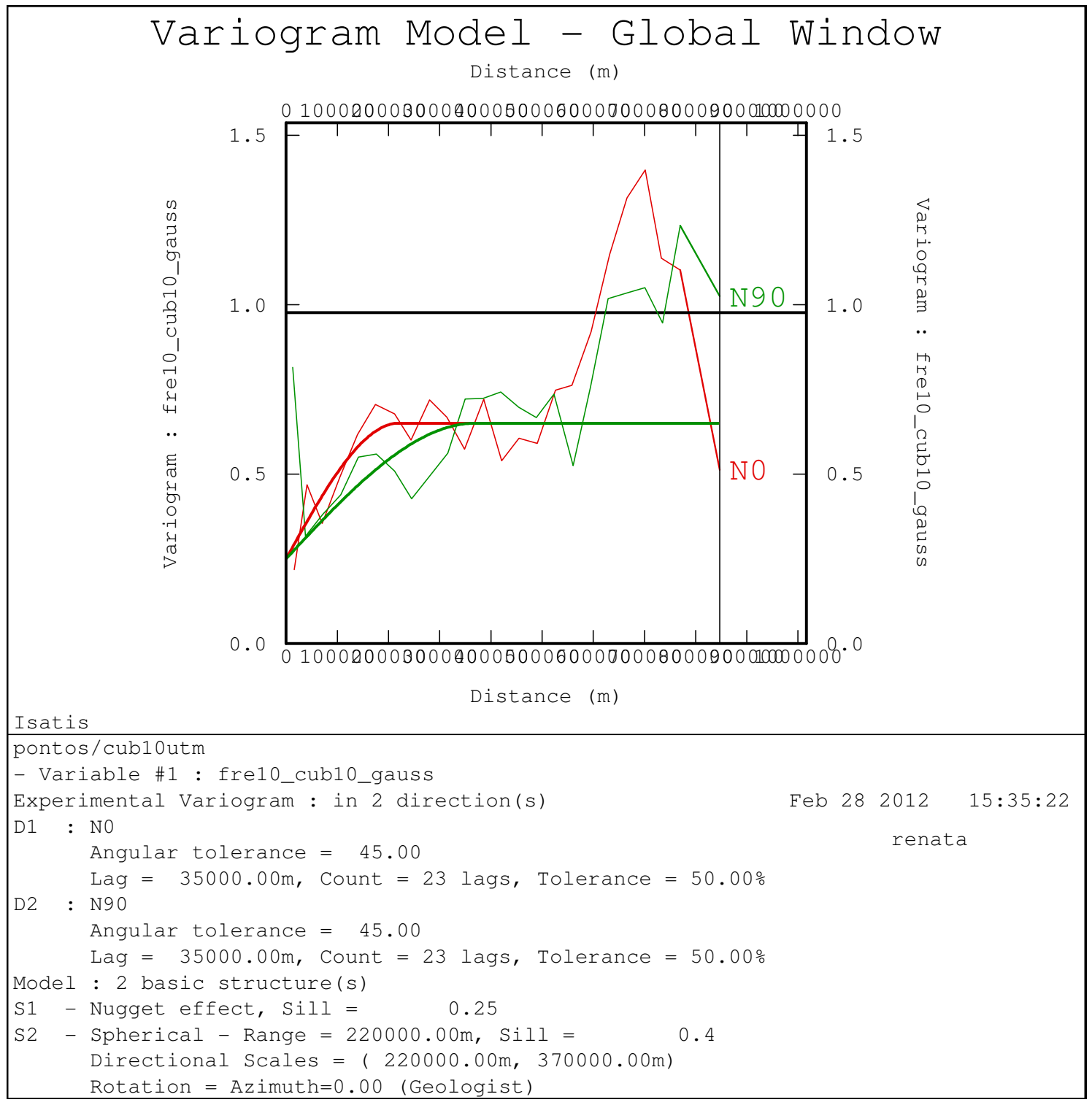

Figura 39. Resultados do modelo do variograma para os fretes do corredor por porto de Santos/Cubatão.

No caso do corredor de Paranaguá foram identificadas 3 estruturas básicas e plotados semivariogramas experimentais nas duas direções $0^{\circ}$ e $90^{\circ}$. No caso de Paranaguá, o alcance dos semivariogramas estimados a partir de modelo esférico foi de $465 \mathrm{~km}$ e $750 \mathrm{~km}$, respectivamente, para patamares de 0,445 na direção de $90^{\circ}$ e 0,805 na direção $0^{\circ}$.

Enquanto que, para o modelo do corredor de Santos, a dependência espacial se dá a uma distância pequena comparada à maior distância encontrada entre as 
amostras (por volta de $1.400 \mathrm{~km}$ ), no modelo de Paranaguá, a dependência espacial alcança até $750 \mathrm{~km}$, para uma amostra com pontos distantes em até $1.400 \mathrm{~km}$ da origem.

A Figura 40 apresenta a saída dos resultados da estimação do variograma e do variograma experimental do corredor do Porto de Paranaguá.

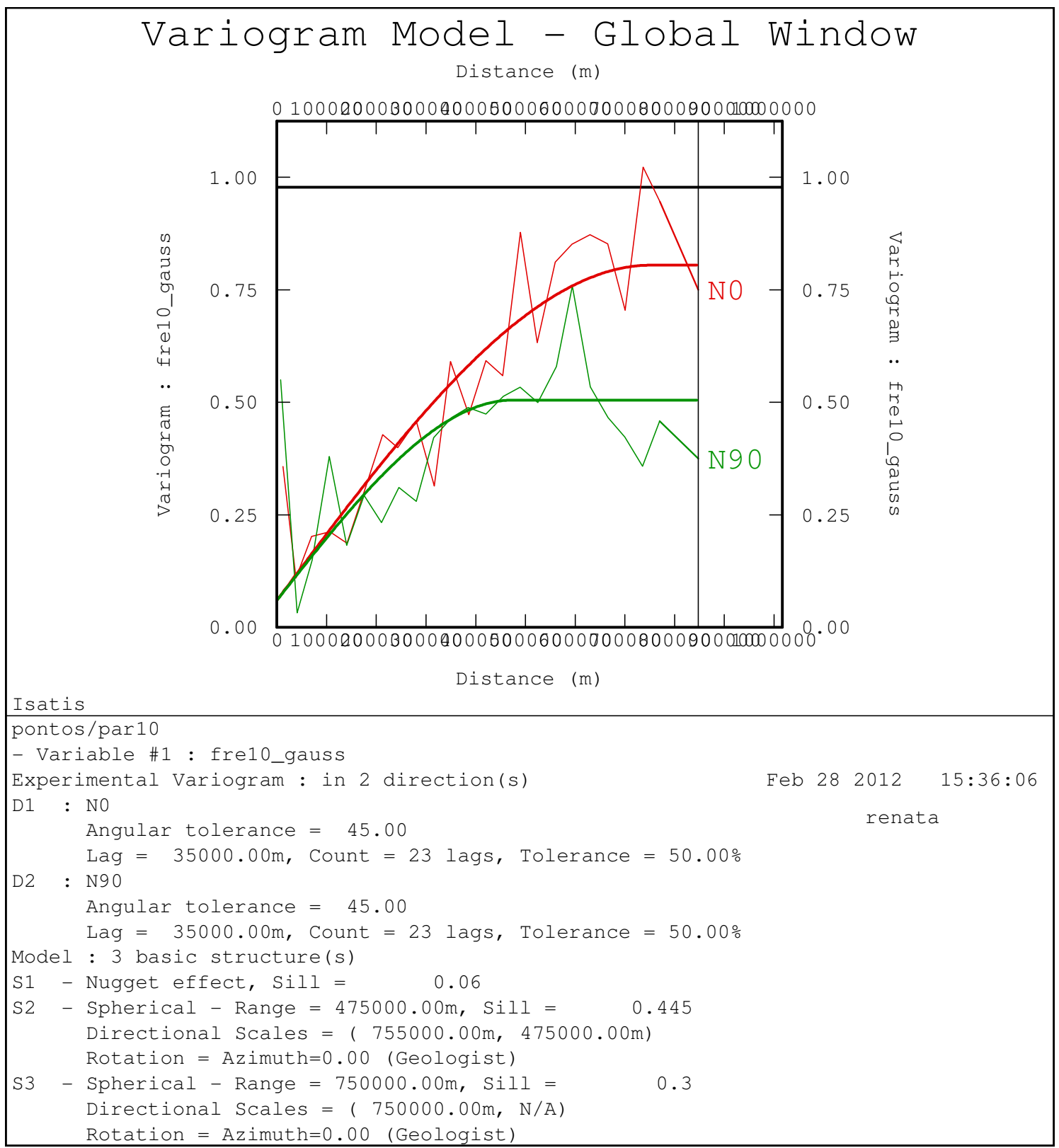

Figura 40. Resultados do modelo do variograma para os fretes do corredor por porto de Paranaguá. 
O modelo estimado para o Porto de Rio Grande apresentou uma só estrutura básica com patamar igual a 0,431 e alcance de $200 \mathrm{~km}$ na direção $0^{\circ}$ e $350 \mathrm{~km}$ na direção 90 . A Figura 41 apresenta a saída dos resultados da estimação do variograma e do variograma experimental do corredor do Porto de Rio Grande.

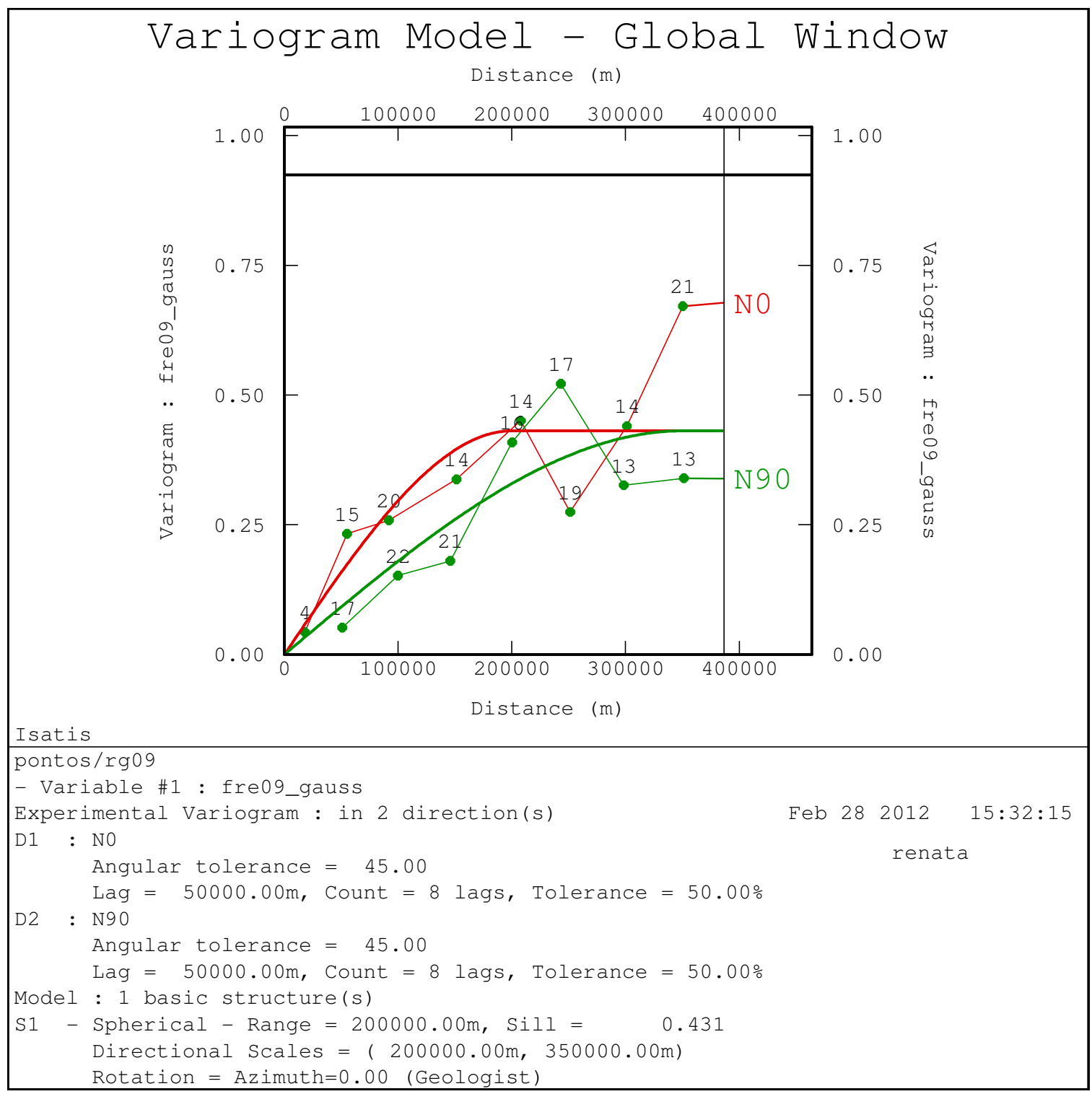

Figura 41. Resultados do modelo do variograma para os fretes do corredor por porto de Rio Grande.

Após calculados os variogramas, foi realizada a validação do modelo teórico do variograma através do método de validação cruzada pelo software Isatis. Na Figura 
42, o primeiro gráfico à esquerda apresenta os valores estimados para os fretes distribuídos espacialmente segundo as coordenadas UTM $(\mathrm{x}, \mathrm{y})$. $\mathrm{O}$ gráfico à direita apresenta a correlação entre os valores estimados $\left(Z^{*}\right)$ pelo semivariograma e os valores reais $(Z)$ de fretes. Vale lembrar que os resultados relacionam-se aos dados transformados (Gauss). Abaixo, à esquerda esta o gráfica da distribuição dos desvios dos valores estimados em relação aos dados reais $\left(Z^{*}-Z\right)$ e a estatística associada à ele. À direita e abaixo estão plotados os desvios em torno do eixo 0 .

No caso do corredor Santos/Cubatão, a correlação entre os valores reais $(Z)$ e os valores estimados $\left(Z^{*}\right)$ a partir do semivariograma foi de $73,9 \%$ (rho=0,739). É possível notar, no quadro entretanto, uma subestimação dos valores mais baixos e superestimação dos valores mais altos (mais distantes da origem). Os resultados são apresentados na Figura a seguir. 


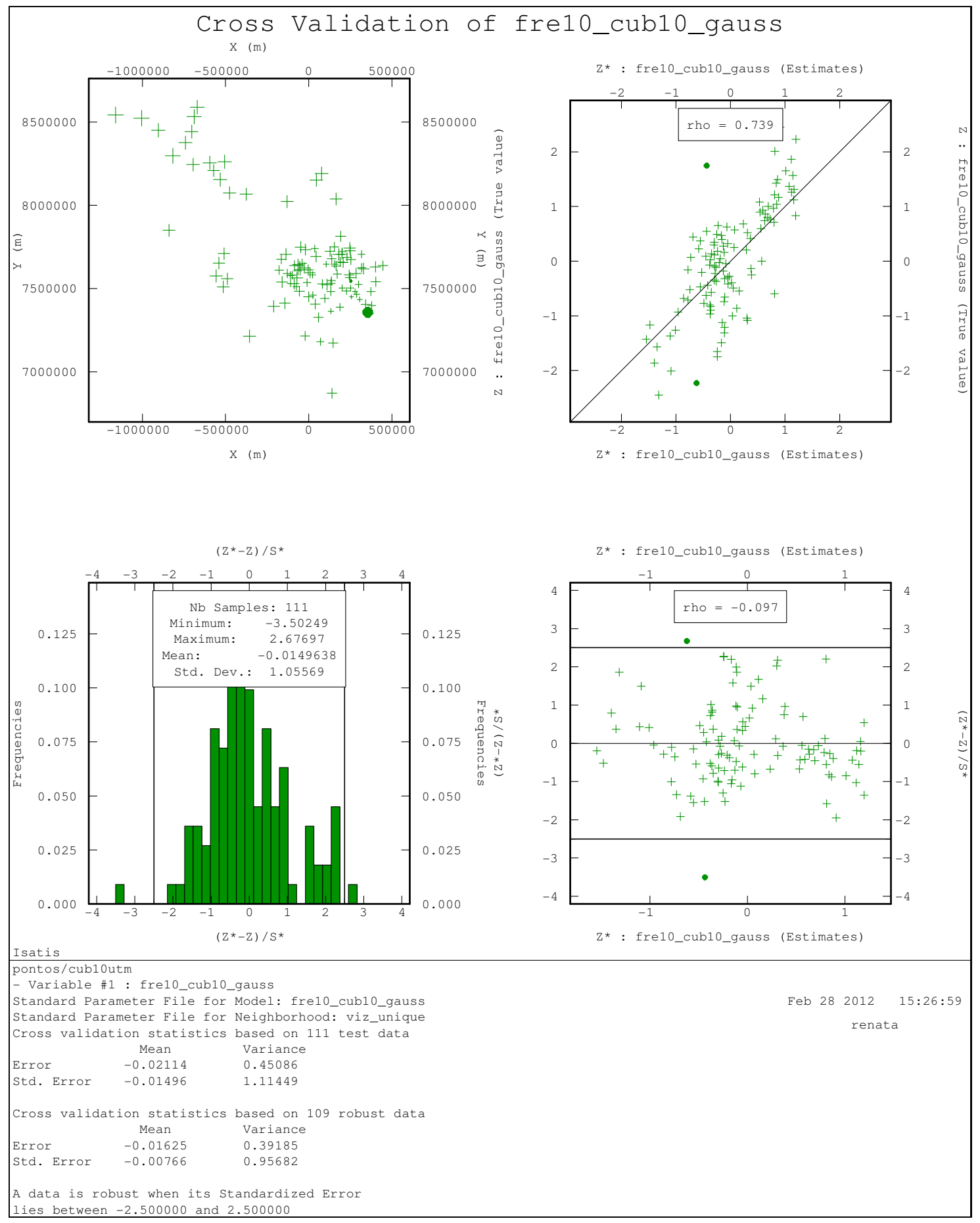

Figura 42. Resultados da validação cruzada do semivariograma estimado para o corredor Santos /Cubatão.

Para o corredor de Paranaguá, na Figura 43, a correlação entre os valores reais e estimados foi de $85,2 \%$ (rho=0,852). Nota-se que 3 pontos ficam bastante 
fora da curva no gráfico de correlação entre os valores estimados e reais, subestimados em relação aos valores reais.

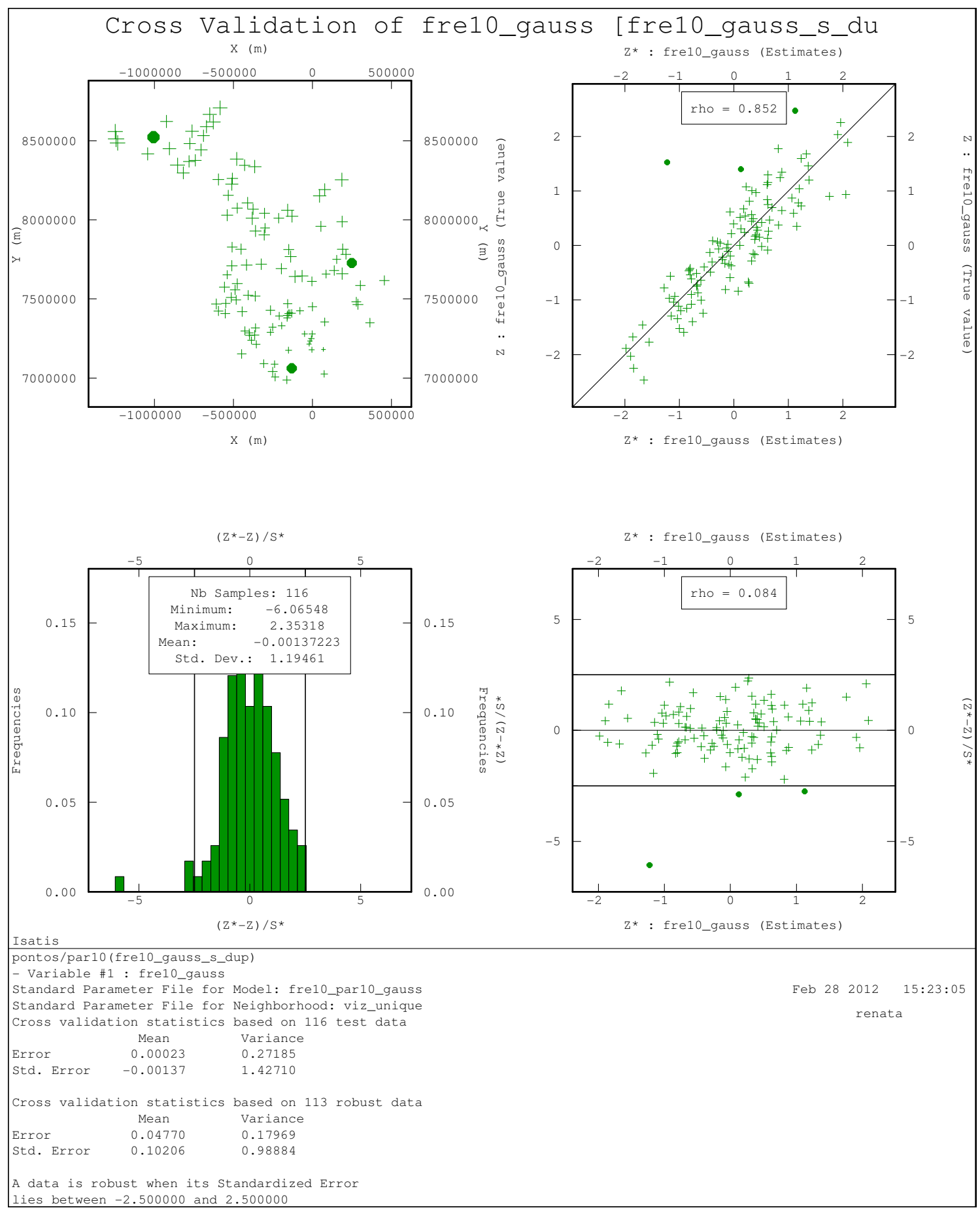

Figura 43. Resultados da validação cruzada do variograma estimado para o corredor de Paranaguá. 
No caso do corredor de Rio Grande (Figura 44), a correlação ente os valores estimados e reais foi de $74,6 \%$ (rho=0,746).

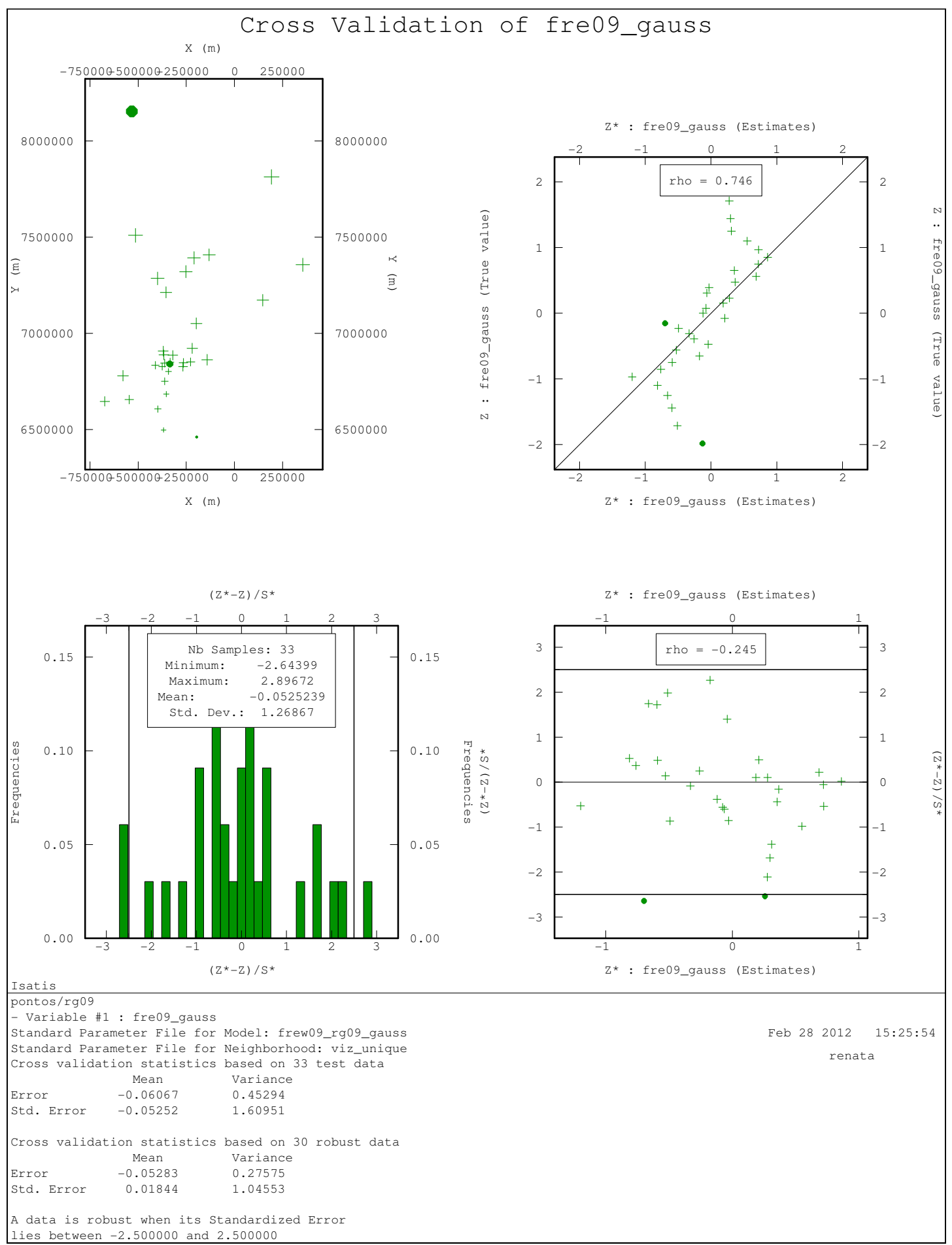

Figura 44. Resultados da validação cruzada do variograma estimado para o corredor de Rio Grande. 
A partir do modelo teórico de variograma ajustado ao variograma experimental, foram interpolados os dados de preços de fretes utilizando-se a krigagem ordinária.

O Mapa da Figura 45 apresenta o resultado da krigagem ordinária baseada nos dados a partir do porto de Paranaguá.

Nota-se que a área resultante da krigagem neste caso foi expandida para 0 norte, para tentar se obter estimativa de dados para regiões além da malha de dados originais (reais). No entanto, esta situação não nos dá segurança estatística acerca dos dados criados acima da área de domínio dos dados reais utilizados para o ajuste do variograma.

Por conta da área ter sido estimada além do ponto de maior distância amostrado, o valor mais alto da legenda acaba sendo superior ao dos demais interpoladores, no entanto, para comparação com os demais resultados, apenas as estimativas com mesma localização dos pontos reais foram consideradas, como nos demais interpoladores e na regressão.

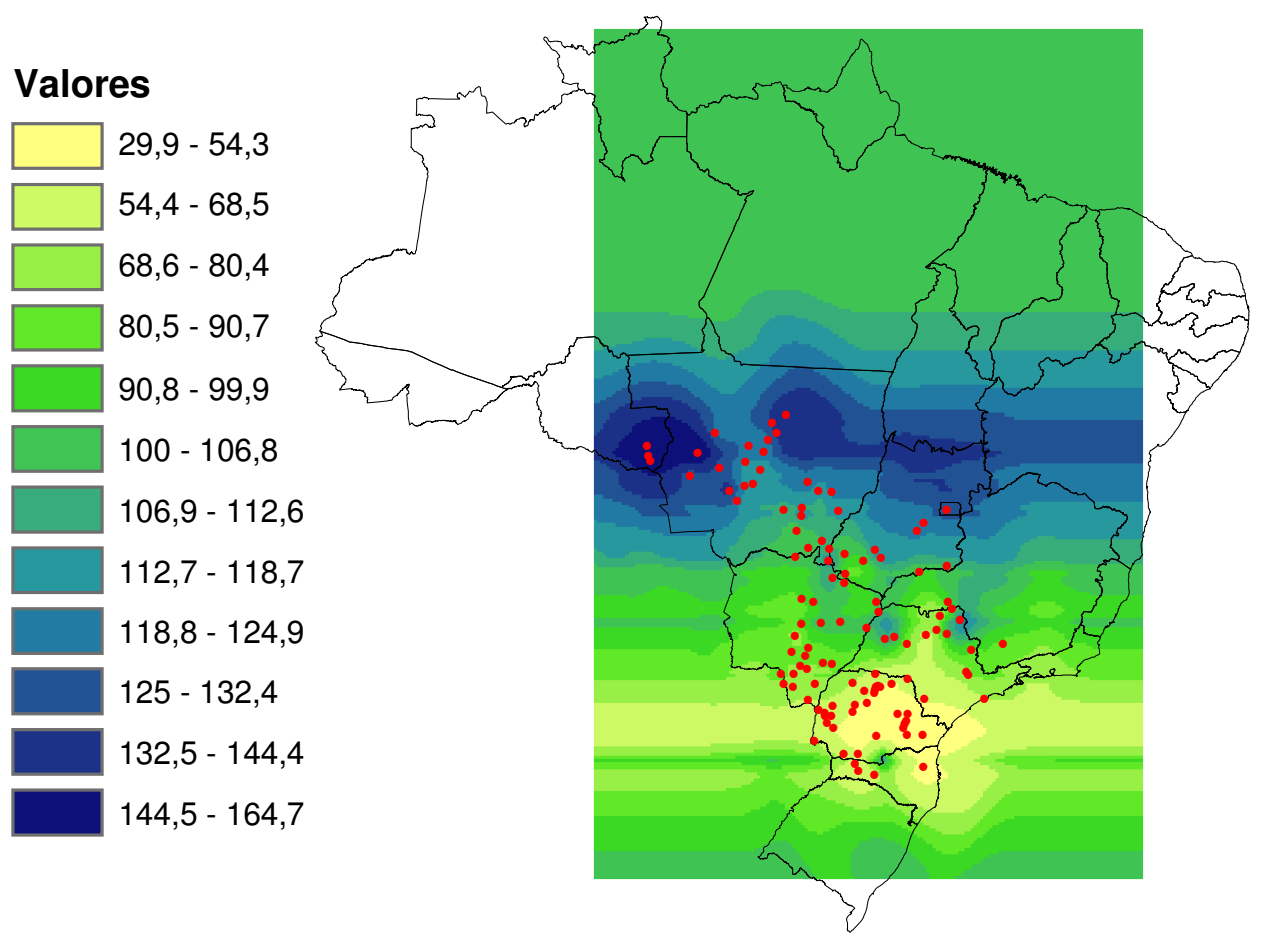

Figura 45. Resultado da interpolação por Krigagem Ordinária e distribuição dos pontos com valores dos fretes disponíveis pelos SIFRECA para o porto de Paranaguá. 


\subsection{Simulações com uso da metologia de Turning Bands (TB)}

Após o ajuste do variograma, utilizou-se a metolodologia de Turning Bands (TB) para processar 100 realizações a partir do modelo do variograma. O resultado das realizações para cada corredor, apresentado a seguir, mostra o comportamento da média, do valor mínimo e máximo de cada uma delas.

O primeiro gráfico da Figura 46 apresenta os resultados das realizações pela metodologia de TB, para o modelo ajustado a partir dos dados do corredor do Porto de Santos/Cubatão. O valor mínimo de frete encontrado nas 100 realizações foi $R \$$ 26, 95 e o máximo foi $R \$ 123,19$. Para as futuras simulações foram escolhidas as realizações que apresentaram a menor e maior média, $R \$ 60,33$ e $R \$ 79,48$, respectivamente. Além delas foram selecionados por meio de processamento, as grades compostas pelos menores valores mínimos entre todas as simulações, pelos maiores valores de máximo entre elas e a grade composta pelas médias de todas as simulações.

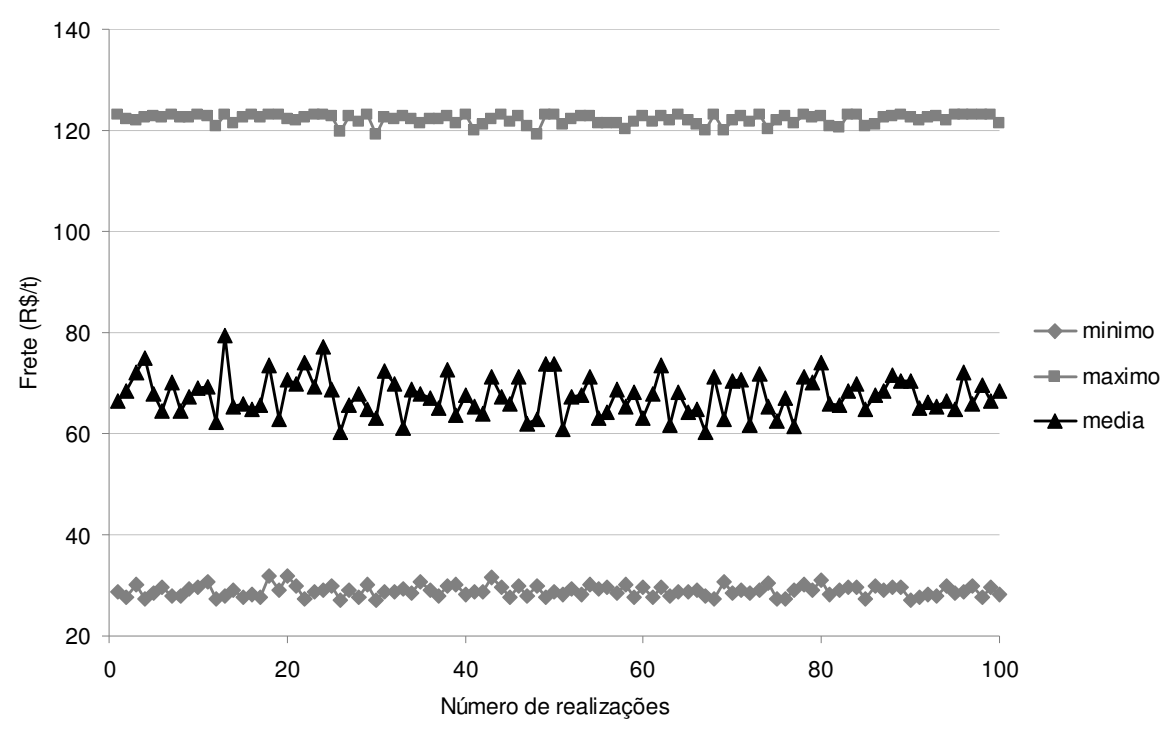

Figura 46. Média, Valor Máximo e Mínimo das realizações pela metodologia de TB, para o modelo ajustado a partir dos dados do corredor do Porto de Santos/Cubatão. 
O segundo gráfico, na Figura 47, apresenta os resultados das realizações pela metodologia de TB, para o modelo ajustado a partir dos dados do corredor do Porto de Paranaguá. O valor mínimo de frete encontrado nas 100 realizações foi $R \$ 23,60$ e o máximo foi $R \$ 172,50$. Assim como no caso de Santos/Cubatão, foram selecionados para futuras simulações as realizações que apresentaram a menor e maior média, ( $R \$ 79,60$ e $R \$ 120,67)$ e as grades compostas pelos menores valores mínimos entre todas as simulações, pelos maiores valores de máximo entre elas e a grade composta pelas médias de todas as simulações.

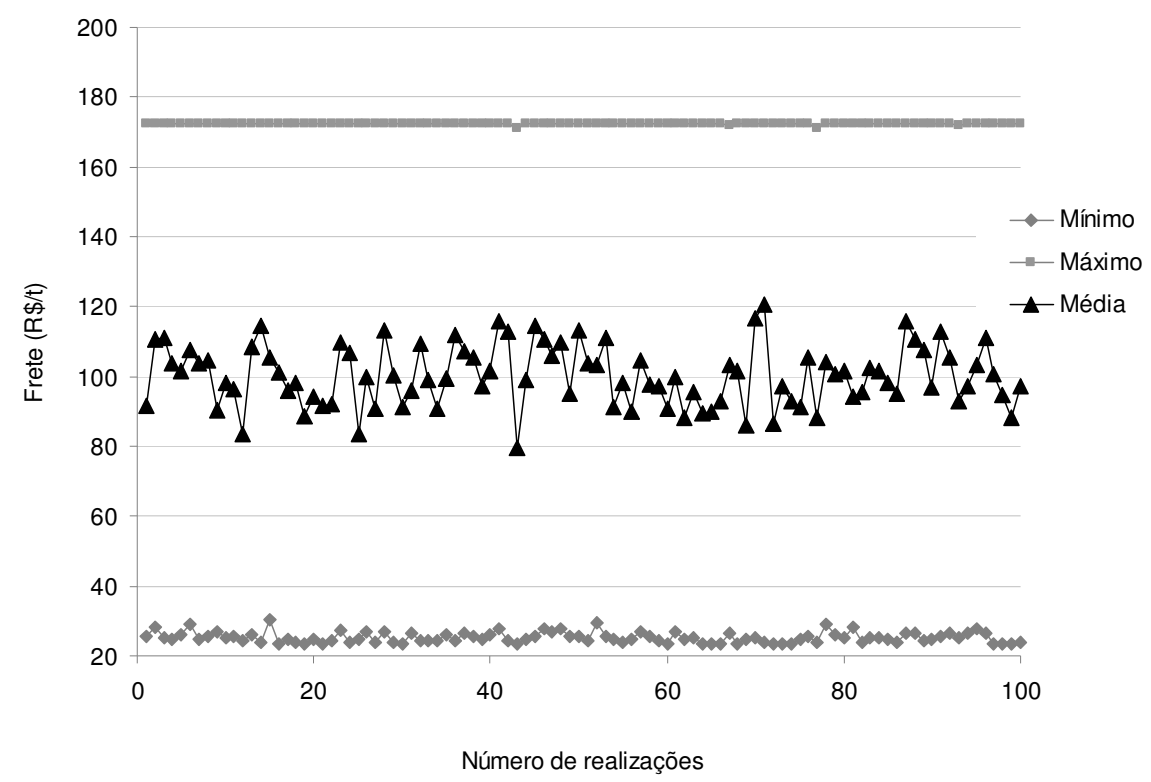

Figura 47. Média, Valor Máximo e Mínimo das realizações pela metodologia de TB, para o modelo ajustado a partir dos dados do corredor do Porto de Paranaguá.

O terceiro gráfico (Figura 48) apresenta os resultados das realizações pela metodologia de TB, para o modelo ajustado a partir dos dados do corredor do Porto de Rio Grande. O valor mínimo de frete encontrado nas 100 realizações foi $R \$ 23,53$ e o máximo de $\mathrm{R} \$ 190,00$. As realizações que apresentaram a menor e maior média, de $R \$ 52,00$ e $R \$ 90,87$, respectivamente, foram as escolhidas para as simulações. Também foram selecionados por meio de processamento, as grades compostas pelos menores valores mínimos entre todas as simulações, pelos maiores valores de máximo entre elas e a grade composta pelas médias de todas as simulações. 


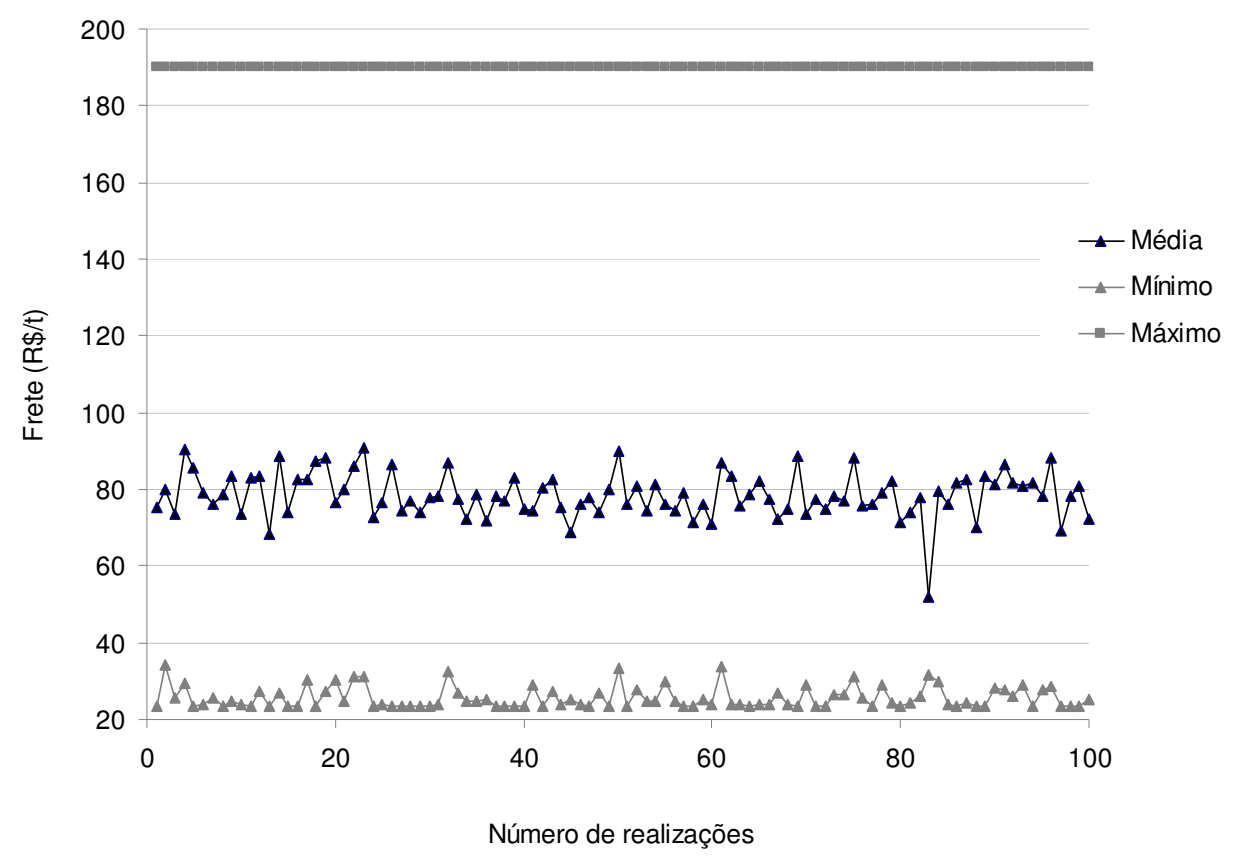

Figura 48. Média, Valor Máximo e Mínimo das realizações pela metodologia de TB, para o modelo ajustado a partir dos dados do corredor do Porto de Rio Grande.

Para as simulações através do Turning Bbands uma área maior que a área delimitada pelos valores extremos dos dados reais foi inserida para testar a utilização do modelo na estimação de valores além do quadrante original dos dados. A mesma área foi utilizada em todos os corredores.

A Figura 49 a seguir apresenta os resultados das duas realizações selecionadas (menor e maior média), e os três processamentos (média, maiores valores e menores valores) a partir das 100 realizações do TB para o corredor do Porto de Santos/Cubatão. 


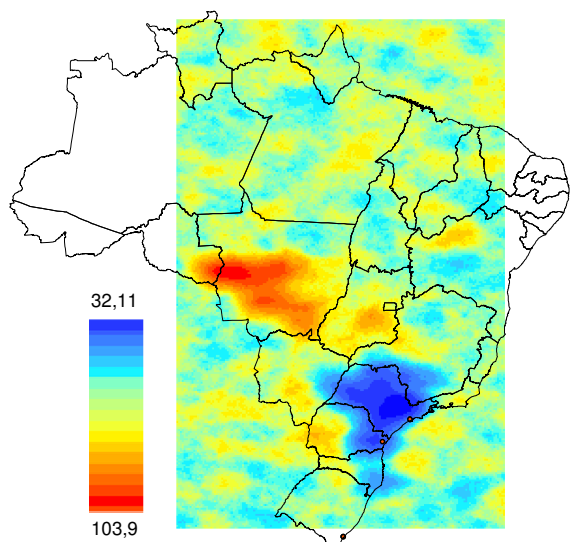

a) Média
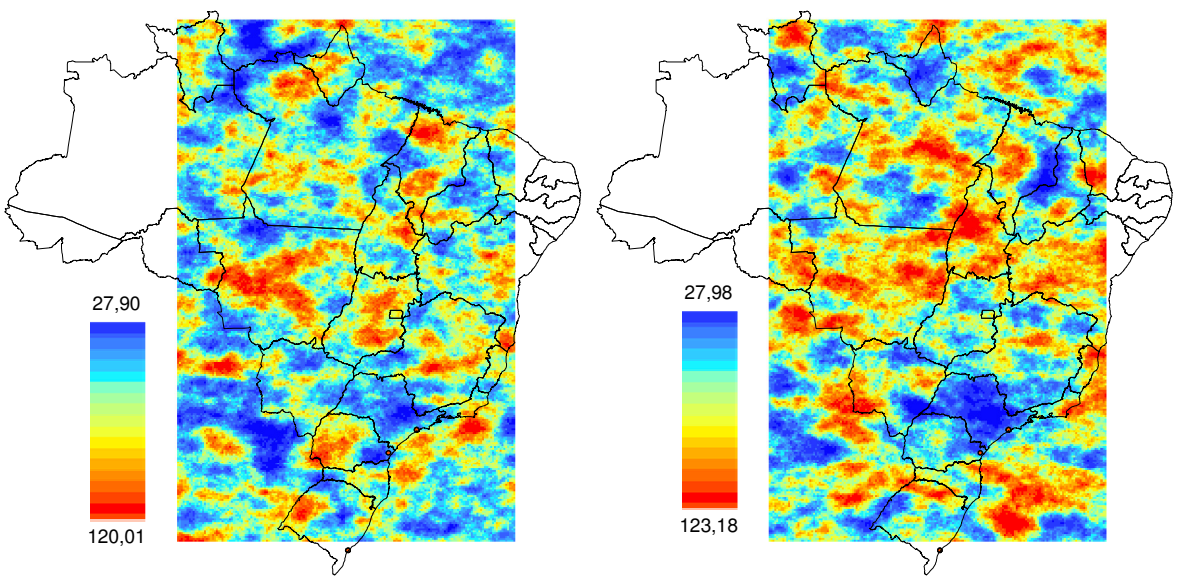

b) Menor média

c) Maior média

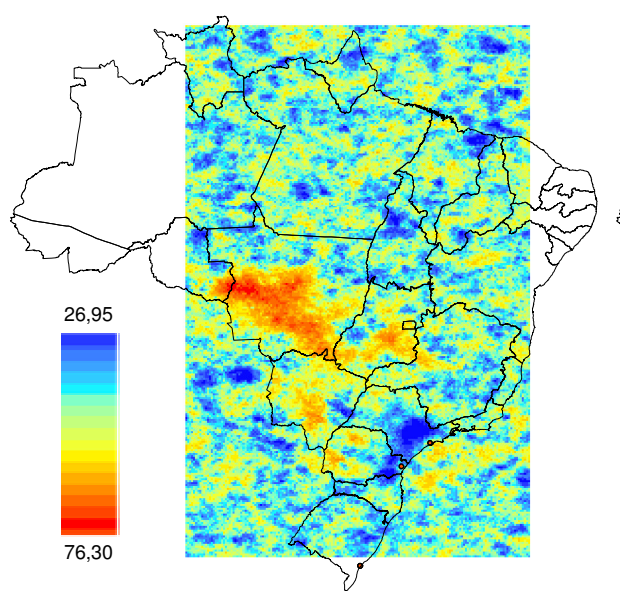

d) Valores mínimos

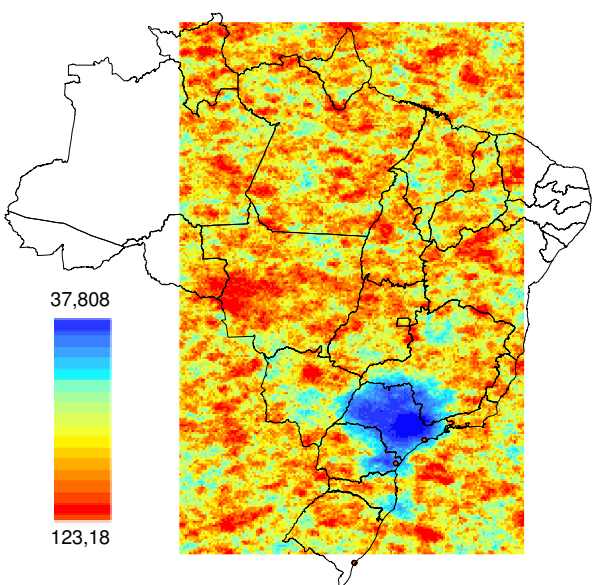

e) valores máximos

Figura 49. Resultados das realizações pela metodologia de TB: (a) Média, (b) menor média, (c) maior média, e processamento das realizações: (d) Valores mínimos de todas as realizações e (e) valores máximos de todas as realizações, para o corredor do Porto de Santos. 
Na Figura 50 estão os resultados das duas realizações selecionadas (menor e maior média), e os três processamentos (média, Maiores valore se menores valores) a partir das 100 realizações do TB para o corredor do Porto de Paranaguá.

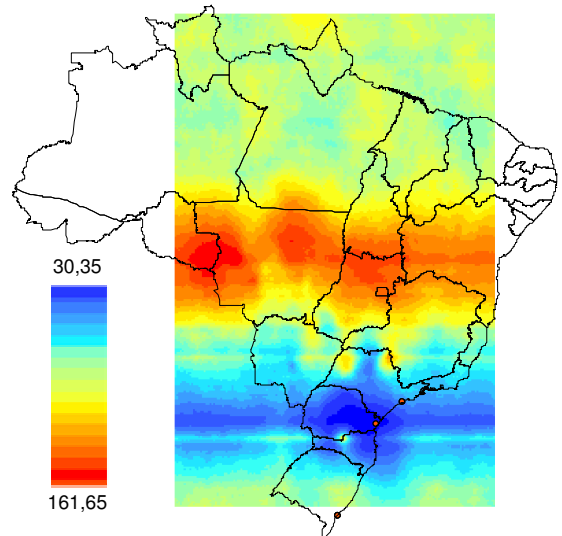

a) Média

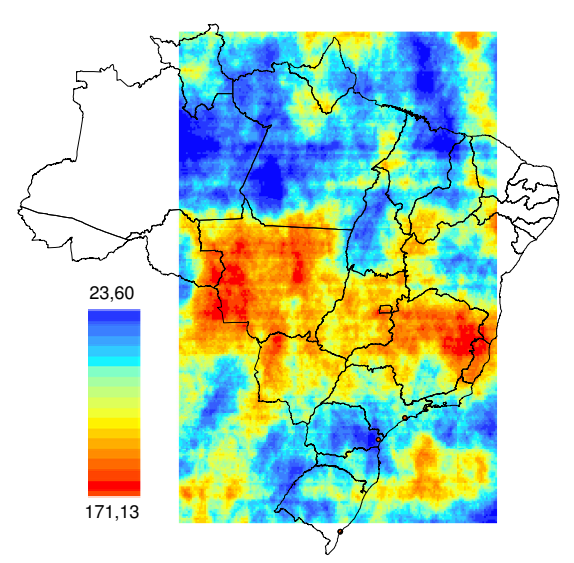

b) Menor média

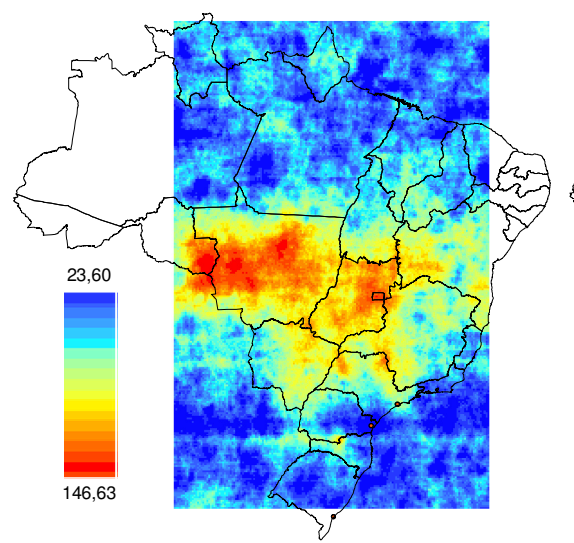

d) Valores mínimos

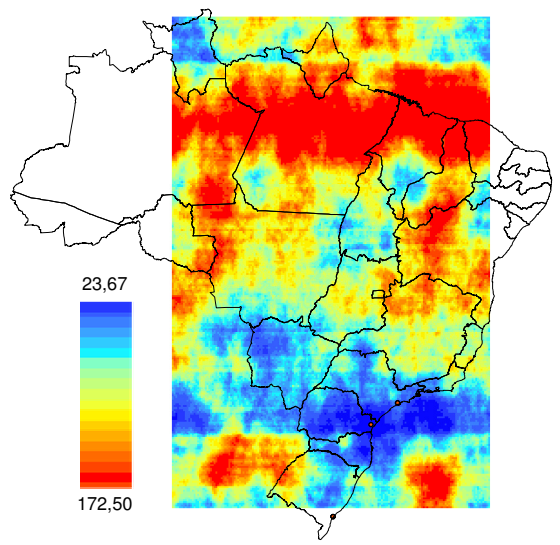

c) Maior média

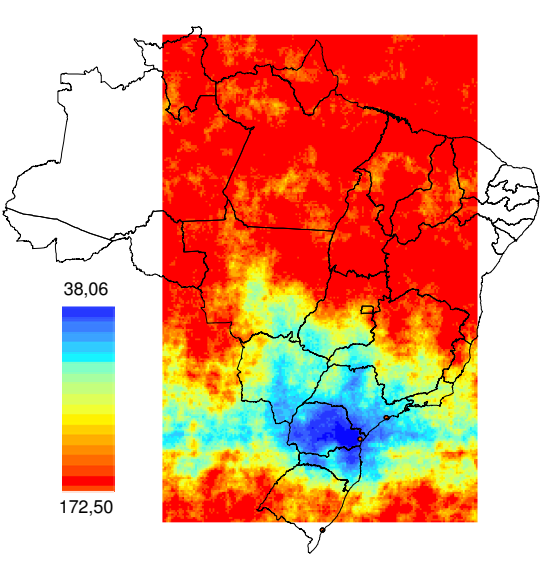

Figura 50. Resultados das realizações pela metodologia de TB: (a) Média, (b) menor média, (c) maior média, e processamento das realizações: (d) Valores 
mínimos de todas as realizações e (e) valores máximos de toadas as realizações, para o corredor do Porto de Paranaguá.

A Figura 51 apresenta os resultados das duas realizações selecionadas (menor e maior média), assim como os três processamentos (média, Maiores valore se menores valores) obtidos a partir das 100 realizações do TB para o corredor do Porto de Rio Grande.

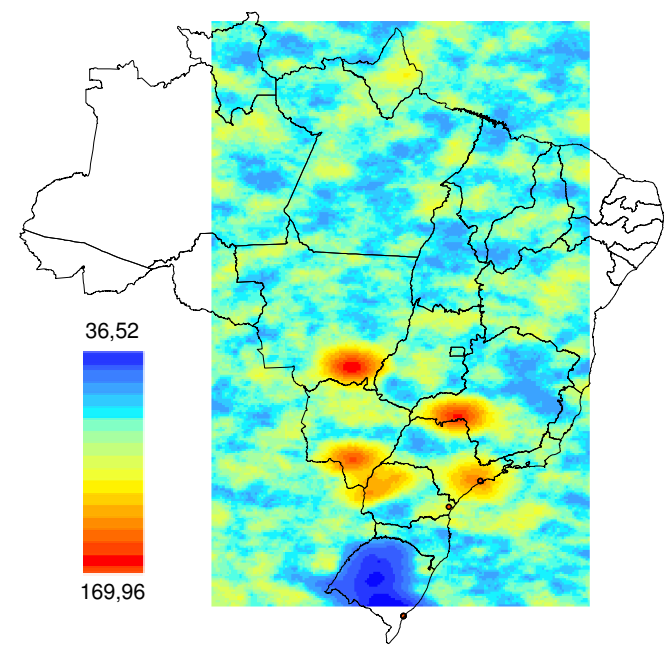

a) Média

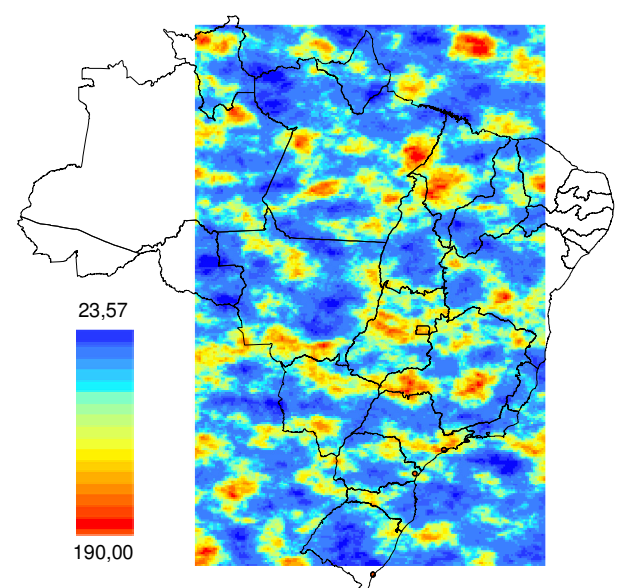

b) Menor média

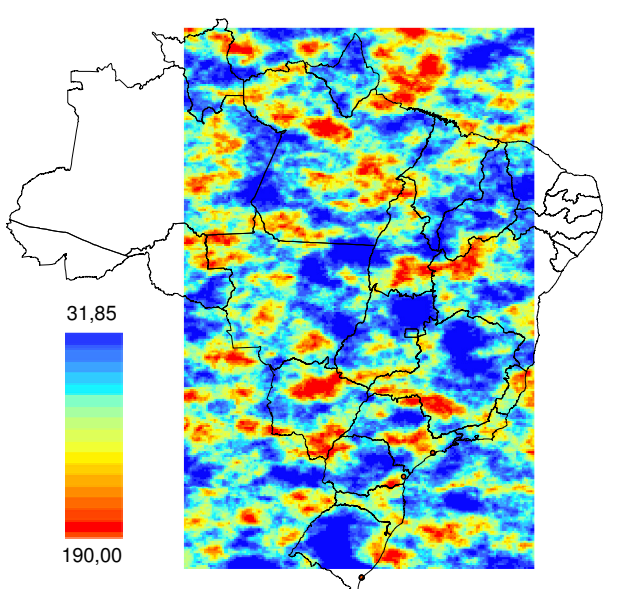

c) Mâior média 


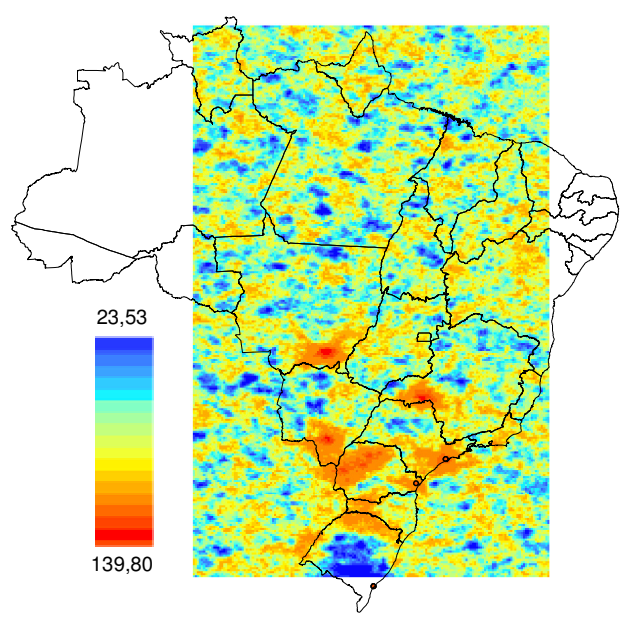

d) Valores mínimos

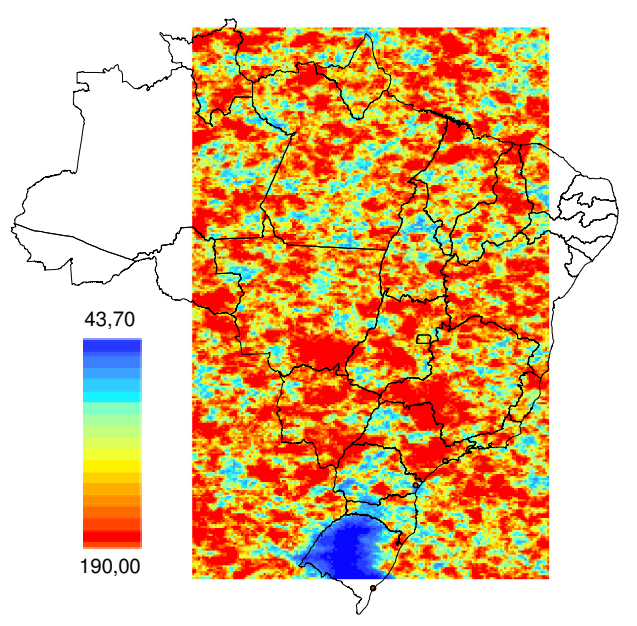

e) valores máximos

Figura 51. Resultados das realizações pela metodologia de TB: (a) Média, (b) menor média, (c) maior média, e processamento das realizações: (d) Valores mínimos de todas as realizações e (e) valores máximos de todas as realizações, para o corredor do Porto de Rio Grande.

\subsection{COMPARAÇÃO ENTRE OS RESULTADOS DAS ESTIMAÇÕES DOS PREÇOS A PARTIR DOS DIVERSOS MÉTODOS}

Após processados todos os interpoladores, as regressões e ajustado o semivariograma e feito a krigagem ordinária, os resultados de todos estes processos foram comparados entre si.

Foram calculadas: - a diferença entre os valores estimados e os valores reais dos pontos com dados de fretes (erros) por meio da Soma dos Erros; a média, a variância, o desvio-padrão e o coeficiente de variação dos resíduos. O método que apresentou o menor erro foi selecionado. 
Também foi calculada a correlação entre os valores estimados e reais, e a variância, o desvio-padrão e o desvio médio dos valores reais e dos estimados para comparação. A tabela 11 apresenta as estatísticas dos erros das regressões.

Tabela 11. Estatística dos erros das regressões

\begin{tabular}{lrrr}
\hline & \multicolumn{3}{c}{ Regressão Log-Log } \\
\cline { 2 - 4 } & Somente & Todos os & Corredores \\
& corredor & Corredores & \multicolumn{1}{c}{ Principais } \\
\hline Soma & 51,59 & $-593,61$ & $-640,42$ \\
Média & 0,44 & $-5,07$ & $-5,47$ \\
Variância & 300,44 & 268,54 & 266,78 \\
Desvio Padrão & 17,33 & 16,39 & 16,33 \\
\hline
\end{tabular}

Fonte: Dados da pesquisa

Os resultados da tabela das estatísticas dos erros das estimativas das regressões não dizem muito por si só. Elas indicam que, apesar do maior desvio dos erros das estimativas, o modelo estimado somente com os dados do corredor de Paranaguá obteve menor soma dos erros em relação aos dados reais. No entanto, os erros positivos, por conta dos valores sobreestimados, compensaram, de certa forma, os valores subestimados.

No caso das regressões estimadas com base nos dados de todos os corredores e somente dos corredores principais, os resultados ficam bastante próximos, com mais dados subestimados, o que dá uma soma dos erros negativa.

As Figuras 52 a 54 mostram os gráficos dos desvios dos erros estimados em relação ao dado real e plotados em relação à distância do porto pelo método da regressão log-log para o corredor de Paranaguá, para todos os corredores e para os principais corredores. 


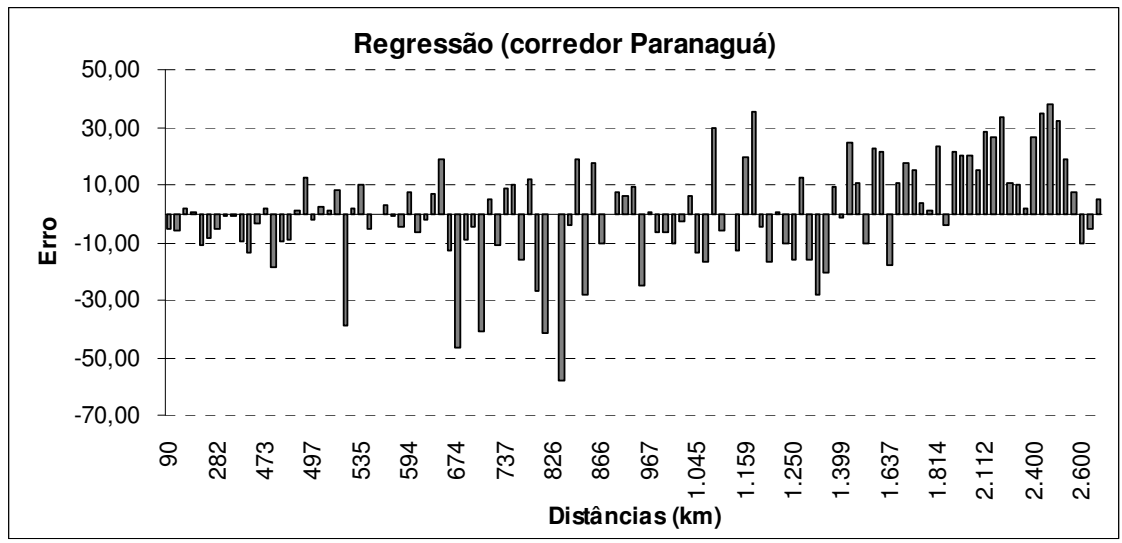

Figura 52. Desvios dos erros dos dados estimados por regressão log-log dos fretes contra distância apenas para o corredor de Paranaguá.

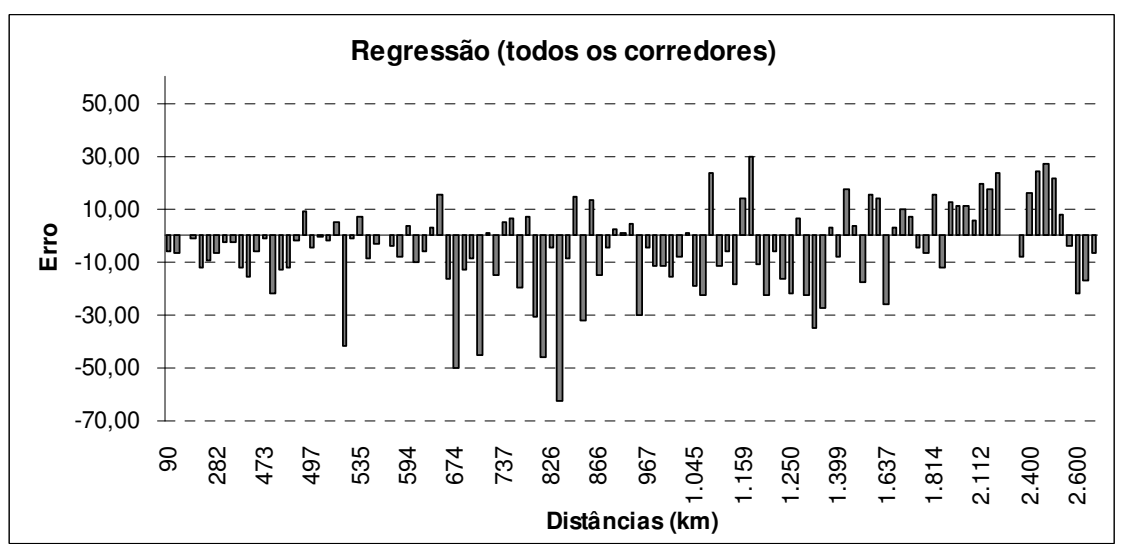

Figura 53. Desvios dos erros dos dados estimados por regressão log-log dos fretes contra distância de todos os corredores.

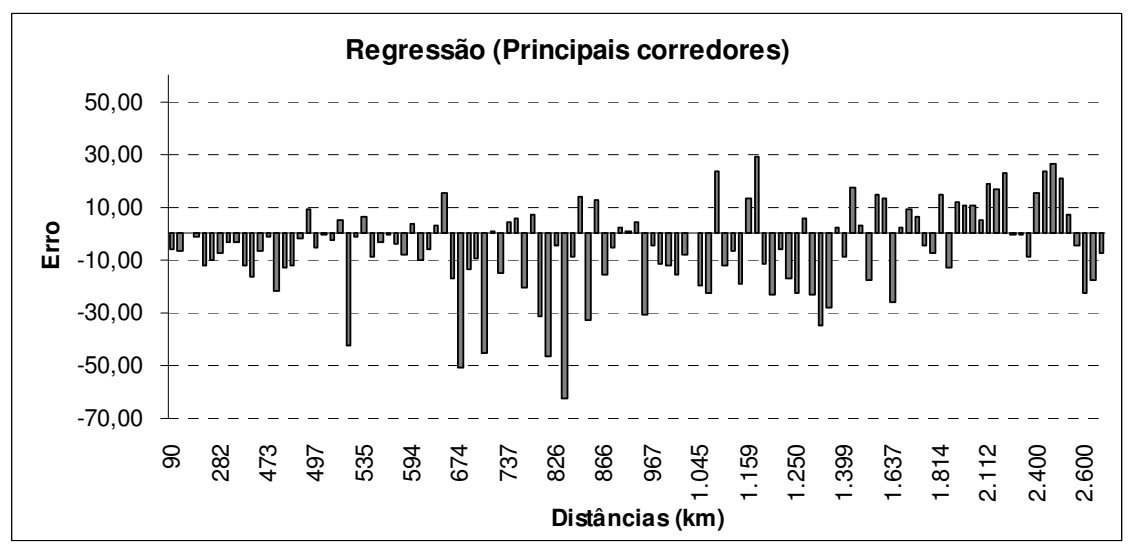

Figura 54. Desvios dos erros dos dados estimados por regressão log-log dos fretes contra distância para os principais corredores. 
Entre os três modelos, o estimado apenas com dados do corredor de Paranaguá é o que apresenta o melhor coeficiente de variação $\left(R^{2}=0,78\right)$ e menor soma dos erros, mas ainda assim, apresenta um grande descolamento das estimativas, algo que foi reduzido em outras formas de estimação dos dados que serão apresentadas na seqüência.

A próxima tabela 12 apresenta as estatísticas dos valores reais e dos estimados a partir das regressões. Observa-se que os resultados de todos os modelos possuem alta correlação com os dados reais, mas coeficientes de variação distintos dos reais, dificultando a seleção da melhor estimativa, ou tornando, de certa forma, a escolha indiferente.

Tabela 12. Estatística dos valores reais e dos estimados pelas regressões

\begin{tabular}{lrrrr}
\hline & \multicolumn{4}{c}{ Regressão Log-Log } \\
\cline { 2 - 5 } & \multicolumn{1}{c}{$\begin{array}{c}\text { Valores } \\
\text { reais }\end{array}$} & $\begin{array}{c}\text { Somente } \\
\text { corredor }\end{array}$ & $\begin{array}{c}\text { Todos os } \\
\text { Corredores }\end{array}$ & \multicolumn{1}{c}{$\begin{array}{l}\text { Corredores } \\
\text { Principais }\end{array}$} \\
\hline \multicolumn{1}{c}{$\boldsymbol{}$} & 0,87751 & 0,87778 & 0,87780 \\
Variância & $1.078,92$ & $1.300,04$ & $1.115,98$ & $1.103,25$ \\
Desvio Padrão & 32,85 & 36,06 & 33,41 & 33,22 \\
Desvio Médio & 27,75 & 29,58 & 27,40 & 27,25 \\
CV (\%) & 36,64 & 40,02 & 39,49 & 39,46 \\
\hline
\end{tabular}

Fonte: Dados da pesquisa

A tabela 13 a seguir apresenta as estatísticas dos erros das interpolações. Os resultados de estimação dos dados obtidos a partir de interpoladores sem uso da geoestatística apresentaram soma dos erros menores, na sua maioria, em relação ás estimativas feitas a partir de regressões. Além disso, os desvios padrão dos erros foram bastante menores que os anteriormente apresentados, sendo que, com o uso de interpoladores, as funções polinomiais locais e globais foram as que apresentaram resultados piores, com altos desvios dos erros.

Destaca-se entre elas as estimativas feitas a partir do IDW, com baixa soma dos erros e baixo desvio dos mesmos. 
Tabela 13. Estatística dos erros das interpolações

\begin{tabular}{lcccc}
\hline & Soma & Média & Variância & $\begin{array}{c}\text { Desvio } \\
\text { Padrão }\end{array}$ \\
\hline KRG Linear & $-0,99$ & $-0,01$ & 0,72 & 0,85 \\
KRG gaussiana & 31,48 & 0,27 & 137,75 & 11,74 \\
KRG Exponencial & $-1,12$ & $-0,01$ & 0,73 & 0,85 \\
KRG Circular & $-1,00$ & $-0,01$ & 0,72 & 0,85 \\
KRG Esférica & $-1,02$ & $-0,01$ & 0,72 & 0,85 \\
Vizinho Natural & 4,38 & 0,04 & 1,78 & 1,34 \\
Função de Base Radial - Thin Plate Spline & 8,93 & 0,08 & 0,37 & 0,61 \\
Função de Base Radial - Inverso do Quadrado & 10,11 & 0,09 & 0,27 & 0,52 \\
Função de Base Radial - Multiquadrática & 5,44 & 0,05 & 0,48 & 0,69 \\
Função de Base Radial - Spline com tensão & 6,98 & 0,06 & 0,79 & 0,89 \\
Local polinomial (g2) & 54,06 & 0,46 & 139,79 & 11,82 \\
Global Polinomial (g2) & $-2,35$ & $-0,02$ & 195,23 & 13,97 \\
IDW & 0,58 & 0,01 & 0,03 & 0,17 \\
\hline
\end{tabular}

Fonte: Dados da pesquisa

Os gráficos das Figuras 55 a 67 mostram que os dados interpolados a partir do algoritmo IDW apresentam o menor desvio em relação aos dados reais de preços de fretes.

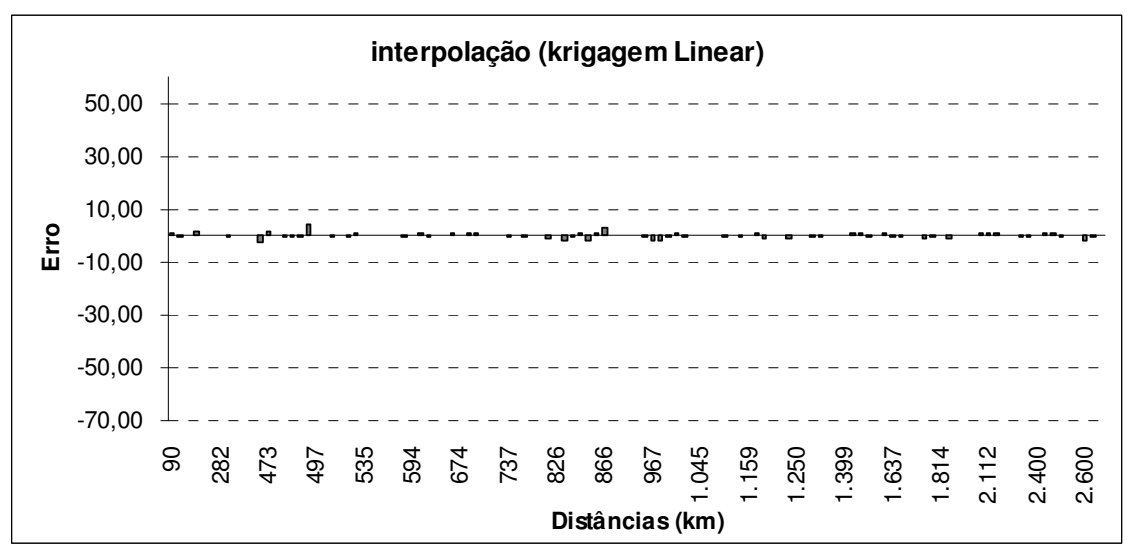

Figura 55. Desvios dos dados interpolados pela krigagem linear em relação aos fretes reais 


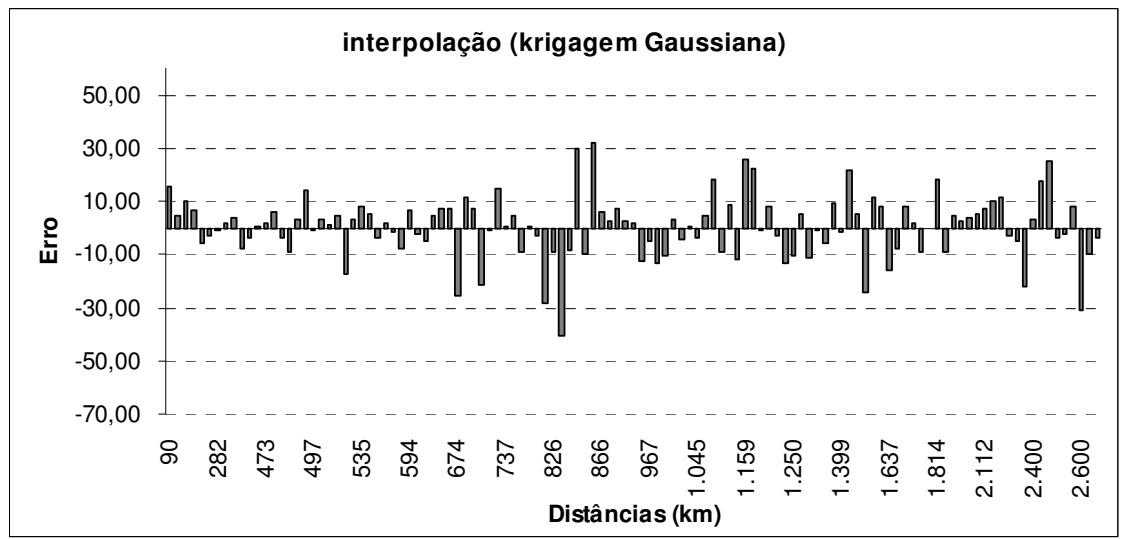

Figura 56. Desvios dos dados interpolados pela krigagem gaussiana em relação aos fretes reais

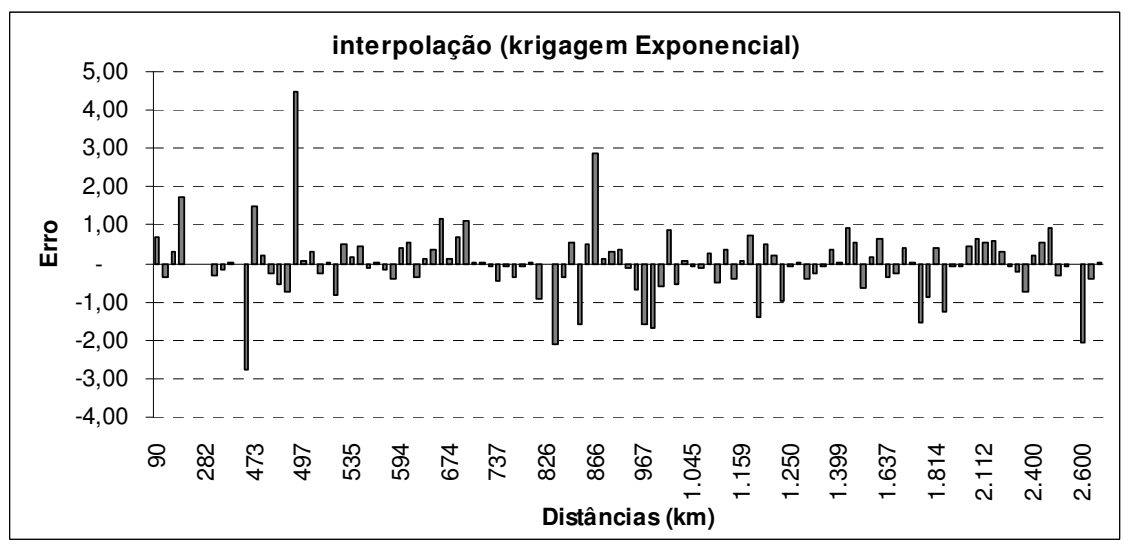

Figura 57. Desvios dos dados interpolados pela krigagem exponencial em relação aos fretes reais

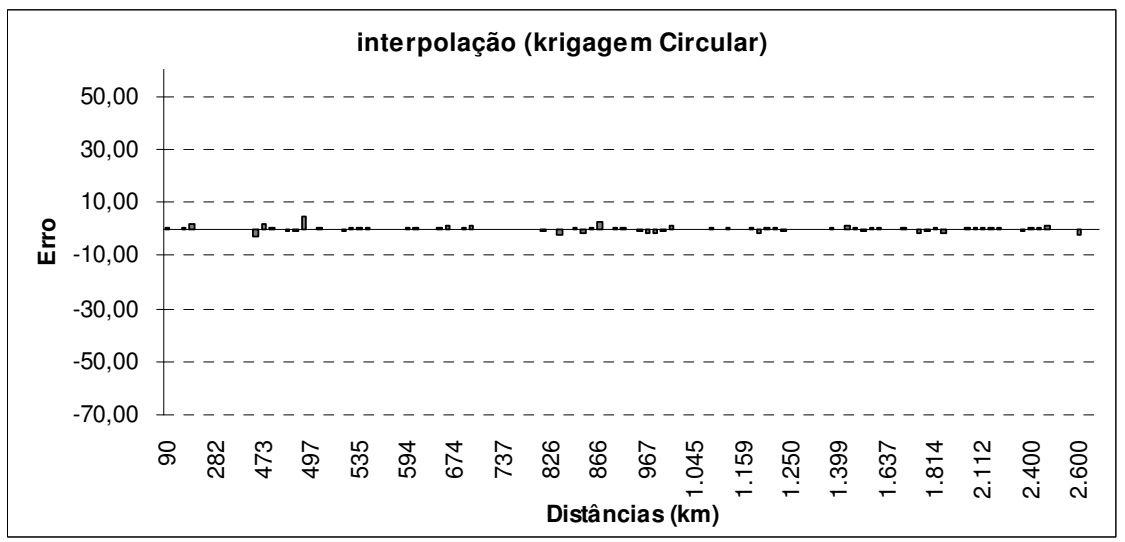

Figura 58. Desvios dos dados interpolados pela krigagem circular em relação aos fretes reais 


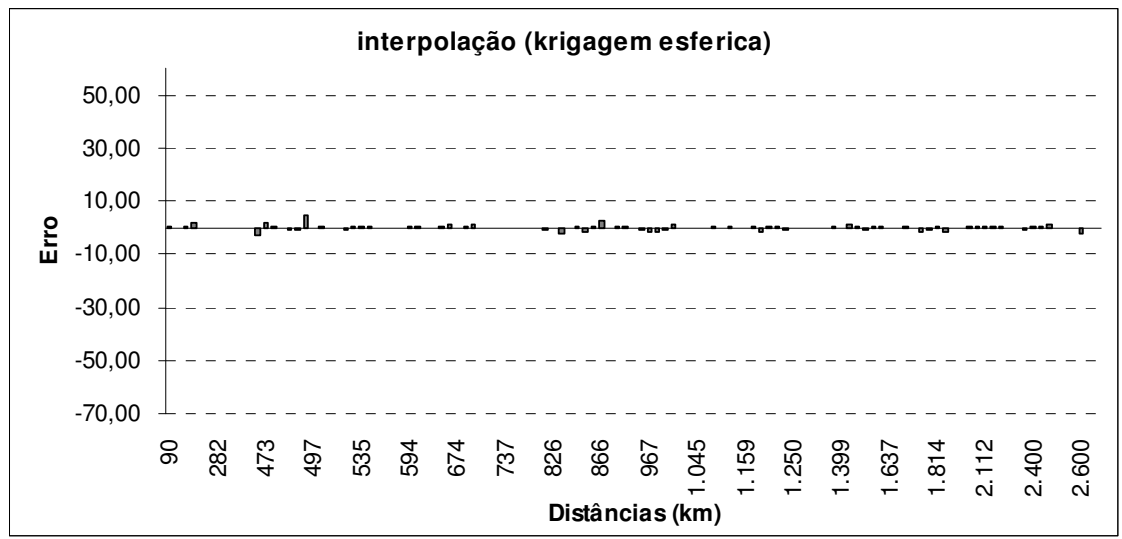

Figura 59. Desvios dos dados interpolados pela krigagem esférica em relação aos fretes reais

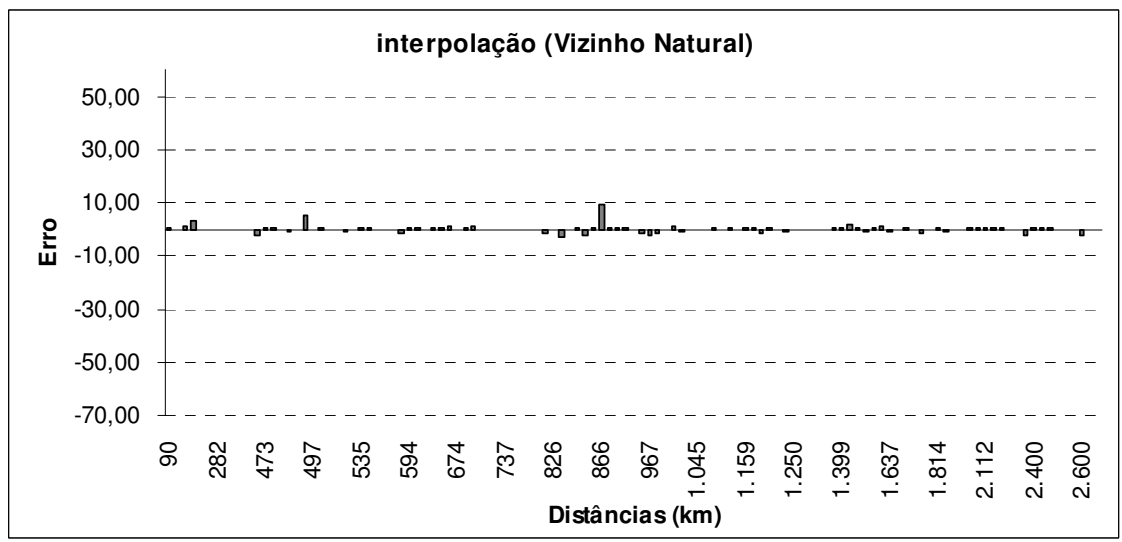

Figura 60. Desvios dos dados interpolados pela algoritmo Vizinho Natural (Natural neighbours) em relação aos fretes reais

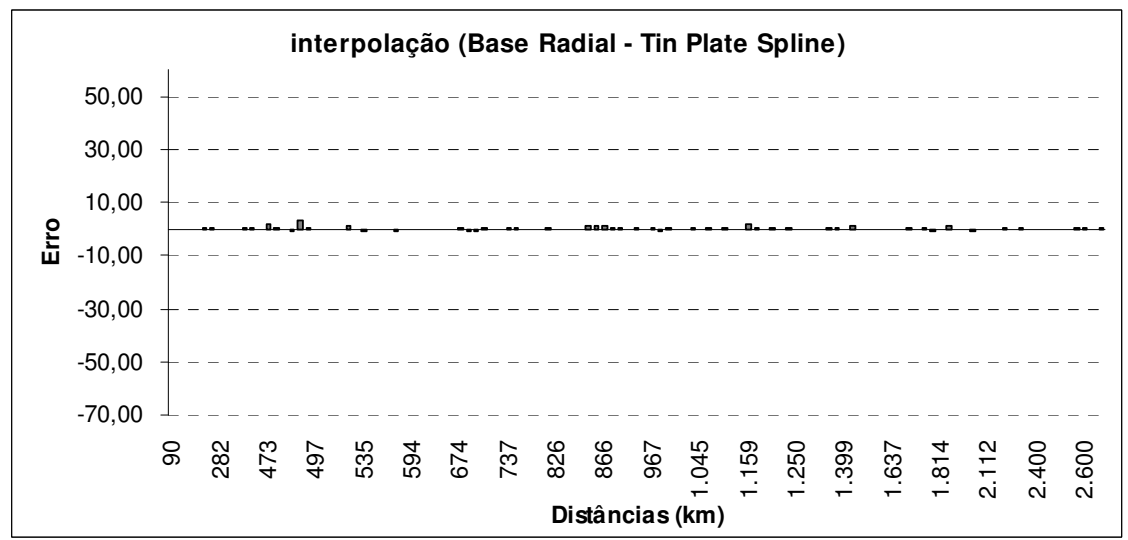

Figura 61. Desvios dos dados interpolados pelo polinômio de base radial - Tin Plate Spline, em relação aos fretes reais 


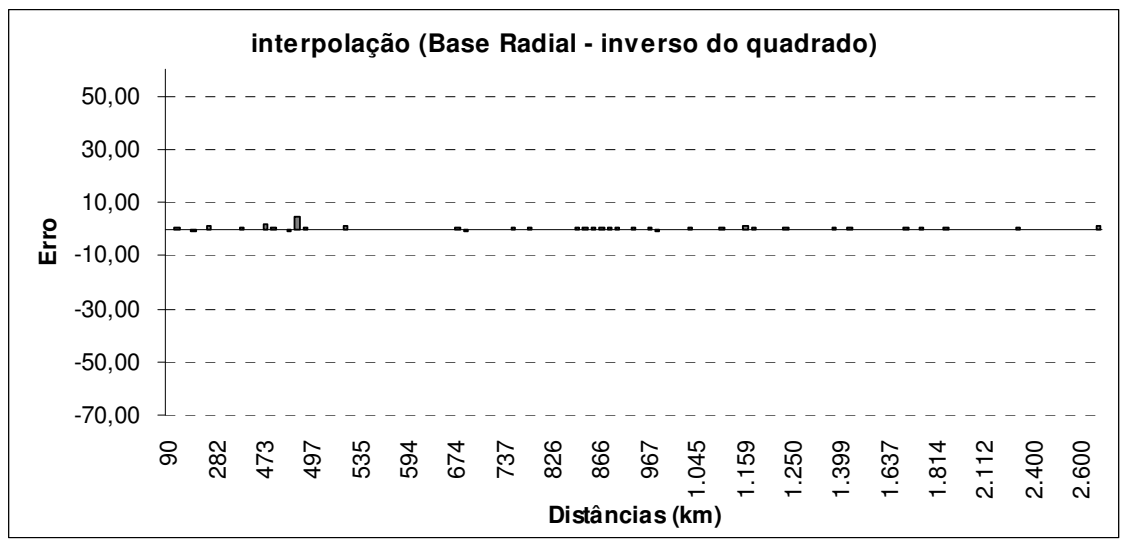

Figura 62. Desvios dos dados interpolados pelo polinômio de base radial - Inverso do quadrado, em relação aos fretes reais

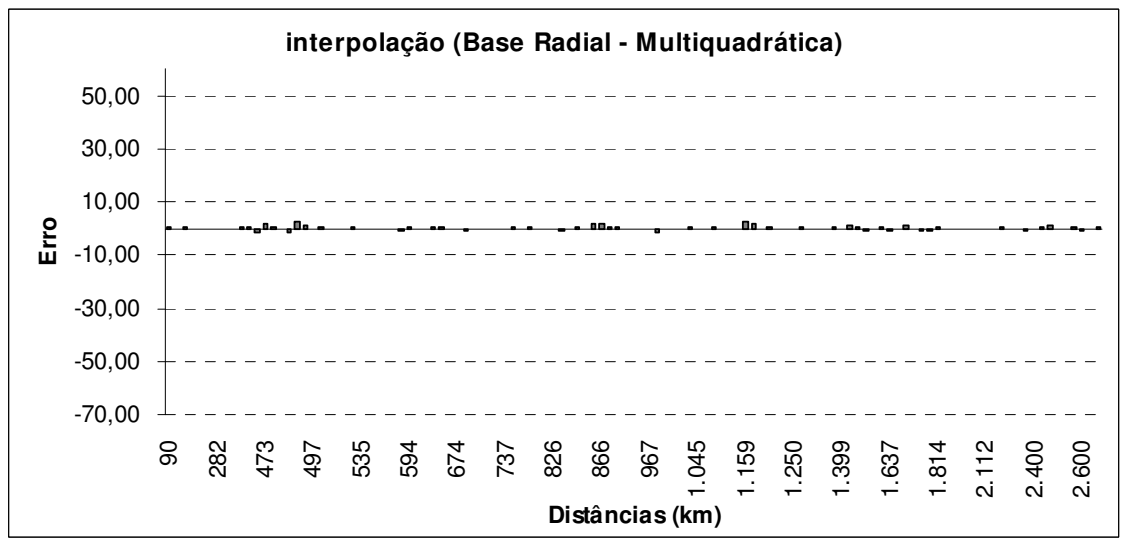

Figura 63 Desvios dos dados interpolados pelo polinômio de base radial Multiquadrática, em relação aos fretes reais

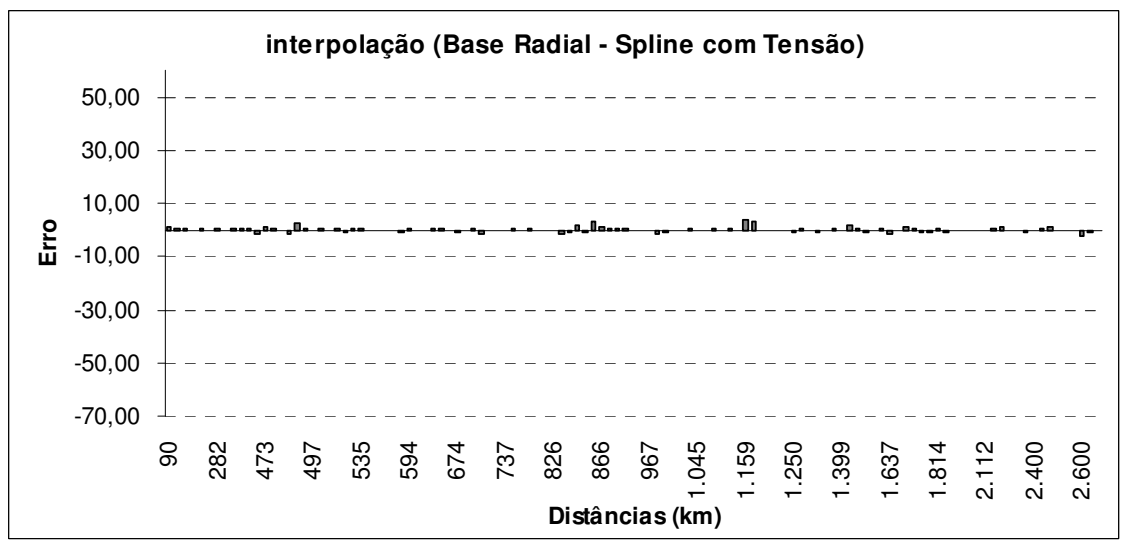

Figura 64. Desvios dos dados interpolados pelo polinômio de base radial - Spline com tensão, em relação aos fretes reais 


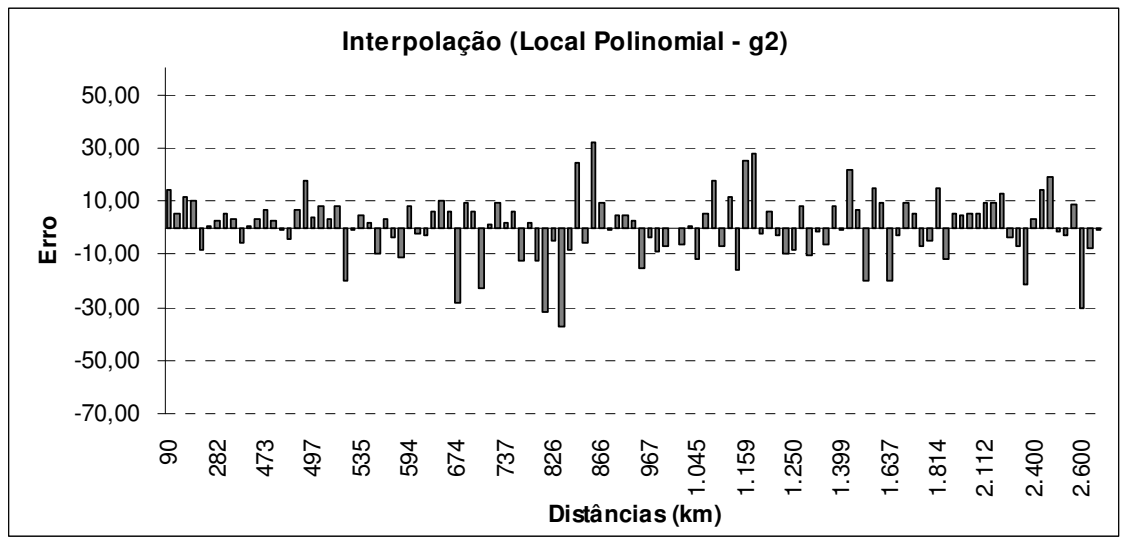

Figura 65. Desvios dos dados interpolados por Polinômio Local (grau 2), em relação aos fretes reais

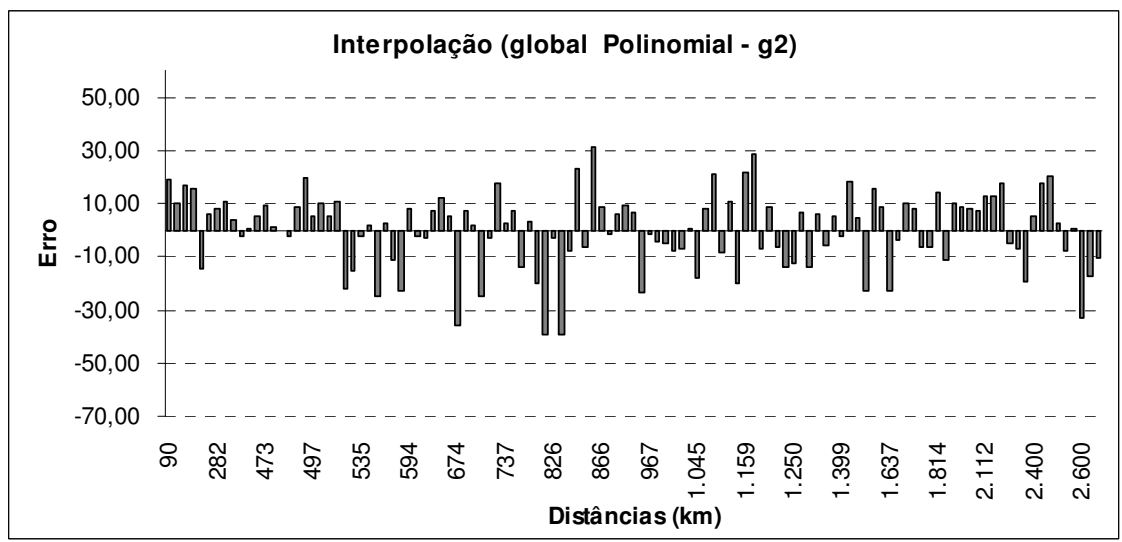

Figura 66. Desvios dos dados interpolados por Polinômio Global (grau 2), em relação aos fretes reais

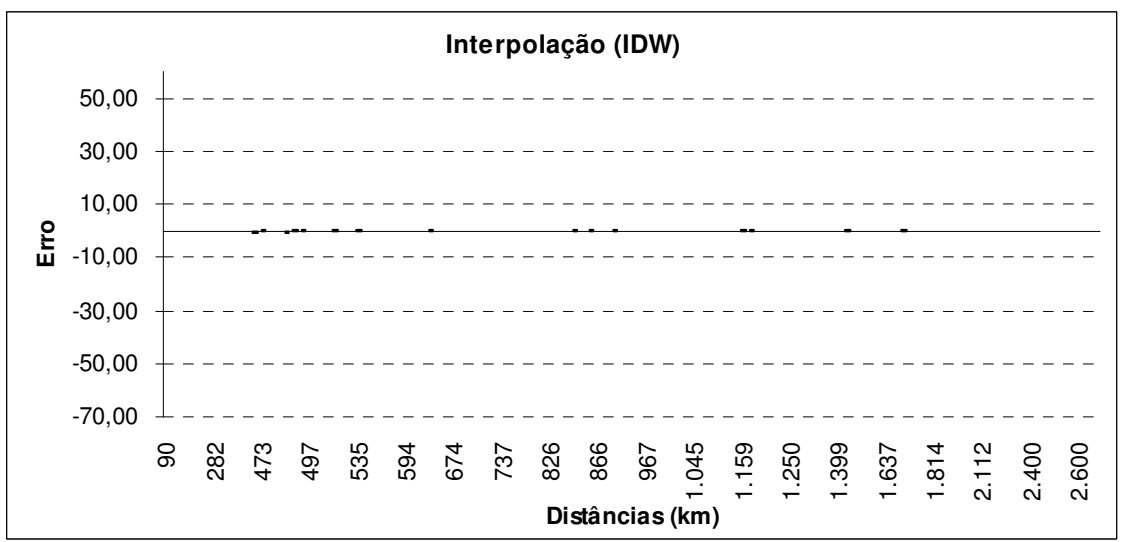

Figura 67. Desvios dos dados interpolados por IDW (Inverso da distância ponderada), em relação aos fretes reais 
A tabela 14 apresenta as estatísticas dos valores reais e dos estimados a partir das interpolações. Eles corroboram com a indicação do IDW como melhor estimador dentre os interpoladores, com alto coeficiente de correlação ( $\rho$ ), desvio padrão e coeficiente de variação $(\mathrm{CV})$ bastante próximos do real. No entanto, houve outros interpoladores que também apresentaram resultados muito próximos dos reais, mas as estatísticas dos desvios dos erros e os gráficos apresentados anteriormente mostram que o IDW apresenta melhor desempenho que os demais.

Tabela 14. Estatística dos valores reais e dos estimados pelas interpolações

\begin{tabular}{lrrrrr}
\hline & \multicolumn{1}{c}{$\rho$} & Variância & $\begin{array}{r}\text { Desvio } \\
\text { Padrão }\end{array}$ & $\begin{array}{l}\text { Desvio } \\
\text { Médio }\end{array}$ & CV (\%) \\
\hline Dados reais & 1,00000 & 1.079 & 32,85 & 27,75 & 36,64 \\
KRG Linear & 0,99969 & 1.064 & 32,62 & 27,58 & 36,38 \\
KRG gaussiana & 0,93405 & 920 & 30,32 & 25,20 & 33,72 \\
KRG Exponencial & 0,99969 & 1.064 & 32,61 & 27,58 & 36,38 \\
KRG Circular & 0,99969 & 1.064 & 32,62 & 27,58 & 36,38 \\
KRG Esférica & 0,99969 & 1.064 & 32,62 & 27,58 & 36,38 \\
Vizinho Natural & 0,99913 & 964 & 31,05 & 26,53 & 34,83 \\
Função de Base Radial - Thin Plate Spline & 0,99983 & 1.077 & 32,81 & 27,70 & 36,57 \\
Função de Base Radial - Inverso do Quadrado & 0,99988 & 1.076 & 32,80 & 27,69 & 36,54 \\
Função de Base Radial - Multiquadrática & 0,99979 & 1.070 & 32,71 & 27,62 & 36,47 \\
Função de Base Radial - Spline com tensão & 0,99968 & 1.058 & 32,53 & 27,48 & 36,26 \\
Local polinomial (g2) & 0,93328 & 893 & 29,88 & 24,88 & 33,15 \\
Global Polinomial (g2) & 0,90501 & 884 & 29,73 & 24,74 & 33,16 \\
IDW & 0,99999 & 1.077 & 32,81 & 27,71 & 36,59 \\
\hline
\end{tabular}

Fonte: Dados da pesquisa

A tabela 15 apresenta as estatísticas dos erros da krigagem ordinária da média das 100 realizações do Turning Bands.

Tabela 15. Estatística dos erros das krigagem ordinária da média das realizações do Turning Bands.

\begin{tabular}{lcc} 
& \multicolumn{2}{c}{ Geoestatística } \\
\hline & Krigagem Ordinária & Media Realizações TB \\
\hline Soma & $-6,94$ & $-11,53$ \\
Média & $-0,06$ & $-0,10$ \\
Variância & 37,23 & 41,79 \\
Desvio Padrão & 6,10 & 6,46 \\
\hline
\end{tabular}

Fonte: Dados da pesquisa 
A próxima tabela 16 apresenta as estatísticas dos valores reais e dos estimados a partir da krigagem ordinária e da média das realizações do Turning Bands (utilizando-se para a comparação os valores médios das 100 realizações do TB) para os mesmos pontos das amostras.

Tabela 16. Coeficiente de Correlação, Variância, Desvio Padrão, Desvio Médio e Coeficiente de Variação dos valores interpolados em relação ao indicador de preço real pela krigagem ordinária e pela média das realizações do Turning Bands.

\begin{tabular}{lccc} 
& & \multicolumn{2}{c}{ Geoestatística } \\
\cline { 3 - 4 } & Dados reais & Krigagem Ordinária & Media Realizações TB \\
\hline$\rho$ & $100,00 \%$ & $91,21 \%$ & $91,65 \%$ \\
Variância & $1.078,92$ & 960,06 & 923,19 \\
Desvio Padrão & 32,85 & 30,98 & 30,38 \\
Desvio Médio & 27,75 & 26,45 & 25,54 \\
CV $(\%)$ & 36,64 & 34,58 & 33,93 \\
\hline
\end{tabular}

Fonte: Dados da pesquisa

Apesar da grande parte dos interpoladores acima citados apresentarem resultados muito próximos dos dados reais, o IDW foi o algoritmo que apresentou a menor variância e desvio padrão dos desvios em relação aos dados reais de indicadores de fretes.

Os dois gráficos apresentados a seguir (Figuras 79 e 80), mostram os desvios dos resultados dos fretes estimados pela krigagem ordinária e a médias das realizações do Turning Bands baseados no ajuste do semivariograma.

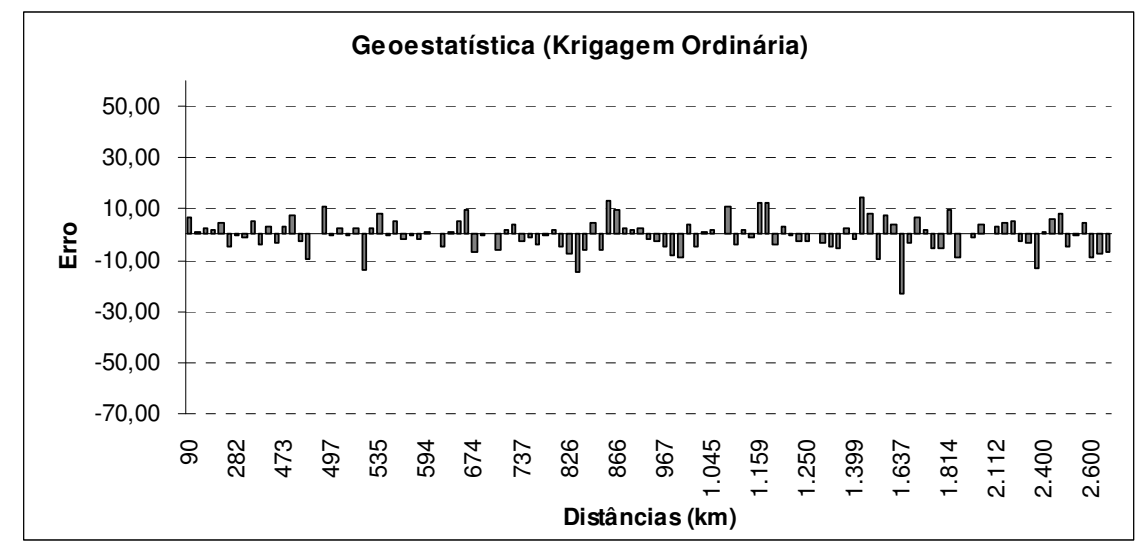

Figura 68. Desvios dos dados interpolados Krigagem Ordinária baseado no semivariograma, em relação aos fretes reais 


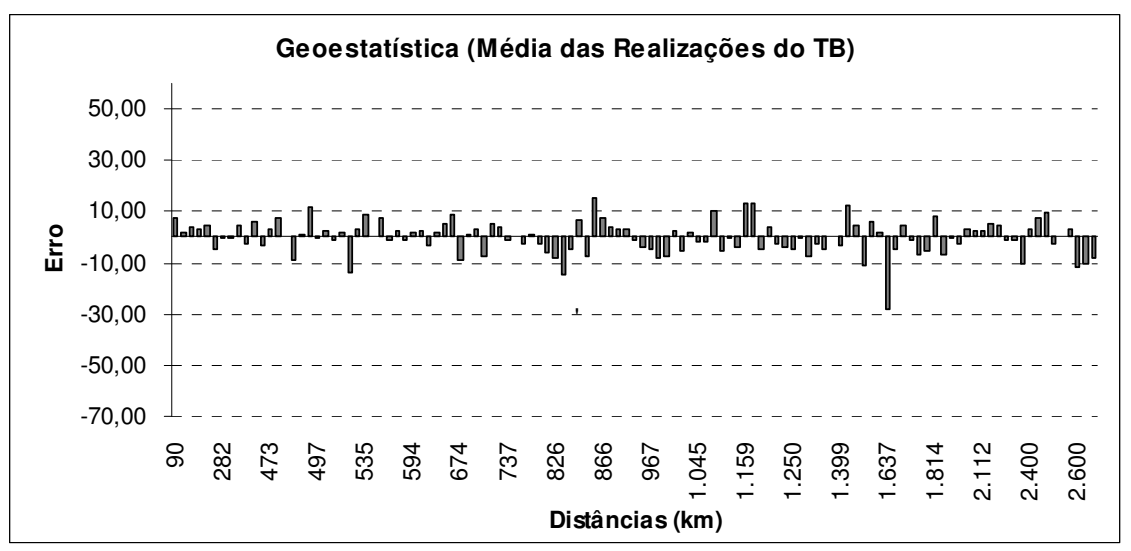

Figura 69. Desvios dos dados estimados pela média dos resultados das realizações do Turning Bands baseado no semivariograma, em relação aos fretes reais

\subsection{ANÁLISE DOS FRETES E INDICADORES DE FERTILIZANTES POR MEIO DE INTERPOLAÇÃO IDW}

Dados os resultados dos resíduos dos valores estimados pelos diversos métodos apresentados na seção anterior, foi escolhido o interpolador IDW para a estimação e posterior análise dos valores dos indicadores dos preços dos fertilizantes importados pelos três principais portos que abastecem o mercado nacional.

Para tanto, houve a necessidade de proceder alguns passos. Em primeiro lugar, os dados reais de fretes dos portos de Santos/Cubatão, Paranaguá e Rio Grande foram a base para a interpolação por IDW dos preços dos fretes de maneira contínua, utilizando-se o software ArcGIS.

O resultado da interpolação dos fretes do corredor de Paranaguá, Santos e Rio Grande são apresentados a seguir. Nelas é apresentado tanto o resultado da interpolação quanto a localização dos pontos com os valores reais que formam a base parba estimação do modelo. 

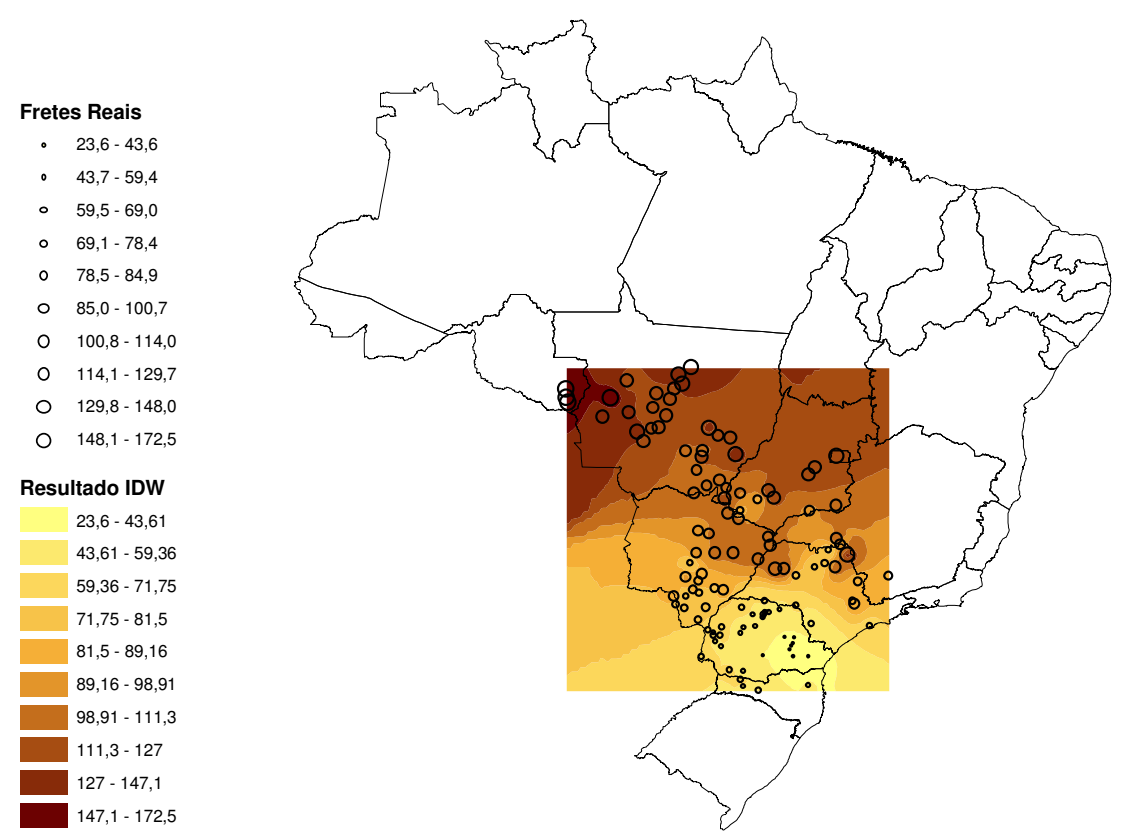

Figura 70. Resultado da interpolação por IDW dos fretes reais com origem no Porto de Paranaguá, sobrepostos pela distribuição dos valores reais dos fretes ambos legendados com a mesma classificação de valores.

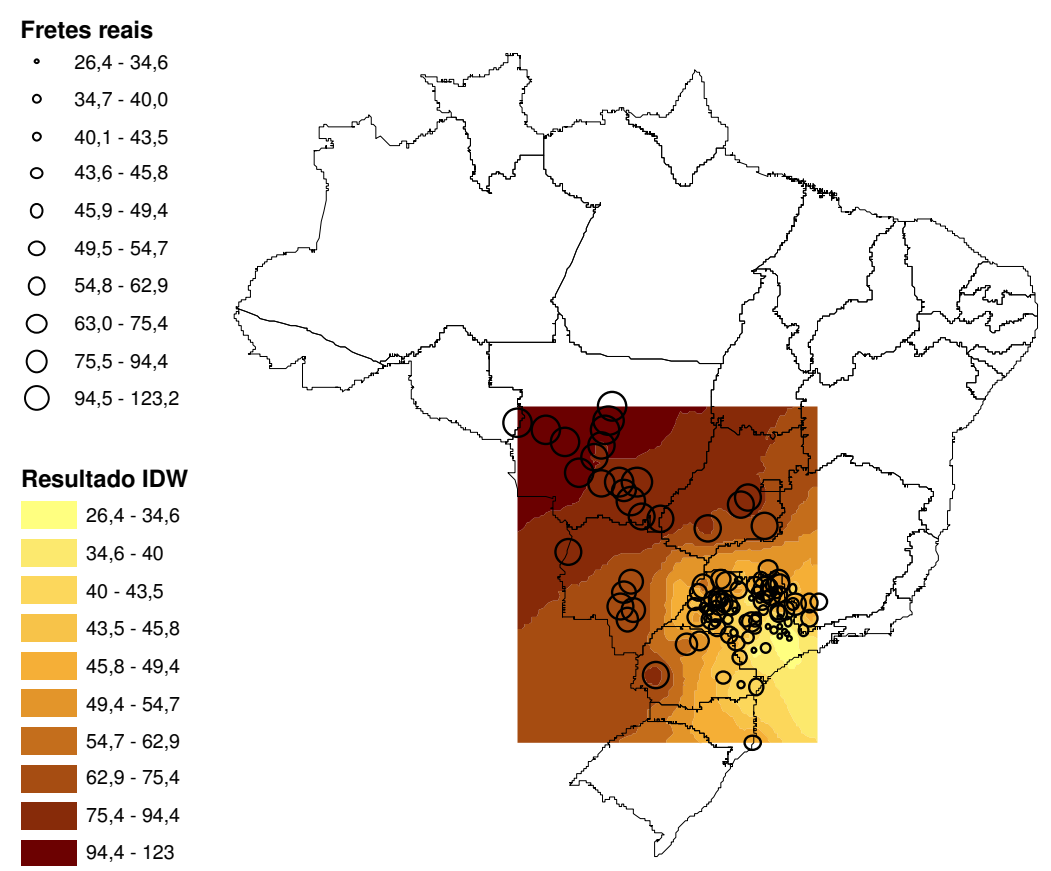

Figura 71. Resultado da interpolação por IDW dos fretes reais com origem no Porto de Santos/Cubatão, sobrepostos pela distribuição dos valores reais dos fretes ambos legendados com a mesma classificação de valores. 


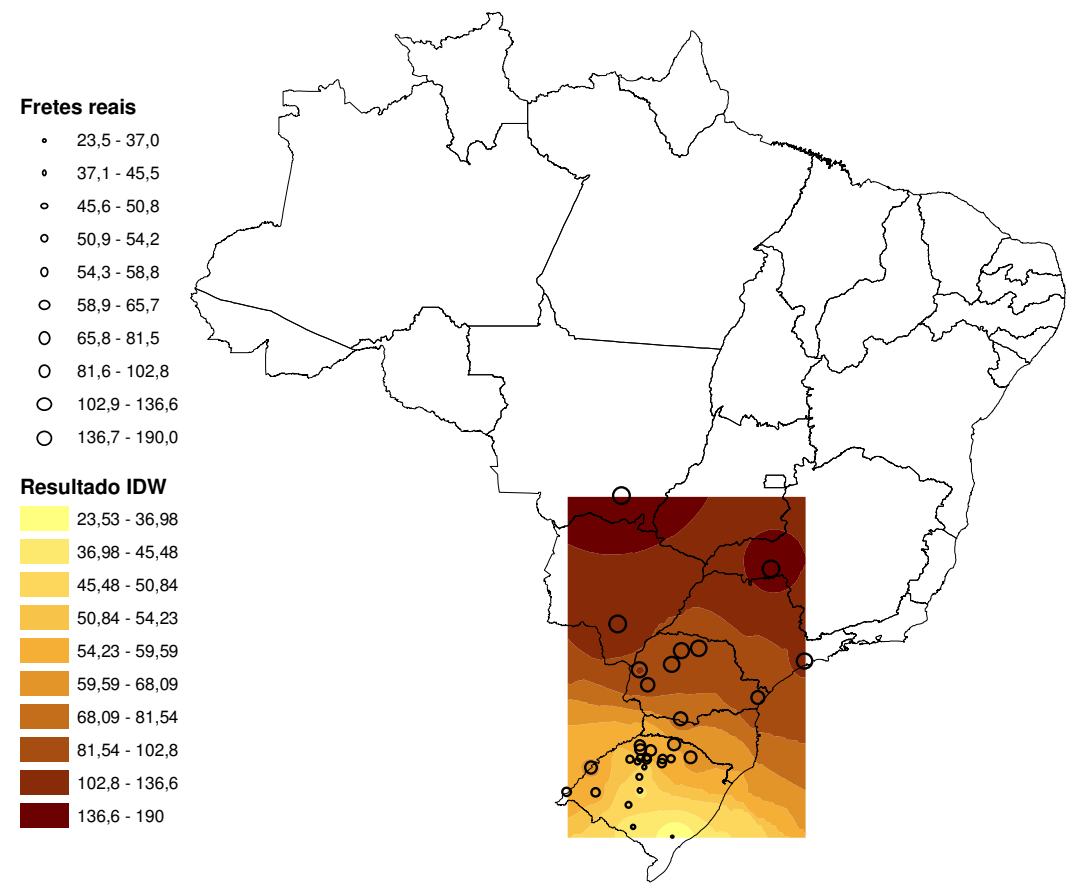

Figura 72. Resultado da interpolação por IDW dos fretes reais com origem no Porto de Rio Grande, sobrepostos pela distribuição dos valores reais dos fretes ambos legendados com a mesma classificação de valores.

Como pode ser notado nos mapas anteriormente apresentados, cada porto possui uma quantidade e distribuição diferente de dados de fretes reais. Por conta disso, a superfície (quadrante) do modelo dos interpoladores é diferente para cada um, tendo como limite os pontos mais extremos em cada caso.

Para se analisar as regiões de influência da cada porto foi necessário estabelecer uma região de abrangência comum entre os três portos. Para isso, foram estimados (preditos) valores, a partir do modelo de interpolação IDW de cada porto, para as sedes dos municípios fornecidas pelo IBGE, utilizando-se para esta predição, o limite da região sul do estado do Maranhão ao Norte, a região central de Rondônia ao Oeste, cobrindo todo o litoral até o ponto mais extremo ao sul do país.

Utilizando-se de ferramentas do ArcGIS, os preços estimados de fretes para todos estes pontos foram preditos a partir do modelo IDW de cada porto. Com estas informações, foi rodado novamente o interpolador IDW, obtendo-se os valores de 
maneira contínua para uma área em comum para os três corredores de transporte de fertilizantes.

Os resultados destes procedimentos são apresentados na seqüência (Figuras 73 a 75).

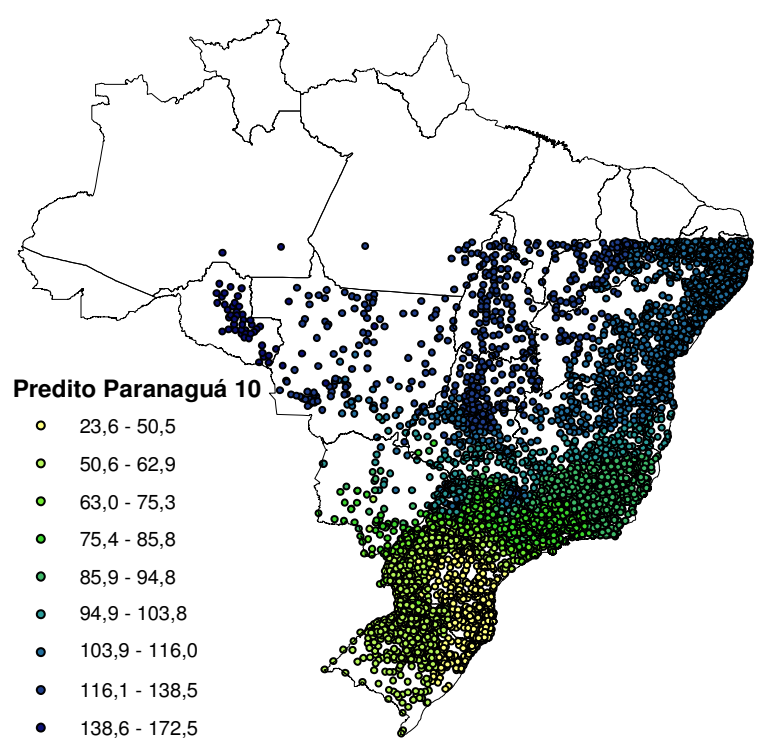

(a)

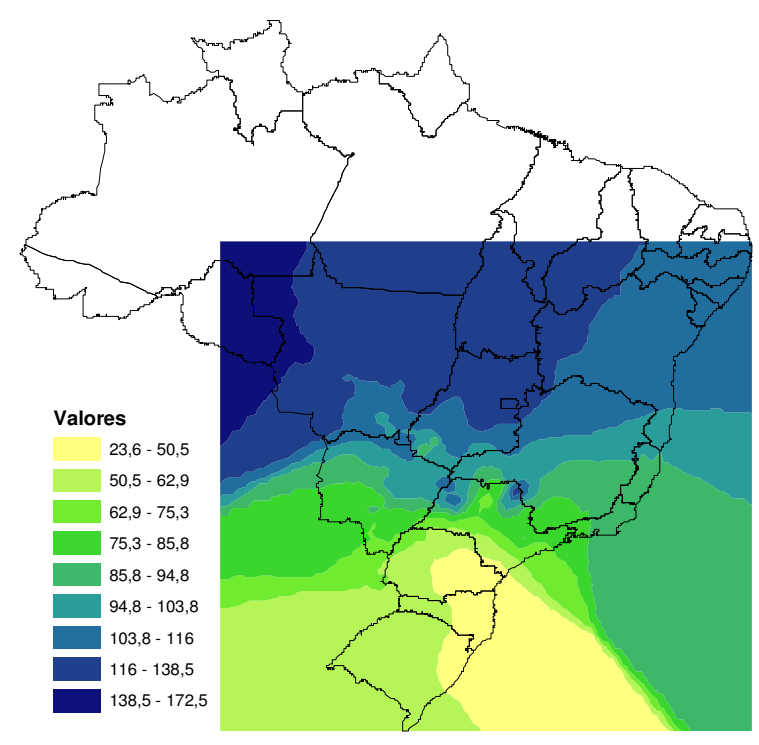

(b)

Figura 73. Predição dos valores a partir do modelo IDW para todas as sedes dos municípios para uma região delimitada (a) e superfície resultante da interpolação destes valores para o porto de Paranaguá (b). 


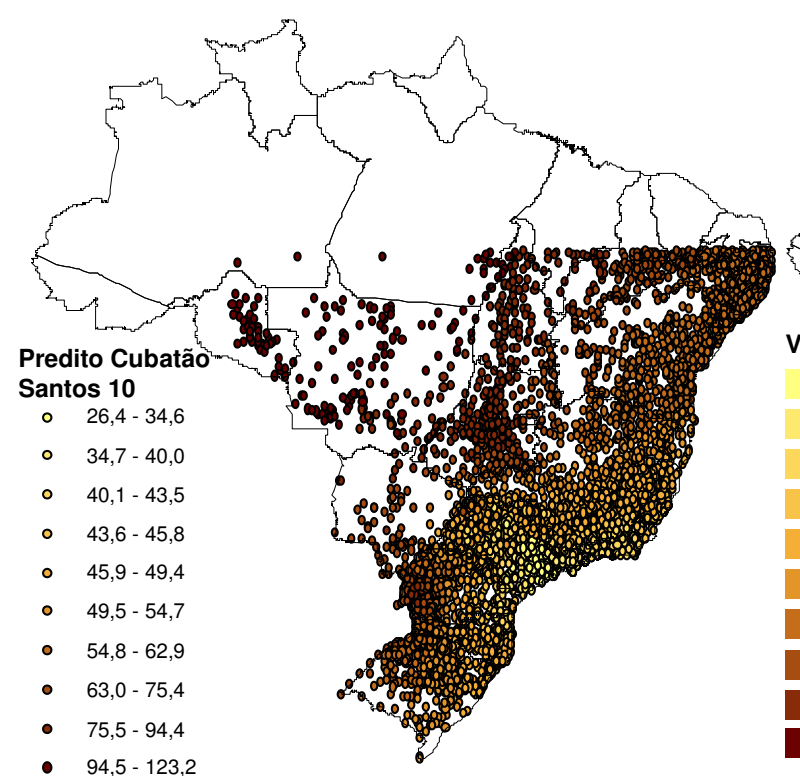

(a)

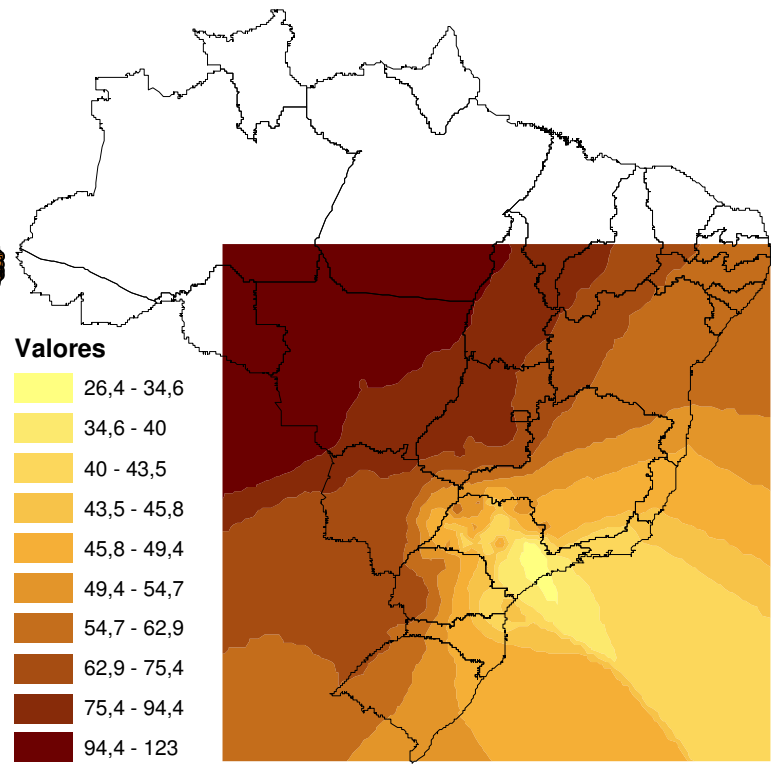

(b)

Figura 74. Predição dos valores a partir do modelo IDW para todas as sedes dos municípios para uma região delimitada (a) e superfície resultante da interpolação destes valores para o porto de Santos /Cubatão (b).

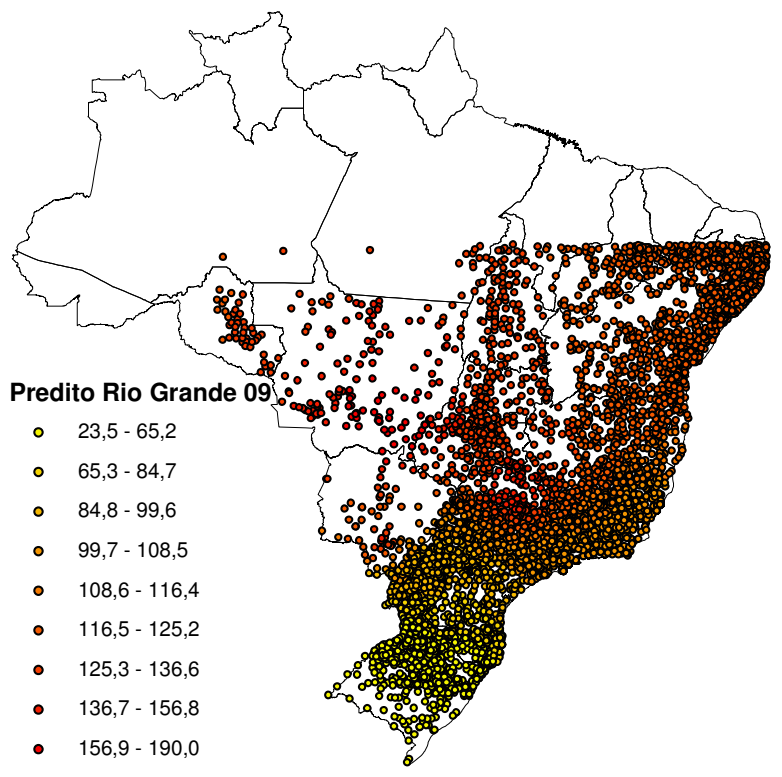

(a)

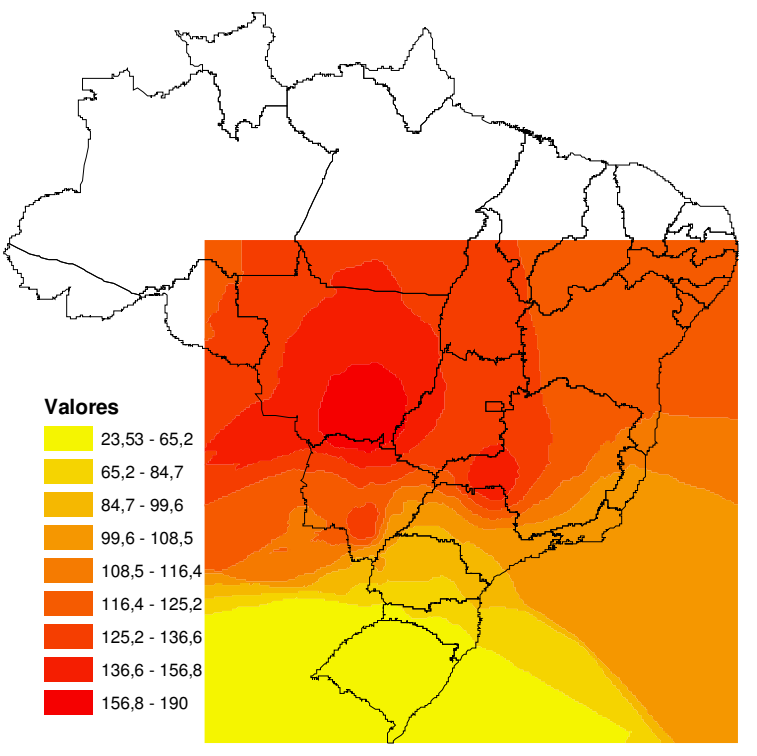

(b)

Figura 75. Predição dos valores a partir do modelo IDW para todas as sedes dos municípios para uma região delimitada (a) e superfície resultante da interpolação destes valores para o porto de Rio Grande (b). 
Após o procedimento, foi efetuado o cruzamento dos mapas utilizando a álgebra de mapas. Com isso obteve-se as regiões de influência dos fretes para os três portos. Ou seja, foram extraídas as áreas de menor preço de frete para os portos dentro da região anteriormente delimitada.

O mapa da figura 86 apresenta este resultado. A região em cinza está sob influência dos fretes (mais baixos) de Santos/Cubatão. A região em amarelo está sob influência dos fretes de Paranaguá e a região em azul estaria sob o domínio dos menores fretes de Rio Grande.

Nota-se que, apesar do estado de São Paulo contar com a rede de rodovias mais pedagiadas, ainda assim, os fretes partindo do porto de Santos são mais baixos que o dos demais. O Porto de Paranaguá, segundo este modelo, teria apenas um faixa de influência que iria do oeste do estado do Paraná ao nordeste de Rio Grande do Sul.

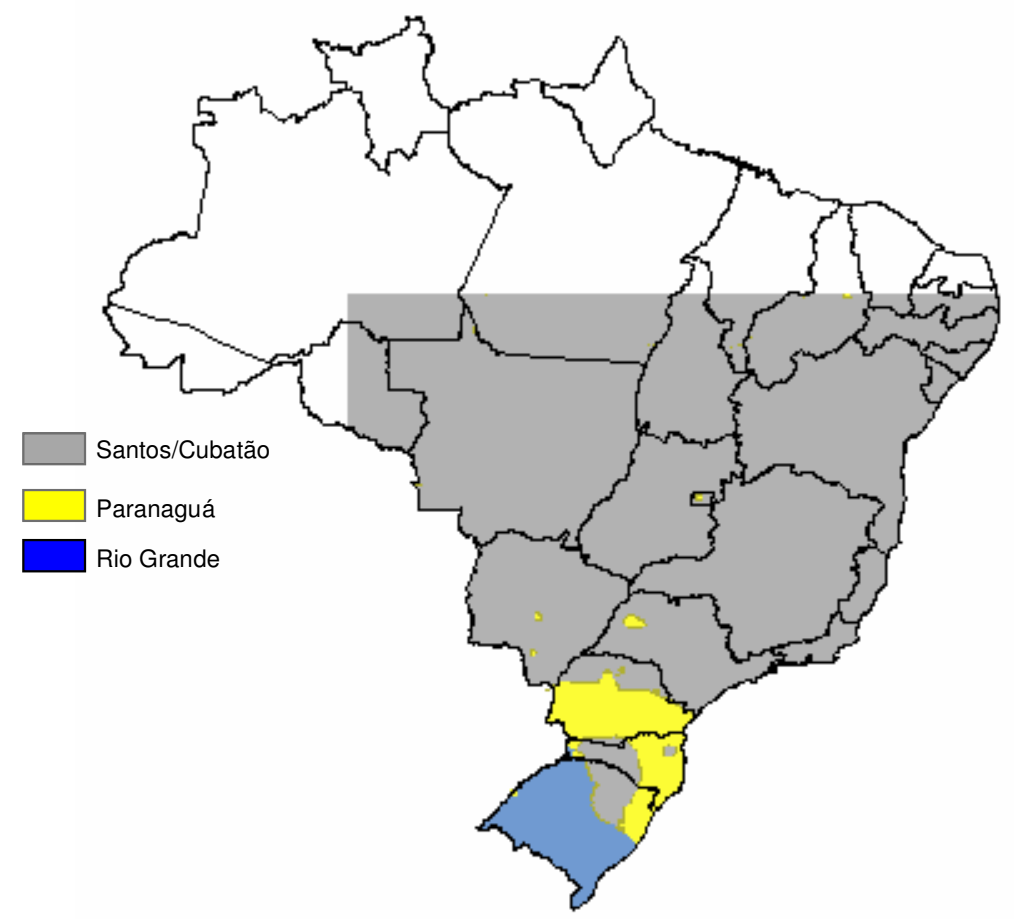

Figura 76. Resultado da álgebra de mapas pela qual foram extraídas as áreas de influência dos três portos de origem dos fertilizantes importados 
Uma outra forma de visualizar o comportamento dos fretes de cada porto é por meio de isolinhas.

$\mathrm{Na}$ Figura 77, as isolinhas de fretes do porto de Santos mostram que o comportamento crescente do fretes se dá na direção da região do centro-oeste, mais precisamente, na direção do Mato Grosso, principal consumidor de fertilizantes do país. O valor do frete para Rondonópolis, partindo dessa origem é de $R \$ 95,40$. Indo para o sul do país, os preços não se distanciam tão rapidamente dos valores do estado de São Paulo.

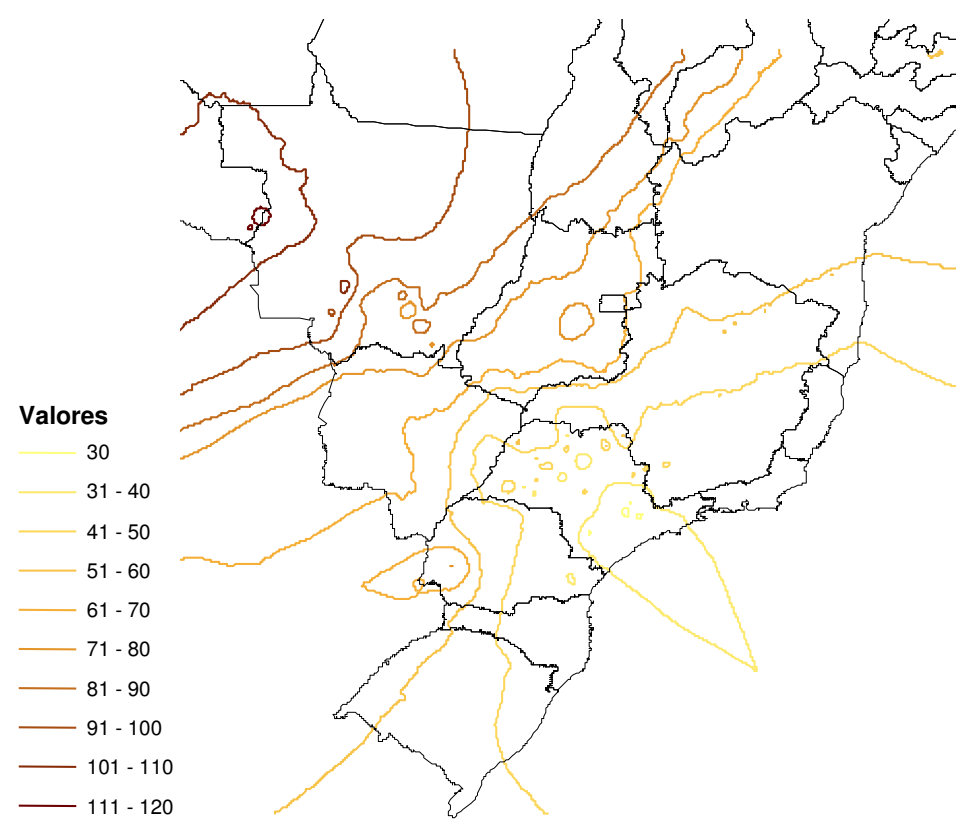

Figura 77. Isolinhas de fretes partindo de Santos

No caso de Paranaguá, os fretes apresentam crescimento, tanto no sentido do centro-oeste quanto para o norte do país. Isto em Rondonópolis, apesar da maior distância percorrida em comparação a Santos-Rondonópolis, o preço do frete chega a $R \$ 96,40$, apenas $R \$ 1$ a mais que no outro corredor. Nota-se portanto, que os fretes com origem em Santos elevam-se com maior velocidade que os originados em Paranaguá. Isto traz certo risco para a competividade das importações com origem em Santos (Figura 78). 


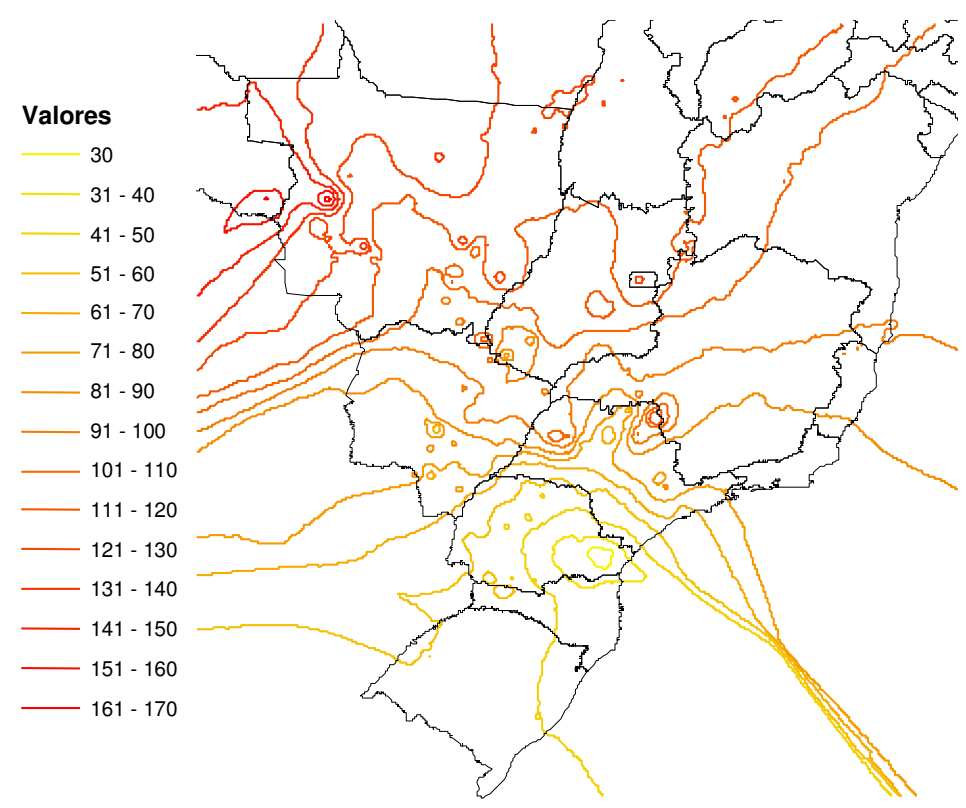

Figura 78. Isolinhas de fretes partindo de Paranaguá

Para o porto de Rio Grande, o crescimento dos preços dos fretes toma a direção norte, comportando-se praticamente de forma linear até o norte do estado de São Paulo (Figura 79). A partir de então, há uma elevação dos preços mais acentuada no sentido do estado do Mato Grosso. Em Rondonópolis, segundo o modelo, o frete chega a $R \$ 189,80$.

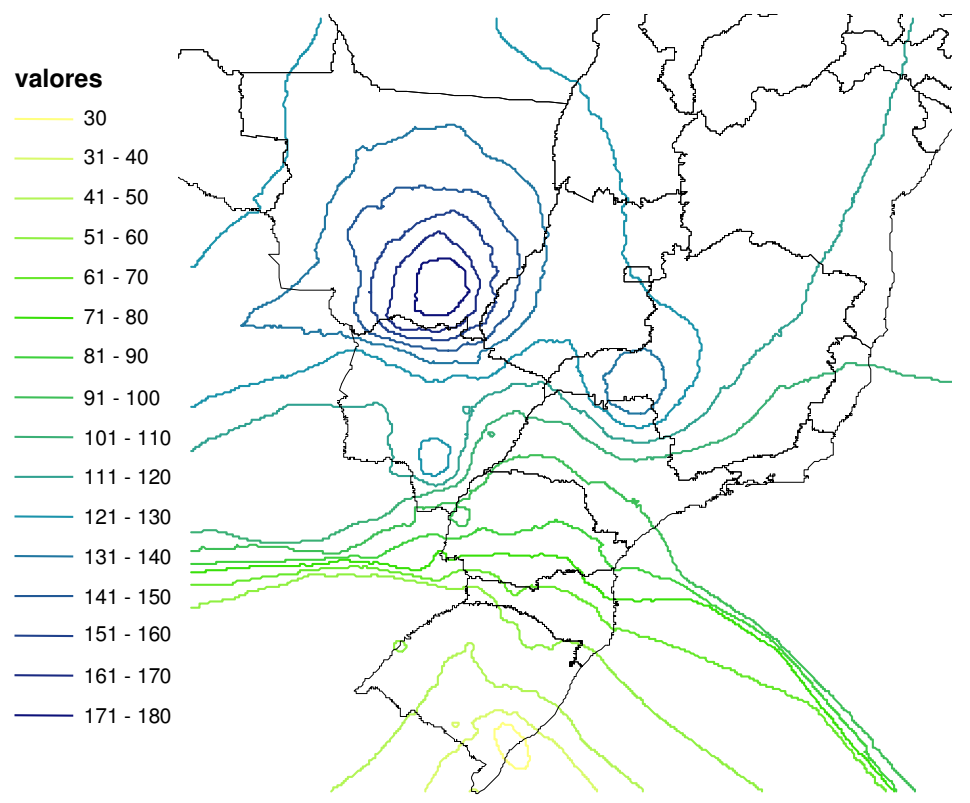

Figura 79. Isolinhas de fretes partindo de Rio Grande 
Para demonstrar o comportamento dos fretes, foi utilizada a técnica do perfil longitudinal, comumente utilizado na topologia, para criar curva que demonstrem o comportamento dos preços dos fretes em relação à distância, para os três portos, chegando a um mesmo destino, no caso, o município de Rondonópolis no Mato Grosso.

Os cortes feitos sobre o modelo de elevação (interpolação IDW) dos fretes reais, mostram os diferentes comportamentos dos preços dos fretes de cada porto, no que tange a velocidade (relação do preço em função da distância) a qual estes aceleram em direção ao destino.

Partindo de cada um dos três portos do estudo, foram traçadas três rotas rodoviárias até o município de Rondonópolis, no sul do estado do Mato Grosso, como mostra a Figura 80.

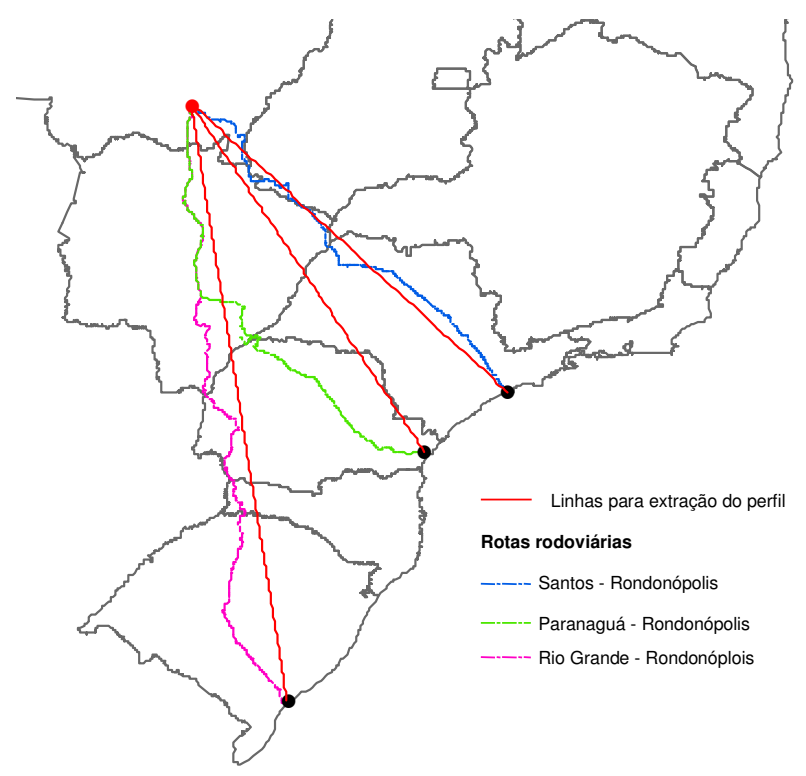

Figura 80. Rotas e retas para extração do perfil dos preços dos fretes por corredor

As Figuras 81, 82 e 83 mostram os perfis criados a partir das rotas entre os portos e Rondonópolis, utilizando-se a extensão 3D Analyst do ArcGIS. 
A Figura 81 mostra o perfil dos fretes entre a rota de Santos/Cubatão e Rondonópolis. Com o perfil é possível notar que existe, próximo do porto, um comportamento errático do modelo. Partindo da origem, os valores de fretes acabam recuando, o que não condiz com um comportamento real dos fretes rodoviários. Até a região central do estado de São Paulo, os preços reais dos fretes variam muito para distâncias semelhantes. Isto deve ocorrer em função da distribuição diferenciada dos pedágios em rodovias estaduais, municipais e estaduais próximas do porto.

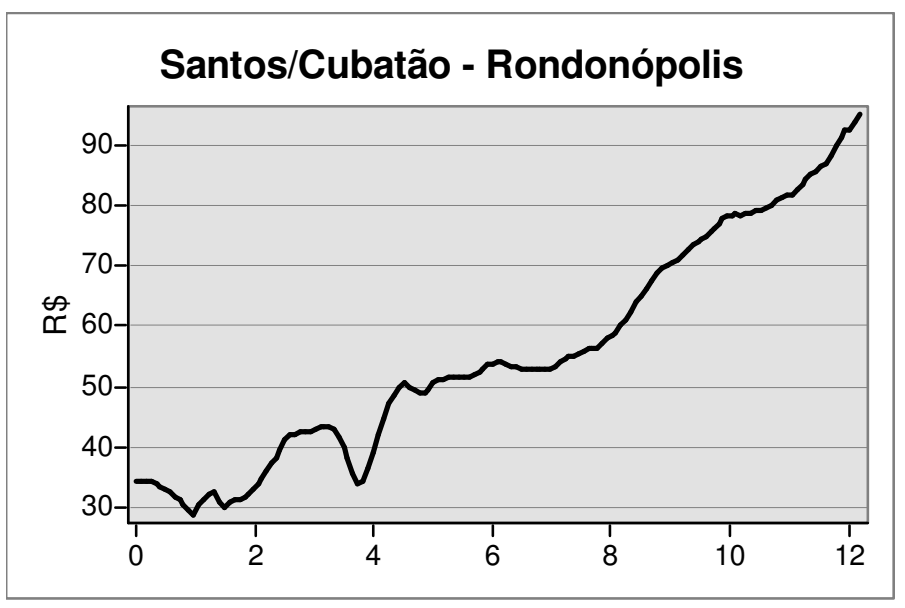

Figura 81. Perfil dos preços do frete entre o porto de Santos e Rondonópolis sobre a rota rodoviária

No caso do porto de Paranaguá (Figura 82) ocorre o mesmo problema que no porto de Santos: em pequenas distâncias os valores reduzem, o que não condiz com a realidade. É possível verificar que os fretes sobem de maneira mais acentudada até metade do caminho aproximadamente, e depois o acréscimo acaba sendo menor, fazendo com que, em distâncias maiores, os valores de Santos e Paranaguá fiquem bastante próximos.

Pouco antes de Rondonópolis o modelo apresenta elevação dos fretes, recuando novamente até chegar ao valor de chegar ao valor de $R \$ 96,00$ em Rondonópolis. Esta elevação é resultado do preço de frete real de $R \$ 125,00$ em Alto Taquari, município que se posiciona na rota entre os dois pontos e acaba causando uma elevação no modelo nesta região. 


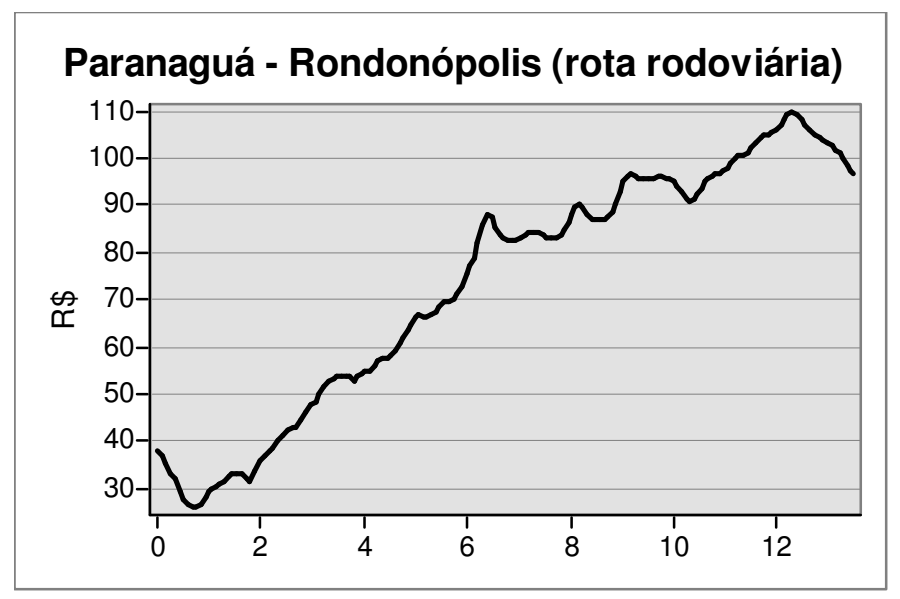

Figura 82. Perfil dos preços do frete entre 0 porto de Paranaguá e Rondonópolis sobre a rota rodoviária

Para a rota Rio Grande - Rondonópolis (Figura 83), o comportamento é bastante estável. A redução do frete a partir do terceiro terço do trecho mostra uma inconsistência do modelo, provavelmente por conta da ausência de dados de preços reais de fretes que esta rota apresenta nesta região, entre o sul do Mato Grosso do Sul e o município de Rondonópolis.

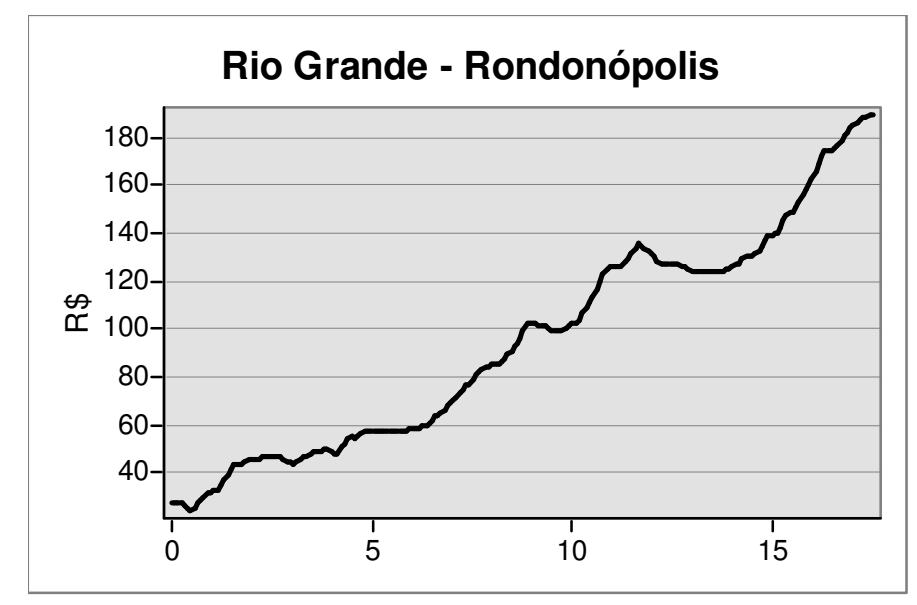

Figura 83. Perfil dos preços do frete entre o porto de Rio Grande e Rondonópolis sobre a rota rodoviária

Depois de criados os modelos de fretes dos três portos, os preços dos fertilizantes MAP, $\mathrm{KCl}$ e Uréia nos portos foram somados a eles para se obter uma grade de indicadores de fretes para os três produtos com origem nos três portos. 
Para este procedimento, foram criadas malhas de mesmo quadrante e tamanho de pixel com valores constantes correspondentes aos preços do fertilizante no porto. Estas malhas foram somadas aos modelos de fretes por meio da álgebra de mapas, tendo como resultado os mapas de indicadores de preços de fertilizantes importados para toda a região de interesse. A partir disso foram feitas novamente as extrações das áreas de influência dos portos.

A Figura 84 mostra as áreas de influência dos portos na importação do fertilizante MAP. A região mais escura corresponde a área de influência de Santos, o tom médio corresponde a Paranaguá e o branco a Rio Grande.

Nota-se que a configuração espacial muda totalmente quando são adicionados os preços dos fertilizantes ao modelo de fretes. Santos acaba perdendo toda a sua influência, no principal estado consumidor de fertilizantes, o Mato Grosso. Até mesmo parte do estado de São Paulo passa a ser influenciado pelos baixos preços de Paranaguá.

O estado do Rio Grande do Sul continua sob influência do porto de Rio Grande. A região em branco ao norte de Mato Grosso, que estaria sob influência e Rio Grande, na verdade representa um problema do modelo. Como visualizado nas curvas de nível, a partir de Rondonópolis, as curvas de nível dos fretes de Rio Grande passam a recuar. Isto indica uma dificuldade do modelo para estimar pontos muito distantes do quadrante formado pelos pontos mais distantes de fretes reais. Muito provavelmente esta região continua sendo dominada pelo Porto de Paranaguá, ou do fertilizante que entra pelos portos da região norte do país.

As regiões pontuais de características opostas às regiões vizinhas, no norte de São Paulo e no centro de Mato Grosso também mostram problemas relacionados a pontos destoantes de fretes reais nestas regiões, que acabam causando falhas nas estimativas. Dificilmente a região no entorno de Brasília ou os pontos esparsos no estado do Mato Grosso seriam regiões de influência diferente do seu arredor. 


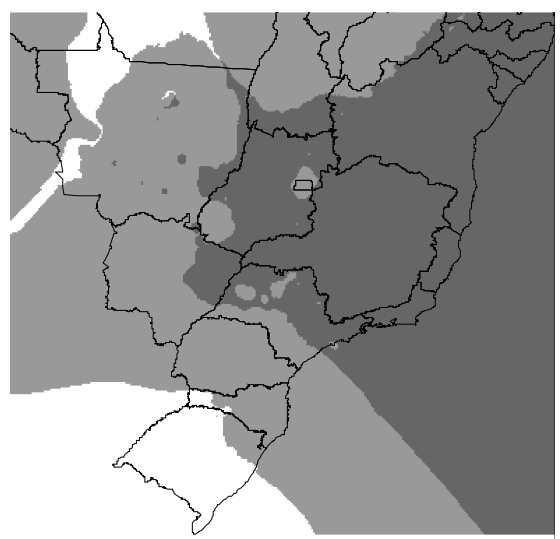

Figura 84. Área de influência dos portos para o fertilizante MAP (escura: Santos, média: Paranaguá e branco: Rio grande)

$\mathrm{Na}$ Figura 85, estão representadas as áreas de influência dos portos na importação de Uréia. A configuração um pouco diferenciada do mapa de MAP está relacionada aos preços do fertilizante no mercado internacional e dos custos marítimos que participam de sua formação, já que os portos de origem dos três fertilizantes são diferentes.

Neste caso, a área de influência de Santos ocupa uma região maior no nordeste do estado do Mato Grosso.

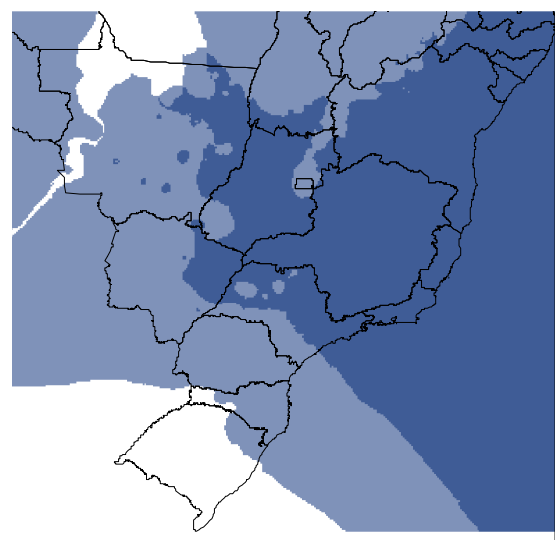

Figura 85. Área de influência dos portos para o fertilizante Ureia (mais escura: Santos, médio: Paranaguá e branco: Rio Grande) 
Para $\circ \mathrm{KCl}$ também ocorrem as pequenas alterações na configuração das áreas de influência dos portos por conta da origem do produto, que é adquirida em Vancouver no Canadá. Também são notadas as mesmas falhas pontuais no centro do Mato Grosso, Noroeste de São Paulo e arredores de Brasília.

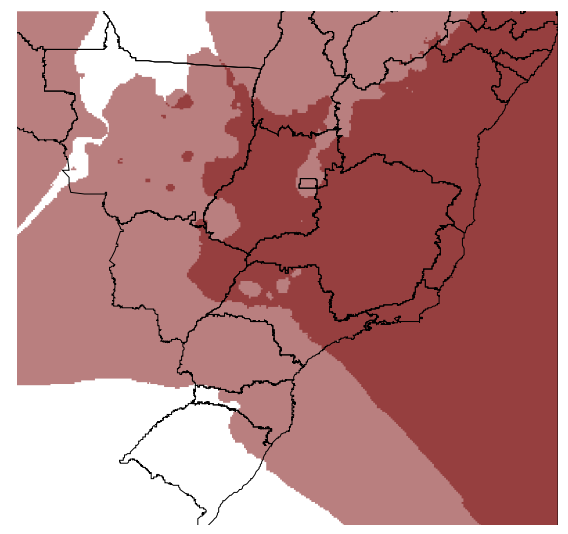

Figura 86. Área de influência dos portos para o fertilizante $\mathrm{KCl}$ (escura: Santos, médio: Paranaguá e branco: Rio Grande)

Se examinados os dados de importação de fertilizantes divulgados pelo Secex, é possível concluir que os custos de importação de Santos influenciam negativamente sua competitividade em relação especificamente ao Porto de Paranaguá.

Isto fica evidente na Figura 87, que mostra as exportações de soja entre 2000 e 2011 pelos principais portos que o Porto de Santos é o maior exportador de soja do país, originada principalmente do estado de Mato Grosso. 


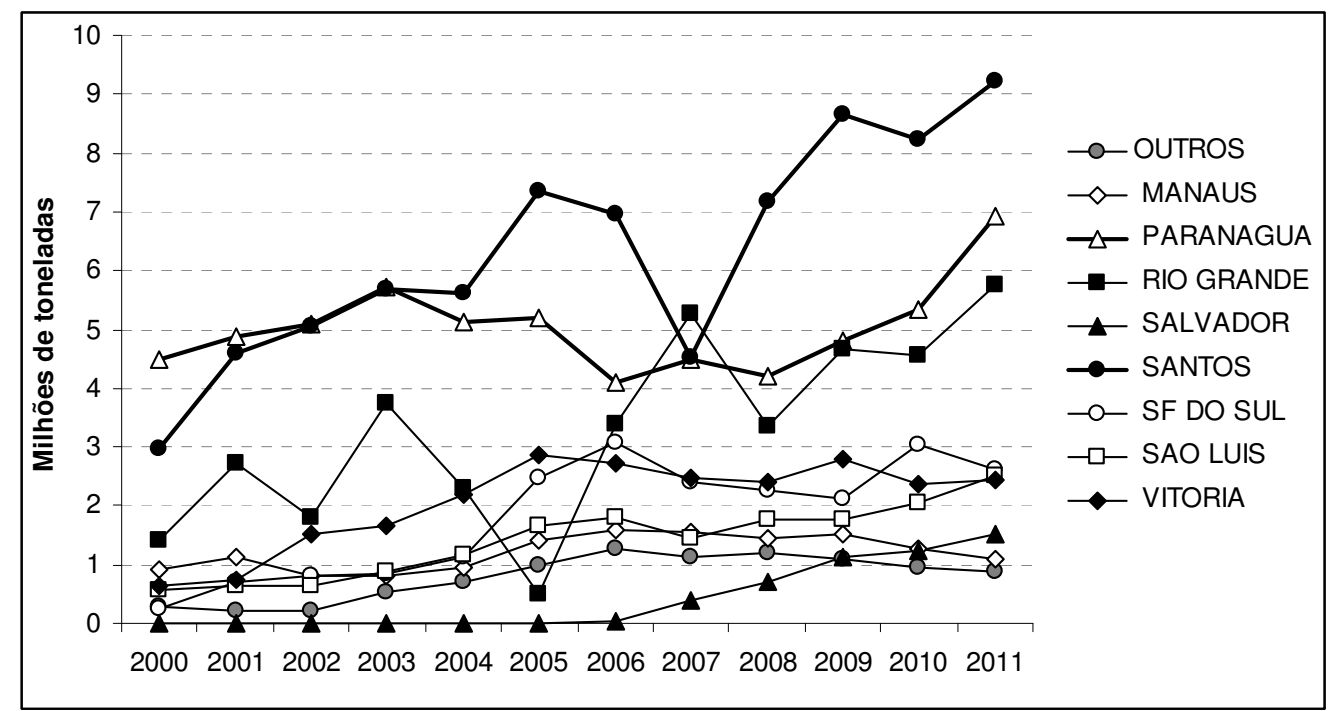

Figura 87. Evolução do volume exportado de soja pelos principais portos. Fonte: Secex. Elaboração do autor

Se pensarmos que os fertilizantes podem ser fretes de retorno da soja, o porto de Santos perde mercado em relação à Paranaguá por conta de suas maiores tarifas de importação. A Figura 88 mostra o volume importado de fertilizantes pelos principais portos entre 2000 e 2011.

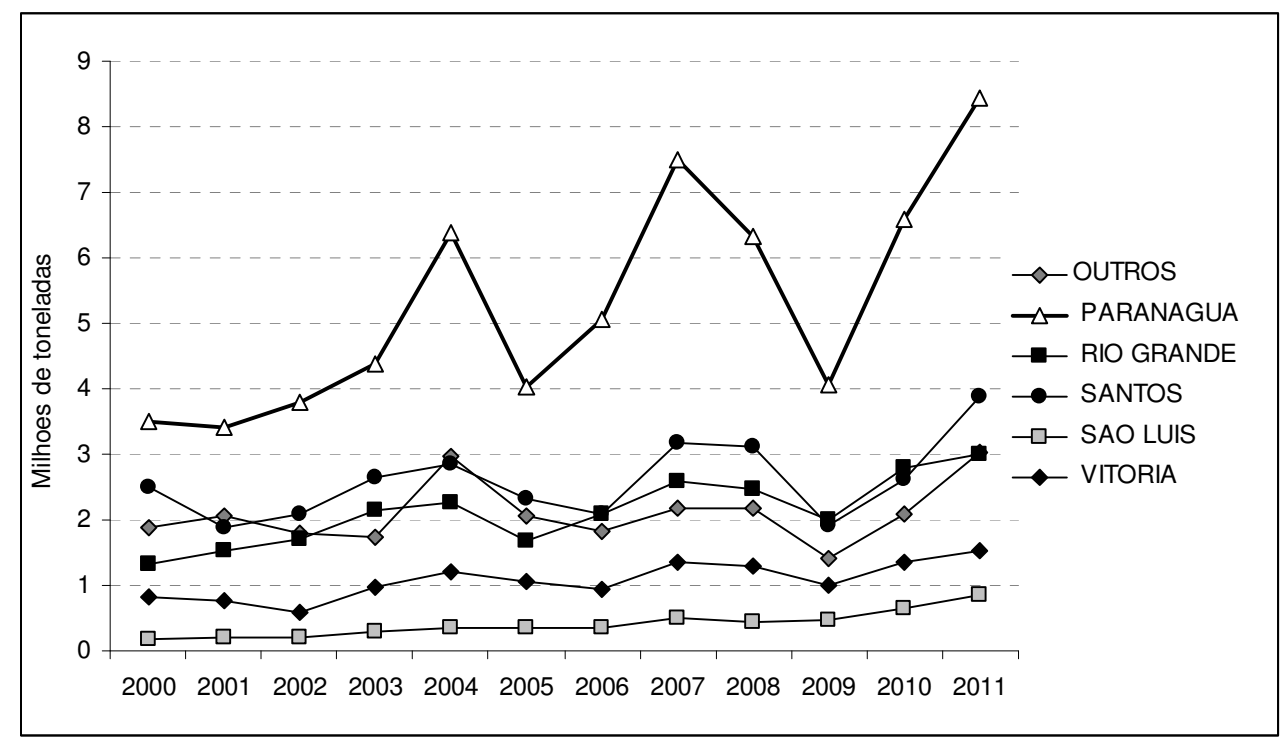

Figura 88. Evolução do volume importado de fertilizantes pelos principais portos Fonte: Secex. Elaboração do autor 
Relacionados o volume importado de fertilizantes com o volume exportado de soja pelos portos de Paranaguá e Santos vemos que no último, a importação de adubos significa apenas $32 \%$, em 2011 , da exportação de soja enquanto que em Paranaguá, a importação de fertilizantes corresponde, em 2011, a 123\% da exportação de soja, sendo que em alguns anos o volume desembarcado de fertilizantes naquele porto superou o embarque de soja em porcentagem.
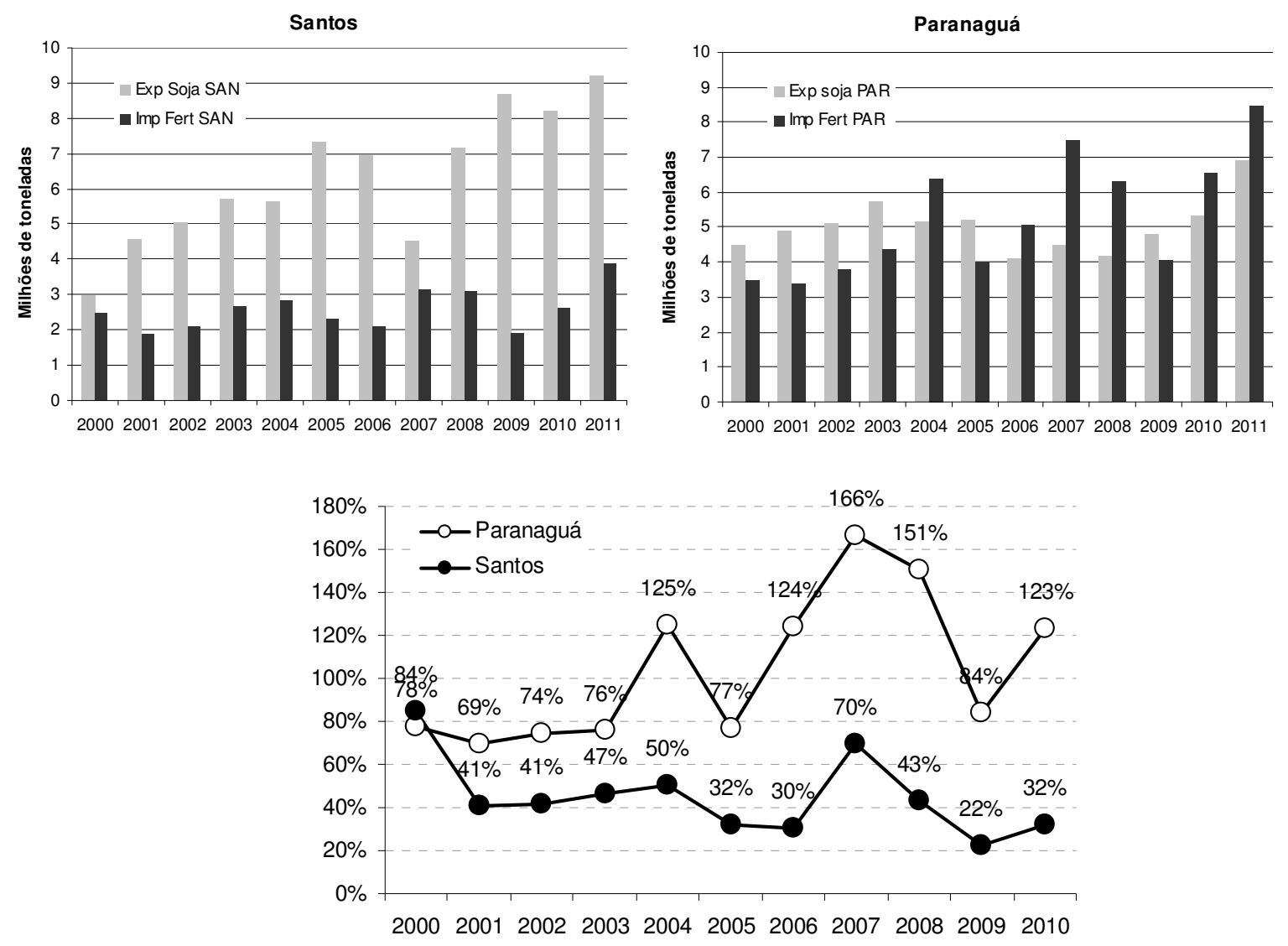

Figura 89. Evolução do volume importado de fertilizante e exportado de soja em Santos e Paranaguá e relação importação de fertilizantes e exportação de soja.

Fonte: Secex. Elaboração do autor

Se considerados demais grãos como milho, por exemplo, que tem aumentado suas exportações nos últimos anos, e açúcar, produto tradicionalmente embarcado por Santos por conta da localização geográfica da cadeia de produção, a situação 
do porto de Santos fica ainda mais dissonante. Este porto é a maior porta de saída das cargas de milho e açúcar do país, sendo que a grande parte desta carga ainda é transportada por caminhões, apesar de ser crescente a entrada do modal ferroviário nestes segmentos. Estas são cargas passíveis de fornecer veículos para o frete de retorno do fertilizante (mais barato que o frete sem retorno), no entanto, os desembarques de fertilizantes continuam a prevalecer em Paranaguá, apesar da distância da região consumidora (áreas agrícolas do Centro-oeste do país, onde também se encontra a grande parte das misturadoras de adubos).

\subsection{SIMULAÇÕES SOBRE OS PREÇOS DOS FRETES POR MEIO DE SIMULAÇÃO ESTOCÁSTICA (TURNING BANDS)}

Para simular alterações nos valores dos preços dos fretes e o impacto na configuração das áreas de influências dos portos, foi tomado como base os preços simulados a partir do método Turning Bands. Para as simulações foram usados os valores mínimos e máximos das simulações para os três portos.

Tais valores foram extraídos das duas grades simuladas pelo mecanismo para os três portos para os mesmos pontos de destino dos dados originais, os mesmos utilizados nas regressões, krigagem e interpolações.

A Figura 90 mostra os dados reais de fretes do porto de Santos e os menores valores obtidos através da simulação por Turning Bands para os mesmos pontos. Em média, os valores obtidos pelo TB ficaram $26 \%$ menores que os valores originais. No entanto, o desvio padrão dos valores simulados foi menor que o desvio dos dados reais. O primeiro foi de 8,9 contra 21,76 do segundo. Com isso, observase que os valores tiveram maior diferença a partir da distância de $1.000 \mathrm{~km}$. 


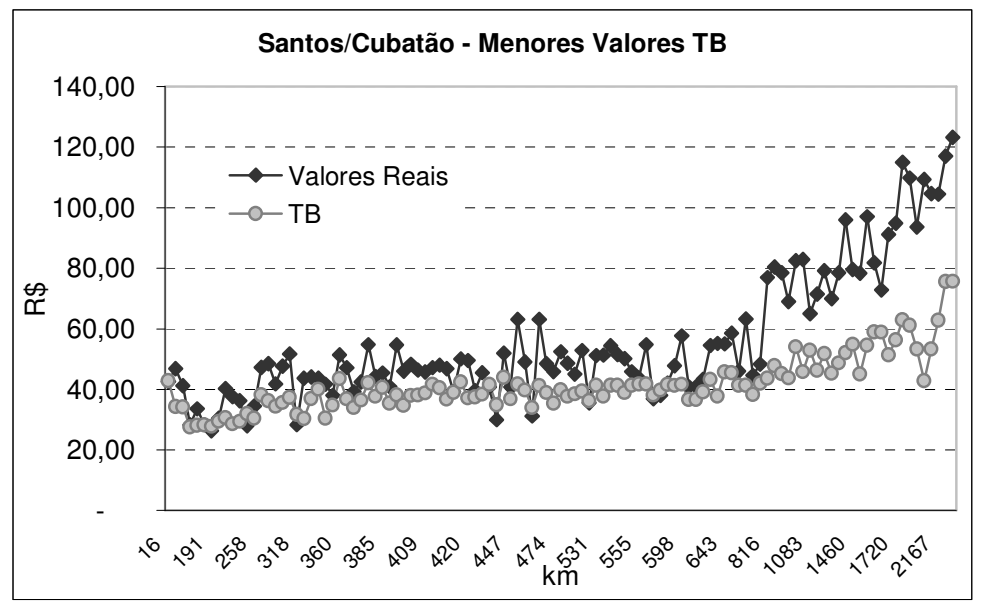

Figura 90. Diferença entre os valores reais de fretes e os menores valores obtidos com a simulação do TB para o Porto de Santos

Para os maiores valores simulados, o frete médio ficou 33\% superior que o valor médio dos fretes reais. O desvio padrão foi de 23,36 dos valores simulados contra 21,76 dos valores reais. As maiores diferenças entre os valores reais e os simulados ficam entre 400 e $1.700 \mathrm{~km}$. Isso pode ser observado na Figura 91.

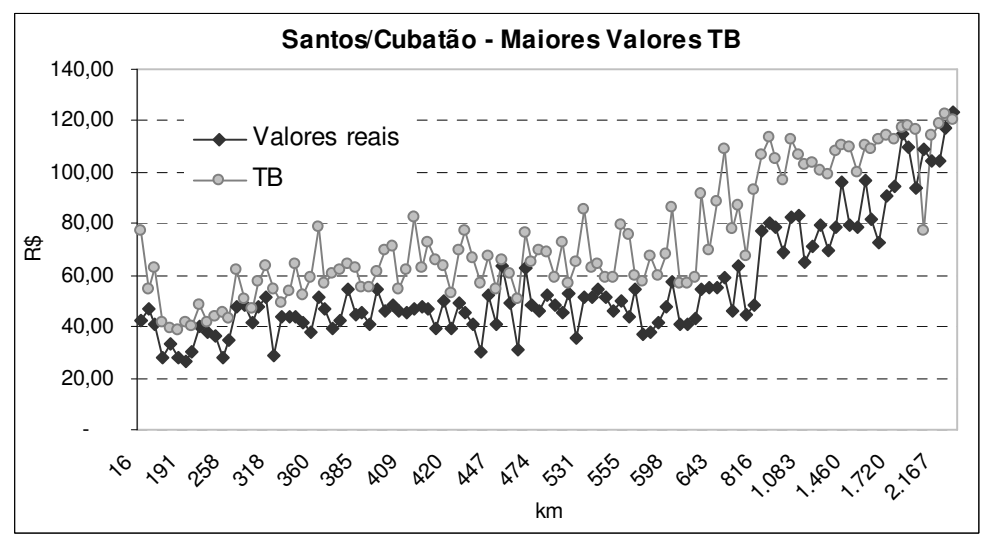

Figura 91. Diferença entre os valores reais de fretes e os maiores valores obtidos com a simulação do TB para o Porto de Santos

No caso do Porto de Paranaguá, a média dos menores valores obtidos através do TB foi $19 \%$ menor que a dos dados reais. As maiores diferenças entre os preços estão entre as distâncias médias, segundo a simulação do TB (Figura 92). 


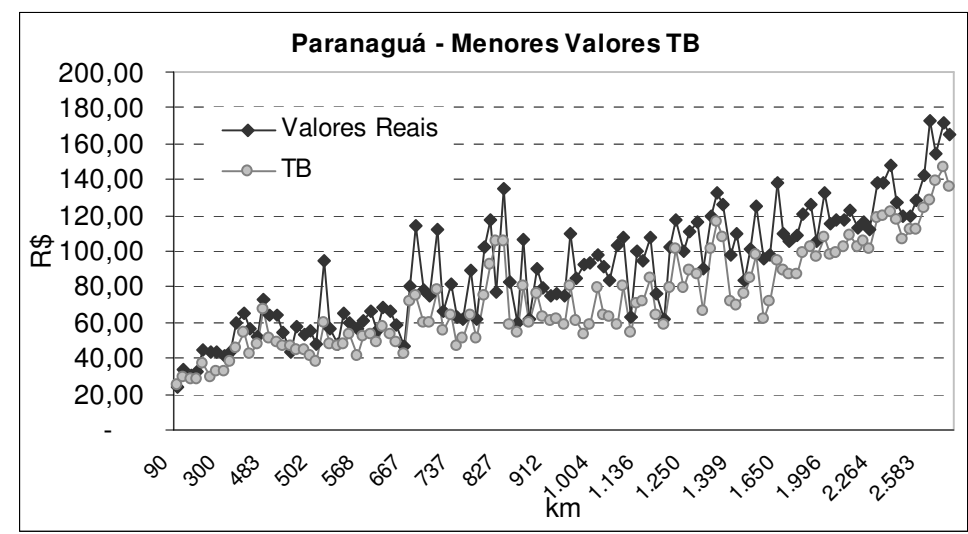

Figura 92. Diferença entre os valores reais de fretes e os menores valores obtidos com a simulação do TB para o Porto de Paranaguá

No caso das maiores valores simulados pelo Turning Bands para o porto de Paranaguá, mostrados na Figura 93, as diferença média entre os valores reais e simulados foi de $20 \%$, com desvio de 31,9 em relação a um desvio de 32,8 para os dados reais.

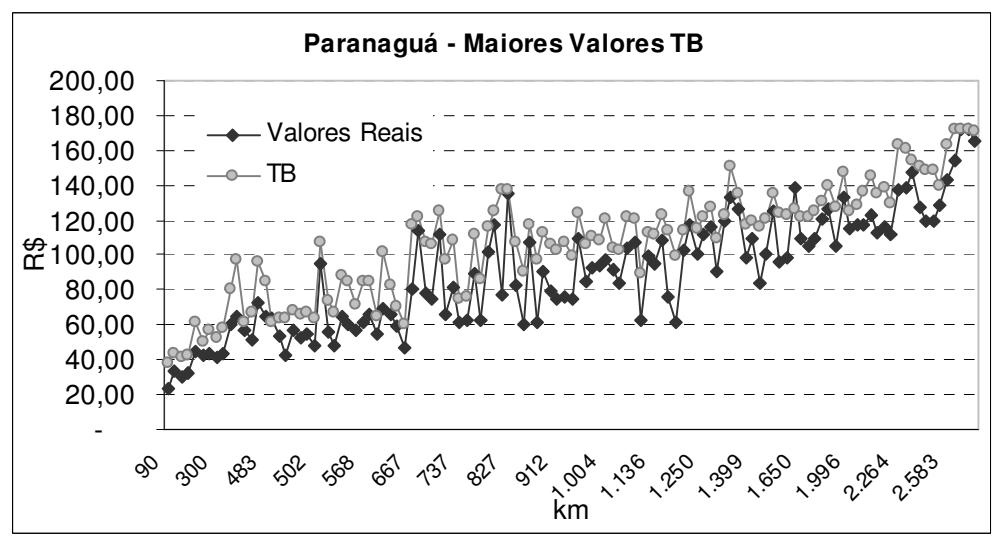

Figura 93. Diferença entre os valores reais de fretes e os maiores valores obtidos com a simulação do TB para o Porto de Paranaguá

A média dos valores mínimos das simulações do Turning Bands para o porto de Rio Grande foi de $\mathrm{R} \$ 62,00,15 \%$ menor que a média dos preços reais, como mostra a Figura 94. O desvio dos dados resultantes da simulação foi de 24,4 frente a um desvio de 34,9 para os dados reais. De acordo com o modelo, a diferença entre os valores reais e simulados começa a ser mais forte após distâncias $950 \mathrm{Km}$. 


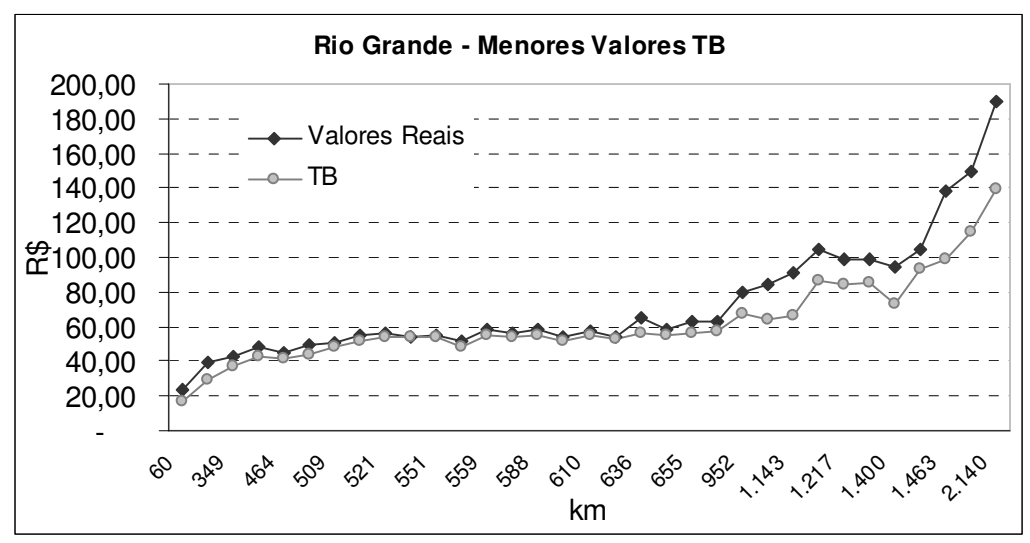

Figura 94. Diferença entre os valores reais de fretes e os menores valores obtidos com a simulação do TB para o Porto de Rio Grande

Os valores máximos das simulações do TB para Rio Grande tiveram média de $\mathrm{R} \$ 84,00,16 \%$ acima da média dos dados reais. O desvio padrão dos valores simulados foi de 40,9 contra 34,9 dos dados reais. A Figura 95 mostra as diferenças entre os valores reais e TB em Rio Grande.

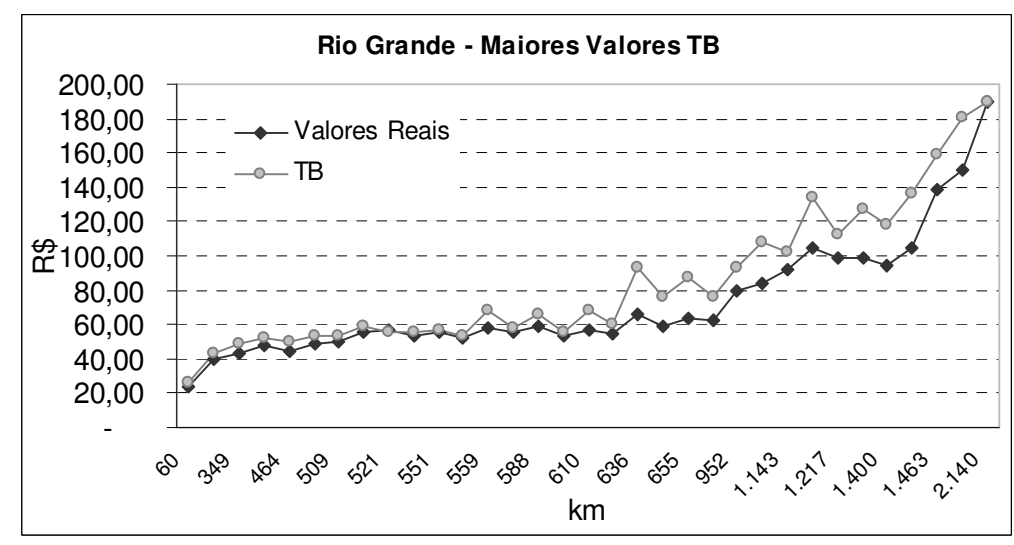

Figura 95. Diferença entre os valores reais de fretes e os maiores valores obtidos com a simulação do TB para o Porto de Rio Grande

A partir de destes dados, o mesmo procedimento para as análises por IDW foram tomadas. Ou seja, com estes valores mínimos e máximos foram interpoladas malhas por IDW, novos valores para um quadrante maior baseado nas sedes dos municípios IBGE foram preditos e as operações de álgebra entre os mapas foram elaboradas para extração das áreas de influência. 
A Figura 96 apresenta o resultado da interpolação por IDW dos menores valores fornecidos para cada ponto pela simulação Turning Bands para o porto de Santos. O menor valor, de menor distância em relação ao porto foi de $R \$ 27,60$ e o maior foi de $\mathrm{R} \$ 75,70$.

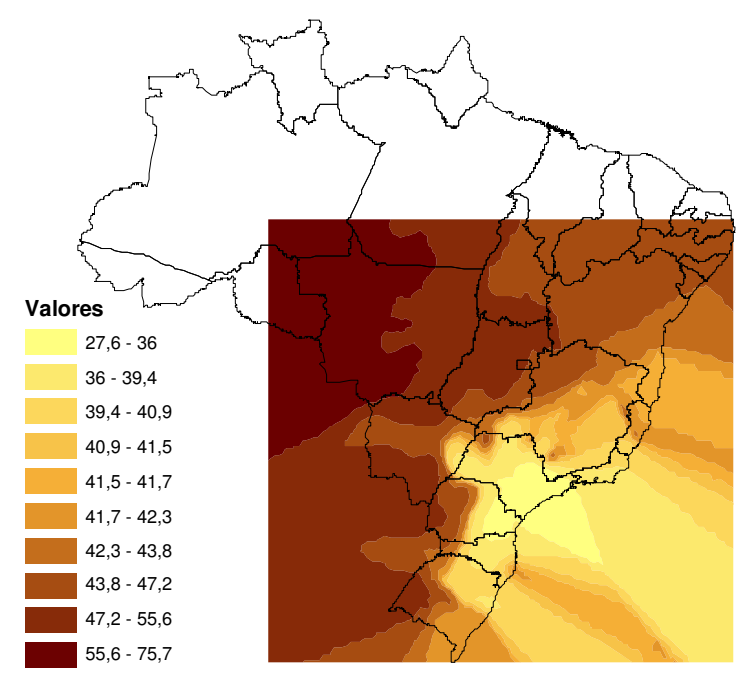

Figura 96 Resultado da interpolação por IDW dos menores valores fornecidos pela simulação Turning Bands para o porto de Santos.

A Figura 97 mostra o resultado da interpolação por IDW dos maiores valores fornecidos para cada ponto pela simulação Turning Bands para o porto de Santos. Neste caso, o frete mais baixo foi de $R \$ 38,5$ e o mais alto de $R \$ 122,60$.

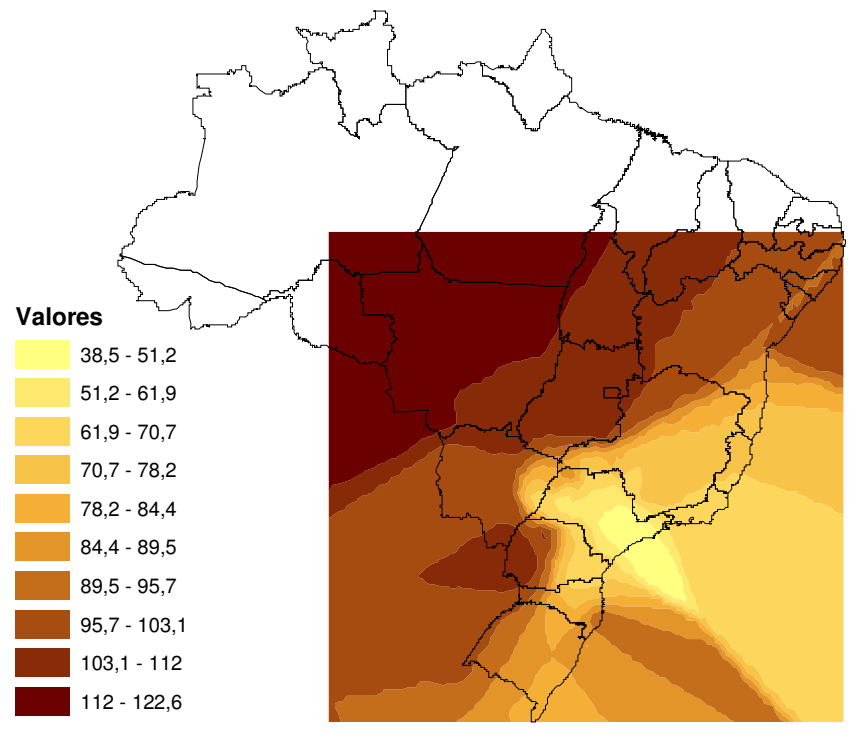

Figura 97 Resultado da interpolação por IDW dos maiores valores máximos fornecidos pela simulação Turning Bands para o porto de Santos. 
Para o porto de Rio Grande, o menor valor obtido após a simulação por TB foi $R \$ 17,20$ e o maior foi $R \$ 139,80$. A Figura 98 mostra o resultado da interpolação por IDW para os menores valores extraídos da simulação TB para este porto.

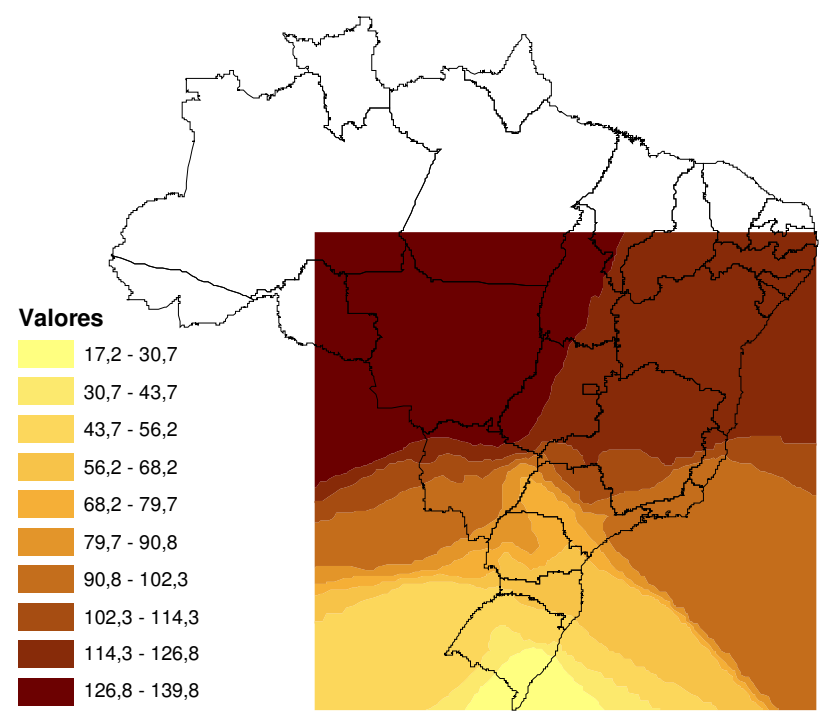

Figura 98. Resultado da interpolação por IDW dos menores valores fornecidos pela simulação Turning Bands para o porto de Rio Grande.

O resultado obtido com a interpolação dos maiores valores da simulação TB para o porto de Rio Grande é mostrada na Figura 99. Neste caso, os menores valores encontrados foram de $R \$ 26,10$ e os maiores de $R \$ 189,90$.

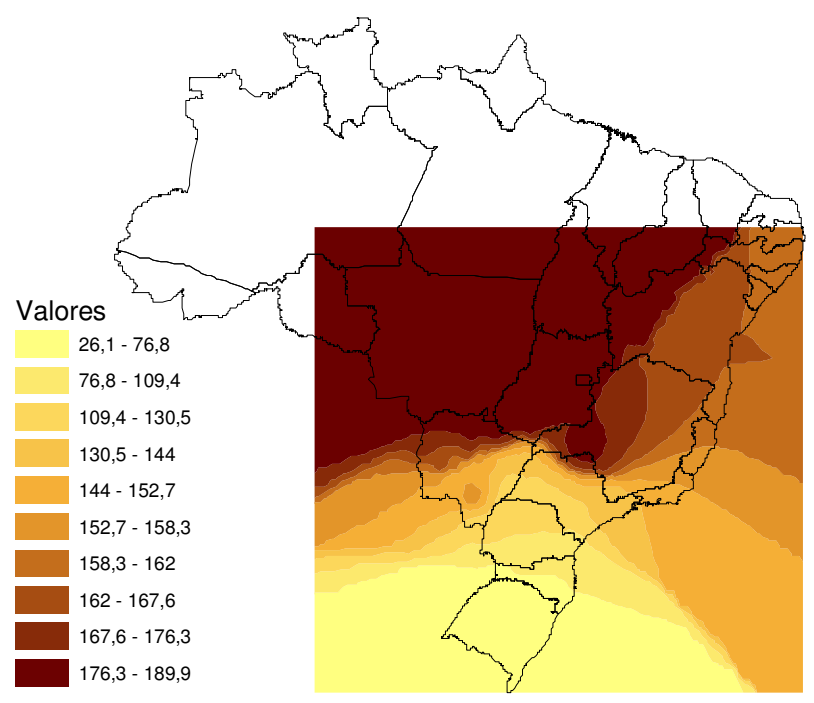

Figura 99. Resultado da interpolação por IDW dos maiores valores fornecidos pela simulação Turning Bands para o porto de Rio Grande. 
Para os menores valores extraídos da simulação Turning Bands para o Porto de Paranaguá, o resultado da interpolação é apresentado na Figura 100. A faixa de valores obtidos com esta simulação vai de $R \$ 25,10$ a $R \$ 146,60$.

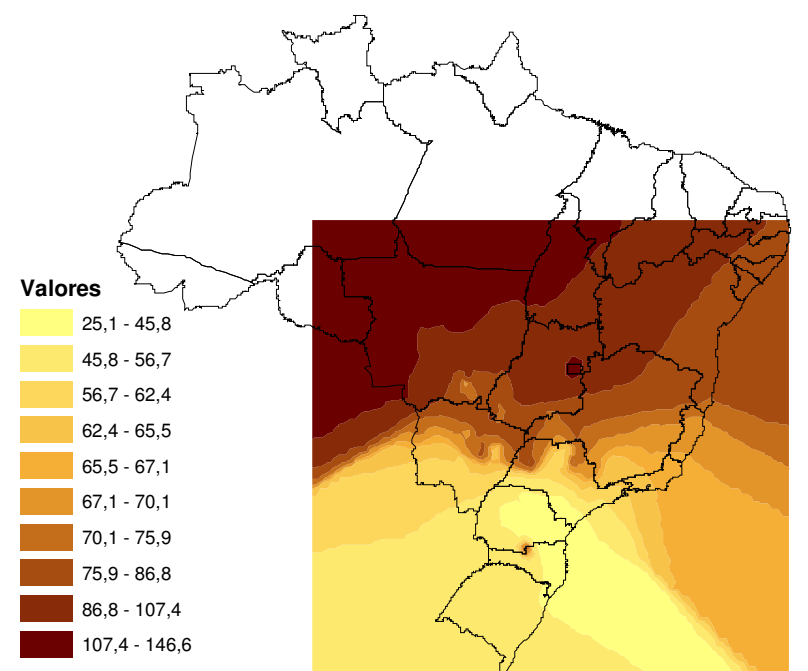

Figura 100. Resultado da interpolação por IDW dos menores valores fornecidos pela simulação Turning Bands para o porto de Paranaguá.

Quando interpolados os maiores valores obtidos pela simulação TB, o resultado conseguido é o apresentado na Figura 101. Para menores distâncias, o valor obtido foi de $R \$ 38,10$ para a maior foi de $R \$ 172,40$.

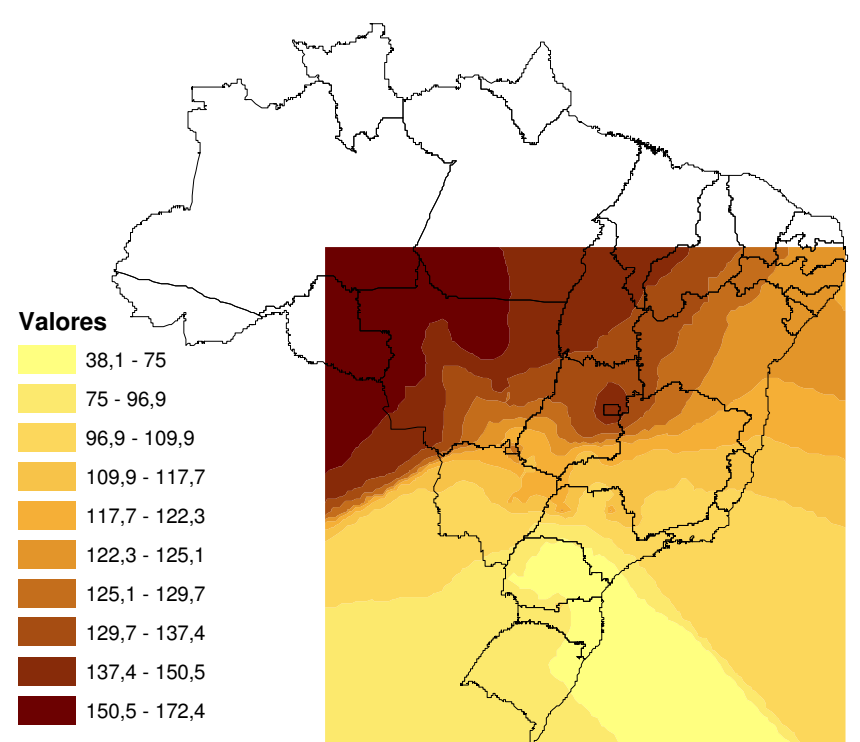

Figura 101. Resultado da interpolação por IDW dos maiores valores fornecidos pela simulação Turning Bands para o porto de Paranaguá. 
Após calcular as diferenças por meio da álgebra de mapas entre os fretes dos portos, nos dois casos, dos maiores valores e menores valores das simulações, obteve-se as áreas de influência do três portos.

Na Figura 102, a região mais escura corresponde á área de influência o porto de Santos. A área em cinza médio é a que está sob influência do porto de Paranaguá e a região em branco situa-se sob Rio Grande. Neste caso, mesmo com uma maior elevação média dos fretes de origem em Santos, de $33 \%$, em relação à elevação de $26 \%$ nos fretes com origem em Paranaguá, a região de influência de Santos continua superior a de Paranaguá, que passa a ocupar uma região maior no norte do Estado do Paraná e sul do Mato Grosso do Sul, em relação ao cruzamento dos dados reais.

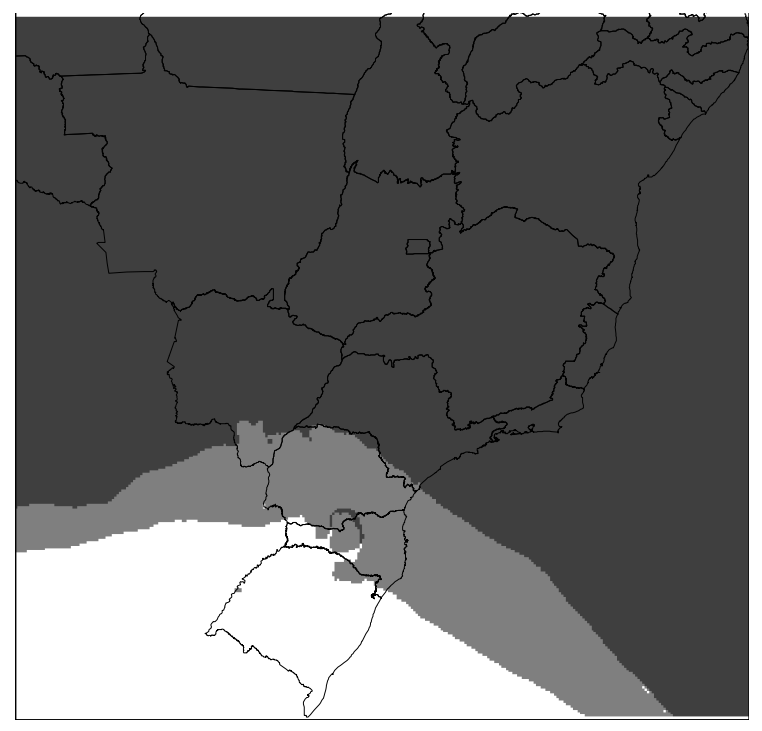

Figura 102. Resultado dos cruzamentos entre as os modelos de fretes de Santos, Paranaguá e Rio Grande a partir dos maiores valores simulados pelo TB

Quanto se extrai as regiões de influência dos modelos interpolados pelos menores valores simulados pelo TB, o resultado é de uma redução forte na área de influência de Paranaguá em relação ao porto de Santos.

Vale comentar aqui que, até a distância de $800 \mathrm{~km}$, o preço médio dos valores simulados pelo TB para o Porto de Paranaguá são $20 \%$ menos que os reais enquanto que para o Porto de Santos, a média dos menores valores simulados é 
$16 \%$ menor que a dos dados reais. Portanto, até esta distância, a queda nos valores em Paranaguá é maior que em Santos, e mesmo assim, a área de influência do porto de Santos continua a prevalecer sobre a área de influência de Paranaguá. Este efeito corrobora a idéia que, mesmo sob influência dos fretes mais elevados, Santos acaba sendo mais competitivo que os demais portos na importação de fertilizantes, quando são considerados apenas os fretes, e não os custos portuários.

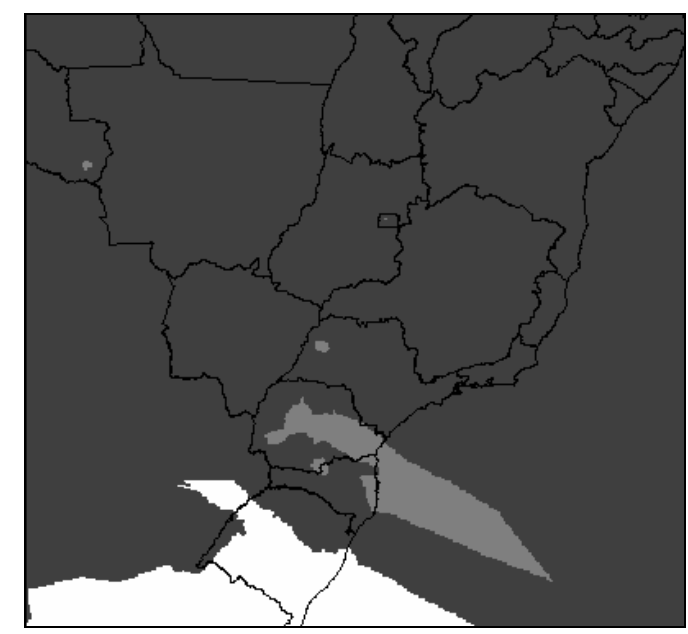

Figura 103. Resultado dos cruzamentos entre as os modelos fretes de Santos, Paranaguá e Rio Grande a partir dos menores valores simulados pelo TB

Aos resultados encontrados pela interpolação por IDW dos valores simulados pelo Turning Bands foram somadas grades de valores constantes dos preços dos fertilizantes nos portos (do MAP, $\mathrm{KCl}$ e Uréia, para cada porto) calculados através do modelo de internalização dos fertilizantes elaborado na primeira parte do trabalho (Figura 104).

Tais procedimentos foram necessários para analisar o comportamento das áreas de influência dos portos a partir de modificações nos indicadores de preços dos fertilizantes ocasionados pelas alterações nos preços dos fretes.

O primeiro mapa abaixo mostra o resultado das extrações das áreas de influência dos portos a partir da simulação de menores valores de fretes pro TB para os indicadores de preço da Uréia. 
Nota-se que o porto de Santos acaba perdendo boa parte de sua área de influência (área em cinza escuro) mesmo com maior redução dos preços dos fretes (de $26 \%$ em média, em relação aos preços reais) em comparação ao porto de Paranaguá que apresentou uma redução no frete médio de 19\% sobre o frete médio real. Isso mostra novamente que os custos portuários de Santos reduzem drasticamente a competitividade do produto internalizado por nele, no que tange sua área de atuação, mesmo na ocasião de uma forte redução dos seus fretes em relação aos demais portos.

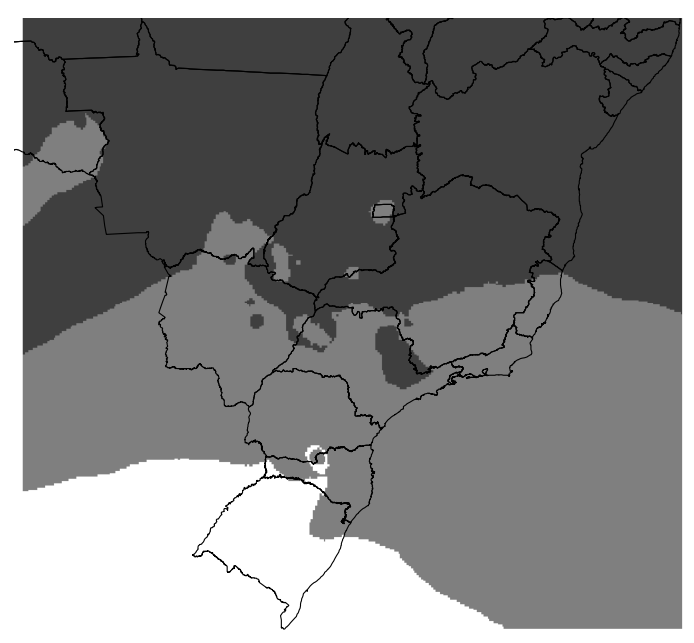

Figura 104. Resultado dos cruzamentos entre as os indicadores de preços de fertilizantes (Uréia) entre os portos de Santos, Paranaguá e Rio Grande a partir dos menores valores de fretes simulados pelo TB

Da mesma forma, para $\circ \mathrm{KCl}$, com pequenas diferenças na configuração por conta dos preços dos fretes marítimos, a redução nos fretes de Santos superior a redução para os demais portos, não assegura a competitividade do porto frente aos demais e a área de influência é reduzida. Ainda assim, nota-se que a grande parte do Mato Grosso, maior estado consumidor, acaba ficando sob a influência de Santos, mas região sob influência de Paranaguá, na região sul do estado, adquire o produto de Paranaguá. Configuração praticamente semelhante ocorre para o MAP, na Figura 105. 


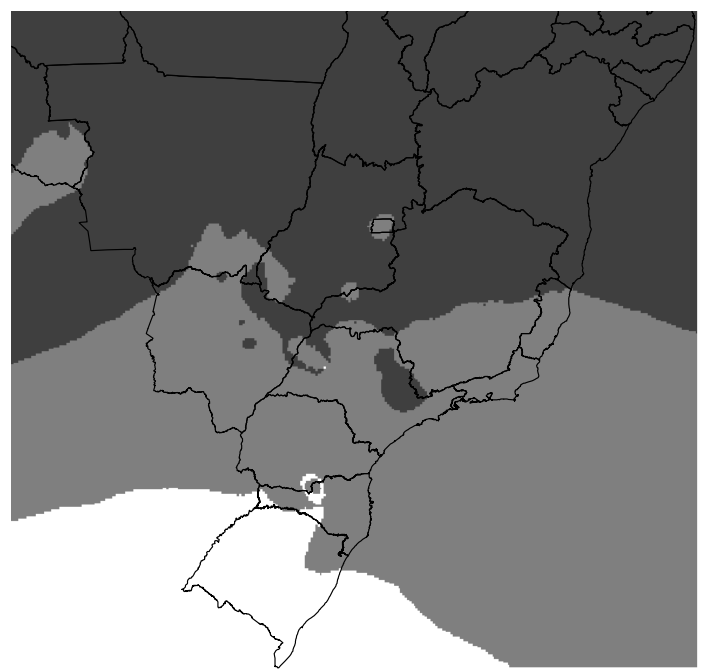

Figura 105. Resultado dos cruzamentos entre as os indicadores de preços de fertilizantes $(\mathrm{KCl})$ entre os portos de Santos, Paranaguá e Rio Grande a partir dos menores valores de fretes simulados pelo TB

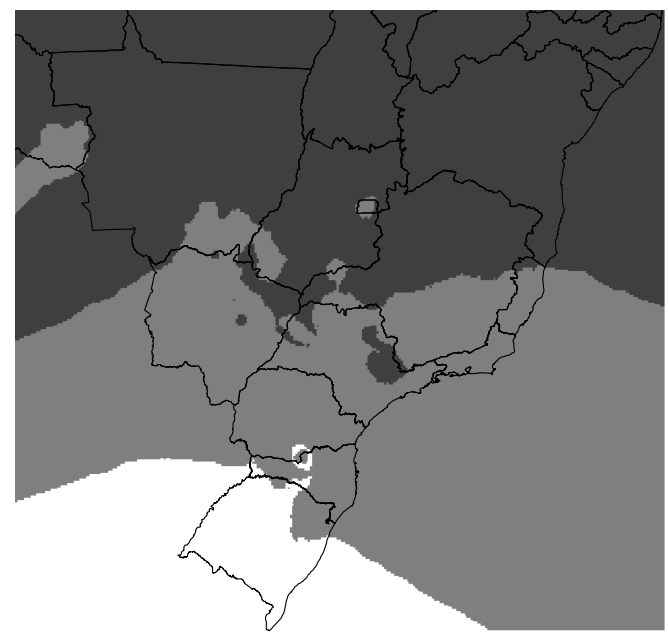

Figura 106. Resultado dos cruzamentos entre as os indicadores de preços de fertilizantes (MAP) entre os portos de Santos, Paranaguá e Rio Grande a partir dos menores valores de fretes simulados pelo TB

Quando são feitos os cruzamentos com os indicadores de preços formados a partir dos maiores valores simulados pelo Turning Bands, o resultado é um ganho de áreas de influência por Paranaguá, quando os preços dos fretes deste porto são elevados $20 \%$, em média, por meio da simulação (Figura 107). Os fretes de origem no porto de Santos se elevam em $33 \%$ na simulação pelo TB neste caso, o que 
explica a perda de competitividade. A região sob influência do porto de Rio Grande acaba obtendo um ganho sobre o estado de Santa Catarina, pois a elevação média nos seus fretes é de $16 \%$ apenas.

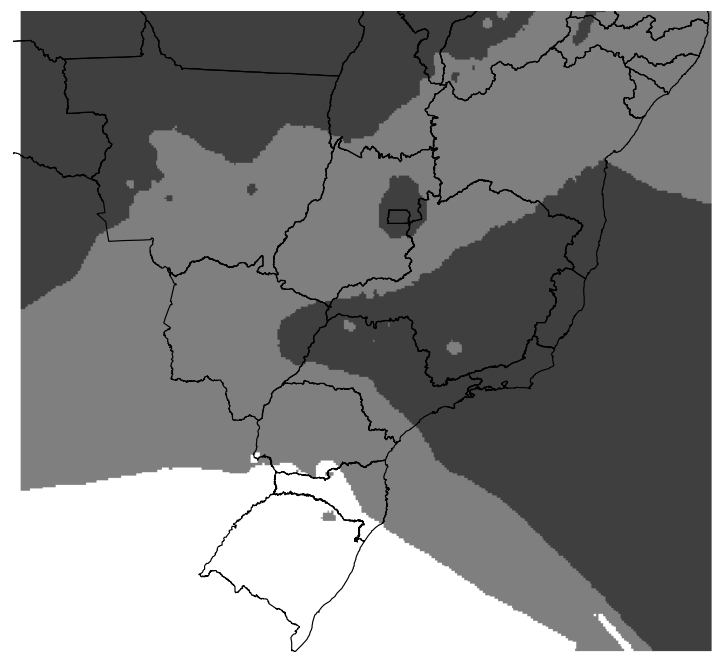

Figura 107. Resultado dos cruzamentos entre as os indicadores de preços de fertilizantes (Uréia) entre os portos de Santos, Paranaguá e Rio Grande a partir dos maiores valores de fretes simulados pelo TB

O mesmo quadro é observado para o KCl e o MAP, nas Figuras 108 e 109.

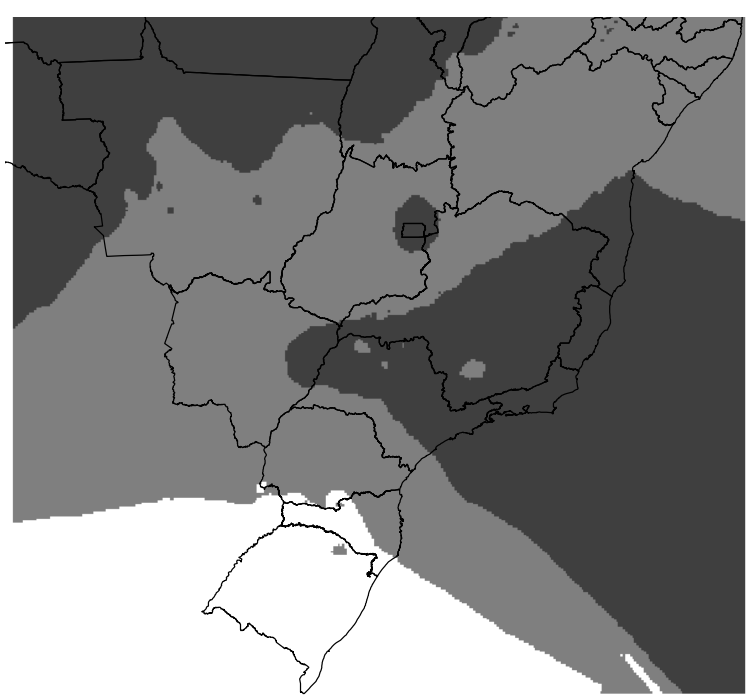

Figura 108. Resultado dos cruzamentos entre as os indicadores de preços de fertilizantes $(\mathrm{KCl})$ entre os portos de Santos, Paranaguá e Rio Grande a partir dos maiores valores de fretes simulados pelo TB 


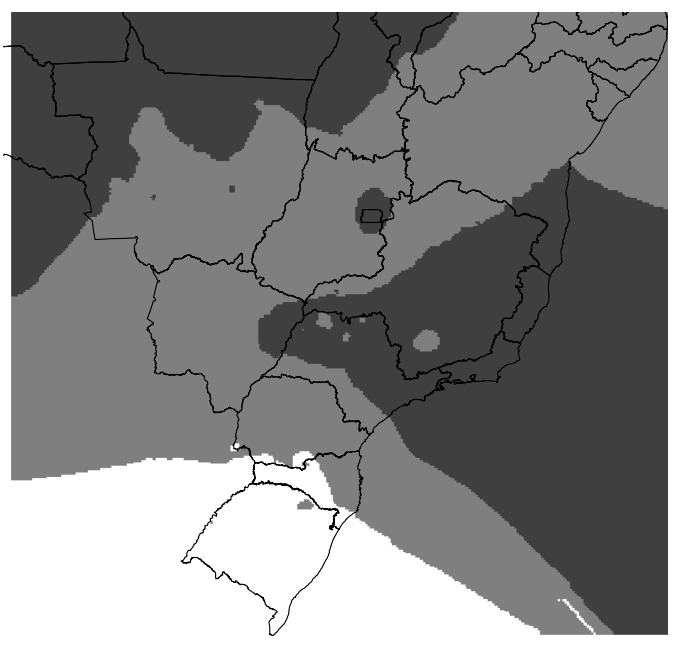

Figura 109. Resultado dos cruzamentos entre as os indicadores de preços de fertilizantes (MAP) entre os portos de Santos, Paranaguá e Rio Grande a partir dos maiores valores de fretes simulados pelo TB 


\section{CONCLUSÕES}

A pesquisa mostrou que é possível demonstrar a dependência espacial da distribuição dos custos de frete da indústria de fertilizantes no Brasil a partir de um Modelo de Elevação Digital para os custos logísticos do setor de fertilizantes brasileiro.

Foi possível, a partir do modelo:

- identificar as regiões de influência dos principais portos importadores destes insumos e simular diferentes quadros de concorrência a partir de manipulações dos preços dos fretes rodoviários;

- mostrar que técnicas de modelagem Digital de Terreno são úteis para a visualização e análise destes dados com relação no espaço.

Também foram comparadas três metodologias diferentes para a estimação dos fretes rodoviários: a análise de regressão, a interpolação e a geoestatística.

Cada uma das técnicas de estimação utilizadas para elaborar os modelos de fretes apresentou pontos positivos e negativos.

Na regressão, os valores obtidos dos erros foram altos em relação aos demais interpoladores e à geoestatística. Há também a necessidade de se utilizar posteriormente um algoritmo para interpolar os resultados encontrados se o objetivo é produzir um modelo digital de terreno, e fazer análises sobre eles, como as simulações e a criação de isolinhas de fretes. Por outro lado, a regressão, se mostrasse resultados mais robustos, possibilitaria extrapolar a análise para todo o território nacional, o que não é possível se utilizados somente os interpoladores e a geoestatística.

Utilizando-se dos interpoladores sem geoestatística, os erros das estimativas foram minimizados e foi possível, a partir do modelo criado pelo IDW, fazer as análises dos dados, criar isolinhas de fretes e usar técnicas de análises como o perfil 
longitudinal para compreender o comportamento dos indicadores de custos dos insumos.

Utilizando-se da geoestatística, a precisão nas estimativas encontradas para os valores de fretes não foram satisfatórias, se comparados com técnicas mais simples de interpolação, como o IDW. No entanto, o seu emprego nos dá a vantagem da possibilidade de se utilizar métodos de simulação estocástica como base para simulações dos modelos.

No trabalho, técnicas de modelagem digital de elevação, usualmente aplicadas na topografia ou em estudos geodésicos foram utilizadas para alcançar os objetivos propostos e possibilitaram obter como produto do estudo, um modelo digital que descreveu o comportamento do preço do fertilizante de uma forma contínua sobre a superfície, o qual também foi utilizado para realizar simulações, avaliando os resultados das oscilações nos preços dos fretes rodoviários.

Enfim, o estudo mostrou que, no caso da disponibilidade de uma base de dados amostrais mais segura e homogeneamente distribuída, a utilização de um modelo digital de elevação mostra-se uma ferramenta útil e de fácil acesso, que possibilita análises da concorrência espacial dos custos que formam os preços dos fertilizantes.

Com esta ferramenta, é possível entender as forças que apresentam maior impacto na formação dos preços, como os resultados acabaram mostrando, por exemplo, que os custos portuários de Santos deprimem sua competitividade em relação à Paranaguá.

O modelo pode ser utilizado também na estimação do mercado potencial para cada porto, no caso de estudar a viabilidade de projetos de investimentos na capacidade instalada de movimentação dos mesmos. 


\section{REFERÊNCIAS BIBLIOGRÁFICAS}

AGROSTAT. Estatísticas de Comercio Exterior do Agronegócio Brasileiro. Ministério da Agricultura, Pecuária e Abastecimento. Disponível em: http://www.fas.usda.gov/psdonline/psdQuery.aspx>. Acesso em: 15 nov. 2010.

AKIMA, H. 1978. A method of bivariate interpolation and smooth surface fitting for irregularly distributed data points. ACM Trans. on Math. Software 4: 148-159.

ALCARDE, J. C.; GUIDOLIN J. A. E LOPES A. S. (1998) Os adubos e a eficiência das adubações. 3.ed. São Paulo. ANDA,1998.(Boletim Técnico, 3)

ALMEIDA, R. B. Análise comparativa do uso da estatística clássica e a geoestatística na espacialização da região semi-árida. Salvador, 2008. 115 f.

ANDA Anuário Estatístico Do Setor De Fertilizantes - 2010. Associação Nacional para Difusão de adubos, Comitê de Estatística, São Paulo

ANDA Anuário Estatístico Do Setor De Fertilizantes - 2011. Associação Nacional para Difusão de adubos, Comitê de Estatística, São Paulo

BARBOSA, R.L., MENEGUETTE JR, M., SILVA, J.F.C., GAITAME, O.Y. Análise estatística da qualidade de um modelo digital do terreno gerado com thin plate spline. Revista Brasileira de Cartografia n. 60/02, Ago 2008. (ISSN 1808-0936)

BARROS, R. S. Avaliação da Altimetria de Modelos Digitais de Elevação Obtidos a Partir de Sensores Orbitais [Rio de Janeiro], 2006. XIX, 172p. (IGEO/ UFRJ), Tese de Doutorado, Geografia

BARROS Filho, M.N.M. Krigagem Ordinária aplicada à análise espacial da habitabilidade intraurbana: o caso da cidade do Recife (Brasil). VII Seminário Internacional da Latin América Real State Society. 25 - 26 de outubro de 2007, São Paulo, Brasil [Online] Disponível na Internet via WWW. URL: http://www.lares.org.br/2007/img/T039-BarrosFilho.pdf. Arquivo consultado em 16 de junho de 2010. 
BERETTA, F.S. Redução da variabilidade da qualidadedo carvão entre pilhas de homogeinização utilizando simulação geoestatítica. 2010. 82p. Dissertação (Mestrado) - Escola de Engenharia. Universidade Federal do Rio Grande do Sul, Porto Alegre, 2010.

BINKLEY, J. K.; HARRER, B. Major determinants of ocean freight rates for grains: an econometric analysis. American Journal of Agricultural Economics, v.63, n.1, p.47-57, Feb. 1981.

BRENNING, A E DUBOIS, G. Towards generic real-time mapping algorithms for environmental monitoring and emergency detection. Stoch Environ Res Risk Assess - SERRA. v. 22. n.5, p. 601-611. Ago, 2008.

BURROUGH, P. A. Principles of geographical information Systems for Land Resources Assessment. New York: Oxford University Press, 193 p. 1986

CAIXETA-FILHO, J. V. E GAMEIRO, A. H. (2001) Transporte e Logística em Sistemas Agroindustriais. Editora Atlas. São Paulo.

CAIXETA-FILHO, J. V.; MARTINS, R. S (2001). Gestão logística de transportes de cargas $\left(1^{\mathfrak{a} e}\right.$ ed.). Editora Atlas. São Paulo.

CÂMARA, G., MONTEIRO, A.M. MEDEIROS, J.S. (2004) "Introdução à Ciência da Geoinformação". São José dos Campos, INPE, 2004.

CEPEA. PIB Agro CEPEA-USP/CNA. 2010. Disponivel em:< http://cepea.esalq.usp.br/pib/> Acesso em: 20 dez. 2011

CORRÊA JUNIOR. G. Determinantes do preço do frete rodoviário para transporte de soja em grãos em diferentes regiões brasileiras: uma análise econométrica. Piracicaba, 2001. 118p. Dissertação (Mestrado). Escola Superior de Agricultura "Luiz de Queiroz", Universidade de São Paulo.

CORREA JÚNIOR, G., REZENDE, M.L., MARTINS, R.S., CAIXETA-FILHO, J.V. Fatores determinantes do valor do frete e o caso das centrais de carga. Editora Atlas. São Paulo, Brasil, 2001 
COSTA, J.F.C.L. Developments in Recoverable Reserves and Ore Body Modeling. 333f. thesis (Phd) - Wh Bryan Mining Geology Centre, the University of Queesland, Australia, 1997.

DEUSTCH, C.V., JOURNEL, A.G. GSLIB Geoestatistical Software Library and User's Guide. Oxford University Press. 340p. 1992.

DIAS, V.P., FERNANDES, E. "Fertilizantes: uma visão global sintética". BNDES Setorial, Rio de Janeiro, n. 24, p. 97-138, set. 2006

DNPM. Economia Mineral do Brasil. Coord. Rodrigues.A.F. da S. Brasília-DF: Departamento Nacional de Produção Mineral - DNPM, 2009. 764 p.

DRUCK, S.; Carvalho, M.S.; Câmara, G.; Monteiro, A.V.M. (eds) (2004) "Análise Espacial de Dados Geográficos". Brasília, EMBRAPA, 2004 (ISBN: 857383-260-6).

EBERLY,S., SWALL,J., HOLLAND,D., COX,B., BALDRIDGE,E. (2004) Developing Spatially Interpolated Surfaces and Estimating Uncertainty - EPA-454/R04-004. EPA - U.S. Environmental Protection Agency. Nov. 2004

FAOSTAT. FAO, Statistics Division 2010. FAO Statistical Yearbook 2010. Disponível em: <http://www.fao.org>. Acesso em: 23 dez.2011.

FELGUEIRAS, C. E GOOCHILD, M.F. Two Papers on Triangulated Surface Modeling: A comparison of three TIN surface modeling methods and associated algorithms. National Center for Geographic Information and Analysis. Technical Report 95-2. Jan 1995

FERNANDES, E.; GUIMARÃES, B.A. e MATHEUS,, R.R. "Principais Empresas e Grupos Brasileiros do Setor de Fertilizantes". BNDES Setorial, Rio de Janeiro, n. 29, p. 203-228, mar.2009

FERNANDES, L. Sumário Mineral 2009. DNPM . v.29, p. 52-53, jun. 2010. ISSN: 01012053

FERNANDES, M.C. Desenvolvimento de Rotina de Obtenção de Observações em superfície Real: Uma Aplicação em Análises Geoecológicas [Rio de Janeiro], 
2004 xxvii, 263 p. (IGEO/ UFRJ, D.Sc., GEOGRAFIA, 2004) Tese - Universidade Federal do Rio de Janeiro, IGEO

FURUIE, R. A. Estudo comparativo de métodos geoestatísticos de estimativas e simulações estocásticas condicionais. 2009 166p. Dissertação (Mestrado) - Instituto de Geociências, Universidade de São Paulo, São Paulo, 2009.

HARTKAMP, A.D., K. De Beurs, A. Stein, and J.W. White. (1999) Interpolation Techniques for Climate Variables. NRG-GIS Series 99-01. Mexico, D.F.: International Maize and Wheat Improvement Center - CIMMYT. ISSN: 1405-7484.

HERMANN, B.M. E HADDAD, E.A. Mercado imobiliário e amenidades urbanas: a view through the window. Estudos Econômicos. v.35, n. 2, p. 237-269. Abr-jun 2005. ISSN 0101-4161.

IBGE. Malha municipal digital do Brasil - 2005. Rio de Janeiro: DGC/ DECAR, 2005. CD-ROM

IMEA - Instituto Mato-grossense de Economia Agropecuária. ANÁLISE DO MERCADO DE TRABALHO DO AGRONEGÓCIO NO ESTADO DE MATO $\begin{array}{lllll}\text { GROSSO } & E & \text { BRASIL. } & \text { Outubro, } & 2011 .\end{array}$ http://www.imea.com.br/upload/pdf/arquivos/2011_10_21mercadodetrabalho_final.pd f. Acessado em 22 dez, 2011

INGRAM, B., CORNFORD, D. e EVANS, D. Fast algoritms for automatic mapping with space-limites covariance functions. Stoch Environ Res Risk Assess SERRA. v. 22. n.5. p. 662-670. Ago, 2008.

JAKOB A.A.E. \&YOUNG, A.F. O uso de métodos de interpolação espacial de dados nas análises sociodemográficas. XV Encontro Nacional de Estudos Populacionais, ABEP, Caxambu, MG. Brasil, Set. 2006. Disponível em: http://www.abep.nepo.unicamp.br/encontro2006/docspdf/ABEP2006_388.pdf> Acessado em $23 \mathrm{dez}, 2011$

JOUNEL, A.G., HUIJBREGTS, Ch. J. Mining Geoestatistics. Academic Press. 600 p. 1978 
LANDIM. P. M. B. Introdução aos métodos de interpolação espacialpara confecção de mapas. Texto Didático 02. Departamento de Geologia Aplicada IGCE. Laboratóriod e Geomatemática - UNESP, 2000

LEE J. Comparison of existing methods for building triangular irregular network models of terrain from grid digital elevations models, IJGIS, v. 5, n. 3, p. 267-285, 1991

McCANN, P. A proof of the relationship between optimal vehicle size, haulage length and the structure of distance transport costs. Transportation Research - Part A, v. 35, p. 671-693, 2001.

MARTINS, R. S. Estudo da formação do frete rodoviário e potencial de Conflitos em negociações em cadeias do agronegócio Brasileiro. Organizações Rurais \& Agroindustriais, vol. 10, ㄲo 1., 2008

MARTINS, R. S. Racionalização da infra-estrutura de transporte no estado do Paraná: o desenvolvimento e a contribuição das ferrovias para a movimentação de grãos e farelo de soja. Piracicaba, 1998. 216p. Tese (Doutorado) - Escola Superior de Agricultura "Luiz de Queiroz", Universidade de São Paulo.

MATHERON, G. The Intrinsic Randon Functions and their Apllications. Advances in Applied probability 5, p.439-468. 1973

MATOS, A.C.O.C. Implementação de Modelos Digitais de Terreno para aplicações na área de geodésia e geofísica na América do Sul. São Paulo, 2005. $355 \mathrm{p}$.

MONTERO, J.M., LARRAZ, B. E CHASCO, C. (2008) Building an Environmental Quality Index for a big city: a spatial interpolation approach with DP2. Human Sciences Research Council. [Online] Disponível na Internet via WWW. URL: http://mpra.ub.uni-muenchen.de/10736/ Arquivo consultado em 15 de junho de 2010.

NAVA, D. B.; HORBE, M. A. As reservas de potássio do Amazonas no contexto do desenvolvimento sustentável da Amazônia e do Brasil. In: CONGRESSO BRASILEIRO DE GEOLOGIA, 44., 26-31 out. 2008, Curitiba, PR. Anais... Curitiba, PR: SBG, 2008. 
OLIVEIRA, L.A.M. Sumário Mineral 2009. DNPM . v.29, p. 76-77, jun. 2010. ISSN: 01012053

OLIVEIRA JR, M.G. (2007) PROJETO GEOMÉTRICO DE VIAS COM MODELAGEM DIGITAL DO TERRENO EM AMBIENTE DE SOFTWARE LIVRE E SISTEMA DE INFORMAÇÕES GEOGRÁFICAS, Marcos Heleno Guerson de Oliveira Junior, Rio de Janeiro, Instituto Militar de Engenharia, 2007.

PODOBNIKAR, T. Production of integrated digital terrain model from multiple datasets of different quality. IJGIS, v. 19, n. 1, p. 69-89. 2005

PODOBNIKAR,T. (2009) Methods for visual quality assessment of a digital terrain model, S.A.P.I.EN.S, 2.2 [Online] Disponível na Internet via WWW. URL: http://sapiens.revues.org/index738.html. Arquivo consultado em 15 de junho de 2010.

REZENDE, F.A.V.S;VARNIER-ALMEIDA, R.M. \& NOBRE, F.F. Diagramas de Voronoi para a definição de áreas de abrangência de hospitais públicos no Município do Rio de Janeiro. Cad. Saúde Pública, Rio de Janeiro, 16(2):467-475, abr-jun, 2000

Secretaria de Acompanhamento Econômico - SEAE. Panorama do mercado de fertilizantes. MINISTÉRIO DA FAZENDA. Maio, 2011 Disponível em: $<$ http://www.seae.fazenda.gov.br/central documentos/panoramassetoriais/i fert seae -11 fertilizantes.pdf. > Acesso em: 26 out. 2012

SRIVASTAVA, R.M. A Overview of Stochastic Methods for Reservoir Characterization in Yarus, J.M. \& Chambers, R.L. (Eds.), Schocastic Modeling and Geoestatistics: Principles, Methods and Case Studies. American Association of Petroleum Geologists - Computer Apllications in Geology, n.3, 1994

STEINBERG, S.J. and STEINBERG, S.L. (2005) Geographic Information systems for the social sciences: investigating space and place. USA. SAGE, 2005. $100 \mathrm{p}$.

THOMPSON, H.L. Freight rate equations. Industrial and Engineering Chemistry, v.52, n.11, p.40A-44A, Nov. 1960.

TOBLER, W.R. A computer movie simulating urban growth in the detroit region. Economic Geography, v.46, p.234-240, 1970 
YU, Z. W. Surface interpolation from irregularly distributed points using surface splines, with Fortran program. Computers \& Geosciences, n. 27, p. 877-882, 2001.

WANG,X., KOCKELMAN.K.M. Forecasting Network Data: Spatial Interpolation of Traffic Counts from Texas Data. Transportation Research Record: Journal of the Transportation Research Board, v. 2105, p. 100-108, 2009

WATANABE, J.; ROCHA, M.M; YAMAMOTO, J.K. (2012) Análise Da Simulação Estocástica Pelo Método De Bandas Rotativas. Disponível em: $<$ http://sbgeo.org.br/pub_sbg/cbg/2004-ARAXA/19_781_WATANABEJ.pdf>. Acesso em: 26 jan. 2012.

WEIRICH NETO, P.H., OSVALDO BUZOLINI JR,O., ROCHA,J.V. BORGHI,E. E SVERZUT, C.B. (2006) Um Estudo Da Variabilidade Espacial Do Conteúdo De Areia Do Solo, Utilizando Diferentes Métodos De Interpolação. Publ. UEPG Exact Earth Sci., Agr. Sci. Eng., Ponta Grossa, 12 (1): 41-49, abr. 2006

WEIR-SMITH, G. AND SCHWABE, C.A. (2010) Spatial interpolation vs neural network propagation as a method of extrapolating from field surveys. GIS Centre, HSRC (Human Sciences Research Council), Pretoria [Online] Disponível na Internet via WWW. URL: http://www.hsrc.ac.za/Document-74.phtml. Arquivo consultado em 13 de junho de 2010.

USDA "Departamento de Agricultura Norte-Americano (USDA)". Foreign Agricultural Service's Production, Supply and Distribution Online (PSDOnline). Disponível em: <http://www.fas.usda.gov/psdonline/psdQuery.aspx>. Acesso em: 20 dez. 2010. 